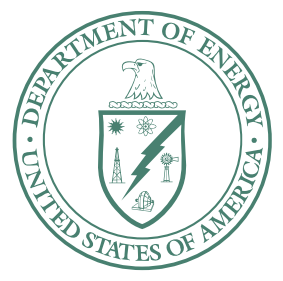

U.S. Department of Energy

Idaho Operations Office

\title{
Idaho CERCLA Disposal Facility Complex Compliance Demonstration for DOE Order 435.1
}

September 2006 

DOE/ID-10956

Revision 1

\section{Idaho CERCLA Disposal Facility Complex Compliance Demonstration for DOE Order 435.1}

September 2006

Prepared for the U.S. Department of Energy Idaho Operations Office 



\section{ABSTRACT}

This compliance demonstration document provides an analysis of the Idaho CERCLA Disposal Facility (ICDF) Complex compliance with DOE Order 435.1. The ICDF Complex includes the disposal facility (landfill), evaporation pond, admin facility, weigh scale, decon building, treatment systems, and various staging/storage areas. These facilities were designed and are being constructed to be compliant with DOE Order 435.1, Resource Conservation and Recovery Act Subtitle C, and Toxic Substances Control Act polychlorinated biphenyl design and construction standards. The ICDF Complex is designated as the central Idaho National Laboratory (INL) facility for the receipt, staging/storage, treatment, and disposal of INL Comprehensive Environmental Response, Compensation and Liability Act (CERCLA) waste streams.

This compliance demonstration document discusses the conceptual site model for the ICDF Complex area. Within this conceptual site model, the selection of the area for the ICDF Complex is discussed. Also, the subsurface stratigraphy in the ICDF Complex area is discussed along with the existing contamination beneath the ICDF Complex area.

The designs for the various ICDF Complex facilities are also included in this compliance demonstration document. These design discussions are a summary of the design as presented in the Remedial Design/Construction Work Plans for the ICDF landfill and evaporation pond and the Staging, Storage, Sizing, and Treatment Facility. Each of the major facilities or systems is described including the design criteria.

This compliance demonstration document also discusses the Waste Acceptance Criteria (WAC) document for the ICDF Complex. The waste streams that are restricted from acceptance into the ICDF Complex are presented. Also, the other restrictions are discussed along with the conditions that must be met to make the waste acceptable into the facility for a variety of operations including disposal.

Each of the DOE Manual 435.1 requirements for Chapters 1, 3, and 4 is evaluated in this compliance demonstration document. The determination that soil and debris contaminated with high-level waste is not "high-level waste" is also presented in this compliance demonstration document as part of the Chapter 2 requirements from DOE Manual 435.1. A crosswalk table for each chapter of DOE Manual 435.1 has been developed and is presented in this document showing the requirement, classification of the requirement, applicable or relevant and appropriate requirements, and CERCLA documents developed that deal with the specific requirements.

Based on the evaluation and analysis in this compliance demonstration document, the ICDF Complex is in compliance with DOE Order 435.1. All of the substantive requirements are met and most of the administrative requirements are met. Requirements not dealing specifically with ICDF are not considered to require compliance. 


\section{CONTENTS}

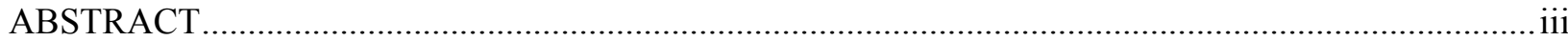

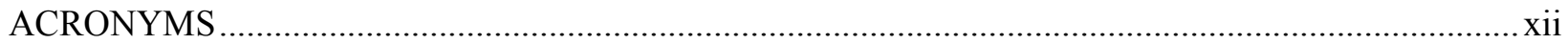

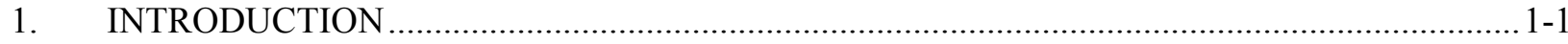

1.1 Purpose of ICDF Complex Compliance Demonstration.................................................. 1-1

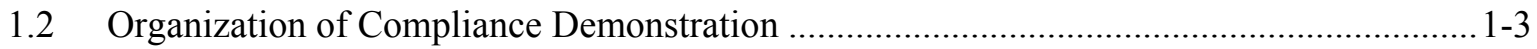

2. ICDF COMPLEX CONCEPTUAL SITE MODEL …..........................................................

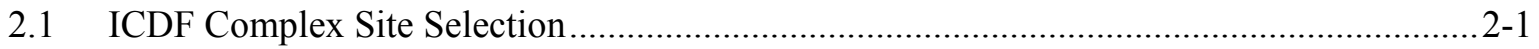

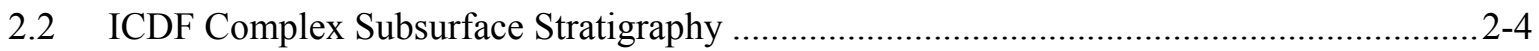

2.3 Existing Contamination at ICDF Complex Location ................................................... 2-7

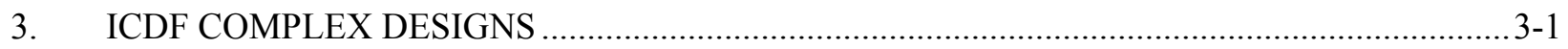

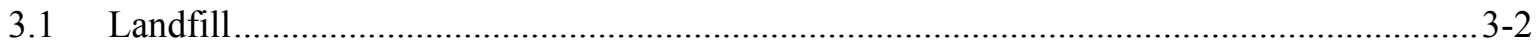

3.1.1 Landfill Disposal Cell Design .................................................................. 3-2

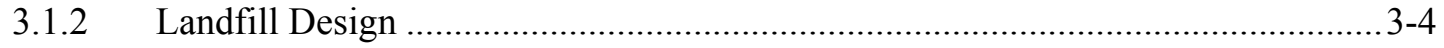

3.1.3 Landfill Engineered Containment Barrier Design .............................................. 3-5

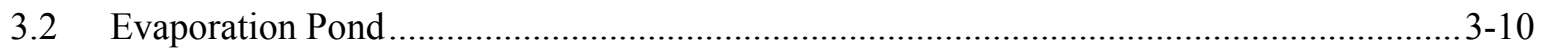

3.2.1 Evaporation Pond Design.................................................................. $3-13$

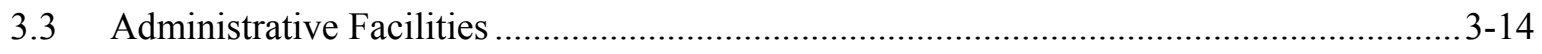

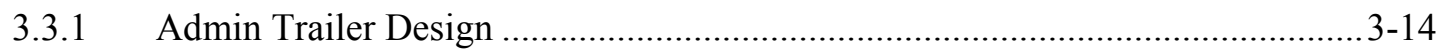

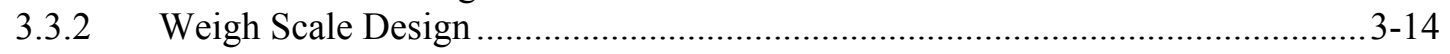

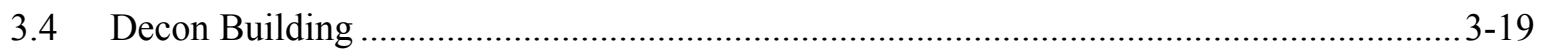

3.4.1 Decon Building Design .............................................................................

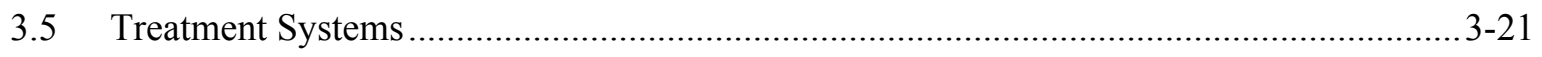

3.5.1 Treatment Systems Design................................................................... $3-21$

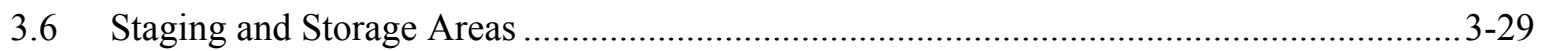

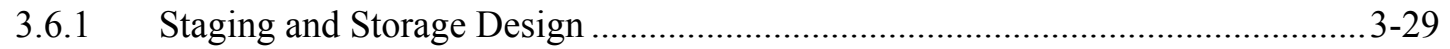

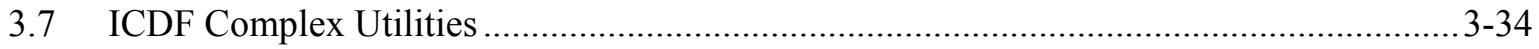

3.8 ICDF Complex Groundwater Monitoring System ...................................................... 3-34 
4. ACCEPTABLE WASTE TYPES FOR THE ICDF COMPLEX ................................................

4.1 Waste Types for Staging and Storage Areas .......................................................... $4-1$

4.2 Waste Types for Treatment Facility .......................................................................... $4-3$

4.3 Waste Types for Landfill ...................................................................................... $4-4$

4.4 Waste Types for Evaporation Pond.............................................................................. $4-6$

5. GENERAL REQUIREMENTS AND RESPONSIBILITIES (DOE ORDER 435.1,

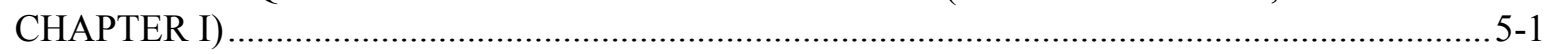

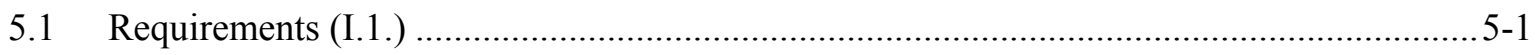

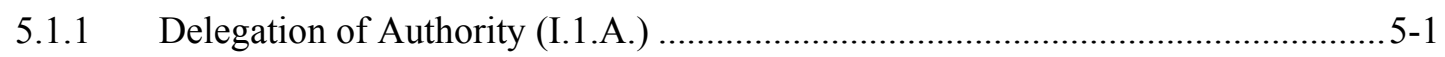

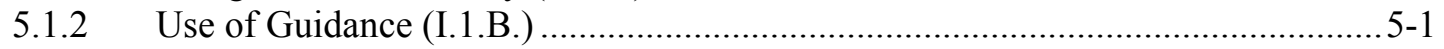

5.1.3 Radioactive Waste Management (I.1.C.) .................................................. $5-2$

5.1.4 Analysis of Environmental Impacts (I.1.D.) ................................................ 5-2

5.1.5 Requirements of Other Regulations and DOE Directives (I.1.E.) ......................... 5-3

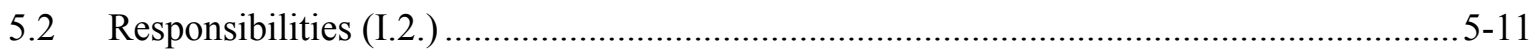

5.2.1 Program Secretarial Officers (I.2.A.) …...................................................... 5-11

5.2.2 Assistant Secretary for Environmental Management (I.2.B.) .............................5-11

5.2.3 Assistant Secretary for Environment, Safety, and Health (I.2.C.) .......................5-12

5.2.4 Deputy Assistant Secretary for Waste Management (I.2.D.) ............................. 5-13

5.2.5 Deputy Assistance Secretaries for Waste Management and Environmental

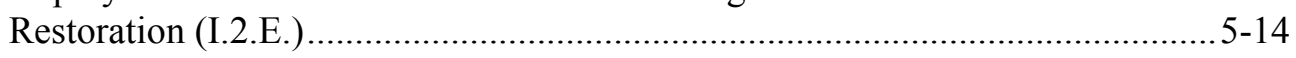

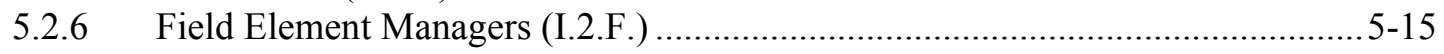

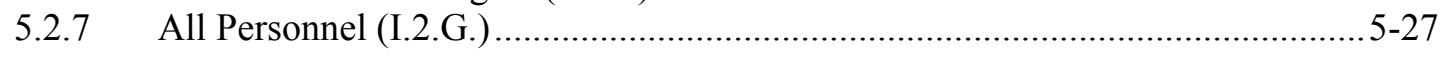

6. HIGH-LEVEL WASTE REQUIREMENTS (DOE ORDER 435.1, CHAPTER II) ..................... 6-1

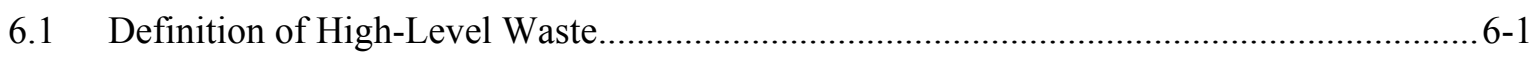

7. TRANSURANIC WASTE (DOE ORDER 435.1, CHAPTER III) …......................................... $7-1$

7.1 Definition of Transuranic Waste (III.A.) …............................................................ $7-1$

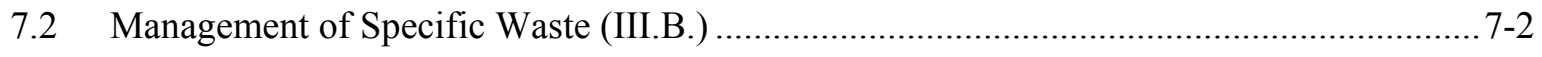

7.2.1 Mixed Transuranic Waste (III.B.1.) …................................................................

7.2.2 TSCA-Regulated Waste (III.B.2.)............................................................. $7-2$

7.2.3 Pre-1970 Transuranic Waste (III.B.3.)........................................................

7.3 Complex-Wide Transuranic Waste Management Program (III.C.) .................................... 7-3

7.4 Radioactive Waste Management Basis (III.D.) ........................................................... $7-3$

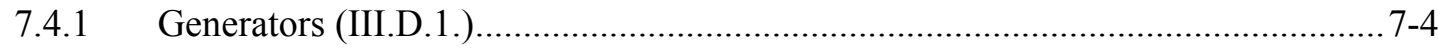

7.4.2 Treatment Facilities (III.D.2.) ……........................................................ 


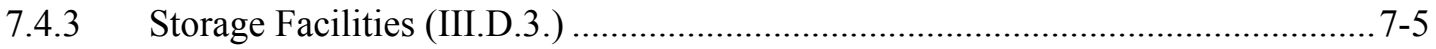

7.4.4 Disposal Facilities (III.D.4.)................................................................................

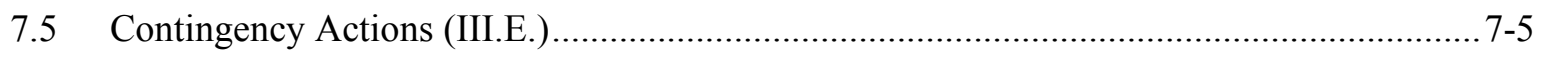

7.5.1 Contingency Storage (III.E.1.) ................................................................

7.5.2 Transfer Equipment (III.E.2.) ................................................................

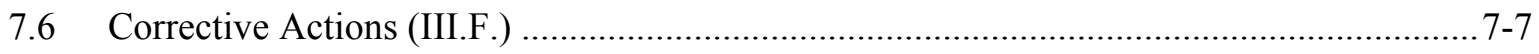

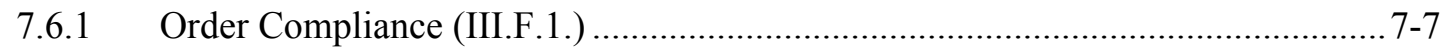

7.6.2 Operations Curtailment (III.F.2.) ….......................................................... $7-7$

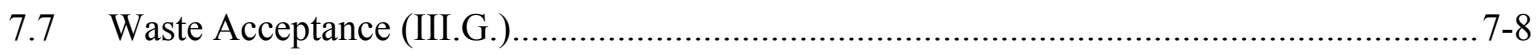

7.7.1 Technical and Administrative (III.G.1.)..........................................................

7.7.2 Evaluation and Acceptance (III.G.2.) ......................................................... $7-9$

7.8 Waste Generation Planning (III.H.) ........................................................................

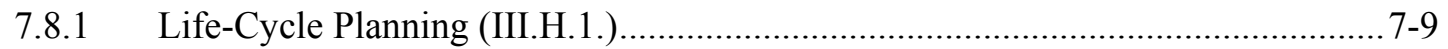

7.8.2 Waste with No Identified Path to Disposal (III.H.2.)....................................... $7-10$

7.9 Waste Characterization (III.I.) …........................................................................ $7-11$

7.9.1 Data Quality Objectives (III.I.1.) …..............................................................

7.9.2 Minimum Waste Characterization (III.I.2.) …................................................ 7-12

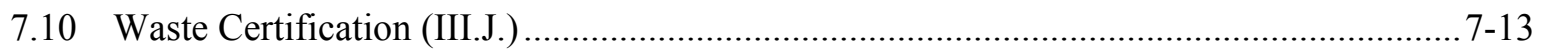

7.10.1 Certification Program (III.J.1.)................................................................... 7-13

7.10.2 Certification Before Transfer (III.J.2.) ..................................................... $7-14$

7.10.3 Maintaining Certification (III.J.3.)........................................................... $7-14$

7.11 Waste Transfer (III.K.) ............................................................................................ $7-15$

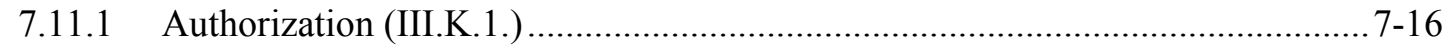

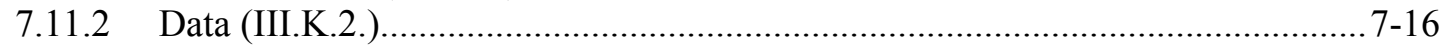

7.12 Packaging and Transportation (III.L.) .................................................................. $7-17$

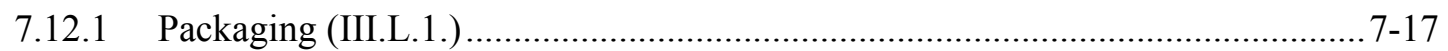

7.12.2 Transportation (III.L.2.) …..................................................................... $7-18$

7.13 Site Evaluation and Facility Design (III.M.) ................................................................ $7-19$

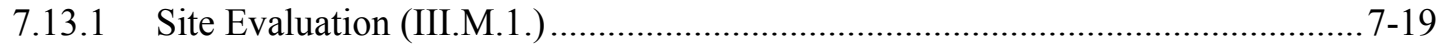

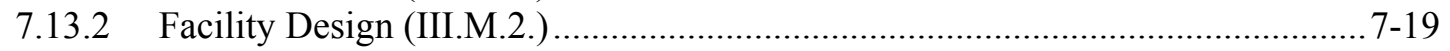

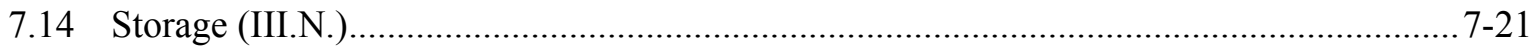

7.14.1 Storage Prohibitions (III.N.1.) ……….......................................................... 7-2

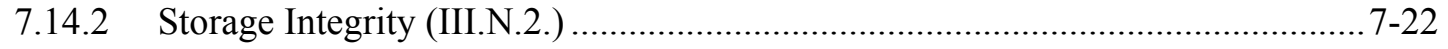




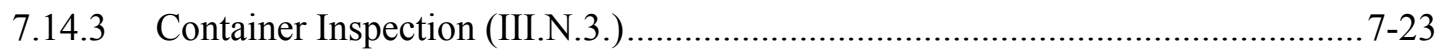

7.14.4 Retrievable Earthen-Covered Storage (III.N.4.) ........................................... 7-23

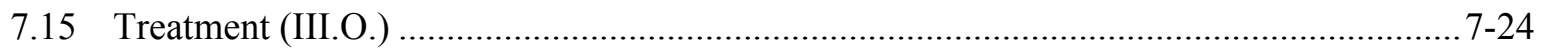

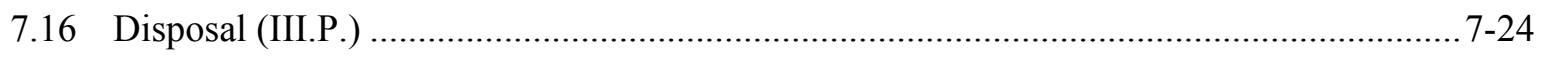

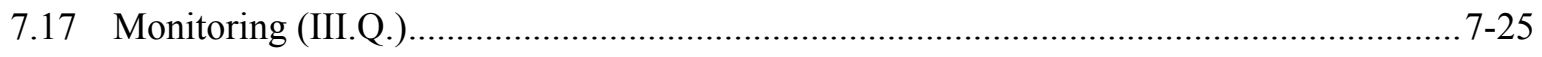

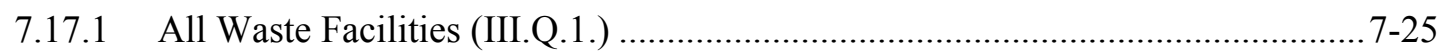

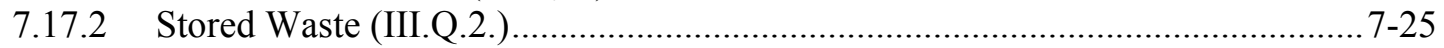

7.17.3 Liquid Waste Storage Facilities (III.Q.3.)................................................... $7-26$

8. LOW-LEVEL WASTE (DOE ORDER 435.1, CHAPTER IV) ................................................. 8-1

8.1 Definition of Low-Level Waste (IV.A.) ...................................................................... 8-1

8.2 Management of Specific Wastes (IV.B.) ................................................................... 8-1

8.2.1 Mixed Low-Level Waste (IV.B.1.) ................................................................. $8-1$

8.2.2 TSCA-Regulated Waste (IV.B.2.) ……................................................... 8 -2

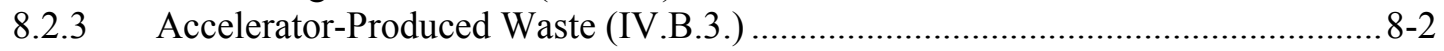

8.2.4 11e.(2) and Naturally Occurring Radioactive Material (IV.B.4.) .......................... 8-3

8.3 Complex-Wide Low-Level Waste Management Program (IV.C.) .................................... 8-3

8.4 Radioactive Waste Management Basis (IV.D.) …........................................................ 8-3

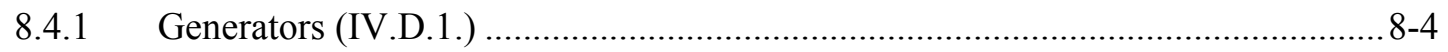

8.4.2 Treatment Facilities (IV.D.2.) …......................................................... 8 -4

8.4.3 Storage Facilities (IV.D.3.) .............................................................. $8-5$

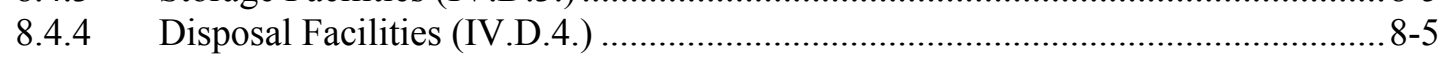

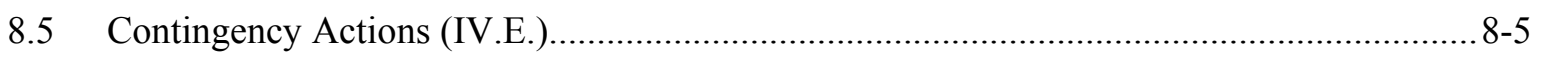

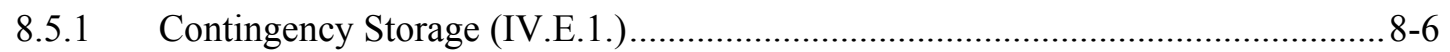

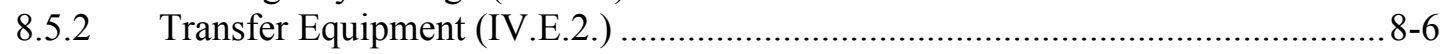

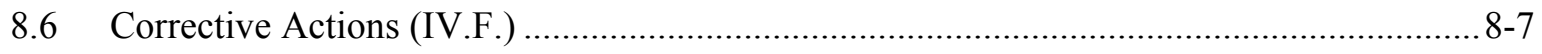

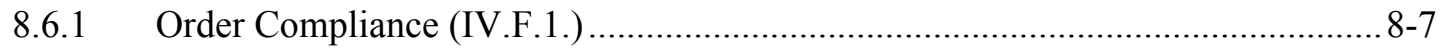

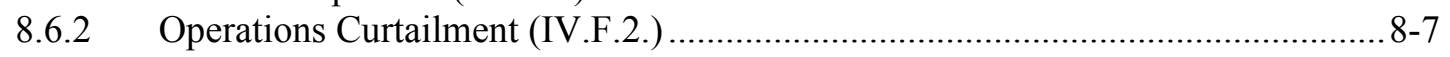

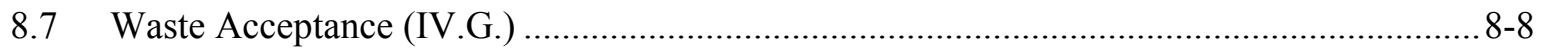

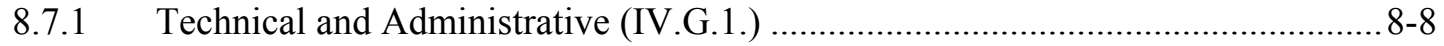

8.7.2 Evaluation and Acceptance (IV.G.2.) ........................................................... 8-10

8.8 Waste Generation Planning (IV.H.) ........................................................................ 8 -10

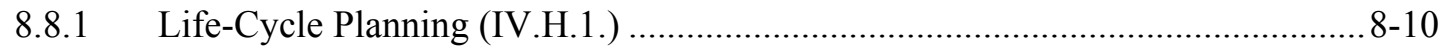

8.8.2 Waste With No Identified Path to Disposal (IV.H.2.) ....................................... 8-11 


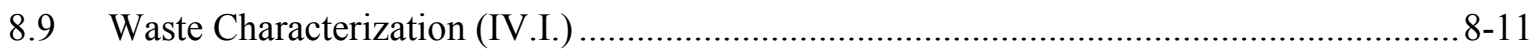

8.9.1 Data Quality Objectives (IV.I.1.) .................................................................. 8 8 - 12

8.9.2 Minimum Waste Characterization Requirements (IV.I.2.) ............................... $8-13$

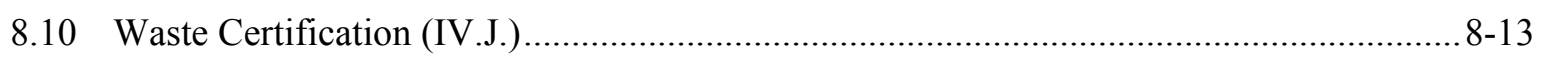

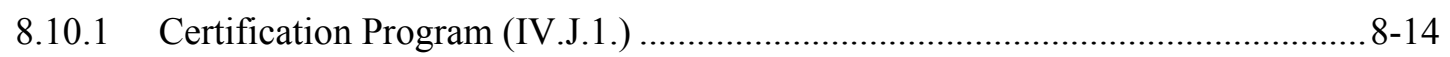

8.10.2 Certification Before Transfer (IV.J.2.)......................................................... 8-15

8.10 .3 Maintaining Certification (IV.J.3.)............................................................ 8 - 15

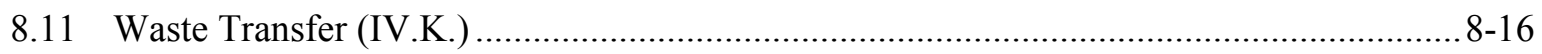

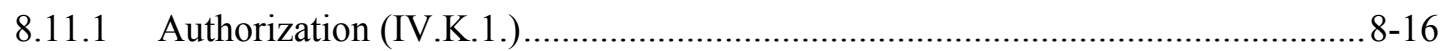

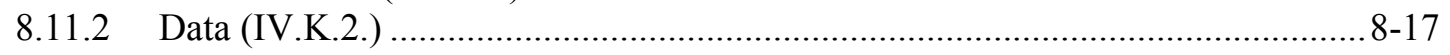

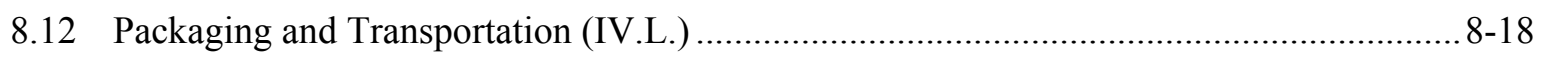

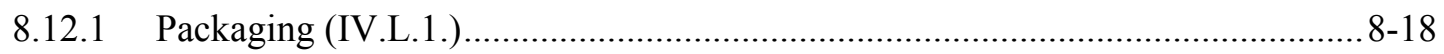

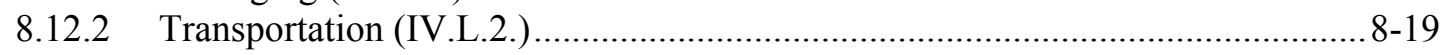

8.13 Site Evaluation and Facility Design (IV.M.) ........................................................... 8-19

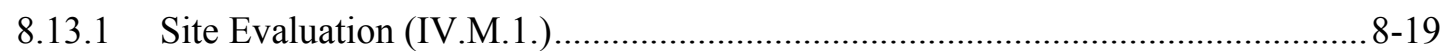

8.13.2 Low-Level Waste Treatment and Storage Facility Design (IV.M.2.).................. 8-21

8.13.3 Low-Level Waste Disposal Facility Design (IV.M.3.) ...................................... 8-23

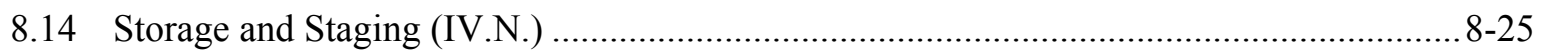

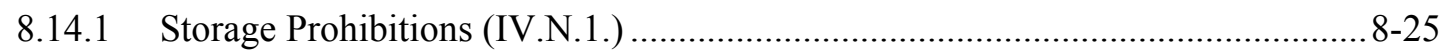

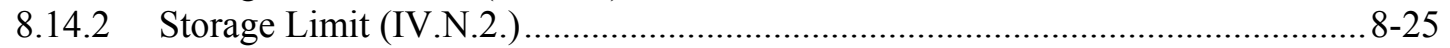

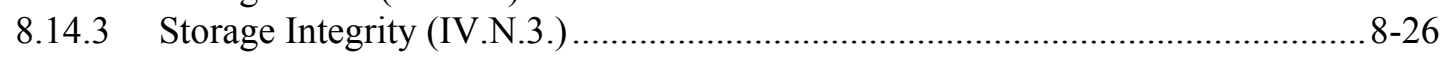

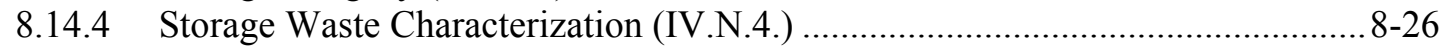

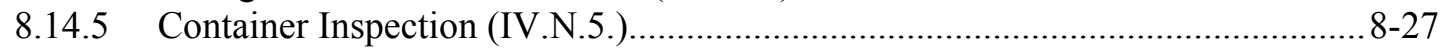

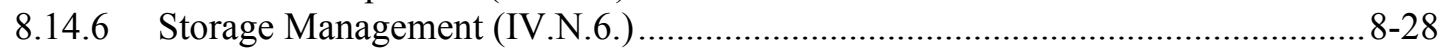

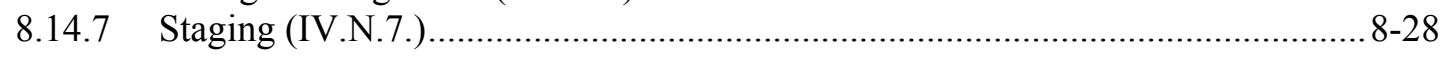

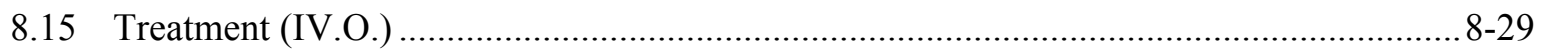

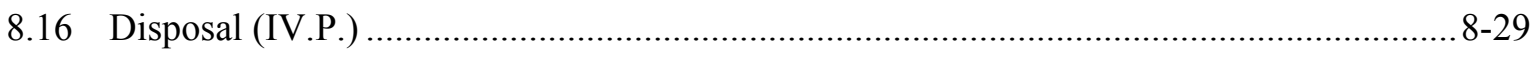

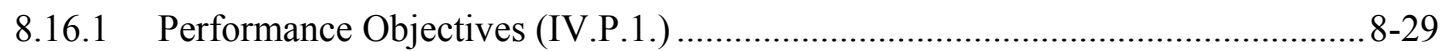

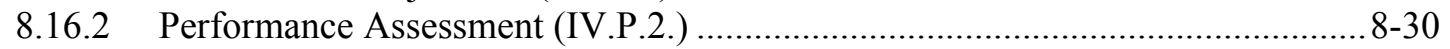

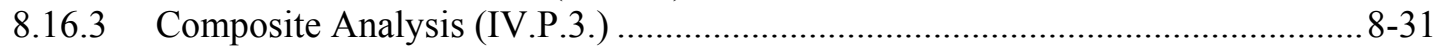

8.16.4 Performance Assessment and Composite Analysis Maintenance (IV.P.4.).........8-32

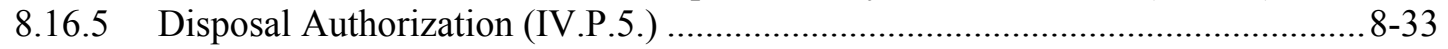

8.16.6 Disposal Facility Operations (IV.P.6.) ........................................................ 8-34

8.16.7 Alternate Requirements for Low-Level Waste Disposal Facility Design and Operation (IV.P.7.)......................................................................... 8-36

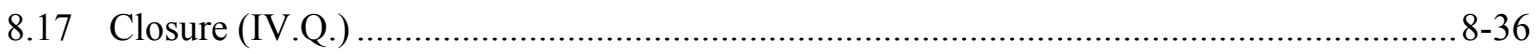


8.17.1 Disposal Facility Closure Plans (IV.Q.1.).................................................... 8-36

8.17.2 Disposal Facility Closure (IV.Q.2.) …...................................................... 8 -38

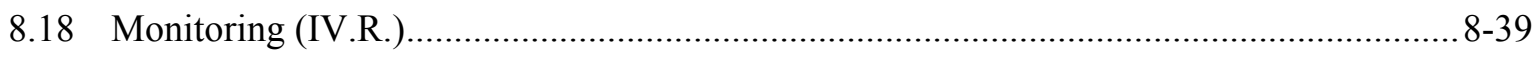

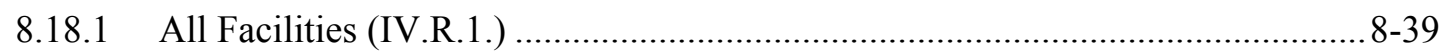

8.18.2 Liquid Waste Storage Facilities (IV.R.2.)..................................................... 8-39

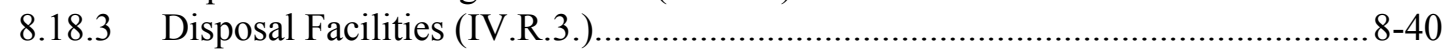

9. CROSSWALK WITH 435.1 REQUIREMENTS ….............................................................. 9-1

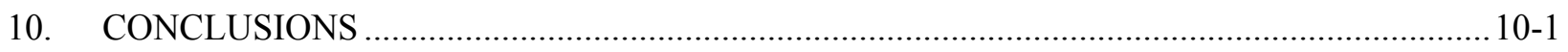

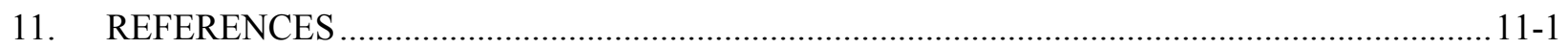

\section{FIGURES}

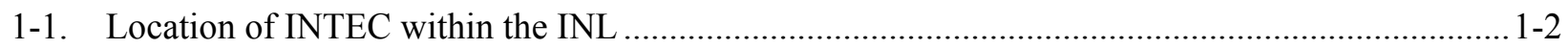

2-1. Location of the ICDF Complex components and proximity to INTEC …..................................2-2

2-2. Operable Unit 3-13 Record of Decision study area for the ICDF Complex................................2-3

2-3. Three-dimensional geologic cross sections of the ICDF Complex area showing the locations of the monitoring wells for the ICDF Complex

2-4a. An east-west geologic cross section south of the ICDF landfill..............................................2-5

2-4b. An east-west geologic cross section north of the ICDF landfill ............................................. $2-6$

3-1. Landfill excavation plan for Cells 1 and 2 showing the top of subgrade .................................... 3-6

3-2. Landfill final grading plan showing the elevations at the top of the operations layer (bottom of waste zone).

3-3. Liner system details for the landfill showing the various layers for leachate collection and recovery along with the other design features

3-4. Liner system details in the sump area for the landfill showing the various layers for leachate collection and recovery along with the other design features.

3-5. Drawing showing the elevations at the top of the engineered contaminant barrier for the closed landfill following construction

3-6. Drawing showing the cross section with the various design features of the engineered containment barrier for the landfill at closure

3-7. Evaporation pond final grading plan showing the elevations at the top of the sacrificial geomembrane (bottom of the liquid waste zone) 
3-8. Liner system details for the evaporation pond showing the various layers for leachate detection and recovery system along with other design features.

3-9. Conceptual drawing of the admin trailer exterior.

3-10. Expected floor plan for the admin trailer showing the various offices and other rooms in the building

3-11. Conceptual drawing of the decon building exterior (north, south, and east sides)......

3-12. Conceptual drawing showing the exterior of the decon building (west side)......

3-13. Floor plan for the decon building showing the various areas including the treatment area and decontamination bay

3-14a. Drawing showing the locations and sizes of the staging and storage areas for the ICDF Complex

3-14b.Drawing showing the location and sizes of the SSA storage area and SSA future staging area

3-15. ICDF Complex groundwater detection monitoring system wells

\section{TABLES}

4-1. Waste types excluded from acceptance into the ICDF Complex

4-2. Summary of WAC restrictions for staging and storage at the ICDF Complex

4-3. Summary of WAC restrictions for treatment in the soils stabilization treatment system

4-4. Summary of WAC restrictions for debris treatment at the ICDF Complex

4-5. Summary of WAC restrictions for landfill disposal at the ICDF Complex.

4-6. Materials restricted from disposal at the ICDF landfill until the listed conditions have been met.. 4-5

4-7. Summary of WAC restrictions for evaporation pond disposal at the ICDF Complex

4-8. Materials restricted from disposal at the ICDF evaporation pond until the listed conditions have been met

9-1. Summary of compliance with DOE Order 435.1 Chapter I requirements.

9-2. Summary of compliance with DOE Order 435.1 Chapter II requirements...

9-3. Summary of compliance with DOE Order 435.1 Chapter III requirements 9-15

9-4. Summary of compliance with DOE Order 435.1 Chapter IV requirements 


\section{ACRONYMS}

ALARA as low as reasonably achievable

ARAR applicable or relevant and appropriate requirements

CAMU Corrective Action Management Unit

CERCLA Comprehensive Environmental Response, Compensation and Liability Act

CFR Code of Federal Regulations

D\&D\&D deactivation, decontamination, and decommissioning

DOE Department of Energy

DOE-ID Department of Energy Idaho Operations Office

EDF Engineering Design File

EPA Environmental Protection Agency

FFA/CO Federal Facility Agreement and Consent Order

FS Feasibility Study

GCL geosynthetic clay layer

HDPE high-density polyethylene

HEPA high-efficiency particulate air

HLW high-level waste

ICDF Idaho CERCLA Disposal Facility

ICP Idaho Cleanup Project

IDAPA Idaho Department of Administrative Procedures Act

IDEQ Idaho Department of Environmental Quality

INL Idaho National Laboratory

INTEC Idaho Nuclear Technology and Engineering Center

ISMS Integrated Safety Management System

LDR land disposal restriction

LLW low-level waste 


\begin{tabular}{|c|c|}
\hline MLLW & mixed low-level waste \\
\hline NESHAP & National Emission Standards for Hazardous Air Pollutants \\
\hline NFPA & National Fire Protection Association \\
\hline NRC & Nuclear Regulatory Commission \\
\hline OU & operable unit \\
\hline $\mathrm{PCB}$ & polychlorinated biphenyl \\
\hline PPE & personal protective equipment \\
\hline RCRA & Resource Conservation and Recovery Act \\
\hline $\mathrm{RD} / \mathrm{CWP}$ & Remedial Design/Construction Work Plan \\
\hline $\mathrm{RI} / \mathrm{BRA}$ & Remedial Investigation/Baseline Risk Assessment \\
\hline ROD & Record of Decision \\
\hline SAP & Sampling and Analysis Plan \\
\hline SRPA & Snake River Plain Aquifer \\
\hline SSA & Staging and Storage Annex \\
\hline SSSTF & Staging, Storage, Sizing, and Treatment Facility \\
\hline TBC & to be considered \\
\hline TRU & transuranic \\
\hline TSCA & Toxic Substances Control Act \\
\hline WAC & Waste Acceptance Criteria \\
\hline WAG & waste area group \\
\hline
\end{tabular}




\section{Idaho CERCLA Disposal Facility Complex Compliance Demonstration for DOE Order 435.1}

\section{INTRODUCTION}

On-Site disposal of the Comprehensive Environmental Response, Compensation and Liability Act (CERCLA) waste streams at the Idaho National Laboratory (INL) (see Figure 1-1) was selected as the remedy for dealing with contaminated soils and debris under the Operable Unit (OU) 3-13 Record of Decision (ROD) (DOE-ID 1999). This alternative consists of the design, construction, operation, closure, and postclosure monitoring of the Idaho CERCLA Disposal Facility (ICDF) Complex, including the necessary support facilities. The major components of the ICDF Complex include the following:

- $\quad$ Disposal cells (landfill)

- $\quad$ Evaporation pond, consisting of two cells

- $\quad$ Admin trailer

- $\quad$ Scale

- Decontamination building (with treatment area)

- Contaminated equipment pad

- $\quad$ Staging and storage areas (includes staging and storage areas within the ICDF Complex along with the Staging and Storage Annex [SSA]).

Together, the above components of the ICDF Complex provide centralized waste acceptance, inspection, treatment, if necessary, and disposal of CERCLA-generated wastes from remediation and deactivation, decontamination, and decommissioning (D\&D\&D) sites at the INL.

\subsection{Purpose of ICDF Complex Compliance Demonstration}

In developing the OU 3-13 ROD (DOE-ID 1999), U.S. Department of Energy (DOE) Order 435.1, "Radioactive Waste Management," was identified as a "to be considered" (TBC) (DOE O 435.1) requirement for the selected on-Site disposal alternative. To demonstrate that the ICDF Complex will be in compliance with DOE Order 435.1 during operations, this document has been developed. Also, under DOE Order 435.1, it is necessary to demonstrate that the disposal facility is protective of human health and the environment, which must be met to obtain the "disposal authorization statement" for the facility to operate. This compliance demonstration provides the documentation to demonstrate that the ICDF Complex will be operated in compliance with DOE Order 435.1.

Under CERCLA, only the substantive requirement of laws and regulations are required to be met. The substantive requirements of the laws and regulations for the ICDF Complex are presented in the OU 3-13 ROD as the applicable or relevant and appropriate requirements (ARARs) for the construction, operation, closure, and postclosure care of the ICDF Complex. To determine what requirements of DOE Order 435.1 apply to the ICDF Complex, it is necessary to determine what requirements within the order 


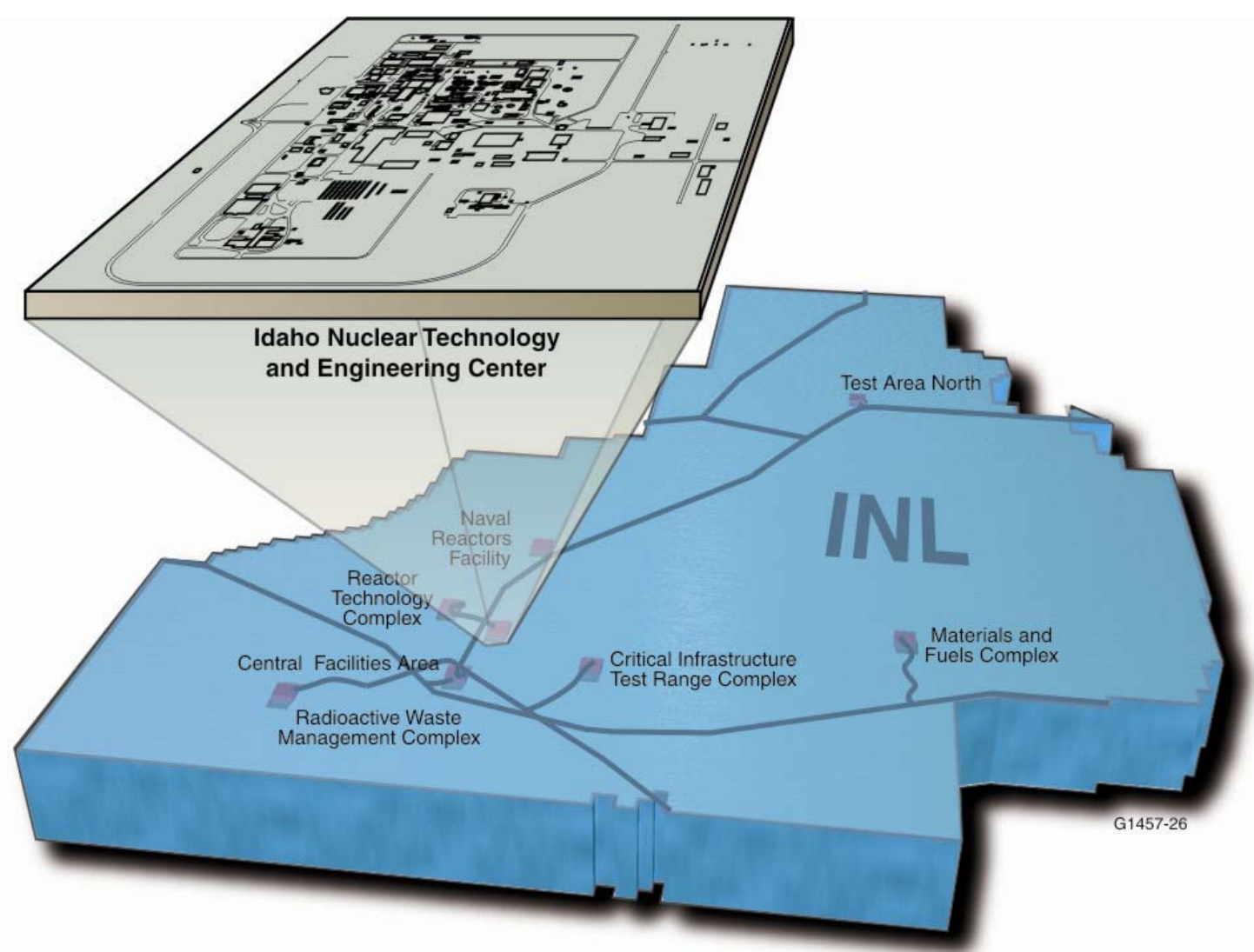

Figure 1-1. Location of INTEC within the INL. 
are administrative and substantive in nature ${ }^{\mathrm{a}}$. Evaluation of the administrative and substantive requirements in DOE Order 435.1 is presented in this compliance demonstration. The determinations of what requirements are administrative versus substantive in nature were accomplished by using the information presented in DOE Order 435.1 "Radioactive Waste Management," DOE Manual 435.1, "Radioactive Waste Management Manual," and DOE Guide 435.1 "Implementation Guide for Use with DOE M 435.1." All of the general, low-level waste (LLW), and transuranic (TRU) waste requirements in DOE Order 435.1 are presented in this compliance demonstration. Also, a discussion of why high-level waste requirements do not apply is included in this compliance demonstration. For the administrative requirements, the requirement is presented along with the statement that the requirement is administrative. Generally, no additional discussion is presented for the administrative requirements. How the substantive requirements in DOE Order 435.1 are being met is discussed in this compliance demonstration. In developing the design, construction, and operational documents for the ICDF Complex, the ARARs and other CERCLA requirements were evaluated in various documents. These CERCLA documents were used to evaluate and demonstrate compliance. DOE Order 435.1 substantive requirements are discussed in this compliance demonstration. This compliance demonstration also presents the ARARs for the ICDF Complex and how they are being complied with for the construction, operation, closure, and postclosure care.

Three major CERCLA documents deal with the design, construction, operation, and closure of the ICDF Complex. The first major document is the Staging, Storage, Sizing, and Treatment Facility (SSSTF) Remedial Design/Construction Work Plan (RD/CWP), which describes the SSSTF design and construction (DOE-ID 2002a). The second major document dealing with design and construction is the ICDF RD/CWP, which describes landfill and evaporation pond design and construction (DOE-ID 2002b). Operation and closure of the ICDF Complex is discussed in the ICDF Complex Remedial Action Work Plan (DOE-ID 2003a). Each major document has many attached documents, which are cited as necessary in this compliance demonstration.

\subsection{Organization of Compliance Demonstration}

Section 2 contains a discussion of the conceptual site model for the ICDF Complex. Within the discussion of the conceptual site model is the site selection with selection criteria. The discussion of the conceptual site model also covers the subsurface stratigraphy and the existing contamination in the ICDF Complex location.

Section 3 contains a discussion on the ICDF Complex designs. The designs for the ICDF landfill, ICDF evaporation ponds, and supporting facilities are presented. Within the discussion of the supporting facilities are the administrative facilities and utilities, decontamination facility, treatment facility, and storage facilities. In addition, a general discussion on the ICDF Complex groundwater monitoring is presented.

\footnotetext{
a. Substantive requirements are those requirements that pertain directly to actions or conditions in the environment. Examples include quantitative health or risk-based standards for certain hazardous substances (e.g., maximum contaminant levels for drinking water) and technology-based standards (e.g., Resource Conservation and Recovery Act minimum technology requirements for double liners and leachate collection systems).
}

\footnotetext{
Administrative requirements are those mechanisms that facilitate the implementation of the substantive requirements of a statute or regulation (e.g., requirements related to approval of, or consultation with, administrative bodies, documentation, permit issuances, reporting, recordkeeping, and enforcement).
}

These definitions were extracted from EPA (1991). 
Section 4 contains a discussion on the types of waste that would be accepted into the ICDF Complex. Within the ICDF Complex, there are different acceptable waste types for each facility. The acceptable types of waste for each of the facility types (staging and storage, treatment, landfill, and evaporation ponds) are presented.

Section 5 contains the discussion on compliance with Chapter I of DOE Order/Manual 435.1. A statement is made concerning whether the particular requirement within Chapter I is considered administrative or substantive, along with how the particular requirement is being met. In addition, a statement is made of how the requirements of Chapter I are being met and what CERCLA documents presented information dealing with the particular requirements.

Section 6 contains the discussion on why Chapter II of DOE Order/Manual 435.1 does not apply to the waste stream acceptable for the ICDF Complex. The ICDF Complex is not designed or constructed to meet design and operation standards for high-level waste (HLW) facilities. This discussion focuses on the evaluation of why spills of waste at the Idaho Nuclear Technology and Engineering Center (INTEC) from various facilities are not considered HLW.

Section 7 contains the discussion on compliance with Chapter III of DOE Order/Manual 435.1. A statement is made concerning whether the particular requirement within Chapter III is considered administrative or substantive along with how the particular requirement is being met. In addition, a statement is made of how the requirements of Chapter III are being met and what CERCLA documents presented information dealing with the particular requirements.

Section 8 contains the discussion on compliance with Chapter IV of DOE Order/Manual 435.1. A statement is made concerning whether the particular requirement within Chapter IV is considered administrative or substantive along with how the particular requirement is being met. In addition, a statement is made of how the requirements of Chapter IV are being met and what CERCLA documents presented information dealing with the particular requirements.

Section 9 presents the evaluation of what specific ICDF Complex ARARs apply to the various requirements for Chapters I, III, and IV of DOE Manual 435.1. Other requirements that meet the various requirements for the Chapters I, III, and IV of DOE Manual 435.1 are also presented. In addition, this section presents whether the requirement was determined to be administrative or substantive along with whether the requirement is being met under the CERCLA process.

Section 10 presents the conclusion of the evaluation of the ICDF Complex for compliance with DOE Order 435.1. 


\section{ICDF COMPLEX CONCEPTUAL SITE MODEL}

The ICDF Complex is designed to handle the INL's CERCLA-generated waste streams. Based on the existing and expected decisions (ROD and potentially CERCLA removal action decision memorandum), there is a large volume of waste that will be generated and require disposal. During the development of the OU 3-13 Remedial Investigation/Baseline Risk Assessment (RI/BRA) Report (DOE-ID 1997a) and OU 3-13 Feasibility Study (FS) Report (DOE-ID 1997b), a large volume of contaminated soils was identified that would need to be managed. One alternative that was evaluated in the OU 3-13 FS Report was for the excavation of the waste and on-Site disposal. Also, the analysis showed that it would be much more cost-effective to construct a new on-Site disposal facility that to ship the waste off-Site to a commercial disposal facility. Recently, an updated evaluation (EDF-2385) of the on-Site versus off-Site cost estimates reconfirmed that on-Site disposal is much more cost effective than off-Site disposal. The on-Site disposal would be a new facility to deal with the OU 3-13 waste streams. This concept was further evaluated in the OU 3-13 FS Supplement Report (DOE-ID 1998) and included expanding the facility to deal with the other INL CERCLA waste streams. In the OU 3-13 ROD (DOE-ID 1999), on-Site disposal was selected as the remedy, and the facility was sized to deal with the identified INL CERCLA waste streams.

With the decision in the OU 3-13 ROD, the ICDF Complex is defined as the centralized INL environmental restoration facility for dealing with the INL CERCLA waste streams. The ICDF Complex is responsible for the receipt, storage, treatment (as necessary), and disposal of INL CERCLA remediation (remedial and removal actions) waste. Within the ICDF Complex, there are functions (facilities) for receipt, weighing, staging and storage, treatment, and disposal of waste soils and debris. Figure 2-1 shows the facilities that compose the ICDF Complex. The treatment equipment is located in the decon building.

In Sections 2.1 through 2.3, the site selection, subsurface stratigraphy, and existing contamination at the facility are discussed.

\subsection{ICDF Complex Site Selection}

In developing the OU 3-13 ROD, the site selection criteria were developed. The site selection criteria considered the criteria associated with siting a hazardous waste landfill under both the Resource Conservation and Recovery Act (RCRA) and Toxic Substances Control Act (TSCA) landfill siting criteria. Also, criteria that the Nuclear Regulatory Commission (NRC) considers for radioactive waste disposal facilities (10 CFR 61) were considered. These siting criteria included (a) outside the 100-year flood plain, (b) outside of wetland areas, (c) not in active seismic zones, (d) not in high surface erosion zones, and (e) not in an area of high historic groundwater table.

As the majority of the waste volume would be generated from INTEC remediation, an area near INTEC was selected as the study area for siting the ICDF Complex. This study is shown in Figure 2-2. With the area selected for study within the area of contamination, additional flexibility for the management of OU 3-13 waste streams is allowed.

Further discussion concerning the selection of the study area is provided in the OU 3-13 ROD (DOE-ID 1999) in Section 11.1.3. A geotechnical investigation (DOE-ID 2000a) was conducted to refine the selected area for the landfill. The study area as presented in the OU 3-13 ROD was 134 acres. Following the geotechnical investigation, the area was reduced to a 40 -acre area, which was large enough for the landfill. This refined 40-acre area located on the west side of the study area had the deepest alluvium thickness and was used for the development of the conceptual design. The geotechnical investigation demonstrated that the selected area met the siting requirements. 


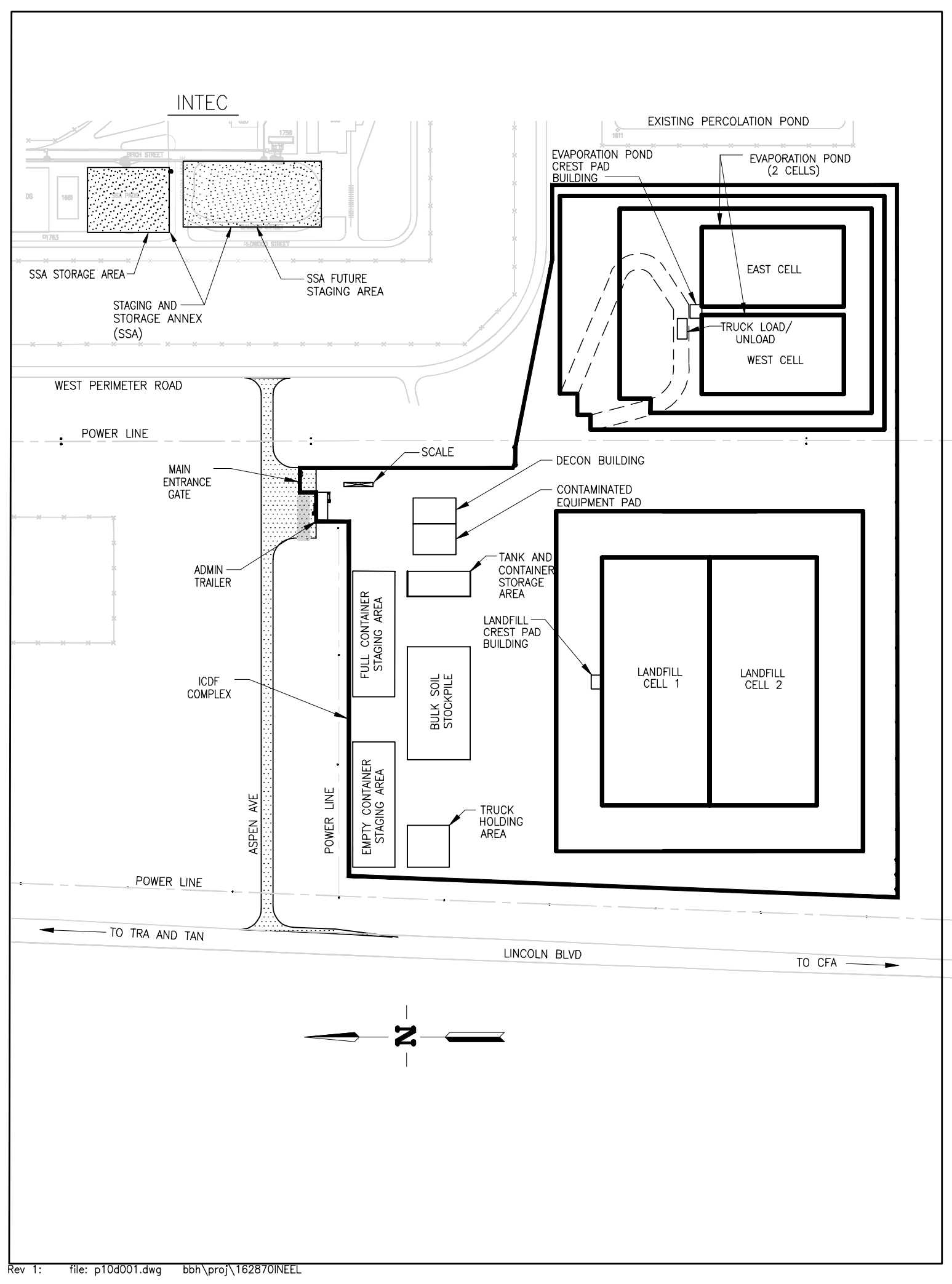

Figure 2-1. Location of the ICDF Complex components and proximity to INTEC. 


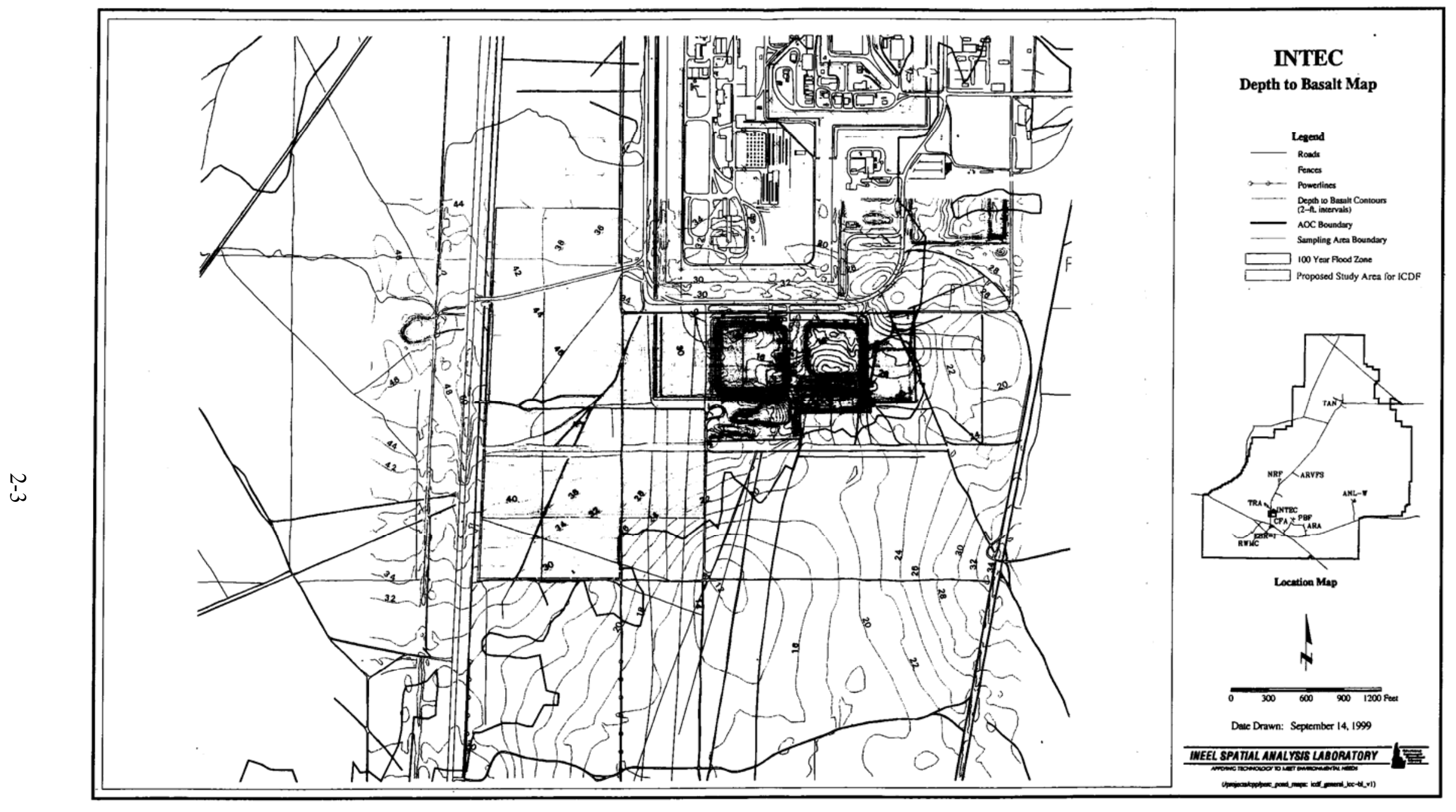

Figure 2-2. Operable Unit 3-13 Record of Decision study area for the ICDF Complex. 
Based on the refined area for the ICDF landfill, a siting study (EDF-1548) was conducted for the support facilities. This siting study evaluated the criteria and services that would be needed to support the operation of the ICDF Complex. An area to the north of the refined landfill 40-acre area was selected for the support facilities. From the selection of both areas, the ICDF Complex area was combined as shown in Figure 2-1.

\subsection{ICDF Complex Subsurface Stratigraphy}

The geology beneath the ICDF Complex is summarized in this section. For a more complete description, see other Department of Energy Idaho Operations Office (DOE-ID) documents (1997a, 1997b, and 1998). The subsurface geology has been characterized through the drilling of numerous Snake River Plain Aquifer (SRPA) and perched water wells and coreholes located in the vicinity of the ICDF Complex and INTEC. Information on the subsurface has been gathered from logs (lithologic, geophysical, and video) as well as tests (geotechnical and hydrologic). The locations of wells closest to the ICDF Complex are shown on Figure 2-3. Two east-west geologic cross sections (south of landfill and north of landfill) through the ICDF Complex are shown on Figures 2-4a and Figure 2-4b and are based on an analysis of lithologic logs and geophysical logs (such as neutron, caliper, and natural gamma) and an inspection of the cores.

\section{Block Diagram Showing Extent of Perched Water from Old INTEC Percolation Ponds}

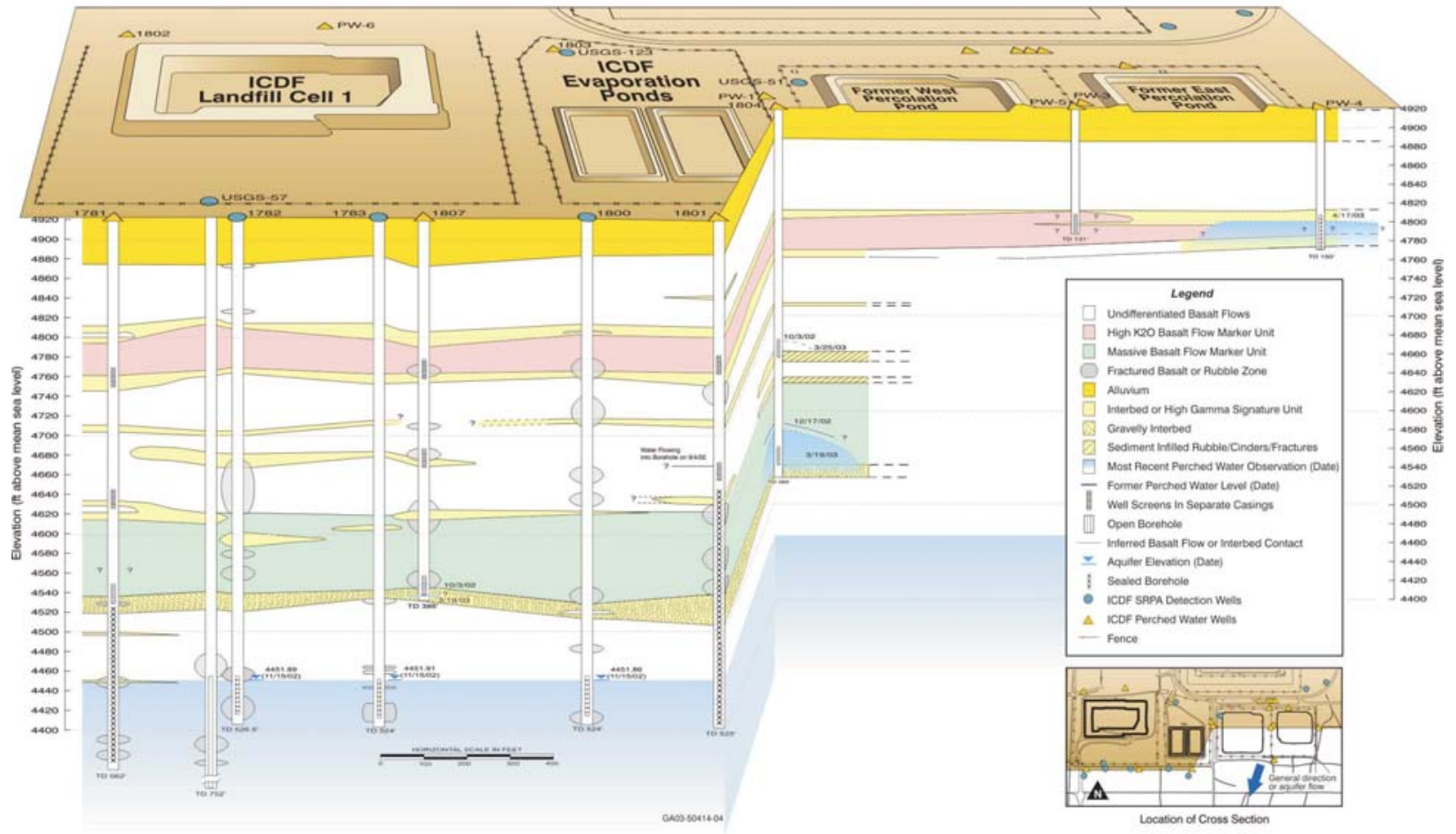

Figure 2-3. Three-dimensional geologic cross sections of the ICDF Complex area showing the locations of the monitoring wells for the ICDF Complex. 
B
West

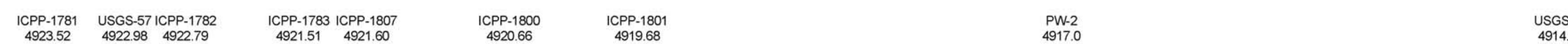

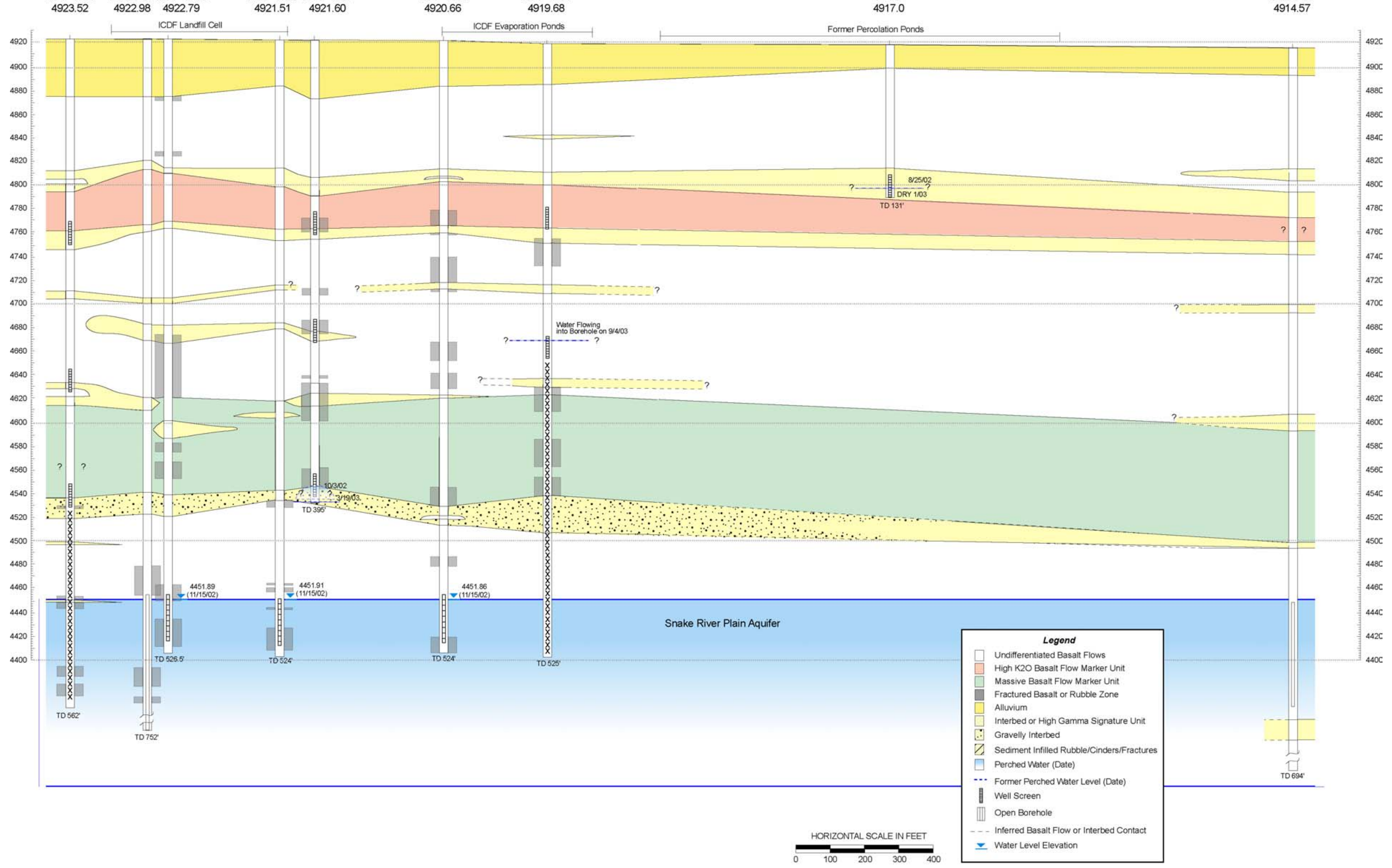

Figure 2-4a. An east-west geologic cross section south of the ICDF landfill. 


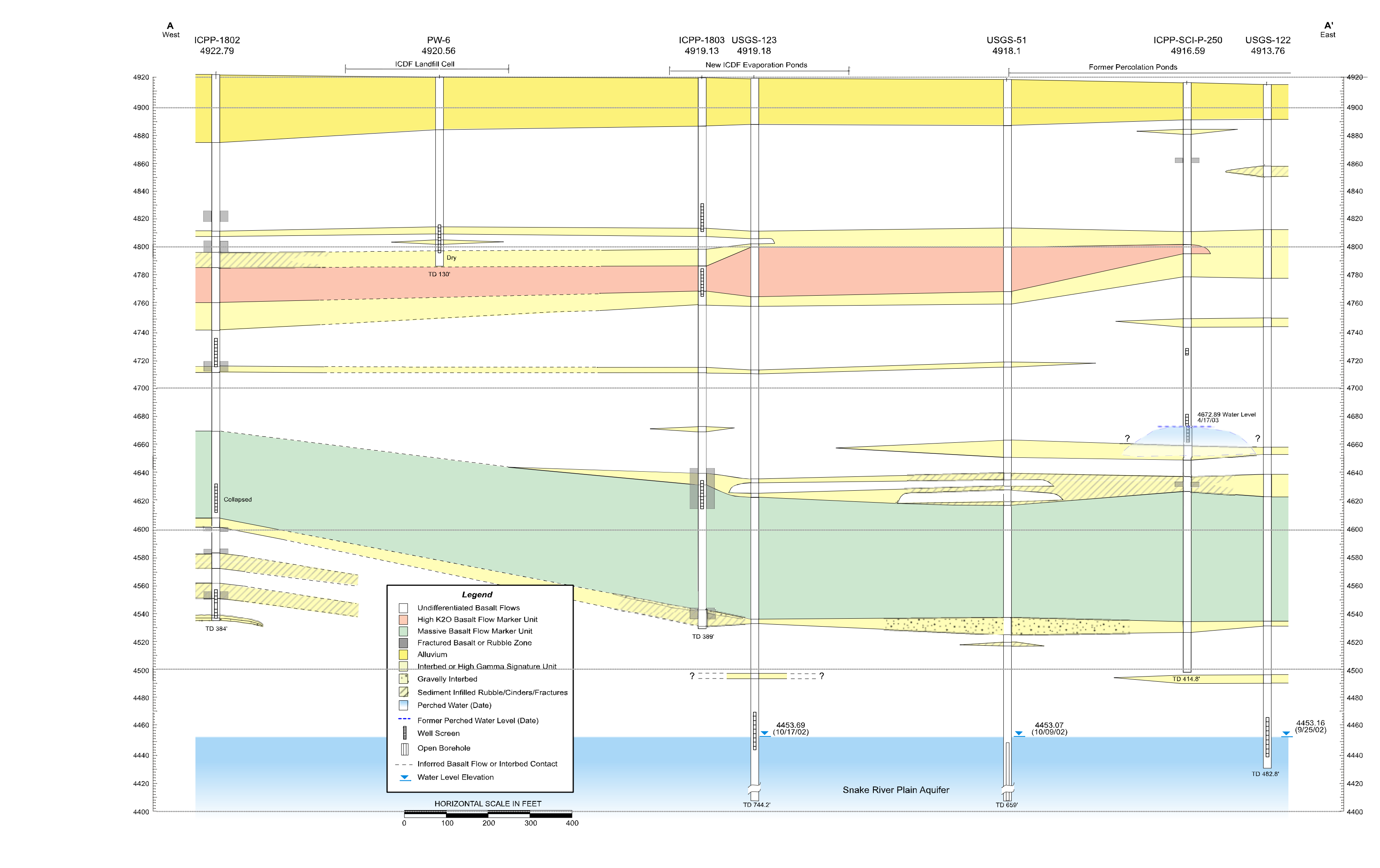


The subsurface beneath the ICDF Complex, as shown on Figures 2-4a and 2-4b, are characterized by approximately 30 to $55 \mathrm{ft}$ of alluvial materials underlain by a series of basalt flows and discontinuous sedimentary interbeds. The surface alluvium at the ICDF Complex has been mapped as a flood delta or fan related to late Pleistocene cataclysmic flooding, most likely from the Pinedale Glaciation (Rathburn 1991). The Pinedale Glaciation occurred between 12,000 and 35,000 years ago. An intermittent layer of fine sand, silt, and clay known as "old alluvium" in the literature (designation SM to CL) ranges in thickness from 0 to $13 \mathrm{ft}$ and occurs at the top of basalt. The thickness correlates to low spots and depressions and tends to increase to the south and west of the ICDF Complex. It is less prevalent in the northwest area. Sand lenses were periodically found within this layer. The sediments overlie vesicular dark gray, olivine basalt bedrock that may be weathered and fractured in the first several feet near the interface (DOE-ID 2000a).

As can be seen in Figures 2-4a and 2-4b, two very distinctive massive basalt flows can be used as marker beds and traced between most boreholes underneath the ICDF Complex. The depth at which these distinctive flows occur varies between boreholes. The CD basalt flow occurs at a depth between approximately 135 and $175 \mathrm{ft}$, and the DE5 basalt occurs at a depth between approximately 320 and $395 \mathrm{ft}$. The CD basalt flow is characterized by a higher-than-average natural-gamma count. Above the CD basalt flow is a fairly continuous series of thin interbeds interspersed with thin basalt flows. This is the most continuous interbed underlying the ICDF Complex and is the location of perched water that forms intermittently in response to wastewater discharges to the percolation ponds. As can be seen on Figures 2-4a and 2-4b, the other interbeds are discontinuous, are less massive, and cannot be traced horizontally between boreholes. The DE5 basalt is among the thickest and most massive of the basalt flows found in the subsurface underlying the ICDF Complex and has a typical thickness of nearly $100 \mathrm{ft}$.

\subsection{Existing Contamination at ICDF Complex Location}

The ICDF Complex is sited in an area of known surface contamination, which is referred to as the Site CPP-95. The real extent of contamination for Site CPP-95 was used for establishing the area of contamination under the OU 3-13 ROD. The surface contamination in the ICDF Complex area is primarily cesium-137 (Cs-137) and other trace radionuclides from the main stack at INTEC during operations. However, during the construction activities, the contamination exceeding approximately the INL background concentrations, was removed from beneath the ICDF Complex area prior to buildup of the pads, berms, and other structures. The contaminated soil was stockpiled and will be disposed of in the ICDF landfill during operations.

The contamination in the SRPA originated primarily from the former injection well (shown as CPP-3 on Figure 2-3). However, contaminated soils and perched water were predicted from modeling during the OU 3-13 RI/BRA to contribute to future SRPA contamination if sites were not remediated (DOE-ID 1997a). The iodine-129 (I-129), strontium-90 (Sr-90), and plutonium isotopes were determined to be the only contaminants that could pose an unacceptable risk to a hypothetical future resident beyond the year 2095. The primary I-129 source was the former injection well. The primary Sr-90 sources were the former injection well and the tank farm soils. The primary source of plutonium isotopes is the tank farm. The major human health threat posed by contaminated SRPA groundwater is exposure to radionuclides via ingestion by future groundwater users.

Sodium and chloride, two primary nonradioactive contaminants, were discharged to the percolation ponds and stemmed from the ion exchange process. Although concentrations vary over the years, average concentration of sodium in wastewater was $103 \mathrm{mg} / \mathrm{L}$ during 1971 to 1973 (Barraclough and Jensen 1976). During 1996 to 1998, approximately 708,000 lb of sodium was discharged to the ponds. The discharge weighted average ranged from $163 \mathrm{mg} / \mathrm{L}$ in 1996 to $124 \mathrm{mg} / \mathrm{L}$ in 1998 (Bartholomay and Tucker 2000). Sodium ranged from $120 \mathrm{mg} / \mathrm{L}$ in PW-6 to $210 \mathrm{mg} / \mathrm{L}$ in PW-1. Similar concentrations were 
reported in SWP-8 and SWP-13 (Tucker and Orr 1998). Barraclough and Jensen (1976) reported background concentrations of sodium in the SRPA as 8 to $10 \mathrm{mg} / \mathrm{L}$.

Discharge of chloride also varies over the years. About 3.6 million lb of chloride were discharged to the ponds between 1989 and 1991, and 3.5 million lb were discharged between 1996 and 1998. The discharge weighted average concentration was $267 \mathrm{mg} / \mathrm{L}$. With the exception of two concentrations from Well PW-6, chloride concentrations in perched water (SWP wells and PW wells) near the ponds reflect chloride concentrations in wastewater. Barraclough and Jensen (1976) reported that the background concentration of chloride in the SRPA is between 8 and $15 \mathrm{mg} / \mathrm{L}$.

Monitoring well MW-17 is north of the percolation ponds near the Building 603 fuel storage basins and was originally completed in three perched water zones. MW-17S monitors shallow perched water, is screened from 181.7 to $191.7 \mathrm{ft}$, and currently has water in it. MW-17P, which is currently dry, is screened from 263.8 to $273.8 \mathrm{ft}$. MW-17D monitored deep perched water and is screened from 360 to $381 \mathrm{ft}$. It is also currently dry. Data from a January 1995 sampling show that MW-17S was very low in all ions, whereas MW-17D had slightly elevated sodium and chloride but not as high as in the PW wells. This may indicate that water in MW-17D mixed with water from the service wastewater.

For comparison, water from SRPA monitoring wells, USGS-51 and USGS-57, located just east and south, respectively, of the ICDF Complex near PW-1, are very different from that in perched water wells in the same area. Similarly, water from the Big Lost River at the Lincoln Boulevard bridge is also distinctly different from the perched water. In addition, there is a distinct difference in water chemistry between the perched water near the ICDF Complex, which stems from the percolation ponds, and the northern perched water from Well 55-06 and from around the tank farm (Well 33-4).

USGS-51, the Big Lost River, and the INTEC water supply samples are very similar. In comparison, USGS-57 has higher chloride. The northern perched water is higher in chloride than the Big Lost River and USGS-51 but lower in chloride than the perched water from the percolation ponds.

The upgradient aquifer (water supply) and Big Lost River are very similar with essentially no nitrate. The perched water around the percolation ponds is also low in nitrate but elevated in chloride. The northern perched zone has intermediate chloride but much more nitrate than other water sources. This nitrate could be from the sewage treatment plant or nitric acid from spills in the tank farm.

The USGS monitored the PW wells around the percolation ponds for Sr-90, H-3, and Cs-137 among other constituents of wastewater discharged to the percolation ponds. USGS data indicate H-3 and Sr-90 contamination in the perched water at similar concentrations to wastewater that was discharged to the ponds (Tucker and Orr 1998). Chloride, manganese, and iron exceeded the federal secondary drinking water standards. Sr-90, H-3, and nitrate have exceeded the primary drinking water standard in the past (INEL 1995).

The percolation ponds adjacent to the ICDF Complex were taken out of service on August 26, 2002, and the discharges are now going to the new percolation ponds, approximately 2 miles west of INTEC. As shown on Figures 2-4a and 2-4b, the water levels in the perched water around the ICDF Complex have begun to decrease and are expected to continue to decrease over time, because the percolation ponds are the primary source of water. In other perched water wells at the INL (Waste Area Group [WAG] 2, for example), contaminant concentrations have been known to spike as wells begin to go dry. Dramatic increases in concentrations are expected for the new perched water wells at the ICDF Complex as water levels decline. 


\section{ICDF COMPLEX DESIGNS}

The ICDF Complex is a facility consisting of a landfill, two evaporation ponds, staging and storage areas, a decontamination facility, a treatment facility, utilities required to operate, and an administrative facility. The ICDF Complex is able to deal with hazardous, low-level, mixed low-level, TRU (limited quantities for temporary storage), and mixed TRU (limited quantities for temporary storage) waste streams from INL CERCLA remediation projects (remedial and removal actions).

The ICDF landfill is an engineered disposal facility with a disposal capacity of 510,000 $\mathrm{yd}^{3}$ that will be constructed in two phases (each phase having approximately $255,000 \mathrm{yd}^{3}$ of disposal capacity). The ICDF landfill is being designed and constructed to meet the requirement of DOE Order 435.1, RCRA Subtitle C (hazardous waste), and TSCA polychlorinated biphenyl (PCB) design and construction standards. The ICDF landfill will be closed by constructing a multi-layer engineered containment barrier (cap) with an expected design life of 1,000 years. The ICDF landfill will accept waste soils and debris from INL CERCLA remediation projects (remedial and removal actions) for disposal.

The ICDF evaporation ponds are expected to undergo clean closure when no longer needed. The ICDF evaporation ponds will be used to treat and dispose of leachate from the operation of the ICDF landfill and other aqueous waste from the ICDF Complex along with INL CERCLA aqueous liquid wastes (e.g., well purge water, well development water).

The ICDF staging and storage areas are for temporary staging of waste material prior to disposal in the ICDF landfill or evaporation pond. In addition, if the waste does not meet the Waste Acceptance Criteria (WAC) of the ICDF landfill or evaporation pond, the staging and storage areas will be used to stage waste for treatment to meet the landfill or evaporation pond WAC and/or for packaging for off-Site disposal. There is also a contaminated equipment storage area for staging equipment prior to decontamination.

The ICDF decontamination facility is a preengineered steel building containing decontamination water sprays and collection sumps for decontaminating equipment. This facility also includes the change rooms, doff/donning areas, and other areas necessary for operation of a radiological/hazardous waste facility.

The ICDF treatment facility is an area within the decontamination facility for treating waste soils by soil stabilization. This will be accomplished by mixing the contaminated soils with Portland cement and other chemicals for stabilization of the waste soil to meet the land disposal restriction (LDR) standards as necessary. In addition, the ICDF treatment facility also will treat boxed debris waste using micro-encapsulation technology by filling the void areas in the boxes with grout.

The ICDF Complex utilities include the potable water, raw water, fire water, sewer, electrical power, telecommunications, and electronic data transfer components of the ICDF Complex. All of these utilities except the electrical power will be received from the Idaho Nuclear Technology and Engineering Center (INTEC). Electrical power will be received from outside of INTEC.

The ICDF Complex administrative facility is the receiving facility for the ICDF Complex. This facility consists of the admin trailer housing the management and office personnel, waste tracking system, the weigh scales, and the physical access controls to the ICDF Complex.

Each of these facilities and structures are discussed further in Sections 3.1 through 3.7. In addition, the groundwater monitoring system is discussed in Section 3.8. 


\subsection{Landfill}

The ICDF landfill is a modular design, consisting of two cells, with a total capacity of $390,000 \mathrm{~m}^{3}$ $\left(510,000 \mathrm{yd}^{3}\right)$. The first cell, Cell 1, has been constructed and construction of Cell 2 will proceed as needed. Contaminated soils will be permanently contained in this engineered facility, which is designed for long-term protection of human health and the environment. Institutional controls will be maintained at the ICDF Complex as long as necessary to ensure long-term protection.

The ICDF landfill is designed and will be operated to meet the substantive requirements of DOE Order 435.1 for radioactive waste landfill design and operating requirements. Additionally, the ICDF landfill will be engineered to meet Idaho Administrative Procedures Act (IDAPA) 58.01.05.008 (40 CFR 264.301) hazardous waste and 40 CFR 761.75 PCB design and operating substantive requirements. The ICDF landfill and evaporation pond will be designed such that cumulative carcinogenic risk from all pathways is less than or equal to $1 \times 10^{-4}$. The ICDF landfill will meet or exceed RCRA, Subtitle C design standards and the PCB Chemical Waste Landfill design requirements. The ICDF landfill and evaporation pond design will be protective of human and ecological receptors. The ICDF Complex will accept only INL on-Site CERCLA wastes meeting the ICDF WAC document (DOE-ID 2005).

\subsubsection{Landfill Disposal Cell Design}

In designing the ICDF landfill, design criteria were developed. These design criteria consisted of three types: general, RCRA, and TSCA PCB design and construction requirements. Each of the requirements is discussed below.

3.1.1.1 Landfill General Design Criteria. The following list provides the general criteria for landfill design:

- $\quad$ The landfill will be designed to be protective of the SRPA, such that groundwater does not exceed a cumulative carcinogenic risk of $1 \times 10^{-4}$, a total hazard index of 1, or applicable State of Idaho groundwater quality standards (e.g., maximum contaminant levels) using a future residential scenario.

- $\quad$ The ICDF landfill will be closed and capped to prevent exposure of the public to a cumulative carcinogenic risk of $1 \times 10^{-4}$ and a total hazard index of 1 using a future residential scenario.

- $\quad$ The ICDF landfill will have a total capacity of approximately $390,000 \mathrm{~m}^{3}\left(510,000 \mathrm{yd}^{3}\right)$, and will be designed for an operational life of 15 years, a postclosure period of 30 years, and an expected cap design life of 1,000 years.

- $\quad$ The ICDF landfill will be designed to minimize precipitation run-on and maximize precipitation run-off to effectively reduce infiltration through the contaminated soils and debris.

- The ICDF landfill will be designed to minimize subsidence of the waste and the landfill cap.

- The ICDF landfill will be designed to ensure that the resulting design protects human and ecological receptors.

- $\quad$ The ICDF landfill will be designed to ensure that the resulting design protects the SRPA. 
3.1.1.2 RCRA Subtitle C Landfill Design Criteria. The following list provides the criteria for RCRA landfill design:

- $\quad$ The ICDF landfill will be engineered to meet the substantive RCRA Subtitle C landfill design requirements, which are identified in 40 CFR 264.301. The technical design requirements include requirements for the liner system and leachate collection and removal system. The liner system must include the following:

- $\quad$ A top liner designed and constructed of materials (e.g., a geomembrane) to prevent the migration of hazardous constituents into such liner during the active life and postclosure care period.

- $\quad$ A composite bottom liner, consisting of at least two components. The upper component must be designed and constructed of materials (e.g., a geomembrane) to prevent the migration of hazardous constituents into this component during the active life and postclosure care period. The lower component must be designed and constructed of materials to minimize the migration of hazardous constituents if a breach in the upper component were to occur. The lower component must be constructed of at least $3 \mathrm{ft}(91 \mathrm{~cm})$ of compacted soil material with a hydraulic conductivity of no more than $1 \times 10^{-7} \mathrm{~cm} / \mathrm{sec}$.

- The leachate collection and removal system immediately above the top liner must be designed, constructed, operated, and maintained to collect and remove leachate from the landfill during the active life and postclosure care period. The leachate collection and removal system between the liners, and immediately above the bottom composite liner in the case of multiple leachate collection and removal systems, is also a leak detection system. This leak detection system must be capable of detecting, collecting, and removing leaks of hazardous constituents at the earliest practicable time through all areas of the top liner likely to be exposed to waste or leachate during the active life and postclosure care period. The requirements for a leak detection system are satisfied by installation of a system that is, at a minimum:

- $\quad$ Constructed with a bottom slope of $1 \%$ or more.

- $\quad$ Constructed of granular drainage materials with a hydraulic conductivity of $1 \times 10^{-2} \mathrm{~cm} / \mathrm{sec}$ or more, and a thickness of $12 \mathrm{in} .(30.5 \mathrm{~cm})$ or more; or constructed of synthetic or geonet drainage materials with a transmissivity of $3 \times 10^{-5} \mathrm{~m}^{2} / \mathrm{sec}$ or more.

- $\quad$ Constructed of materials that are chemically resistant to the waste managed in the landfill and the leachate expected to be generated, and of sufficient strength and thickness to prevent collapse under the pressures exerted by overlying wastes, waste cover materials, and equipment used at the landfill.

- $\quad$ Designed and operated to minimize clogging during the active life and postclosure care period.

- $\quad$ Constructed with sumps and liquid removal methods (e.g., pumps) of sufficient size to collect and remove liquids from the sump and prevent liquids from backing up into the drainage layer. Each unit must have its own sump(s). The design of each sump and removal system must provide a method for measuring and recording the volume of liquids present in the sump and of liquids removed. 
- The owner or operator shall collect and remove pumpable liquids in the leak detection system sumps to minimize the head on the bottom liner. The owner or operator of a leak detection system that is not located completely above the seasonal high water table must demonstrate that the operation of the leak detection system will not be adversely affected by the presence of groundwater.

3.1.1.3 TSCA PCB Landfill Design Criteria. The following list provides the criteria for TSCA PCB landfill design:

- $\quad$ Technical requirements for chemical waste landfills used for the disposal of PCBs and PCB items are established in 40 CFR 761.75. The landfill site shall be located in thick, relatively impermeable formations such as large-area clay pans. Where this is not possible, the soil shall have a high clay and silt content with the following parameters:

- $\quad$ In-place soil thickness of $4 \mathrm{ft}$ or compacted soil liner thickness of $3 \mathrm{ft}$

- $\quad$ Permeability $(\mathrm{cm} / \mathrm{sec})$ equal to or less than $1 \times 10^{-7}$

- $\quad$ Percent soil passing No. 200 Sieve $>30$

- $\quad$ Liquid limit $>30$

- $\quad$ Plasticity index $>15$.

- $\quad$ Synthetic membrane liners shall be used when the hydrologic or geologic conditions at the landfill require such a liner in order to provide at least a permeability equivalent to the soils listed in the bullets above. Whenever a synthetic liner is used at a landfill site, special precautions shall be taken to ensure that its integrity is maintained and that it is chemically compatible with PCBs. Adequate soil underlining and soil cover shall be provided to prevent excessive stress on the liner and to prevent rupture of the liner. The liner must have a minimum thickness of 30 mils.

\subsubsection{Landfill Design}

Using these design criteria in Section 3.1.1, the design for the ICDF landfill was developed. The various layers contained in the ICDF landfill construction, above the subgrade, are as follows:

- A 3-ft-thick operations layer

- A primary composite drainage net drainage layer

- A 60-mil textured primary high-density polyethylene (HDPE) geomembrane

- $\quad$ An internally reinforced geosynthetic clay layer (GCL)

- A secondary composite drainage net drainage layer

- A 60-mil textured secondary HDPE geomembrane

- $\quad$ A 3-ft-thick low-permeability compacted clay (soil-bentonite admix) liner (CCL). 
Figure 2-1 shows the general site layout for the ICDF Complex including the landfill, evaporation pond cells, administrative and decon/treatment buildings along with the staging and storage areas. The excavation plan for the ICDF landfill (both cells) is presented in Figure 3-1. Figure 3-2 is the final grading plan (top of landfill operations layer) for both landfill cells. Figures 3-3 and 3-4 present the liner system cross-sections for the ICDF landfill cells. Additional information concerning the design and the analysis conducted to support the design is contained in the ICDF RD/CWP (DOE-ID 2002b) and supporting design analysis documents.

\subsubsection{Landfill Engineered Containment Barrier Design}

In designing the engineered containment barrier (cap) for the ICDF landfill at closure, design criteria were developed. These design criteria consisted of three types: general, RCRA, and construction requirements. Each of the requirements is discussed below.

3.1.3.1 Landfill Closure General Design Criteria. The following list provides the general criteria for landfill closure:

- Access restrictions to prevent intrusions into the closed area, including the creation of a buffer zone surrounding the capped ICDF landfill and supporting structures.

- Access controls, monitoring, and maintenance will remain in place for as long as the contents of the landfill remain a threat to human health or the environment if uncontrolled.

- $\quad$ Ensure that the final cover is designed to serve as an intrusion barrier for a period of at least 1,000 years.

- $\quad$ Minimize subsidence of the landfill and its final cover.

- $\quad$ Place easily located permanent markers at all corner boundaries for each cell landfill that identify the potential exposure hazards.

- $\quad$ Place permanent land use restrictions, zoning restrictions, and deed restrictions on the ICDF landfill and evaporation pond and its adjacent buffer zone to permanently preclude industrial or residential development until unacceptable risk no longer remains at the site.

- Include the disposal records and surveyed permanent marker locations in the land use restriction documents.

3.1.3.2 RCRA Subtitle C Landfill Closure Design Criteria. The following provides the RCRA criteria for landfill closure:

- $\quad$ Meet the substantive requirements of RCRA Subtitle $\mathrm{C}$ closure and postclosure care requirements specified in IDAPA 58.01.05.008 (40 CFR 264.310[a][1][2][3][4][5] and 40 CFR 264.310[b][1][4][5][6]). 


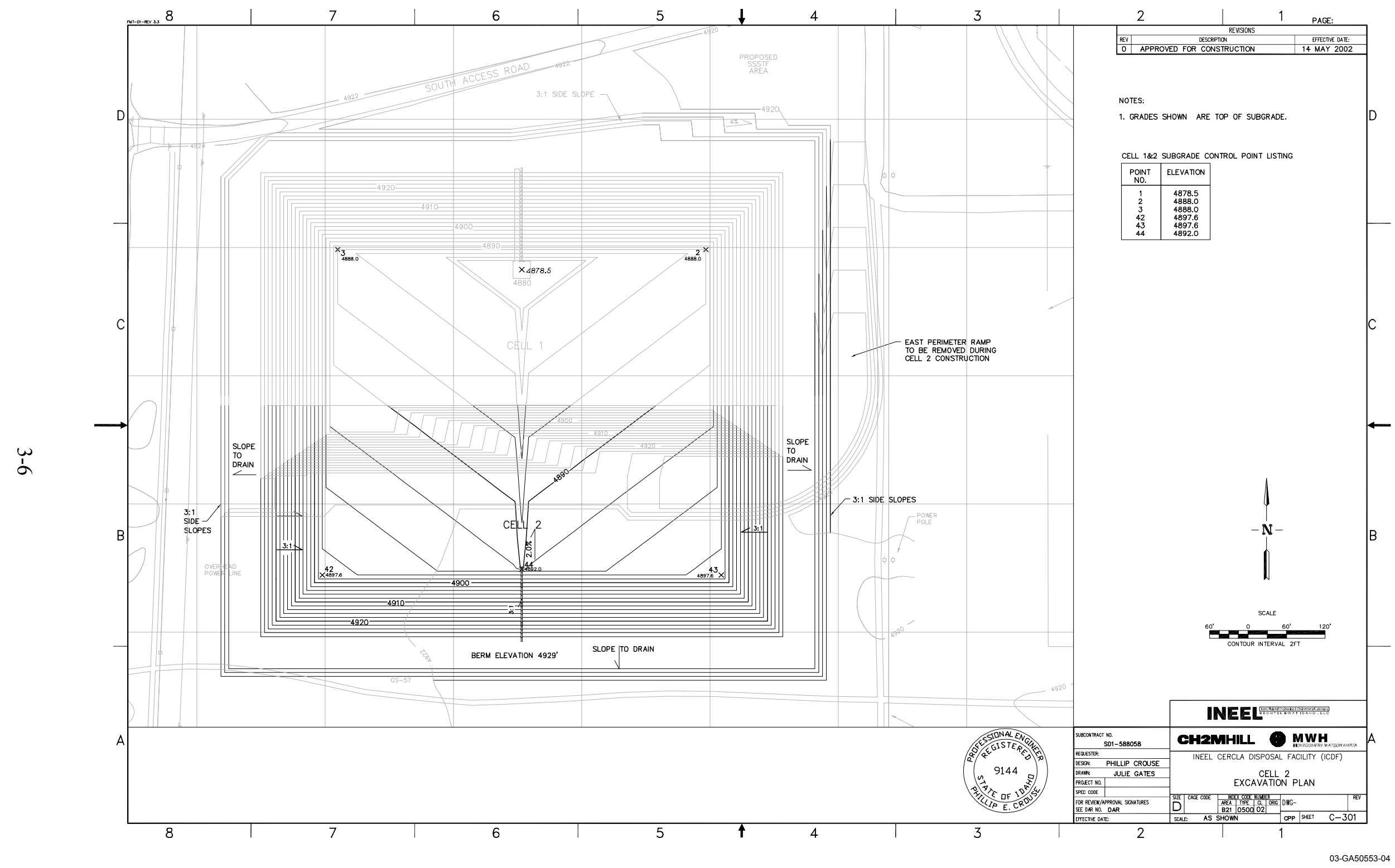

Figure 3-1. Landfill excavation plan for Cells 1 and 2 showing the top of subgrade. 


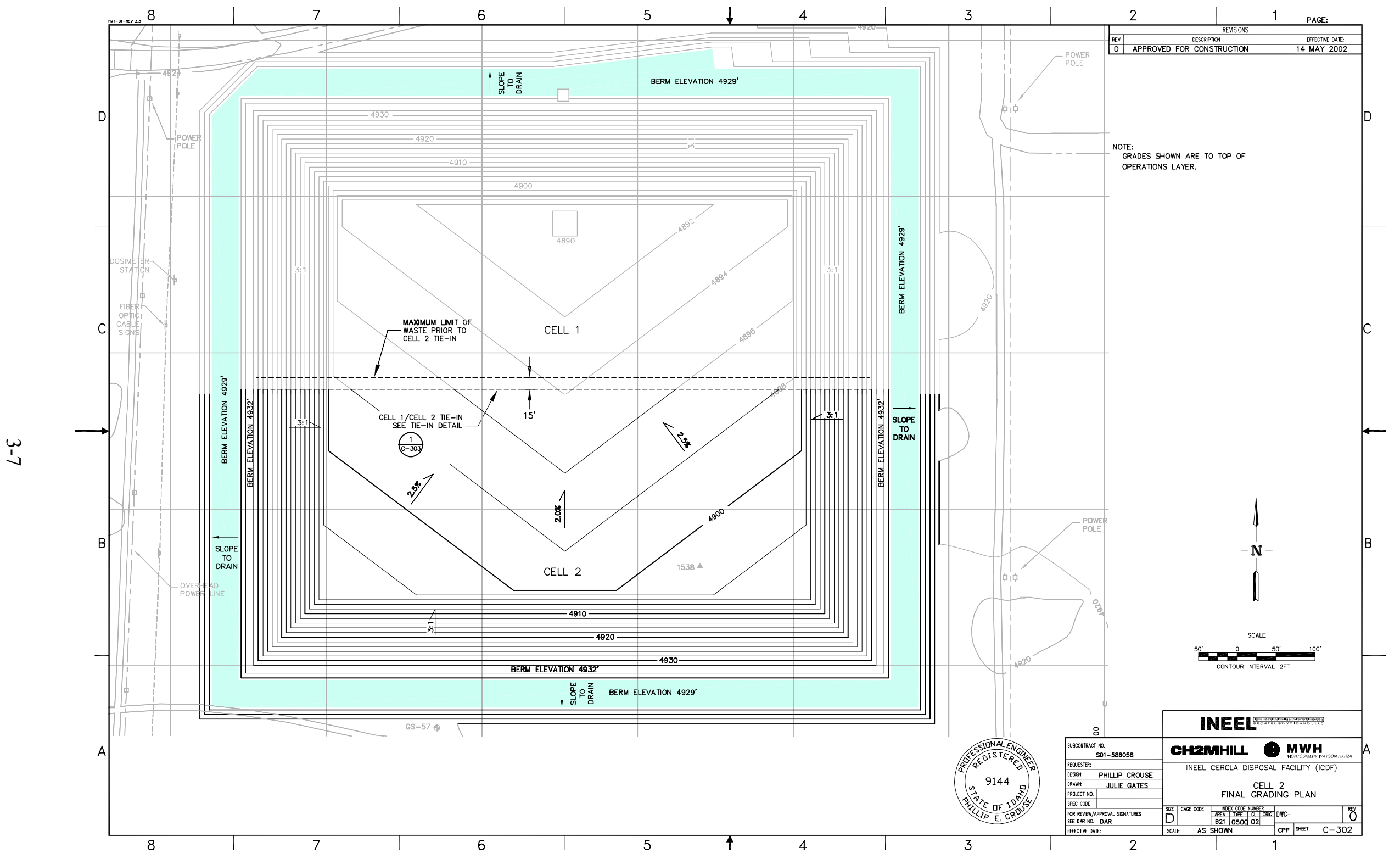

Figure 3-2. Landfill final grading plan showing the elevations at the top of the operations layer (bottom of waste zone). 


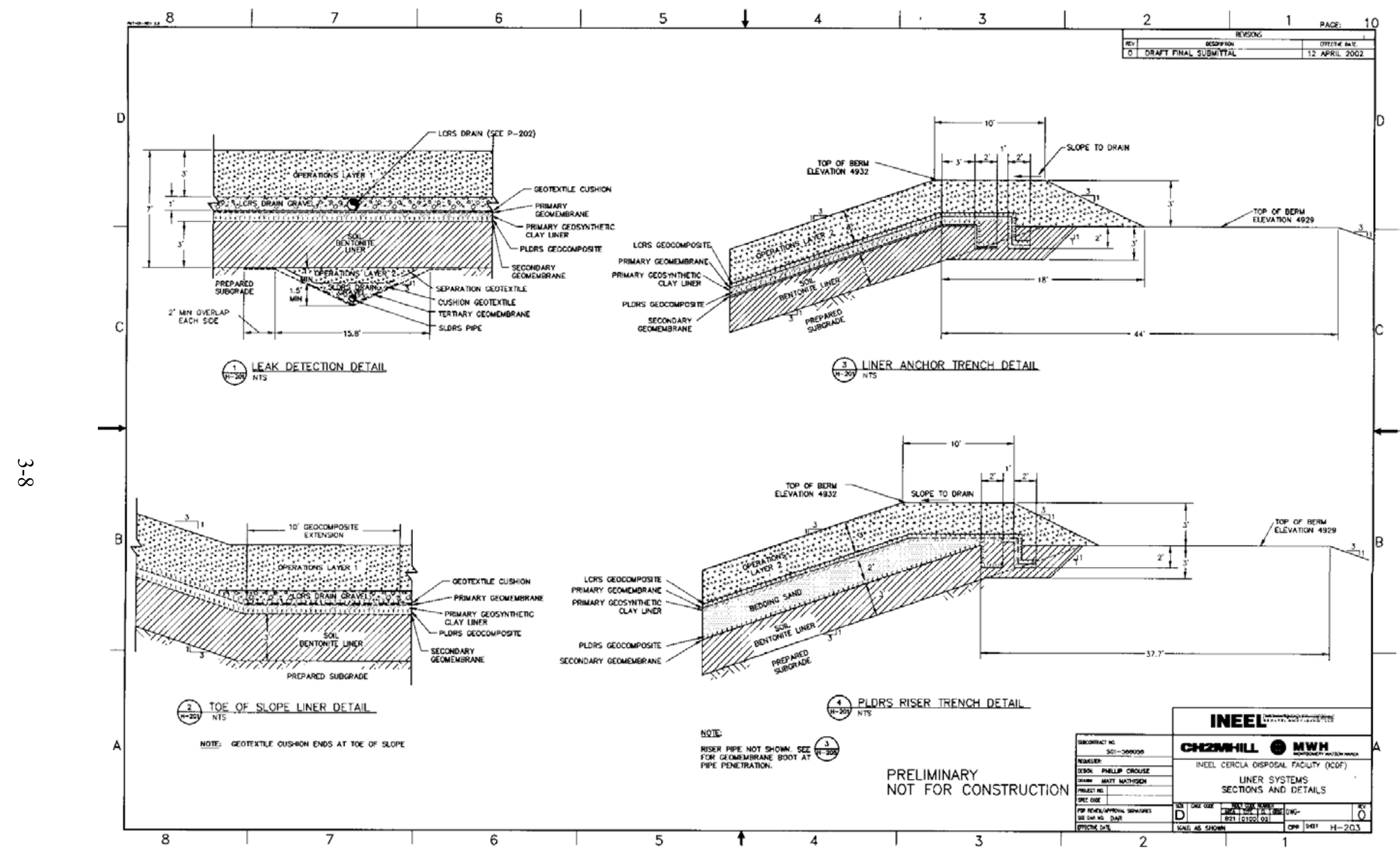

Figure 3-3. Liner system details for the landfill showing the various layers for leachate collection and recovery along with the other design features. 


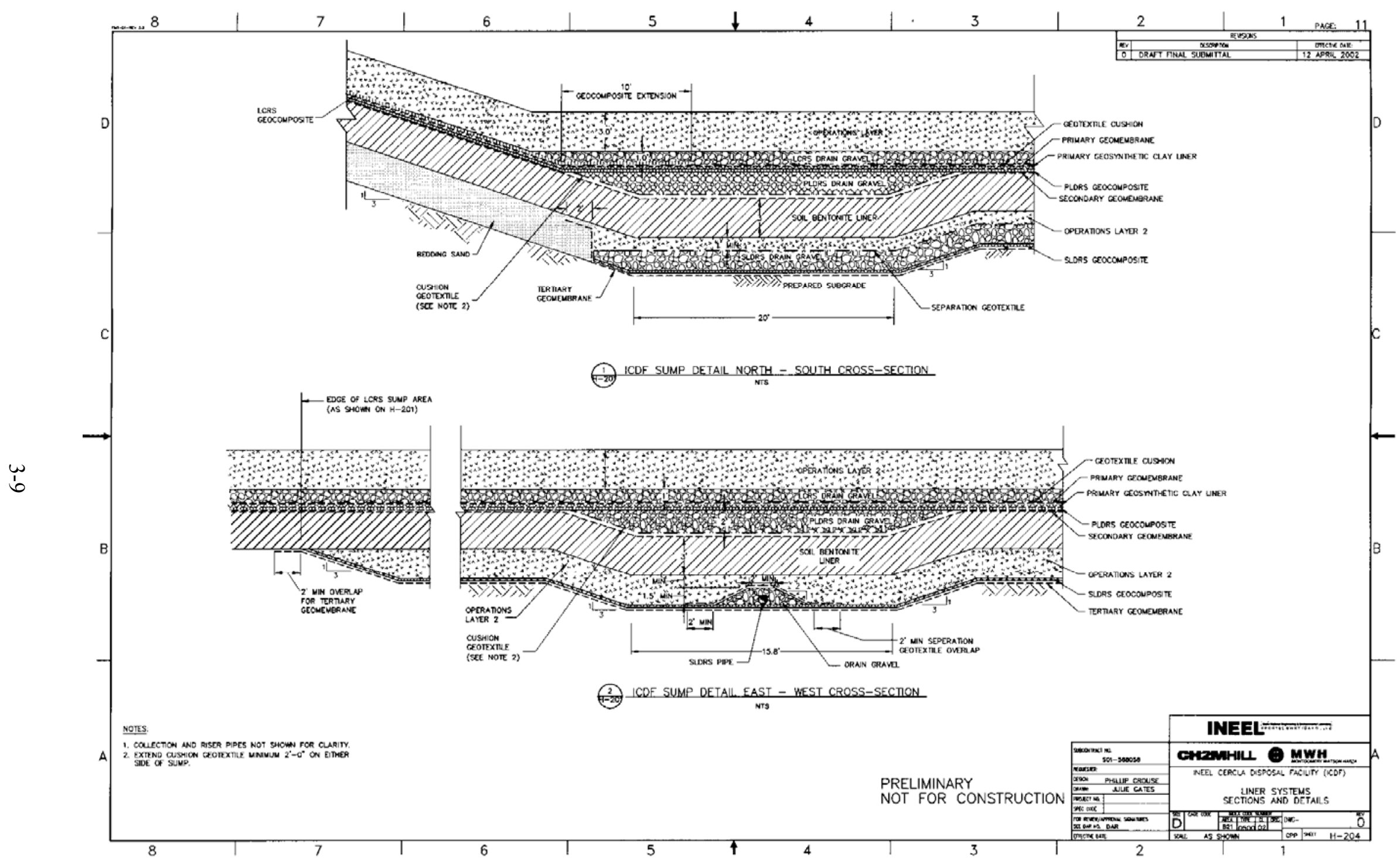

Figure 3-4. Liner system details in the sump area for the landfill showing the various layers for leachate collection and recovery along with the other design features. 
3.1.3.3 Landfill Closure Design. Using these design criteria in Section 3.1.3, the design for the ICDF landfill engineered containment barrier was developed. The various layers contained in the ICDF landfill engineered containment barrier, above the subgrade, are as follows:

- A structural fill layer

- $\quad$ A 2-ft-thick low permeability compacted clay (soil-bentonite admix) liner (CCL)

- A geomembrane

- A 1-ft-thick type 1 lower-filter sand layer

- A 1-ft-thick type 2 lower-filter gravel layer

- A 2.5-ft-thick type 3 armor layer

- $\quad$ A 1-ft-thick type 2 upper-filter gravel layer

- $\quad$ A 1-ft-thick type 1 upper-filter sand layer

- $\quad$ An 8-ft-thick engineered structural fill layer for water storage

- A 1-ft-thick layer of topsoil/gravel

- Vegetation

- Additional protection included for the outside edges of the engineered containment barrier.

Figure 3-5 is the final grading plan (top of the landfill engineered containment barrier) for both closed landfill. The cross-sectional details for the engineered containment barrier are presented in Figure 3-6. Additional information concerning the design and the analysis conducted to support the design is contained in the ICDF RD/CWP (DOE-ID 2002b) and supporting design analysis documents.

\subsection{Evaporation Pond}

The ICDF evaporation pond is designated as a Corrective Action Management Unit (CAMU) in accordance with the substantive requirements of IDAPA 58.01.05.008 (40 CFR 264.552 and 40 CFR 264, Subparts K and CC) for the purpose of managing ICDF landfill leachate, other aqueous wastes generated as a result of operating the ICDF Complex, and INL CERCLA aqueous wastes that meet the evaporation pond WAC. The evaporation pond will accept ICDF landfill leachate and potentially contaminated aqueous waste streams generated from the INTEC and other INL CERCLA actions, development water from monitoring well drilling operations, and secondary aqueous wastes generated from waste processing and decontamination activities in the SSSTF and other INL CERCLA projects. The ICDF evaporation pond system consists of two 2,200,000-gallon capacity ponds that will contain the aqueous wastes. The evaporation pond design consists of two individual cells to allow for maintenance in one cell while operations continue in the other pond. The pump system will track the volume of waste disposed to the pond. Wastes accepted in the ICDF evaporation pond will meet the ICDF Complex WAC (DOE-ID 2005). 


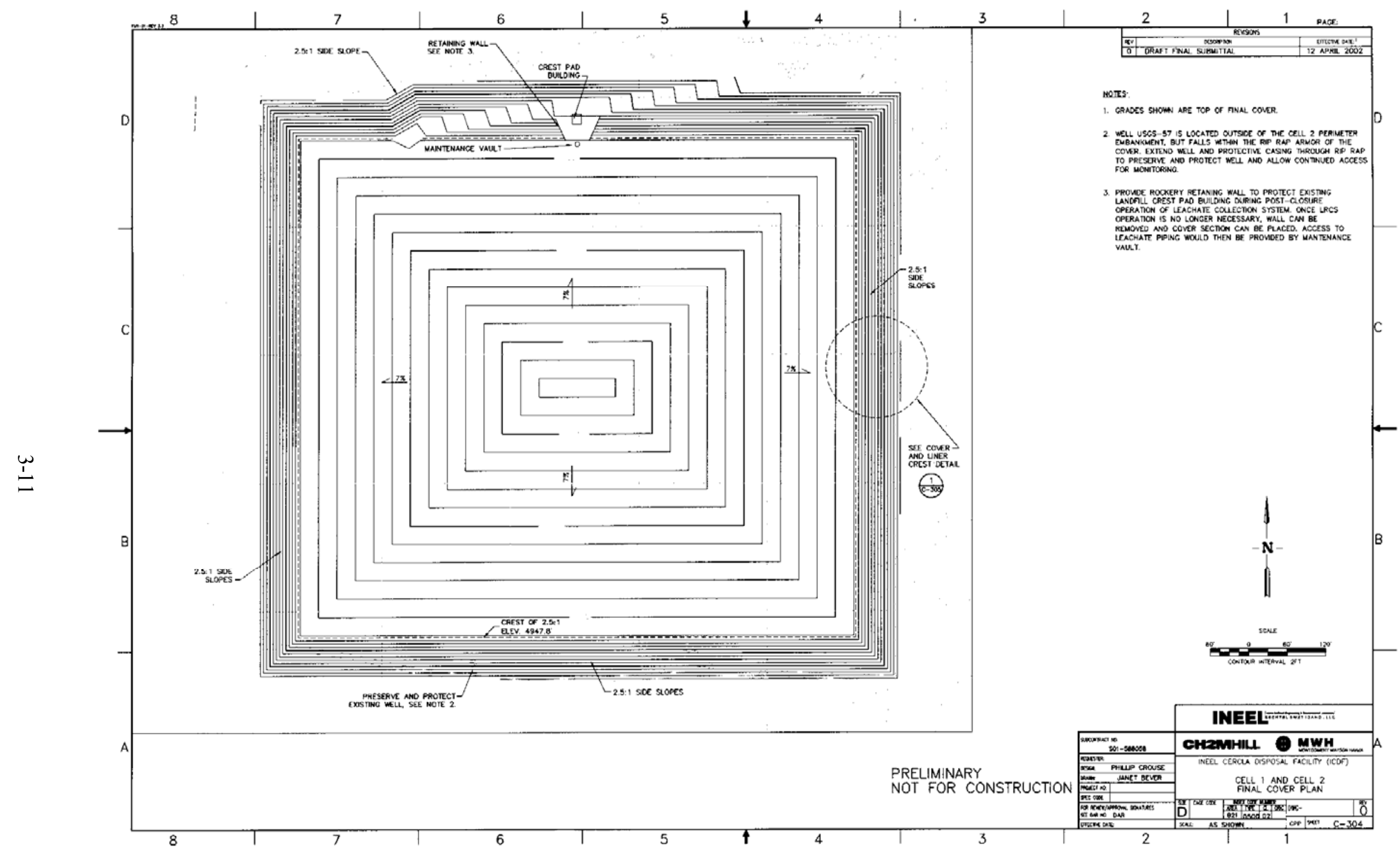

Figure 3-5. Drawing showing the elevations at the top of the engineered contaminant barrier for the closed landfill following construction. 


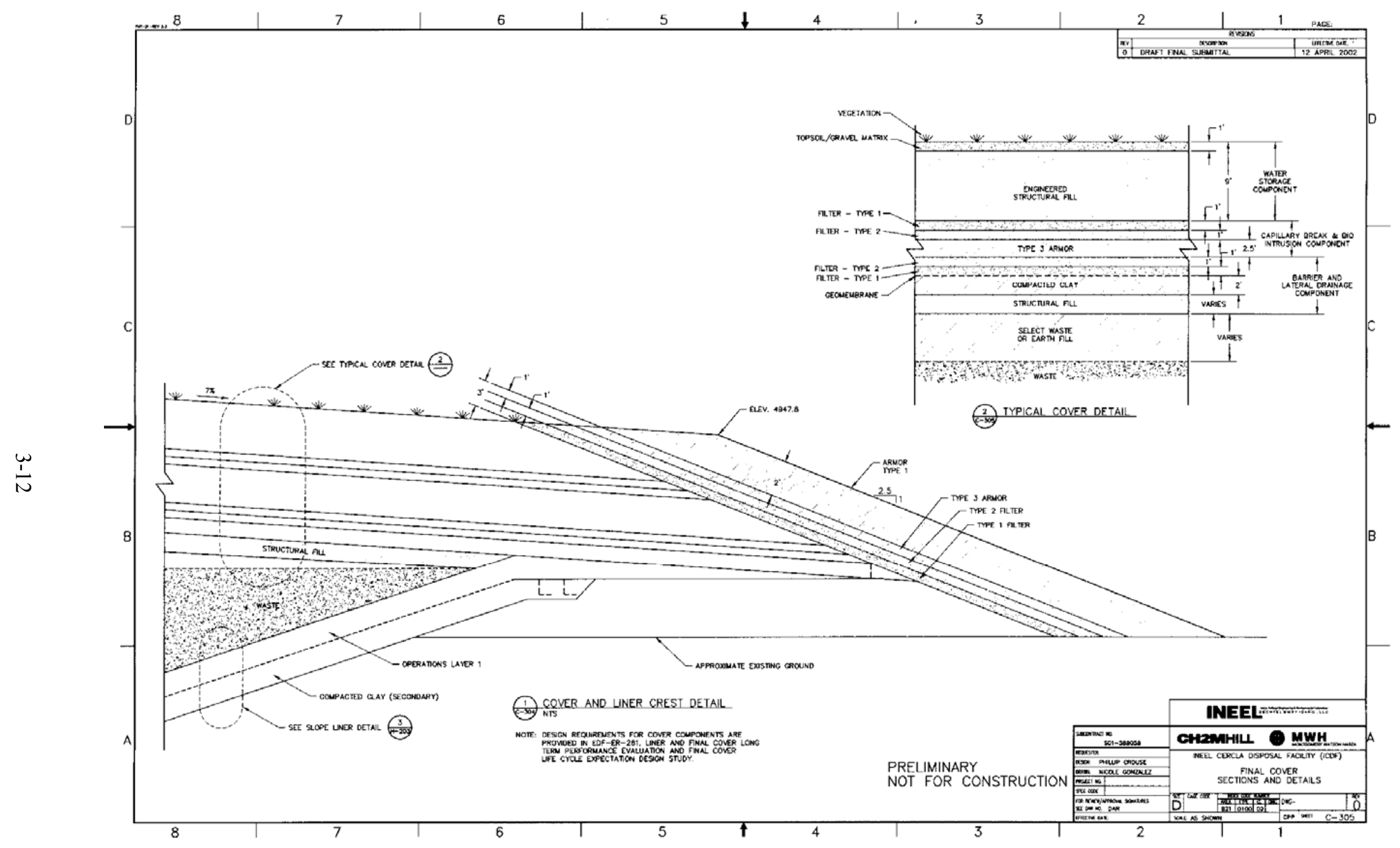

Figure 3-6. Drawing showing the cross section with the various design features of the engineered containment barrier for the landfill at closure. 


\subsubsection{Evaporation Pond Design}

In designing the ICDF evaporation pond, design criteria were developed. These design criteria consisted of three types: general, RCRA, and TSCA PCB design and construction requirements. For the ICDF evaporation pond, these design and construction requirement were generally the same criteria used for the ICDF landfill.

3.2.1.1 Other Evaporation Pond Design Criteria. The ICDF evaporation pond closure is expected to be "clean closure" with the addition of the following criteria. This eliminated the need for a engineered containment barrier for the evaporation pond as the waste would be removed and disposed in a disposal facility.

For the purpose of evaporation pond sizing, active storage in the evaporation pond will be required to handle up to three years in a row of maximum leachate production. These would be concurrent with the worst-case (highest) precipitation years.

3.2.1.2 Evaporation Pond Design. Using these design criteria, the design for the ICDF evaporation pond was developed. However, the evaporation pond liner design includes an alternative liner system. This liner system is designed to minimize waste by reducing the prescriptive operations layer required by regulation. The Subtitle $\mathrm{C}$ design requirements allow for an equivalency determination to propose a liner design that is equally protective of human health and the environment. To aid the equivalency analysis, an Engineering Design File (EDF) was prepared to demonstrate the equivalency of the proposed evaporation pond liner system. The EDF (EDF-ER-312) titled, "Evaporation Pond Lining System Equivalency Analysis," presented the request for equivalency. During Agency comment resolution and finalization of EDF-ER-312, it was decided that the evaporation pond liner system would

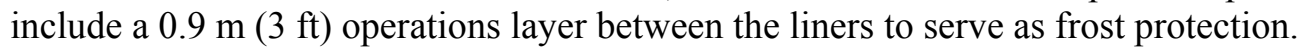

The liner design for the ICDF evaporation pond above the subgrade includes the following layers:

- $\quad$ Low permeability base soil from Rye Grass Flats as the base course

- $\quad$ Secondary GCL

- $\quad$ Secondary HDPE

- Geotextile cushion

- $\quad$ Operations layer $-0.9 \mathrm{~m}(3 \mathrm{ft})$

- $\quad$ Primary GCL

- $\quad$ Primary HDPE

- $\quad$ Sacrificial HDPE.

The upper HDPE geomembrane is a sacrificial liner that provides protection from ultraviolet light and a measure of puncture protection to the upper, primary geomembrane. The bottom GCL is provided as equivalent protection to one layer $3 \mathrm{ft}$ of $1 \times 10^{-7} \mathrm{~cm} / \mathrm{sec}$ clay (beneath the secondary geomembrane) to allow the pond to function through temperature extremes at the INL (EDF-ER-312). The upper GCL was included in the design and construction to minimize the amount of liquid that could leak into the leak detection system and contaminate the operations layer materials. This was done to minimize the closure cost while providing an increase in the protection of the SRPA. The evaporation ponds are designed for operating periods of 15 years for the active life of the landfill, and 30 years for postclosure. 
Figure 2-1 shows the general site layout for the ICDF Complex including the landfill, evaporation pond cells, administrative and decon/treatment buildings along with the staging and storage areas.

The final grading plan for the ICDF evaporation pond is presented in Figure 3-7. Figure 3-8 presents the liner system cross-sections for the ICDF evaporation pond cells. Additional information concerning the design and the analysis conducted to support the design is contained in the ICDF RD/CWP (DOE-ID 2002b) and supporting design analysis documents.

\subsection{Administrative Facilities}

The administrative facility consists of the admin trailer and the scales for weighing trucks entering and exiting the ICDF Complex. Administrative functions include weighing and verifying waste coming into or out of the facility, determining waste disposition, tracking the waste stream through the ICDF Complex and to final disposition, administering treatment verification and other quality activities, processing and maintaining required records associated with the waste disposition, and performing overall management functions.

\subsubsection{Admin Trailer Design}

This admin trailer is a temporary, relocatable office space. This trailer consists of two parts. One part houses a conference/lunchroom area with a kitchenette, office space, data tracking technician office, document storage room, restrooms; another part has utility rooms, restrooms, and janitor closet. The trailer is manufactured to comply with all federal regulations applicable to manufactured housing, including the Federal Highway Administration Department of Transportation standards and the Federal Motor Carrier Safety Regulations. The trailers come in two units, and combined, provide an area of 1,960 $\mathrm{ft}^{2}(28 \mathrm{ft} \times 70 \mathrm{ft})$. Figure 3-9 shows the conceptual drawing of the outside of the admin trailer and Figure 3-10 shows the expected floor plan for admin trailer. When the ICDF Complex mission is completed, the admin trailer will be removed from the site (clean closure).

Additional information concerning the design and the analysis conducted to support the design is contained in the SSSTF RD/CWP (DOE-ID 2002a) and supporting design analysis documents.

\subsubsection{Weigh Scale Design}

A load weighing scale shall be located at the admin trailer site. All waste shipments coming into the ICDF Complex are weighed and documented at this location. Tare weights of out-going vehicles are also obtained. The weigh data are electronically recorded into the waste database in the admin trailer. The scale shall accommodate standard commercial tractor-trailer units and shall have a capacity of 60 tons with an accuracy of within $0.1 \%$ of full scale. When the ICDF Complex mission is completed, the weigh scale will be removed from the site (clean closure).

Additional information concerning the design and the analysis conducted to support the design is contained in the SSSTF RD/CWP (DOE-ID 2002a) and supporting design analysis documents. 


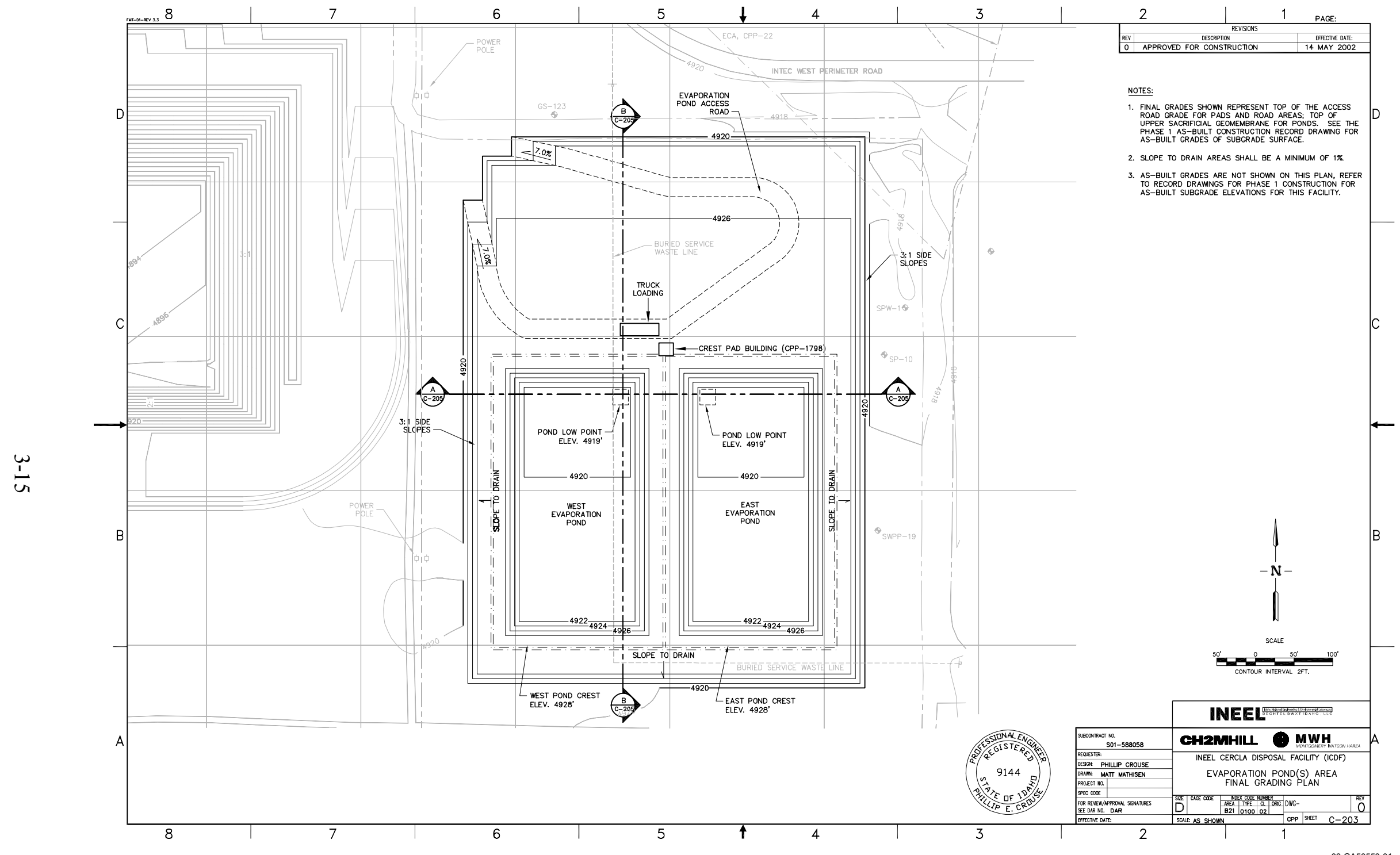

Figure 3-7. Evaporation pond final grading plan showing the elevations at the top of the sacrificial geomembrane (bottom of the liquid waste zone). 


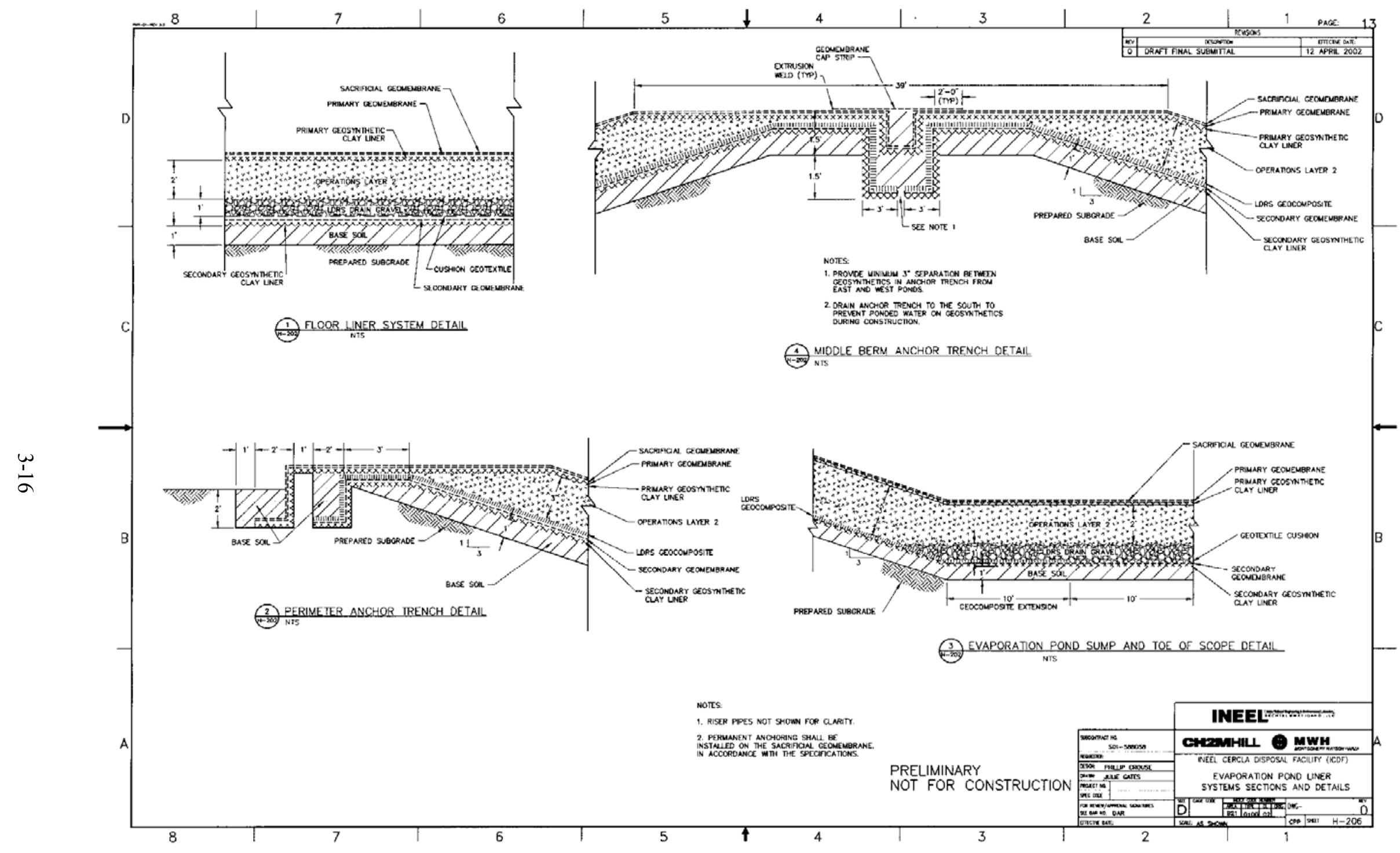

Figure 3-8. Liner system details for the evaporation pond showing the various layers for leachate detection and recovery system along with other design features. 


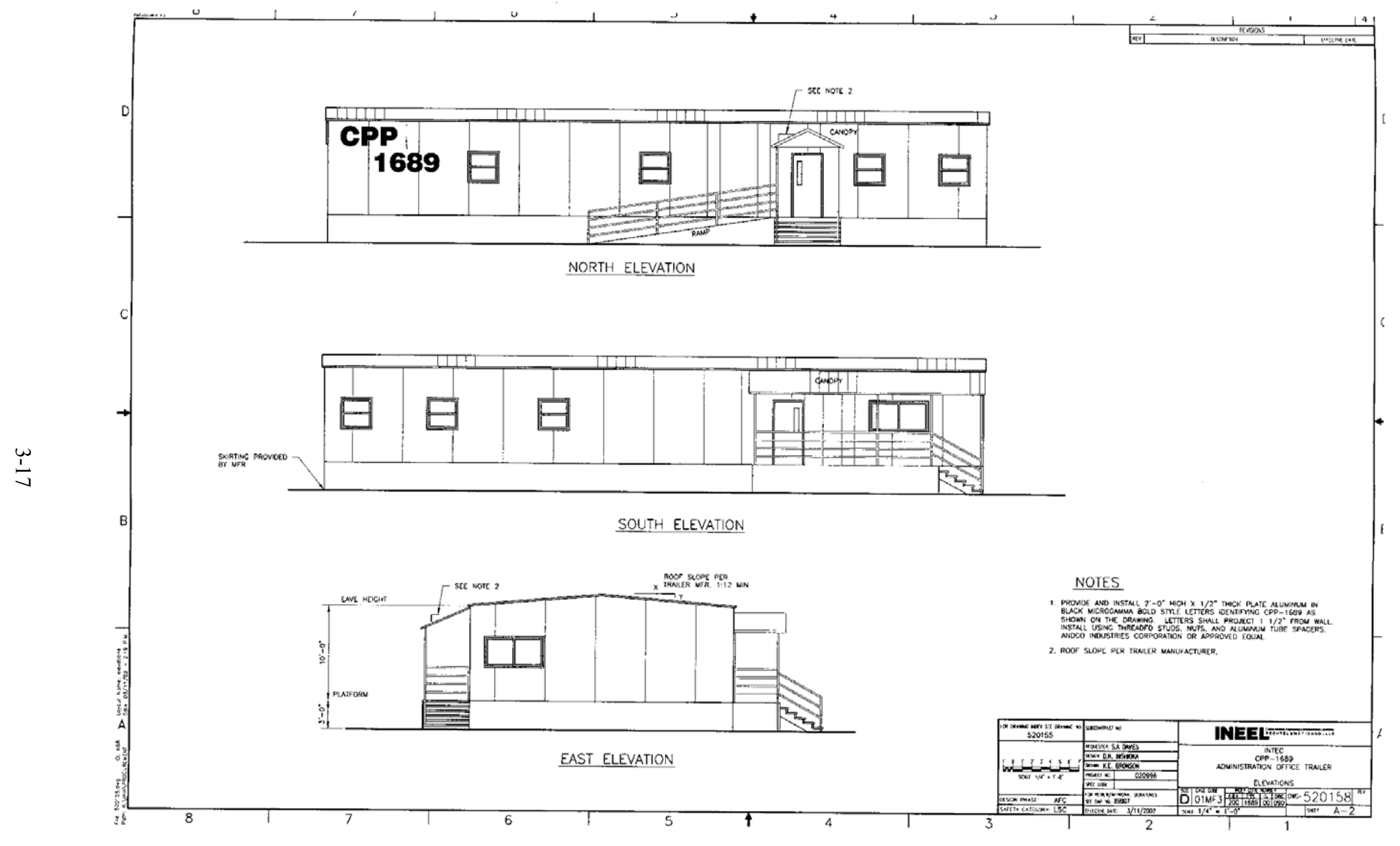

Figure 3-9. Conceptual drawing of the admin trailer exterior. 


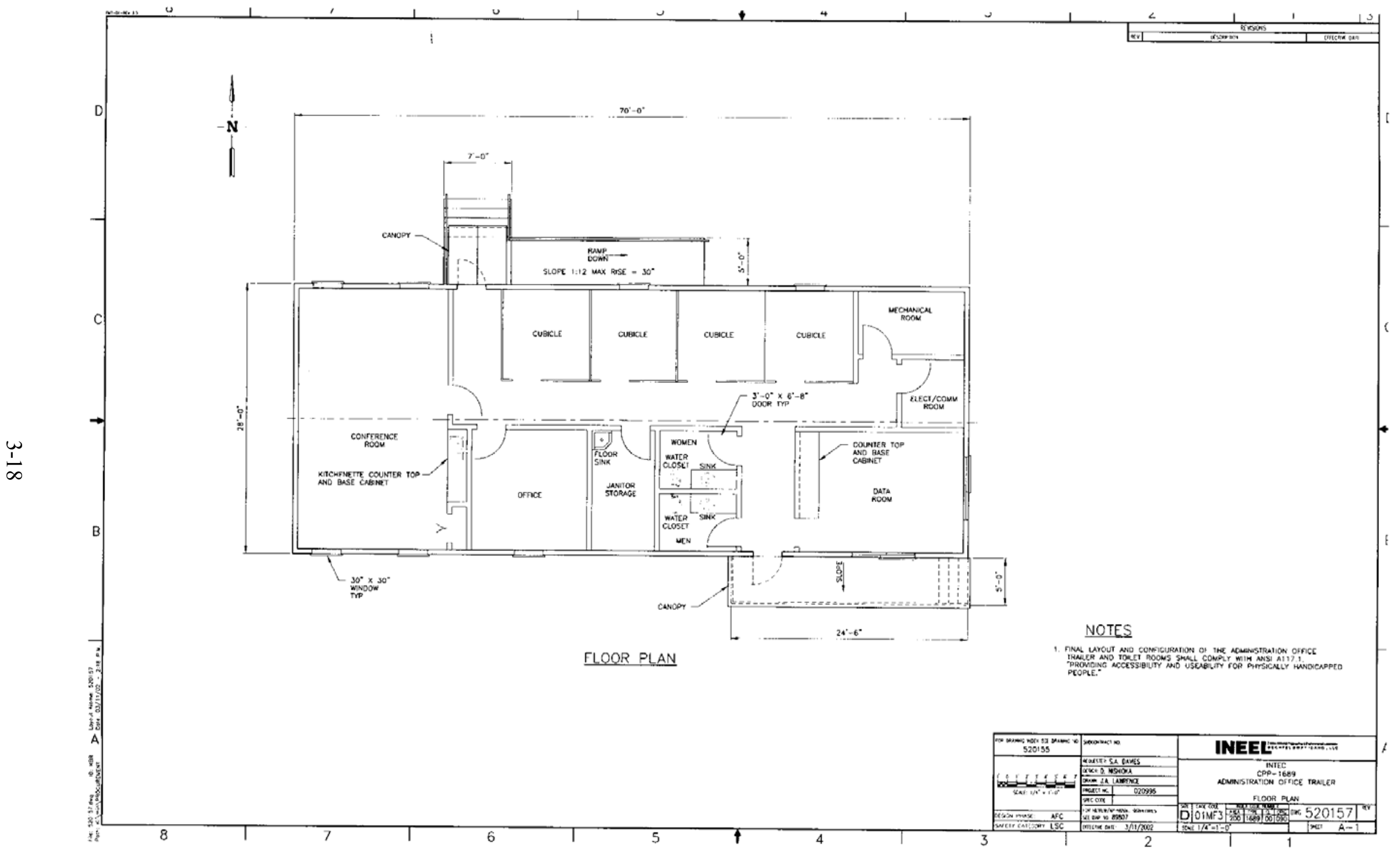

Figure 3-10. Expected floor plan for the admin trailer showing the various offices and other rooms in the building. 


\subsection{Decon Building}

The decontamination facility is an engineered metal building to be located near the ICDF landfill for decontaminating trucks and equipment. The decon building is used to remove radiological and hazardous contamination from waste transport vehicles, waste containers, and equipment to acceptable radiological and hazardous contamination levels. This building is generally divided in to three sections. The decontamination bay, the treatment area, and the remaining support areas including radiological control instrument storage, change rooms, and restrooms. The building also provides an enclosed facility for waste handling and stabilization of boxed soil along with micro-encapsulation of debris waste streams.

\subsubsection{Decon Building Design}

In designing the decon building, design criteria were developed. These design criteria included general building criteria and specific criteria dealing with RCRA regulation and radiation control requirements.

3.4.1.1 Decon Building Design Criteria. All wastewater generated in the decon building drains into collection trenches designed to meet the 40 CFR 264, Subpart DD, "Containment Buildings," requirements. Additionally, the wastewater requires solids removal, which is accomplished by sedimentation in the trench and an oil/water separator installed as a best management practice. However, the primary purpose of the oil/water separator is to remove oily fluids from the wastewater prior to draining into the lift station where it is pumped to the evaporation pond system. The wastewater piping from the decon building and contaminated equipment storage pad requires secondary containment to comply with ARARs.

The decon building shall be provided with a once-through high-efficiency particulate air (HEPA) filter exhaust ventilation system capable of providing a minimum air exchange rate based on a Uniform Building Code F-2 occupancy classification. The HVAC system provides negative air pressure in relation to the external environment. The negative air pressure assists in the confinement of airborne radiological and hazardous constituents.

The design includes establishment of acceptable limits to contamination, provisions for physical and administrative safeguards, and controls to limit and/or confine exposure to contaminants. The radiation is required to be controlled at the source. Radiological control instrumentation is required to verify that this is being accomplished. The following is a list of overall design basis for the decon building regarding radiological and dust controls:

- The design and physical controls shall be optimized to assure that occupational exposure is maintained as low as reasonably achievable (ALARA). Regarding the control of airborne radioactive material, the design objective shall be to avoid release to the workplace atmosphere and, in any situation to control the inhalation of such material by workers to levels that are ALARA, confinement and ventilation shall normally be used.

- $\quad$ The decon building design supports the use of automated personnel contamination monitors.

- Design provisions are included to limit (through physical design features and administrative control) emissions of radionuclides to not exceed levels established in DOE O 435.1 and to comply with National Emission Standards for Hazardous Air Pollutants (NESHAP) emission limits. 
- The decon building shall include design provisions to control dust to a level to ensure compliance with the ACGIH standards. Appropriate precautions per IDAPA 58.01.01.650 include the use of water or chemicals, application of dust suppressants, or use of control equipment.

- $\quad$ No controls shall be installed at any exit that would prevent rapid evacuation of personnel under emergency conditions.

3.4.1.2 Decon Building Design. The decontamination facility is an engineered metal building to be located near the ICDF landfill for the decontamination of trucks and equipment. The building is qualified under the Type IIN construction (Type IIN construction stipulates noncombustible materials). A portion of this building also houses the minimal treatment equipment. A high-pressure water sprayer is used to wash containers, when necessary. After decontamination, the containers are stored at the empty container storage pad until they are required or are returned to the waste generating site. Equipment and trucks are washed to eliminate any external radiological contamination prior to leaving the ICDF Complex, as necessary. Decontamination washwater drains to a lift station located adjacent to the decon building and is pumped directly to the evaporation pond. The decon building is divided into three main sections:

1. One half of the building consists of a decontamination bay. This where transport vehicles, waste containers, and other equipment can be washed and cleaned of any contamination.

2. Approximately $1 / 4$ of the building has been designated as a treatment area. When it is required, this area is used to treat contaminated debris, soil, and aqueous waste that do not meet either the ICDF landfill WAC or the ICDF evaporation pond WAC, as defined in the ICDF Complex WAC (DOE-ID 2005).

A portion of the treatment area is set aside for storage of PCB-contaminated waste. This waste is stored in a TSCA-compliant unit that includes a 6-in. curb.

3. The third area consists of a mechanical room, fire riser room, electrical room, personal protective equipment (PPE) change room, a radiological controls equipment room, and men's and women's restrooms with showers. These rooms support the function of the decontamination and treatment portions of the building (see project plans for the layout and details of these rooms and facilities). The ceiling of the fire riser and electrical rooms consists of a precast, hollow-core panels designed to support the HVAC equipment for building. The voids in the slab are to reduce the dead load of the slab.

The floor slabs in the decon building pad are posttensioned with high-strength cables to attenuate shrinkage and cracking. In addition, water stops are in place to satisfy the containment requirements. The building slabs are also coated with a high-grade epoxy coating.

The decon building has been classified as a containment building under 40 CFR 264.1100 (40 CFR 264, Subpart DD). This regulation states that a "containment building used to manage hazardous waste containing free liquids or treated with free liquids must be designed with secondary containment features to prevent contamination of subsurface soils." To meet this requirement, a secondary containment system employing an HDPE liner system has been designed for use under the concrete floors in the building. Any leakage of water through the concrete pad is drained through this secondary containment system to the secondary-containment piping system. Through the piping, the water flows to the secondary containment of the lift station. Sensors are placed in the lift station to monitor any leaking that may occur. 
A concrete P-trap is constructed inside the treatment area. The intent of the P-trap is to provide a water block separating the outside air from the air inside the decon building. A negative pressure must be maintained in the building to control contaminated dust. The P-trap prevents the outside air from entering the building and equalizing the internal air pressure.

The wastewater piping from the contaminated equipment storage pad and decon building is sized large enough that, in the event of a fire in the decon building, the volume of water generated will be piped to and temporarily stored on the contaminated equipment storage pad which is contained with curbing. To accomplish this, the concrete pad is $1 \mathrm{ft}$ below the finished floor of the building. It is also sloped $0.015 \mathrm{ft} / \mathrm{ft}$ away from the building. After the fire, the water will be drained to the lift station where it will then be pumped to the evaporation pond system for disposal.

When the ICDF Complex mission is completed, the decon building will be removed from the site (clean closure).

Figures 3-11 and 3-12 show conceptual drawings of the outside of the decon building and Figure 3-13 shows the expected floor plan for the decon building. Additional information concerning the design and the analysis conducted to support the design is contained in the SSSTF RD/CWP (DOE-ID 2002a) and supporting design analysis documents.

\subsection{Treatment Systems}

The ICDF Complex provides treatment capabilities to treat limited volumes of soil and debris waste along with secondary waste streams generated during ICDF operations. In addition, the treatment capabilities include treating small volumes of aqueous liquids/sludges containing chemical and radiological constituents similar to those of the soil wastes. A portion of the decontamination facility is used for treating the soil and debris waste streams. The soils stabilization treatment system is housed in a dedicated section of the decon building.

\subsubsection{Treatment Systems Design}

In designing the treatment systems, design criteria were developed. These design criteria included general criteria and specific criteria dealing with RCRA regulation and radiation control requirements.

3.5.1.1 Treatment Systems General Design Criteria. The treatment process in the decon building shall treat boxed, nonaqueous waste to meet LDR and ICDF landfill WAC levels. Following treatment, the treated waste that meets the ICDF landfill WAC is transported to the landfill for final disposition. Treated waste that fails to meet the ICDF landfill WAC requirements shall be reprocessed in the decon building treatment facilities. The treated waste is also required to contain no free liquid as determined by visual examination and the paint filter test (as defined in Paint Filter Liquids Test SW-846 Method 9095) (EPA 1986). Additional requirements for treatment of both debris and soil include

- The treatment process is designed to prevent releases of waste to ensure protection of human health and the environment.

- $\quad$ The treatment process equipment shall be able to be decontaminated.

Measures shall be taken during stabilization operations in the decon building to maintain radiation exposure in controlled areas ALARA through facility and equipment design and administrative controls. The primary methods used shall be physical design features (e.g., confinement, ventilation, remote handling, and shielding). The proposed physical controls are an environmental enclosure with filtered air. Additionally, air emissions from the stabilization process shall meet NESHAP (40 CFR 61) and Idaho dust emission standards (IDAPA 58.01.01.650). 


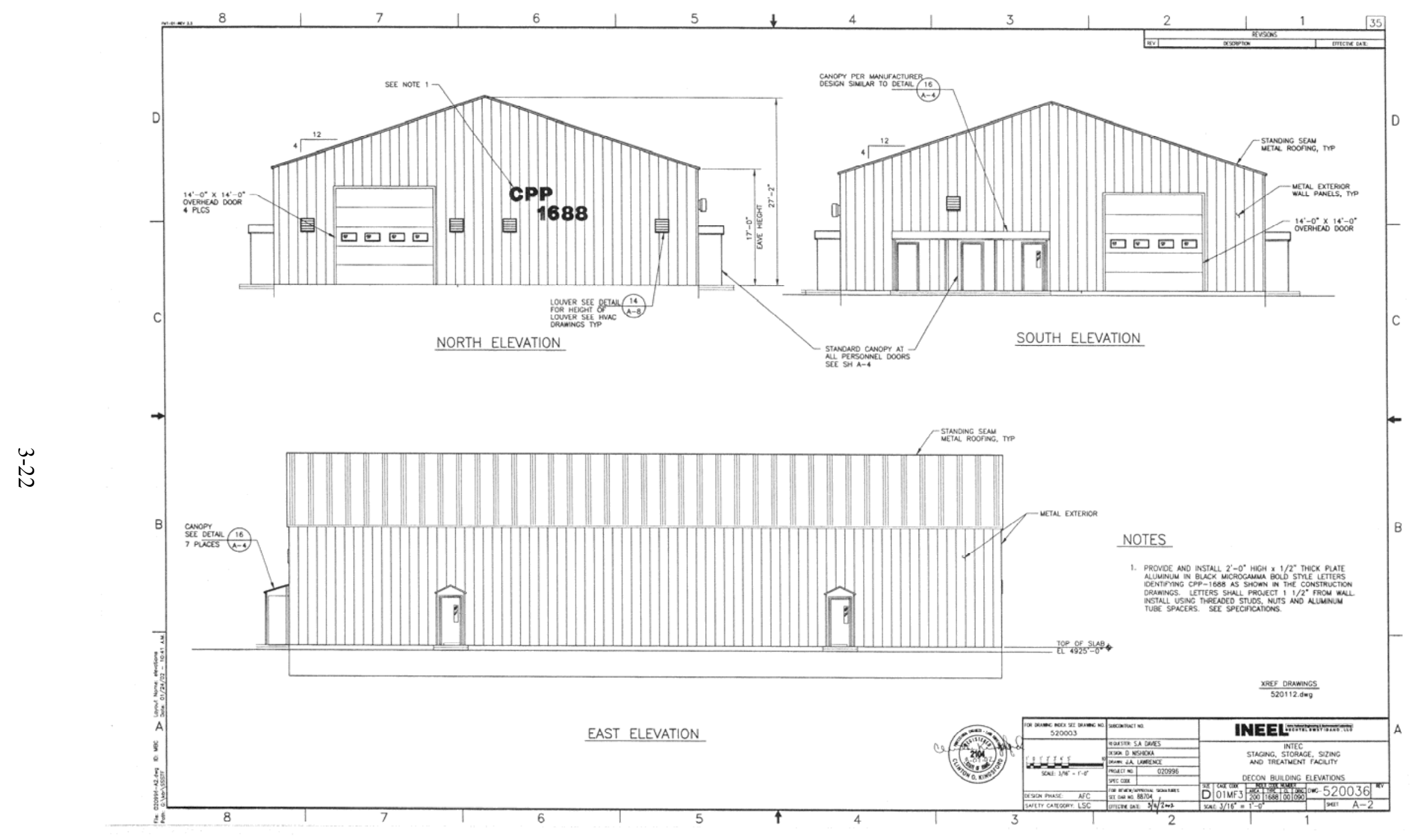

Figure 3-11. Conceptual drawing of the decon building exterior (north, south, and east sides). 


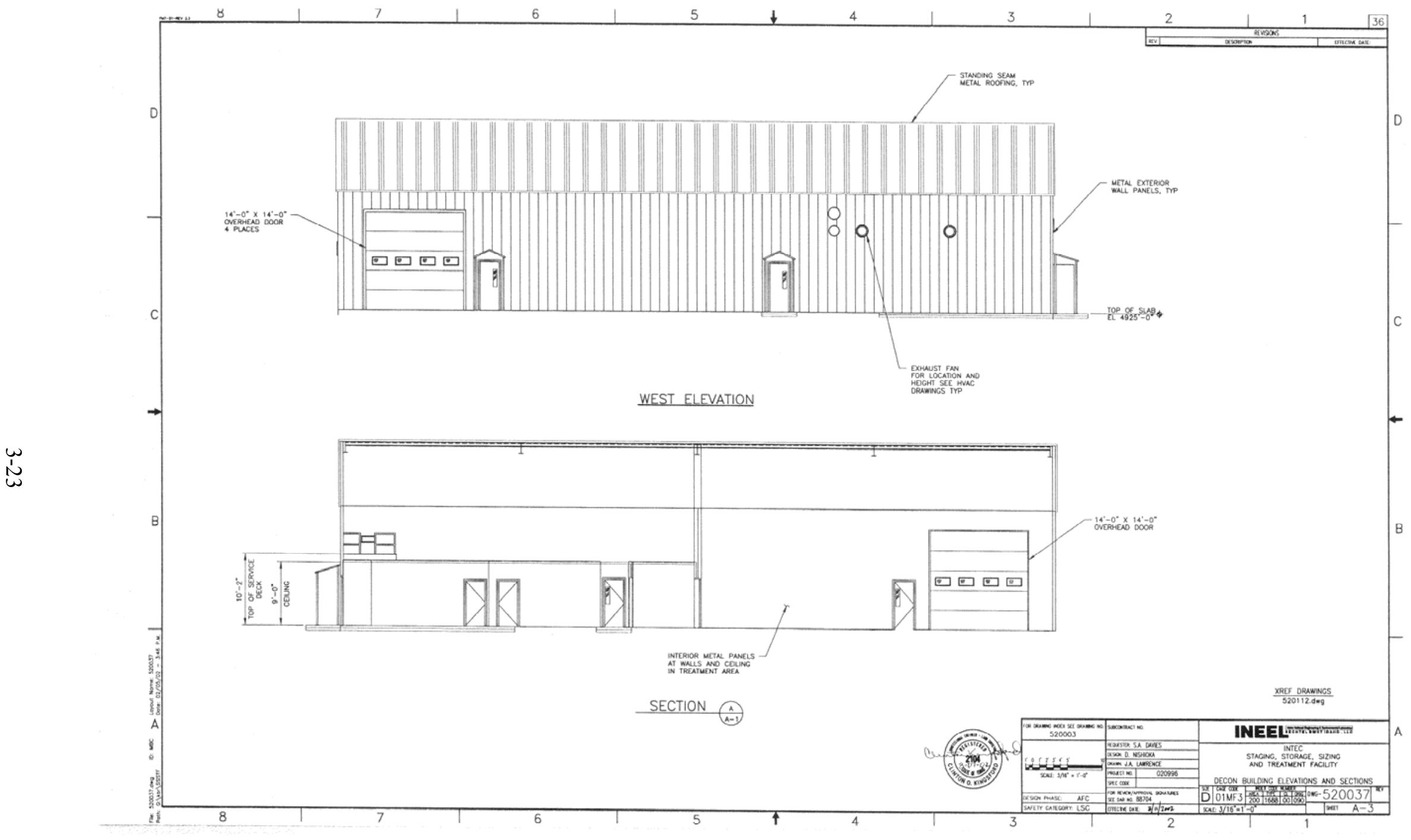

Figure 3-12. Conceptual drawing showing the exterior of the decon building (west side). 


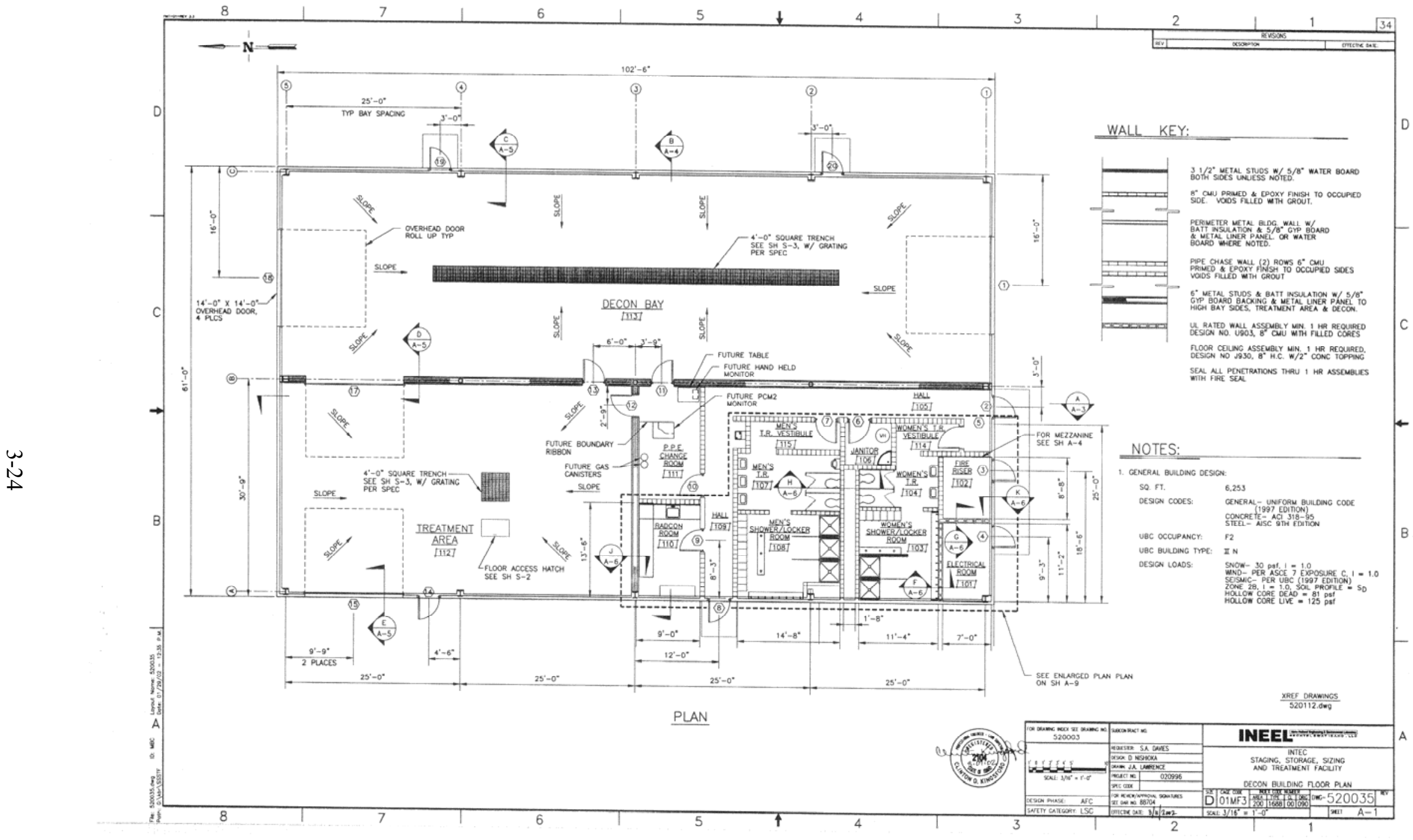

Figure 3-13. Floor plan for the decon building showing the various areas including the treatment area and decontamination bay. 
3.5.1.2 Soil Stabilization Treatment Process Design Criteria. The Title I (30\%) design identified a Portland cement-based system as a viable method of treating the identified waste soils. These soils are assumed to contain heavy metals as the only contaminants of concern; organic contaminants were either below regulatory concern or nonexistent in the waste forms. Based on this assumption, the object of cement stabilization was to produce a treated soil that met the following criteria:

- $\quad$ Reduce the heavy metal leachability to LDR/Universal Treatment Standard levels to meet the ICDF landfill WAC

- $\quad$ Exhibit no free liquid.

Additionally, the stabilized soil should have a friable or crumbly consistency to allow easier posttreatment handling of waste.

The treatment process must deliver a product meeting the criteria listed above and meet the following requirements and constraints:

- $\quad$ The waste throughput is $10 \mathrm{yd}^{3}$ per day.

- $\quad$ The waste must be removed from $2 \times 4 \times 8$-ft wooden boxes, roll-on/roll-offs, or other approved containers.

- $\quad$ Boxes of soil waste to be treated are assumed $85 \%$ full and weigh up to $8,000 \mathrm{lb}$.

- $\quad$ Reagents include fine flowable solids (cement, flyash, granulated blast furnace slag), water, and small quantities (less than 1 gal) of liquid reagents.

- Dust from the waste materials must be contained within the treatment system or collected in some manner to minimize the spread of contamination.

- The footprint of the mixer and peripheral equipment must reside in a $900-\mathrm{ft}^{2}$ area, with a roof height of $17 \mathrm{ft}$ at the eave and $21 \mathrm{ft}$ at the pitch. (These dimensions would allow the equipment to be compatible with the current building design.)

- $\quad$ The unit must be able to accommodate aqueous waste liquids/sludges.

- $\quad$ The unit shall have decontamination features, such as spray wands for water washing.

A summary of other components with additional design requirements for the soil treatment system are provided below:

Mixer - The mixer shall be capable of providing a homogeneous blend of soil and reagent and have a minimum capacity of $13,000 \mathrm{lb}$. The system must be robust enough to provide mixing for a wide range of feed with aggregates up to 6 in. while at the same time providing enough sheer to generate a homogeneous mixture. At the same time, the mixer must be able to accept and adequately mix aqueous liquid/sludge wastes with no leakage.

After the mixer has produced a homogeneous blend of contaminated soil and reagent, the mixer shall be capable of delivering the soil into empty boxes $(2 \times 4 \times 8 \mathrm{ft})$ or, alternatively, a mobile loading device capable of discharging the treated soil mixture into the standard truck-mounted 20 -yd $\mathrm{d}^{3}$ roll-on/roll-off container. 
Box Unloader-The soil handling system (box unloader) shall be capable of unloading boxes $(2 \times 4 \times 8 \mathrm{ft})$ into the mixer with minimal amount of soil transfers and no contamination exposure to personnel. The contamination control confinement system shall have dust pick-ups capable of tying into the air scavenger system. It is anticipated that confined equipment would need to be used to accomplish this task. There must also be provisions made for the emptying of the soil boxes without allowing the plastic liner to fall into the mixer.

This system shall also be capable of automatically introducing a recipe of cement, fly ash, and other dry additives to the mixer for stabilization of hazardous soil constituents. The bags of dry material may also be loaded into the hopper and conveyed up to the mixer.

Air Scavenger System-An air scavenger system must provide total elimination of fugitive dust emissions during soil transfer, soil mixing, and soil unloading activities. The mixer enclosure must be sealed or controlled such that fugitive dust does not occur. If possible, a minimum vacuum of 0.10-in. w.g. must be maintained on the soil feed system. Exhaust air shall be filtered with at least a single roughing filter and dual nuclear-grade HEPA filters. Differential pressure gages shall be installed to monitor pressure drop across the pre-filter bank and each HEPA filter bank. The exhaust system is designed to meet the requirements of National Fire Protection Association (NFPA) 801 (NFPA 1998). The need for a baghouse filtration system upstream of the exhaust filter bank must be evaluated. The air introduced into the HEPA filter banks must be maintained below $90 \%$ relative humidity by utilizing duct heaters as necessary.

Remote Station Process Control Requirements-Due to the radioactive nature of the soil, the treatment system employs remote monitoring/communication/process control. As a minimum, the process control/monitoring system monitors motor temperature, gearbox temperature, motor current draw, and automatic lubrication system temperature and pressure and provides start/stop control and alarms when system operating parameters are out of normal operating range. All process system controls shall be housed in a NEMA 4X enclosure for indoor and housed in NEMA 3R enclosures for outdoor equipment. The remote station control house shall have the following requirements:

- $\quad$ Insulated

- $\quad$ Contain a safety glass window for viewing of the treatment operation

- $\quad$ Air-conditioned/heated

- Wired for lights/receptacles

- Accommodate a personal computer station for data acquisition involving the process

- Located sufficiently far enough away from the treatment system to allow for shielding as necessary.

3.5.1.3 Debris Treatment Process Design Criteria. As stated previously, hazardous debris, subject to the "Treatment Standards for Hazardous Debris," (40 CFR 268.45) are also processed in the ICDF Complex and must be processed accordingly. Although soil and debris processing requirements are similar, they are subject to different standards. 
Hazardous debris is defined as debris that contains a hazardous waste listed in Subpart D of 40 CFR 261 or that exhibits a characteristic of hazardous waste, as identified in Subpart C of 40 CFR 261. The waste is not debris if a specific treatment standard exists in Subpart D of 40 CFR 268. The following is the definition of debris as extracted from 40 CFR 268.2:

Debris means solid material exceeding $60 \mathrm{~mm}$ particle size that is intended for disposal that is: a manufactured object; plant or animal matter; or natural geologic material. However, the following materials are not debris: Any material for which a specific treatment standard is provided in Subpart D, part 268, namely acid batteries, cadmium batteries, and radioactive lead solids; Process residuals such as smelter slag, and residuals from the treatment of waste, wastewater sludges, or air emission residuals; and Intact containers of hazardous waste that are not ruptured and that retain at least $75 \%$ of their original volume. A mixture of debris that has not been treated to the standards provided by 268.45 and other material is subject to regulation as debris if the mixture is comprised primarily of debris, by volume, based on a visual inspection.

Cement-based micro-encapsulation was selected as the primary debris treatment process to be utilized for debris treatment. This process is a RCRA-approved technology, in accordance with Subpart D of 40 CFR 268.45. Adherence to this requirement is necessary so that the treated debris waste may be disposed in the ICDF landfill.

A flowable grout is required in order to fill debris boxes without removal of the box lids or handling of the debris. Other grout properties that are desirable include:

- $\quad$ Low quantities of bleed water as setting occurs

- $\quad$ Low shrinkage to minimize cracks and voids

- $\quad$ Adequate strength to minimize potential for cracks during box handling

- $\quad$ Low unit weight, if feasible, in order to minimize the box weight.

As stated previously, there are two sizes of debris boxes. All of the treated debris will be disposed of in the ICDF, which is a Subtitle C landfill specifically designed and operated to manage this type of waste.

3.5.1.4 Treatment Systems Design. The ICDF Complex provides limited treatment capabilities to treat small volumes of soil and debris waste along with secondary waste streams generated during ICDF Complex operations. In addition, the treatment system has the capability of treating small volumes of aqueous liquids/sludges with chemical and radiological constituents similar to those of the soil wastes. The two treatment systems (soil stabilization and debris treatment) are further discussed below.

3.5.1.5 Soils Stabilization Treatment Process. Currently, the soil waste from Sites CPP-92, -98 , and -99 is packaged in approximately 675 plastic-lined wooden boxes measuring either $2 \times 4 \times 8 \mathrm{ft}$ or $4 \times 4 \times 8 \mathrm{ft}$. Also, approximately $800 \mathrm{yd}^{3}$ of soil waste from CFA- 04 that has not been excavated is considered for treatment in the soil stabilization treatment system. The treatment process consists of a cement-based stabilization process for the soils contaminated with heavy metals. Using Portland cement, or similar hydraulic binders, is an accepted technology for rendering the soils nonhazardous. The hydraulic binders do this by reducing the leachability of the contaminant metals to acceptable levels. The main ingredients may consist of Portland cement, flyash, granulated blast furnace slag, chemical reagents, chemical plasticizers, and water. 
The recipe that will be used, following a treatability study, is intended to provide a dry, nonslab final waste product that is similar in physical character to the original soil. Other recipes and/or reagent types may be used to improve the performance as long as the test objectives are met. While the Portland cement-based system is the baseline chemical fixation and stabilization formulation, other systems that can be shown to meet the objectives may be substituted.

As stated previously, treatment is to occur in the designated area of the decon building. The process consists of the following steps:

- $\quad$ The waste soil is transferred from plastic-lined wooden boxes or other approved containers to a mixing vessel, while maintaining minimum dust release (contamination) to the adjoining area.

- In the mixer, the soil is combined with a hydraulic binder (Portland cement or Portland cement blend) and possibly a small amount of chemical reagents and admixtures. A minimum amount of water is also added; ideally, a relatively dry, crumbly, or friable waste/cement mixture is obtained. A high-intensity or high-efficiency mixer is desirable to ensure thorough mixing of the soil with the other ingredients. Additionally, the mixer should be able to accept a significant variation in soil particle/rubble size as segregation or screening of the waste is not anticipated.

- After mixing is complete, the soil/cement must be transferred (with minimal dust release) into a container and staged where curing is completed.

Additional information concerning the design and the analysis conducted to support the design is contained in the SSSTF RD/CWP (DOE-ID 2002a) and supporting design analysis documents.

3.5.1.6 Debris Treatment Process. Another of the processes to occur in the decon building is treatment of "hazardous or mixed debris" which is one of the CERCLA cleanup activities identified in the OU 3-13 ROD. Hazardous debris is defined as debris that contains a hazardous waste listed in Subpart D of 40 CFR 261 or that exhibits a characteristic of hazardous waste, as identified in Subpart C of 40 CFR 261.

Several debris treatment technologies were identified in accordance with the Alternative Treatment Standards for Debris (see table in 40 CFR 268.45). These technologies considered were from three general categories: extraction, destruction, and immobilization. The technologies were prescreened and further analyzed against evaluation criteria, including quality control, operations, cost, implementability, inherent safety, and flexibility. Based on the analysis performed, cement-based micro-encapsulation was selected as the primary debris treatment process to be utilized in the ICDF Complex. Micro-encapsulation is the easiest to perform, least expensive, easily meets the performance standard, and is the safest with the least amount of worker exposure to the hazardous and radioactive contaminants.

The performance specification for micro-encapsulation is to reduce the leachability of the hazardous contaminants on the debris. This treatment process is performed in a nonintrusive, nonlabor-intensive manner to reduce exposure potential to those workers conducting the treatment and is expected to consist of the following steps:

- $\quad$ The box containing the hazardous debris would be placed in the working area.

- Two holes would be cut into each end on the top of the box with a hole saw. The operator ensures that the holes breach the plastic liner on the inside of the box.

- A flowing cement grout is injected into one of the holes until the grout rises and begins to come out of the other hole. 
- $\quad$ The cement grout would then be allowed to cure. Once cured, a forklift would place the box on a flat bed truck where it would be transported to the ICDF for placement.

Additional information concerning the design and the analysis conducted to support the design is contained in the SSSTF RD/CWP (DOE-ID 2002a) and supporting design analysis documents.

\subsection{Staging and Storage Areas}

The ICDF Complex provides staging and storage capabilities to stage/store soil and debris waste along with secondary waste streams generated during ICDF operations. In addition, the staging/storage capabilities include capacity for storing some aqueous liquids containing chemical and radiological constituents similar to those of the soil wastes. Various locations within and associated with the ICDF Complex comprise these staging and storage areas.

\subsubsection{Staging and Storage Design}

In designing and designating the staging and storage areas for the ICDF Complex, design and operational requirements were evaluated. These design and operational requirements are contained in the RCRA regulations. The staging areas will be managed in accordance with 40 CFR 264.554, and the storage areas will be managed in accordance with 40 CFR 262.34(a)(1). Stored containerized waste will meet the substantive requirements of 40 CFR 264, Subpart I, and aqueous waste stored in tanks will meet the substantive requirements of 40 CFR 264, Subpart J.

Wastes consolidated within staging piles operated in accordance with 40 CFR 264.554 are not considered storage, and placement will not occur provided the waste is removed within 2 years of the date that the waste was moved into the staging pile. This operational approach is important since it allows the ability to stage CERCLA waste during the winter months, when the ICDF landfill is not operational. The use of staging and storage areas will allow sufficient flexibility to operate the ICDF Complex for waste staging and consolidation. These waste units will be placed within the fenced boundaries of the ICDF Complex or at the SSA, a part of the ICDF Complex, to facilitate operations.

3.6.1.1 Staging and Storage Location Standards. The following three criteria were identified as the applicable location standards for the staging and storage areas at the ICDF Complex.

- $\quad$ Location at the ICDF Complex-The staging and storage areas have been designated within the limits of the ICDF Complex, which includes the SSA, as identified in the ICDF Complex Remedial Action Work Plan (DOE-ID 2003a).

- $\quad$ Number - Three staging areas: full container staging area, bulk soil stockpile staging area, and SSA future staging area; and two storage areas, tank and container storage area and SSA storage area are established to facilitate ICDF Complex operations.

- $\quad$ Physical Location-The locations of the staging and storage areas are shown in Figures 3-14a and 3-14b.

3.6.1.2 Staging and Storage Design Standards. The following six standards were identified as the applicable design standards for the staging and storage areas at the ICDF Complex.

- Hydrogeologic Conditions-The hydrogeologic conditions for the staging and storage areas within the ICDF Complex are the same as the landfill area. Also, the SSA located inside of INTEC has the same hydrogeologic conditions as the rest of the ICDF Complex. Therefore, all areas will utilize have the same acceptable hydrogeologic conditions. 


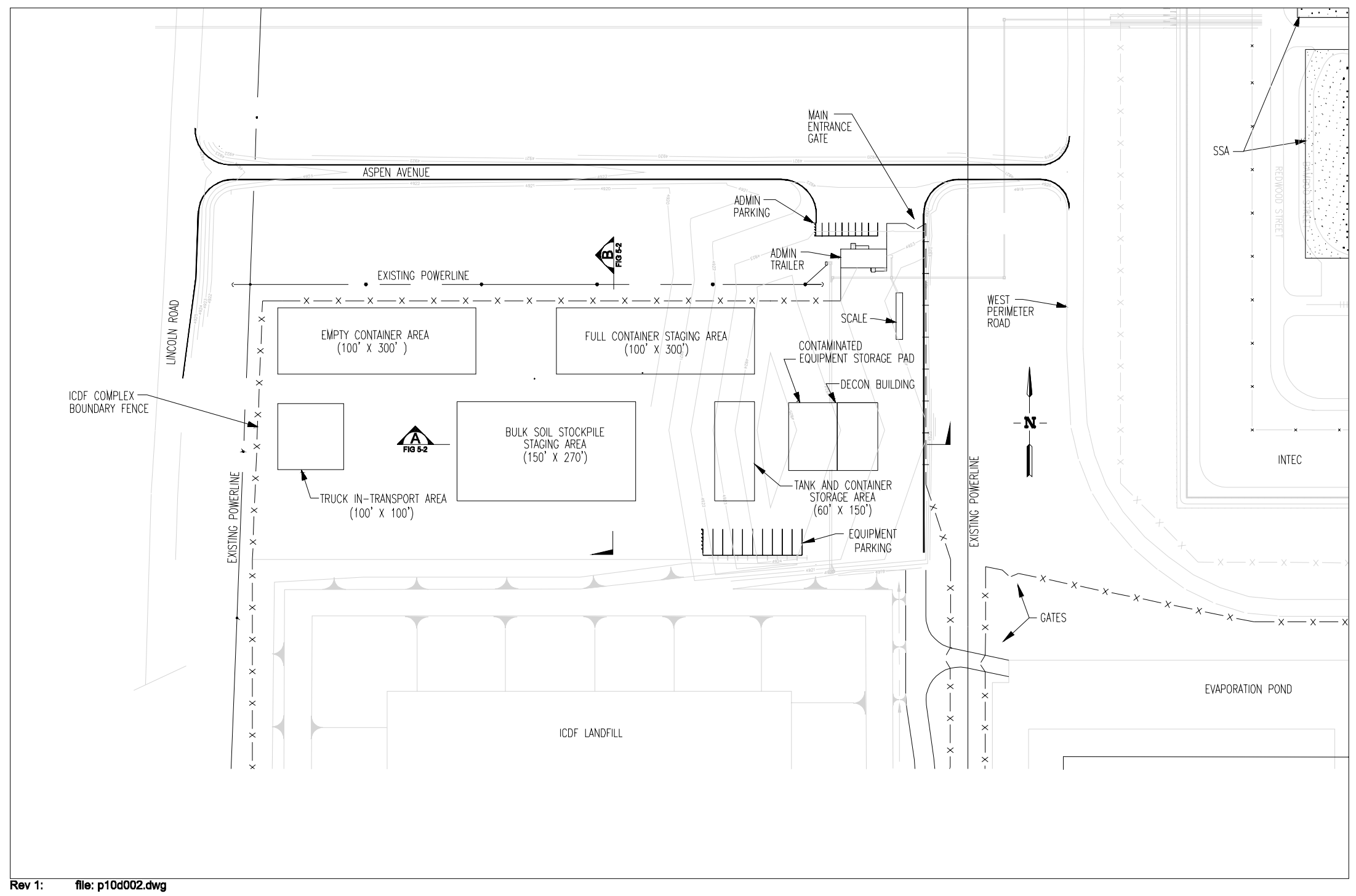

Figure 3-14a. Drawing showing the locations and sizes of the staging and storage areas for the ICDF Complex. 


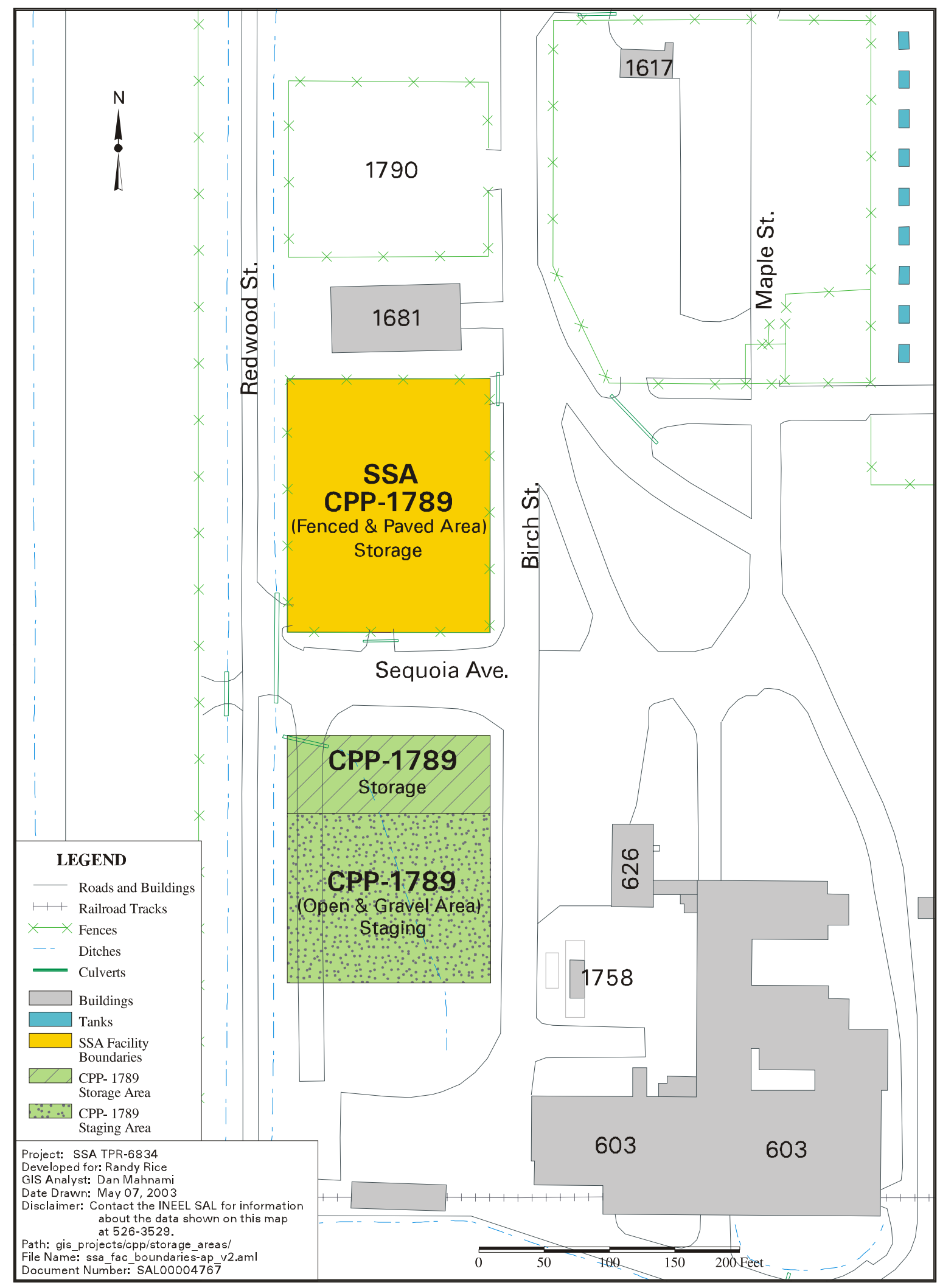

Figure 3-14b. Drawing showing the location and sizes of the SSA storage area and SSA future staging area. 
Fenced Areas - The staging and storage areas are within the fenced area of the ICDF Complex, with the exception of the SSA. The SSA has its own fence and is also within the fenced area of INTEC.

- $\quad$ Boundaries - The staging and storage areas will be roped off and posted with appropriate signs.

- $\quad$ Physical Dimensions - The dimensions of the staging and storage areas are shown in Figures 3-14a and 3-14b.

- $\quad$ Base Material-The base of the staging area will be the same as the base of the ICDF Complex infrastructure, which includes sloped compacted gravel.

- Independent Professional Engineer Certification-An independent professional engineer (PE) certification will be obtained for any tanks within a storage area, in accordance with the requirements of 40 CFR 264, Subpart J.

3.6.1.3 Staging and Storage Operational Conditions. The following eleven conditions were identified as the applicable operational conditions for the staging and storage areas at the ICDF Complex.

- Designation - Staging and storage areas were designated in the ICDF Complex Operations and Maintenance Plan (DOE-ID 2003b) as shown on Figures 3-14a and 3-14b. Operations of the staging and storage areas will comply with the operational requirements for waste placement and tank management.

- $\quad$ Waste Tracking - The waste received into and moved through the ICDF Complex, including disposal in the landfill or evaporation pond, will be tracked. Waste tracking in the staging and storage areas is performed in accordance with waste tracking plan for the ICDF Complex (PLN-914).

- $\quad$ Time Limits-The time limit for staging wastes is 2 years; it is then disposed of or moved to an appropriate storage location. Justification will be provided if a waste is staged beyond the 2-year limitation. Waste placement and LDR issues may be applicable after the 2-year time period.

- $\quad$ Permitted Waste Types - Solid, nonflowing wastes are permitted in the staging areas. Storage areas are designated to receive aqueous wastes.

- Incompatible Wastes - If any, may not be stored in close proximity.

- Consolidation of Waste-A prefabricated TSCA-compliant, PCB storage container may be located at the ICDF Complex, south of the bulk soil stockpile area. This container will be an enclosed portable unit with a steel roof and walls. The footprint of the storage area is approximately $20 \mathrm{ft} \times 50 \mathrm{ft}\left(1,000 \mathrm{ft}^{2}\right)$ with a usable storage capacity of approximately $5,000 \mathrm{ft}^{3}$. The prefabricated container will have interior lighting, heating, loading ramps that will be connected following placement, and a built-in spill containment sump. Although the unit is portable, it will be located within the tank and container storage area.

- $\quad$ Nonflowing wastes may be consolidated within containers (e.g., roll-on/roll-off, drum, waste box, etc.) within the staging area.

- $\quad$ Waste may be consolidated within a designated staging area in soil piles on liners, with appropriate dust and leachate control. 
- $\quad$ Tanks may be placed in the tank and container storage areas or the SSA storage area, as shown on Figures 3-14a and 3-14b.

- $\quad$ Run-on/Run-Off Control-Adequate run-on/run-off control is provided as part of the ICDF Complex design.

- $\quad$ Fugitive Dust Control-The fugitive dust emissions will be controlled.

- Inspections - The staging areas will be inspected weekly and the tank storage areas will be inspected daily for releases.

- $\quad$ Containers - Containers in staging areas will be managed in accordance with the ICDF Complex Operations and Maintenance Plan (DOE-ID 2003b).

- $\quad$ Closure - At the close of the active life of the ICDF Complex, all staging areas will be closed in accordance with 40 CFR 264.554(k) and storage areas closed in accordance with 40 CFR 264, Subparts I and J, as applicable.

3.6.1.4 Staging and Storage Design. Within the ICDF Complex, there are five staging and storage areas. Each of these areas is listed below with a brief description of its purpose. Locations of these areas are shown on Figures 3-14a and 3-14b.

The five staging and storage areas within the ICDF Complex are as follows:

- $\quad$ Full container staging area $\left(100 \mathrm{ft} \times 300 \mathrm{ft}\right.$, capacity $\left.10,000 \mathrm{yd}^{3}\right)$ - Containerized waste waiting for treatment or the toxicity characteristic leaching procedure or other analytical results and containerized waste staged as a result of processing delays will be located in this area.

- $\quad$ Bulk soil stockpile staging area $\left(150 \mathrm{ft} \times 270 \mathrm{ft}\right.$, capacity 7,500 $\left.\mathrm{yd}^{3}\right)$ - This area is allocated for contaminated soil stockpile that is awaiting treatment by the treatment unit in the decon building. This area is intended to be operated in a modular mode and can accommodate a volume of 2,400 to $3,000 \mathrm{yd}^{3}$.

- $\quad$ SSA storage area (capacity 5,000 $\mathrm{yd}^{3}$ ) - Containerized waste waiting for treatment or the toxicity characteristic leaching procedure or other analytical results and containerized waste staged as a result of processing delays will be located in this area.

- $\quad$ SSA future staging area (capacity 5,000 $\mathrm{yd}^{3}$ ) - Containerized waste waiting for treatment or the toxicity characteristic leaching procedure or other analytical results and containerized waste staged as a result of processing delays will be located in this area.

- $\quad$ Tank and container storage area $(60 \mathrm{ft} \times 150 \mathrm{ft}$, capacity $56,000 \mathrm{gal})$ - The tank storage area is for storage of liquid waste prior to treatment, movement into other portions of the ICDF Complex, and/or discharge to the evaporation ponds.

Other areas are set aside to facilitate ICDF Complex operations, as well as staging and storage actions and include the following:

- $\quad$ Empty container area $(\mathbf{1 0 0} \mathbf{f t} \times \mathbf{3 0 0} \mathbf{f t})-$ This area may hold clean, empty containers that meet the free-release criteria such as roll-offs, waste boxes, etc. The empty container staging area is not a waste staging or storage area. 
- $\quad$ Truck in-transport area $(100 \mathrm{ft} \times 100 \mathrm{ft}$, capacity 25 trucks $)$-The purpose of this area is to allow for truck parking until resolution of waste acceptance with the ICDF Complex user. Should conditions arise which prevent the off-loading or transportation of containers, the vehicle may be parked inside this area.

Figures 3-14a and 3-14b show the locations of the staging and storage areas for the ICDF Complex. Additional information concerning the design and the analysis conducted to support the design is contained in the ICDF Remedial Action Work Plan (DOE-ID 2003a) and Operations and Maintenance Plan (DOE-ID 2003b), along with the supporting design analysis documents.

\subsection{ICDF Complex Utilities}

In developing the design for the ICDF Complex, many utilities and/or services were considered. The design criteria for the utilities depended upon the type of utility (raw water) and the design complied with the applicable standards. For example, lines that transfer hazardous and/or radioactive waste between ICDF Complex structures, such as the leachate from the landfill to the evaporation pond, are double contained. Electrical power from Substation 2 (outside of INTEC fence) will be used for the ICDF Complex and the power line will be buried underground. The remaining normal utilities (sewage, potable water, communications, fire water, etc.) will be tied into the INTEC systems. Additional information concerning the design and the analysis conducted to support the design is contained in the SSSTF RD/CWP (DOE-ID 2002a) and ICDF RD/CWP (DOE-ID 2002b) along with the supporting design analysis documents.

\subsection{ICDF Complex Groundwater Monitoring System}

Groundwater monitoring will be performed to meet the operational and postclosure requirements for the ICDF landfill and evaporation pond. The monitoring will also assess the remedy performance of the ICDF landfill and evaporation pond in relation to the ROD remedial action objectives and remediation goals (DOE-ID 1999). A groundwater monitoring plan (DOE-ID 2002c) has been developed to provide the necessary data to evaluate operational and postclosure performance, and provide the necessary data to evaluate the remedial action objectives and remediation goals. Additionally, the groundwater monitoring plan is designed to establish background water quality in the SRPA prior to startup of the ICDF Complex operations using an existing upgradient well and eleven new wells downgradient from the evaporation pond and landfill. Samples will be collected from the tertiary leak detection system sump and the LCS sump for comparison, and to determine if the landfill or evaporation pond liners have failed.

Figure 3-15 shows the wells that will be used for the ICDF Complex groundwater monitoring detection system. Additional information concerning the design and the analysis conducted to support the design is contained in the ICDF RD/CWP (DOE-ID 2002b) and supporting design analysis documents. 


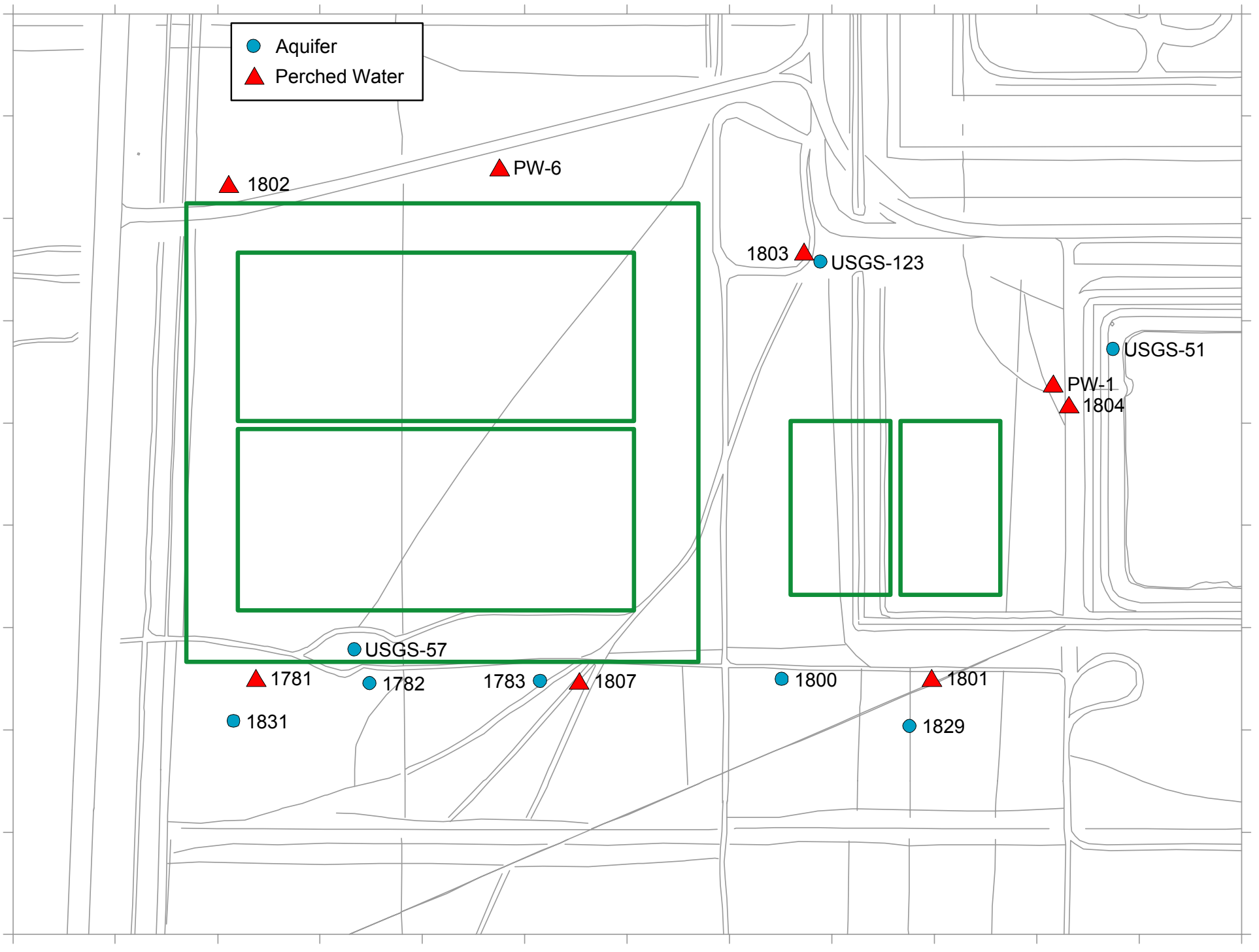

03-GA-50553-02

Figure 3-15. ICDF Complex groundwater detection monitoring system wells. 


\section{ACCEPTABLE WASTE TYPES FOR THE ICDF COMPLEX}

There are a variety of waste streams being considered for receipt into the ICDF Complex for staging, storage, treatment, and/or disposal. The radiological and chemical characteristics of these waste streams vary from site to site. However, the waste streams can be classified as hazardous waste, low-level waste (LLW) (radioactive), and mixed low-level waste (MLLW) (radioactive), TSCA PCB waste, asbestos containing materials, transuranic (TRU) waste, and mixed TRU waste. In addition to the classification, the waste steams acceptance for the ICDF Complex includes soil, debris, sludges, and aqueous liquid waste.

Each candidate waste stream is documented on a Waste Profile (Material Profile). These Material Profiles are submitted to the ICDF Complex for approval. If the Material Profile meets the ICDF Complex WAC, a shipping schedule is developed for the waste stream. For additional information on the Material Profile development and approval process, see the ICDF Complex Waste Tracking Plan (PLN-914). Also, a guidance document has been developed that gives the waste generators instructions concerning what information is necessary to develop and complete an acceptance Material Profile for the ICDF Complex. This guidance is presented in the ICDF Complex Material Profile Guidance (DOE-ID 2003c) document.

The WAC for the ICDF Complex is defined in the ICDF Complex WAC document (DOE-ID 2005). In developing the WAC document, a common set of prohibited waste types was excluded from acceptance into the ICDF Complex. These prohibited waste types are presented in Table 4-1.

Table 4-1. Waste types excluded from acceptance into the ICDF Complex.

\begin{tabular}{ll}
\hline \multicolumn{1}{c}{ Waste Type } & \multicolumn{1}{c}{ Comments } \\
\hline High-level waste & $\begin{array}{l}\text { Highly radioactive waste material, including liquid waste, resulting from } \\
\text { reprocessing spent nuclear fuel, will not be accepted. }\end{array}$ \\
$\begin{array}{l}\text { Spent nuclear fuel that has been withdrawn from a nuclear reactor following irradiation and } \\
\text { that has not been reprocessed to remove its constituent elements. }\end{array}$ \\
$\begin{array}{l}\text { Waste capable of } \\
\text { detonation or } \\
\text { explosive reactivity }\end{array}$ & $\begin{array}{l}\text { Waste capable of detonation or explosive reaction when subjected to a strong } \\
\text { initiating source, or if heated under confinement. }\end{array}$ \\
$\begin{array}{l}\text { Wastes with } \\
\text { criticality concerns } \\
\begin{array}{l}\text { Wastes capable of } \\
\text { generating toxic } \\
\text { gases }\end{array}\end{array}$ & $\begin{array}{l}\text { Waste containing sufficient quantities of fissile constituents to be of concern } \\
\text { from a criticality concern will not be accepted. }\end{array}$ \\
\hline
\end{tabular}

There are four functional areas within the ICDF Complex. These functional areas are staging/storage, treatment, landfill, and evaporation pond. The ICDF Complex WAC document (DOE-ID 2005) addresses criteria for all four of these areas. Additional restrictions for the ICDF Complex functional areas are discussed in Sections 4.1 through 4.4.

\subsection{Waste Types for Staging and Storage Areas}

Only INL CERCLA waste streams are acceptable for staging and storage in the ICDF Complex. The staging and storage functions of the ICDF Complex can deal with both solid and liquid waste streams. The allowable waste classifications from INL CERCLA remedial or removal actions for staging 
and storage at the ICDF Complex are LLW, hazardous waste, mixed (radioactive and hazardous) waste, PCBs, TRU waste, and mixed TRU wastes. Also, investigation and decontamination and dismantlement waste streams can be accepted into the ICDF Complex for staging or storage.

There are few additional restrictions beyond those stated in Section 4 and Table 4-1 for the staging and storage functions are presented in Table 4-2. The additional restrictions deal with the specific WAC for the staging and storage functions at the ICDF Complex.

Table 4-2. Summary of WAC restrictions for staging and storage at the ICDF Complex.

\begin{tabular}{lll}
\hline \multicolumn{1}{c}{ Criteria } & \multicolumn{1}{c}{ Solid Waste } & \multicolumn{1}{c}{ Liquid Waste } \\
\hline Physical criteria & $\begin{array}{l}\text { Sized to allow for handling of the waste and if } \\
\text { destined for treatment or disposal must meet } \\
\text { the appropriate physical criteria. }\end{array}$ & Not applicable \\
Chemical criteria & $\begin{array}{l}\text { Limited to concentrations that will not cause } \\
\text { an exceedence of IDAPA 58.01.01.585 and } \\
\text {.586 concentrations. }\end{array}$ & Same as for solid waste \\
Radiological concentration & $\begin{array}{l}\text { Limited to concentrations that will not cause } \\
\text { an exceedence of NESHAP limits. }\end{array}$ & Same as for solid waste \\
limits & $\begin{array}{l}\text { Limited to inventory for less than Category 3 } \\
\text { Radiological and chemical } \\
\text { inventory limits }\end{array}$ & Same as for solid waste \\
alternative release fractions (see HAD-136). & \\
Criticality safety limits & $\begin{array}{l}\text { Limited to inventory that will not result in a } \\
\text { criticality concern (see DOE-ID 2005). }\end{array}$ & $\begin{array}{l}\text { Same as for solid waste } \\
\text { Package dose rate limits }\end{array}$ \\
$\begin{array}{l}\text { Limited to less than 500 mrem/hr at 1 m. } \\
\text { Higher dose rates are allowed if shielding is } \\
\text { utilized to shield workers. }\end{array}$ & $\begin{array}{l}\text { Same as for solid waste } \\
\text { Various types containers are allowed } \\
\text { including bulk staging in a waste staging pile } \\
\text { for solid wastes (see DOE-ID 2005). }\end{array}$ & $\begin{array}{l}\text { Various types } \\
\text { containers are allowed } \\
\text { for staging/storage of } \\
\text { liquid wastes (see } \\
\text { DOE-ID 2005) }\end{array}$ \\
\hline & &
\end{tabular}




\subsection{Waste Types for Treatment Facility}

There are two treatment systems within the ICDF Complex. The first treatment system is the soils stabilization treatment system, which deals with the treatment of soils. This treatment system can also treat sludges. Under certain conditions, the soils stabilization treatment system can treat aqueous waste streams by using the aqueous waste as the makeup water in the treatment recipe.

The intent of the soils stabilization is to produce a soil like stabilized waste form following the treatment. As stated in Section 3.5, the soils stabilization treatment is accomplished by mixing the soil with Portland cement and other chemical along with a minimal amount of water to stabilize the hazardous constituents in the treated waste. However, if it is necessary to treat significant volumes of aqueous waste, the treated liquid waste form would be a solid mass similar to a block of grout. This would require the treated waste to be disposed in the same manner that treated debris would be disposed.

There are several additional restrictions for the soils stabilization treatment system above the requirements for receipt and staging/storage. These additional restrictions are presented in Table 4-3.

Table 4-3. Summary of WAC restrictions for treatment in the soils stabilization treatment system.

\begin{tabular}{ll}
\hline \multicolumn{1}{c}{ Waste Type } & \multicolumn{1}{c}{ Comment } \\
\hline $\begin{array}{l}\text { Waste outside size } \\
\text { limits for treatment unit }\end{array}$ & Waste greater than 6 in. will not be accepted. \\
$\begin{array}{l}\text { Waste outside chemical } \\
\text { criteria }\end{array}$ & $\begin{array}{l}\text { Waste that has chemical concentrations greater than the treatment recipe } \\
\text { can handle will not be accepted without development of an adequate recipe. }\end{array}$ \\
$\begin{array}{l}\text { Waste above the } \\
\text { radioactive criteria }\end{array}$ & $\begin{array}{l}\text { Wastes }>500 \mathrm{mrem} / \mathrm{hr} \text { at } 1 \text { meter if shield or other institutional/engineering } \\
\text { controls are not implemented will not be accepted. }\end{array}$ \\
$\begin{array}{l}\text { Transuranic waste } \\
\text { Transuranic and mixed transuranic waste will not be accepted for treatment }\end{array}$ \\
\hline
\end{tabular}

The second treatment system is the micro-encapsulation debris treatment system, which deals with the treatment of debris waste streams. This system can treat a variety of waste streams from concrete to personnel protective equipment to contaminated equipment. Many other waste streams can be treated in this system provided they meet the definition of debris and there is not another method specified in 40 CFR 268.45 for that waste stream. Also, it is possible to use this treatment system can also treat aqueous waste and potentially event sludge waste streams. This could be accomplished by using the aqueous waste and/or the sludge materials as ingredients in the grout used for the micro-encapsulation.

The intent of the micro-encapsulation treatment process is completely encapsulate the debris and resist degradation by the debris and it contaminants and materials which it may come in contact after disposal. As stated in Section 3.5, the debris treatment is accomplished by using a flowable grout material to fill the void spaces in the container holding the debris material. This results in a treated debris waste form that is essentially a solid block of grout and debris.

There are several additional restrictions for the debris treatment system above the requirements for receipt and staging/storage. These additional restrictions are presented in Table 4-4. 
Table 4-4. Summary of WAC restrictions for debris treatment at the ICDF Complex.

\begin{tabular}{ll}
\hline \multicolumn{1}{c}{ Waste Type } & \multicolumn{1}{c}{ Comment } \\
\hline $\begin{array}{l}\text { Wood boxes } \\
\text { Concrete debris }\end{array}$ & Boxes must be no larger than $4 \times 4 \times 8 \mathrm{ft}$. \\
& Concrete may be sent to the ICDF Complex in one of two different forms: \\
& $-\quad$ Reduced to rubble with a maximum dimension of approximately $1 \mathrm{ft}$
\end{tabular}

\subsection{Waste Types for Landfill}

Only INL CERCLA waste stream are acceptable for disposal in the ICDF landfill. The ICDF landfill was designed and constructed to protect the SRPA from contamination exceeding the maximum contaminant levels, cumulative risk of $10^{-4}$, and a hazard quotient of 1 . To ensure this protection, the contaminant loading in the ICDF landfill was modeled. This modeling resulted in an acceptable inventory for all constituents considered, based on the design inventory (EDF-ER-264), that would not cause an exceedence of the groundwater protection criteria. Along with the inventory (kg or curies) for the contaminants, a concentration guideline, based on the inventory divided by the disposal volume (mass) was developed. This information is presented in the landfill section of the ICDF Complex WAC (DOE-ID 2005).

There were other criteria, in addition to impacts on the SRPA, that were considered in the development of the ICDF landfill WAC. These other criteria were considered impacts on the liner materials (degradation of the various liner materials) and regulatory limits (TSCA PCB and Class C limits) or commitments in the OU 3-13 ROD (limited TRU constituents to $10 \mathrm{nCi} / \mathrm{g}$ ). Also, the impacts of operating the ICDF landfill at the ICDF WAC limits has been evaluated for risk to workers (EDF-2236, EDF-2237, EDF-ER-290, and EDF-ER-327) and ecological receptors (EDF-ER-311). It was determined that the ICDF landfill WAC limits were protective.

There are several additional restrictions beyond those stated in Section 4 and Table 4-1 for disposal in the ICDF landfill. These additional restrictions are presented in Table 4-5 for disposal in the ICDF landfill. Additional requirements that must be met for selected waste stream destined for disposal in the ICDF landfill are presented in Table 4-6. The full list of acceptable waste types and limits is presented in the ICDF Complex WAC (DOE-ID 2005) along with the process used to develop the limits. 
Table 4-5. Summary of WAC restrictions for landfill disposal at the ICDF Complex.

\begin{tabular}{|c|c|}
\hline Waste Type & Comment \\
\hline $\begin{array}{l}\text { Waste with greater than } \\
10 \mathrm{nCi} / \mathrm{g} \text { TRU } \\
\text { constituents }\end{array}$ & $\begin{array}{l}\text { Wastes with greater than } 10 \mathrm{nCi} / \mathrm{g} \text { TRU constituents, as disposed, are } \\
\text { prohibited from disposal in the ICDF landfill. }\end{array}$ \\
\hline $\begin{array}{l}\text { Waste containing } \\
\text { greater than } 500 \mathrm{ppm} \\
\text { PCBs }\end{array}$ & $\begin{array}{l}\text { Waste having concentrations of PCBs in excess of } 500 \mathrm{ppm} \text { are excluded } \\
\text { from disposal in the ICDF landfill. }\end{array}$ \\
\hline Free liquids & $\begin{array}{l}\text { Wastes containing free liquids are prohibited from disposal in the ICDF } \\
\text { landfill without treatment (stabilization) of the free liquid. }\end{array}$ \\
\hline $\begin{array}{l}\text { Waste capable of } \\
\text { detonation, explosive } \\
\text { decomposition, or } \\
\text { reaction }\end{array}$ & $\begin{array}{l}\text { Waste capable of detonation or explosive decomposition is prohibited from } \\
\text { disposal in the ICDF landfill. This includes ordnance and explosive } \\
\text { materials that may be encountered during excavation of waste. }\end{array}$ \\
\hline $\begin{array}{l}\text { Waste capable of } \\
\text { generating toxic gases, } \\
\text { vapors, or fumes. }\end{array}$ & $\begin{array}{l}\text { Waste capable of generating toxic gases, vapors, or fumes harmful to } \\
\text { persons transporting, handling, and disposing the waste are prohibited. The } \\
\text { only allowable degradable wastes are wood, building demolition debris, } \\
\text { PPE, and metals. }\end{array}$ \\
\hline Gaseous waste & All gaseous waste containers must be empty and flattened. \\
\hline $\begin{array}{l}\text { Waste exceeding the } \\
\text { Class C limit }\end{array}$ & $\begin{array}{l}\text { Waste exceeding the Class C radioactive waste limit, as defined in } \\
10 \text { CFR } 61.55 \text { is prohibited from disposal in the ICDF landfill. }\end{array}$ \\
\hline $\begin{array}{l}\text { Waste containing } \\
\text { greater than } 1 \% \\
\text { chelating compounds }\end{array}$ & $\begin{array}{l}\text { Waste containing greater than } 1 \% \text { chelating compounds by weight are } \\
\text { prohibited. Examples of chelating compounds are glycinate, salicylate, } \\
\text { chelidamic acid, and phthalic acid. }\end{array}$ \\
\hline $\begin{array}{l}\text { Volatile organic wastes } \\
\text { exceeding } 500 \mathrm{ppm}\end{array}$ & $\begin{array}{l}\text { Waste containing volatile organic compounds greater than } 500 \mathrm{ppm} \text { are } \\
\text { prohibited from disposal in the ICDF landfill. }\end{array}$ \\
\hline
\end{tabular}

Table 4-6. Materials restricted from disposal at the ICDF landfill until the listed conditions have been met.

\begin{tabular}{|c|c|}
\hline Restricted Material & Condition to be Met \\
\hline $\begin{array}{l}\text { Hazardous waste outside area of } \\
\text { contamination }\end{array}$ & $\begin{array}{l}\text { Hazardous waste from outside the area of contamination must } \\
\text { be treated to meet LDRs. }\end{array}$ \\
\hline \multirow[t]{2}{*}{$\begin{array}{l}\text { Bulk disposal of waste containing } \\
\text { free liquids }\end{array}$} & $\begin{array}{l}\text { Free liquids must be eliminated by stabilization (adding materials } \\
\text { to chemically immobilize the free liquids in the waste). }\end{array}$ \\
\hline & $\begin{array}{l}\text { If necessary, the presence of free liquids shall be determined } \\
\text { by EPA Method } 9095 \text { ("Paint Filter Liquids Test") } \\
\text { (EPA 1986) before shipment to the ICDF Complex. }\end{array}$ \\
\hline \multirow[t]{2}{*}{$\begin{array}{l}\text { Containerized waste holding free } \\
\text { liquids, unless one of the following } \\
\text { conditions has been met: }\end{array}$} & $\begin{array}{l}\text { All freestanding liquid has been decanted, solidified with } \\
\text { nonbiodegradable sorbent materials, stabilized, or otherwise } \\
\text { eliminated. }\end{array}$ \\
\hline & $\begin{array}{l}\text { The waste has been converted into a form that contains as } \\
\text { little freestanding and noncorrosive liquid as is reasonably } \\
\text { achievable. In no case shall the liquid exceed } 1 \% \text { of the waste } \\
\text { volume in a disposal container or } 0.5 \% \text { of the waste volume } \\
\text { processed to a stable form. }\end{array}$ \\
\hline
\end{tabular}


Table 4-6. (continued).

\begin{tabular}{|c|c|}
\hline Restricted Material & Condition to be Met \\
\hline LDR—Restricted waste & Must meet LDR requirements for 40 CFR 268. \\
\hline $\begin{array}{l}\text { Refrigerant-bearing equipment } \\
\text { containing chlorofluorocarbons }\end{array}$ & chlorofluorocarbon removal has been completed (40 CFR 82). \\
\hline Pyrophoric waste & $\begin{array}{l}\text { The waste must be treated, prepared, and packaged to be } \\
\text { nonflammable prior to being disposed. }\end{array}$ \\
\hline $\begin{array}{l}\text { Infectious waste, as defined in } \\
10 \text { CFR } 61 \text { (including "any substance } \\
\text { that may harbor or transmit } \\
\text { pathogenic organisms," which may } \\
\text { apply to septic tank sludge) }\end{array}$ & Special handling procedures will be developed. \\
\hline $\mathrm{pH}<2$ or $>12.5$ & Neutralized. \\
\hline $\begin{array}{l}\text { Wastes containing }>500 \mathrm{ppm} \text { volatile } \\
\text { organics }\end{array}$ & $\begin{array}{l}\text { Must be treated to reduce volatile organics to }<500 \mathrm{ppm} \\
(40 \text { CFR } 264.1082[\mathrm{c}][1]) .\end{array}$ \\
\hline $\begin{array}{l}\text { Trinitrotoluene Royal Dutch } \\
\text { explosives }\end{array}$ & $\begin{array}{l}\text { The waste must not be capable of detonation, explosive } \\
\text { decomposition, or reaction at normal pressures and } \\
\text { temperature, or explosive reaction with water. }\end{array}$ \\
\hline
\end{tabular}

\subsection{Waste Types for Evaporation Pond}

Only certain INL CERCLA waste stream are acceptable for disposal in the ICDF evaporation pond. The ICDF evaporation pond was designed and constructed to protect the SRPA and surface receptors from unacceptable risk or impacts. The development of ICDF evaporation pond WAC was done differently than for the ICDF landfill WAC. As the operations of the evaporation pond is a short term operation in comparison to the landfill as a disposal unit, including the postclosure period, the impacts on the SRPA were not modeled. The evaporation pond can be repaired if leaks, in excess of the allowable leakage rate, develop. Impacts on the evaporation pond liner (degradation of the various liner materials) and compliance with regulatory limits (40 CFR 761.75; 40 CFR 264, Subparts BB and CC; and 10 CFR 61 for Class C limits) or commitments in the OU 3-13 ROD (limited TRU constituents to $10 \mathrm{nCi} / \mathrm{g}$ ) were the limiting factors in the development of the ICDF evaporation pond WAC. The resulting concentration limits $(\mathrm{mg} / \mathrm{L}$ or $\mathrm{pCi} / \mathrm{L})$ for the contaminants were developed for the ICDF evaporation pond and are presented in the ICDF Complex WAC (DOE-ID 2005). Also, the impacts of operating the ICDF evaporation pond at the ICDF evaporation pond WAC limits has been evaluated for risk to workers (EDF2236, EDF-2237, EDF-ER-290, and EDF-ER-327) and ecological receptors (EDF-ER-311). It was determined that the ICDF evaporation pond WAC limits were protective.

There are several additional restrictions beyond those stated in Section 4 and Table 4-1 for disposal in the ICDF evaporation pond. These additional restrictions are presented in Table 4-7 for disposal in the ICDF evaporation pond. Additional requirements that must be met for selected waste stream destined for disposal in the ICDF evaporation pond are presented in Table 4-8. The full list of acceptable waste types and limits is presented in the ICDF Complex WAC (DOE-ID 2005) along with the process used to develop the limits. 
Table 4-7. Summary of WAC restrictions for evaporation pond disposal at the ICDF Complex.

Waste Type

Comment

Non-WAG 3/ICDF

Complex

groundwater

monitoring

Non-ICDF Complex

aqueous waste

streams

Waste with greater

than $10 \mathrm{nCi} / \mathrm{g}$ TRU

constituents

TSCA waste

Aqueous wastes generated from groundwater monitoring activities other than

WAG 3 or ICDF Complex groundwater monitoring activities is prohibited

from disposal in the ICDF evaporation pond.

Other aqueous waste streams not associated with operation of the ICDF

Complex (ICDF landfill leachate, storm water, decontamination, secondary

waste from treatment, etc.) are prohibited from disposal in the ICDF evaporation pond.

Wastes with greater than $10 \mathrm{nCi} / \mathrm{g}$ TRU constituents, as disposed, are prohibited from disposal in the ICDF landfill.

TSCA waste is prohibited from disposal at the ICDF evaporation pond as described by the following:

Asbestos waste is not aqueous waste.

Direct disposal of PCB wastes ( $>50 \mathrm{ppm})$ is prohibited. Although unlikely, PCBs may be a component of the ICDF leachate. As a CAMU for the ICDF leachate, the evaporation pond may accept FO39 (landfill leachate) waste.

Waste capable of Waste capable of detonation or explosive decomposition is prohibited from detonation, explosive decomposition, or reaction disposal in the ICDF landfill. This includes ordnance and explosive materials that may be encountered during excavation of waste.

Waste capable of generating toxic gases, vapors, or fumes.

Waste exceeding the Class C limit

Waste containing greater than $1 \%$ chelating compounds

Volatile organic wastes exceeding Waste capable of generating toxic gases, vapors, or fumes harmful to persons transporting, handling, and disposing the waste are prohibited. The only allowable degradable wastes are wood, building demolition debris, PPE, and metals.

Waste exceeding the Class $\mathrm{C}$ radioactive waste limit, as defined in 10 CFR 61.55 is prohibited from disposal in the ICDF landfill.

Waste containing greater than $1 \%$ chelating compounds by weight are prohibited. Examples of chelating compounds are glycinate, salicylate, chelidamic acid, and phthalic acid.

Waste containing volatile organic compounds greater than $500 \mathrm{ppm}$ are prohibited from disposal in the ICDF landfill. 
Table 4-8. Materials restricted from disposal at the ICDF evaporation pond until the listed conditions have been met.

\begin{tabular}{|c|c|}
\hline Restricted Material & Condition to be Met \\
\hline Pyrophoric waste & $\begin{array}{l}\text { The waste must be treated, to be nonflammable prior } \\
\text { to being disposed. }\end{array}$ \\
\hline $\begin{array}{l}\text { Liquid acid waste that exhibit the } \\
\text { characteristic of low pH under the corrosivity } \\
\text { tests of } 40 \text { CFR } 261.22\end{array}$ & Must be neutralize to $\mathrm{pH}>2$ or $<12.5$. \\
\hline $\begin{array}{l}\text { Infectious waste, as defined in } 10 \text { CFR } 61 \\
\text { (including "any substance that may harbor or } \\
\text { transmit pathogenic organisms," which may } \\
\text { apply to septic tank sludge) }\end{array}$ & Special handling procedures will be developed. \\
\hline Presence of oil sheen & PCB testing to verify no PCBs are present. \\
\hline Solids & Filter liquid waste using a 30 -micron filter. \\
\hline
\end{tabular}




\section{GENERAL REQUIREMENTS AND RESPONSIBILITIES (DOE ORDER 435.1, CHAPTER I)}

Chapter I of DOE Manual 435.1 deals with the general requirement and responsibilities associated with the generation, storage, treatment, handling, and disposal of radioactive waste material. This section of the ICDF Complex compliance demonstration discusses the general requirements and responsibilities contained in DOE Manual 435.1. An evaluation is presented to determine whether requirements and responsibilities in Chapter I of DOE Manual 435.1 are administrative or substantive (see Section 1.1) in function. If the requirement or responsibility is administrative, minimal additional discussion is presented. For the substantive requirements and responsibilities under DOE Manual 435.1, additional information is presented on (1) how the requirement or responsibility is being satisfied and (2) if the requirement or responsibility was identified as an ARARs or TBCs, and (3) references to Section 9 discussing the CERCLA documents that provide supplemental and/or supporting information regarding the how the requirement or responsibility is met.

Within Chapter I, the requirements and responsibilities are organized into 2 major sections. The two major sections are (1) Requirements (I.1.) and (2) Responsibilities (I.2.). The evaluation and information for the ICDF Complex concerning these sections are presented in Sections 5.1 and 5.2.

\subsection{Requirements (I.1.)}

Chapter I.1 of DOE Manual 435.1 contains the general requirements for management of radioactive waste. Within Chapter I.1 of DOE Manual 435.1, there are five major subsections dealing with requirements for management of radioactive waste. These major subsections are (1) Delegation of Authority (I.1.A), (2) Use of Guidance (I.1.B.), (3) Radioactive Waste Management (I.1.C.), (4) Analysis of Environmental Impacts (I.1.D.), and (5) Requirement of Other Regulations and DOE Directives (I.1.E.). The evaluations and information for the ICDF Complex concerning these sections are presented in Sections 5.1.1 through 5.1.5.

\subsubsection{Delegation of Authority (I.1.A.)}

In DOE Manual 435.1, the requirement for delegation of authority is as follows:

Managers charged with responsibilities may delegate authority for tasks to another manager. All delegations of authority shall be documented.

This requirement is classified as administrative. However, both DOE-ID and the ICP contractor have processes and procedures in place to formally document the delegation of authorities. This specific requirement was not identified as an ARAR or TBC in the OU 3-13 ROD and is not specifically addressed in other CERCLA documents for the ICDF Complex.

\subsubsection{Use of Guidance (I.1.B.)}

In DOE Manual 435.1, the requirement for use of guidance is as follows:

Additional information supporting the requirements in this Manual is contained in the Implementation Guide for use with DOE M 435.1-1, Radioactive Waste Management Manual. This Guide, DOE G 435.1-1, Implementation Guide for DOE M 435.1-1, shall be reviewed when implementing the requirements of this Manual. The Guide provides additional information and acceptable methods for 
meeting the requirements. Other methods may be used but must ensure an adequate level of safety commensurate with the hazards associated with the work and be consistent with the radioactive waste management basis.

This requirement is classified as administrative. However, the guidance document (DOE G 435.1) associated with DOE Order 435.1 and DOE Manual 435.1 was consulted to better understand the nature and scope of the various requirements in all four chapters of DOE Manual 435.1. This specific requirement was not identified as an ARAR or TBC in the OU 3-13 ROD and is not specifically addressed in other CERCLA documents for the ICDF Complex.

\subsubsection{Radioactive Waste Management (I.1.C.)}

In DOE Manual 435.1, the requirement for radioactive waste management is as follows:

All radioactive waste subject to DOE O 435.1, Radioactive Waste Management, and the requirements of this Manual shall be managed as high-level waste, transuranic waste, LLW, or MLLW.

This requirement is classified as substantive. The various waste types that will be received, stored/staged, treated, and/or disposed of at the ICDF Complex will be classified based on the definitions used Chapters II, III, and IV of DOE Manual 435.1. Following classification of the waste type, the waste will be managed according to the specific requirements for the waste type as described in DOE Manual 435.1 and further discussed below in Sections 6, 7, and 8.

This specific requirement was not identified as an ARAR or TBC in the OU 3-13 ROD. However, the classification and management of waste will be in compliance with DOE Manual 435.1. In Section 9, this requirement is addressed and shows the associated ARARs and CERCLA documents addressing this requirement.

\subsubsection{Analysis of Environmental Impacts (I.1.D.)}

In DOE Manual 435.1, the requirement for analysis of environmental impacts is as follows:

Existing and proposed radioactive waste management facilities, operations, and activities shall meet the requirements of 10 CFR Part 1021, National Environmental Policy Act Implementing Procedures; and DOE O 451.1A, National Environmental Policy Act Compliance Program. All reasonable alternatives shall be considered, as appropriate. Nothing in this Order is meant to restrict consideration of alternatives to proposed actions.

This requirement is classified as substantive. The CERCLA process is functionally equivalent to the NEPA process (DOE 1994). As such, separate NEPA documentation and associated process is not required. The CERCLA process was documented and approved with the signature of the OU 3-13 ROD (DOE-ID 1999). During the development of the OU 3-13 FS Report (DOE-ID 1998), the environmental impacts for the construction and operations of the ICDF Complex were analyzed and determined to be acceptable. Also, in the OU 3-13 FS Report, the environmental impacts for disposal at an off-Site disposal facility were evaluated.

This specific requirement was not identified as an ARAR or TBC in the OU 3-13 ROD. However, subsequent analysis of the environmental impacts of the ICDF Complex has been conducted as part of the 
design and operation planning activities. In Section 9, this requirement is addressed and shows the CERCLA documents developed during the design and operational planning addressing this requirement.

\subsubsection{Requirements of Other Regulations and DOE Directives (I.1.E.)}

In DOE Manual 435.1, the requirement for requirements of other regulations and DOE Directives is as follows:

The following requirements and DOE directives are required for all DOE radioactive waste management facilities, operations, and activities as applicable. Any of the requirements for the following Departmental directives may be waived or modified through application of a DOE-approved requirements tailoring process, such as the "Necessary and Sufficient Closure Process" in DOE P 450.3 and DOE M 450.3-1, or by an exemption processed in accordance with the requirements of that directive or DOE M 251.1-1A, Directives System Manual.

This requirement is classified as administrative. However, the ICDF Complex is being designed and constructed in compliance with DOE Order and DOE Directives along with the ARARs and TBCs identified in the OU 3-13 ROD. There are specific requirements within DOE Manual 435.1 that are not applicable to the ICDF Complex. These requirements are discussed further in Sections 5.1.5.1 through 5.1.5.21. This specific requirement was not identified as an ARAR or TBC in the OU 3-13 ROD and is not specifically addressed in other CERCLA documents for the ICDF Complex.

5.1.5.1 Analysis of Operations Information (I.1.E.1.). In DOE Manual 435.1, the requirement for analysis of operations information is as follows:

Analysis of Operations Information. Data that measure the environment, safety, and health performance of radioactive waste management facilities, operations, and activities shall be identified, collected, and analyzed as required by DOE O 210.1, Performance Indicators and Analysis of Operations Information.

This requirement is classified as administrative. The ICDF Complex is being constructed and will be operated in compliance with DOE Order and DOE Directives along with the ARARs and TBCs identified in the OU 3-13 ROD. Construction and operations of facilities on the INL are required to collect, analyze, and disseminate environmental, safety, and health indicating parameters as part of the normal operating environment. For the ICDF Complex, other types of operational information will be collected. This information is used to identify issues and develop processes and procedures to prevent and fix problems. This specific requirement was not identified as an ARAR or TBC in the OU 3-13 ROD. In Section 9, this requirement is addressed and shows the associated ARARs and CERCLA documents addressing this requirement.

5.1.5.2 Classified Waste (I.1.E.2.). In DOE Manual 435.1, the requirement for classified waste is as follows:

Radioactive waste to which access has been limited for national security reasons and cannot be declassified shall be managed in accordance with the requirements of DOE 5632.1C, Protection and Control of Safeguards and Security Interests, and DOE 5633.3B, Control and Accountability of Nuclear Materials. 
This requirement is classified as administrative. However, the ICDF Complex is currently not considering any waste streams that would be classified as "classified waste." If a future classified waste stream is identified for the ICDF Complex, procedure and processes would be developed to declassify the waste stream to the maximum extent practical or turn the waste stream over to other INL programs dealing with classified waste for disposition. This specific requirement was not identified as an ARAR or TBC in the OU 3-13 ROD and is not specifically addressed in other CERCLA documents for the ICDF Complex.

5.1.5.3 Conduct of Operations (I.1.E.3.). In DOE Manual 435.1, the requirement for conduct of operations is as follows:

Radioactive waste management facilities, operations, and activities shall be conducted in a manner based on consideration of the associated hazards. Waste management facilities, operations, and activities shall meet the requirements of DOE 5480.19, Conduct of Operations Requirement for DOE Facilities.

This requirement is classified as substantive. The planning and processes being used in the construction and subsequently in operations do consider and implement the conduct of operations requirements and issues. When the detailed procedures for operations are developed, the requirements and issues in DOE Order 5480.19 will be considered and included as practical. Also, activities done at the INL are required to follow and be in compliance with the requirement of DOE Order 5480.19. This specific requirement was not identified as an ARAR or TBC in the OU 3-13 ROD. In Section 9, this requirement is addressed and shows the associated ARARs and CERCLA documents addressing this requirement.

5.1.5.4 Critically Safety (I.1.E.4.). In DOE Manual 435.1, the requirement for critically safety is as follows:

Radioactive waste management facilities, operations, and activities shall be covered by a criticality safety program in accordance with DOE O 420.1, Facility Safety.

This requirement is classified as substantive. For the operations of the ICDF Complex, conservative limits for the amount of fissile material that is allowed in the facility have been established. These limits were extracted from a standard dealing with criticality issues (ANS 1981) and incorporated into the ICDF Complex WAC document (DOE-ID 2005). Also, these limits are imposed on the ICDF landfill and evaporation pond through the ICDF Complex WAC document).

The waste streams that are currently planned for receipt at the ICDF Complex do not have sufficient quantities of fissile material to pose a potential criticality concern. However, the conservative limits are considered to be the limiting amount (concentration and configuration) allowed in the ICDF Complex. No additional critically analysis is planned for the ICDF Complex other that to maintain the inventories below the established limits. This specific requirement was not identified as an ARAR or TBC in the OU 3-13 ROD. In Section 9, this requirement is addressed and shows the associated ARARs and CERCLA documents addressing this requirement.

5.1.5.5 Emergency Management Program (I.1.E.5.). In DOE Manual 435.1, the requirement for emergency management program is as follows: 
Radioactive waste management facilities, operations, and activities shall maintain an emergency management program in accordance with DOE O 151.1, Comprehensive Emergency Management System.

This requirement is classified as substantive. The ICDF Complex is being constructed and will be operated in compliance with DOE Order and DOE Directives along with the ARARs and TBCs identified in the OU 3-13 ROD. Construction and operations of facilities on the INL are required to develop, implement, and maintain an emergency management program as part of the normal operating environment. This program is used to deal with emergency situations and problems. This specific requirement was not identified as an ARAR or TBC in the OU 3-13 ROD. In Section 9, this requirement is addressed and shows the associated ARARs and CERCLA documents addressing this requirement.

5.1.5.6 Environmental and Occurrence Reporting (I.1.E.6.). In DOE Manual 435.1, the requirement for environmental and occurrence reporting is as follows:

Radioactive waste management facilities, operations, and activities shall meet the reporting requirements of DOE O 231.1, Environment, Safety and Health

Reporting, and DOE O 232.1A, Occurrence Reporting and Processing of Operations Information.

This requirement is classified as administrative. However, the ICDF Complex is being constructed and will be operated in compliance with DOE Order and DOE Directives along with the ARARs and TBCs identified in the OU 3-13 ROD. Construction and operations of facilities on the INL are required to ensure appropriate and timely identification, categorization, response, notification, investigation, and reporting of abnormal conditions and events as part of the normal operating environment. This information is used to identify problems and unacceptable conditions that when resolved will prevent future problems and unacceptable conditions. This requirement was not identified as an ARAR or TBC in the OU 3-13 ROD and is not specifically addressed in other CERCLA documents for the ICDF Complex.

5.1.5.7 Environmental Monitoring (I.1.E.7). In DOE Manual 435.1, the requirement for environmental monitoring is as follows:

Radioactive waste management facilities, operations, and activities shall meet the environmental monitoring requirements of DOE 5400.1, General Environmental Protection Program, and DOE 5400.5, Radiation Protection of the Public and Environment.

This requirement is classified as substantive. The ICDF Complex was designed to protect the public and workers from unacceptable exposures. For the operations of the ICDF Complex, there are several types of monitoring that will be conducted. These monitoring requirements are necessary to demonstrate that the facility is being operated safely and not adversely impacting the public, workers, or the environment. The monitoring required at the ICDF Complex consists of air monitoring, leachate monitoring, evaporation pond liquid, and groundwater monitoring in addition to the routine monitoring for radiation exposure at a operating radiological facility. While this section of DOE Manual 435.1 was not directly cited as an ARAR, DOE Order 5400.5 was cited as a TBC for exposure to the public will be kept ALARA in the OU 3-13 ROD. In addition, there are several ARARs for the ICDF Complex dealing with emissions monitoring from the ICDF Complex during construction, operations, and closure. In Section 9, this requirement is addressed and shows the associated ARARs and CERCLA documents addressing this requirement. 
5.1.5.8 Hazard Analysis Documentation and Authorization Basis (I.1.E.8.). In DOE

Manual 435.1, the requirement for hazard analysis documentation and authorization basis is as follows:

Radioactive waste management facilities, operations, and activities shall implement DOE Standards, DOE-STD-1027-92, Hazard Categorization and Accident Analysis Techniques for Compliance with DOE 5480.23, Nuclear Safety Analysis Reports, and/or DOE-EM-STD-5502-94, DOE Limited Standard: Hazard Baseline Documentation, and shall, as applicable, prepare and maintain hazard analysis documentation and an authorization basis as required by DOE O 425.1A, Startup and Restart of Nuclear Facilities, DOE 5480.21, Unreviewed Safety Questions, DOE 5480.22, Technical Safety Requirements, and DOE 5480.23, Nuclear Safety Analysis Reports

This requirement is classified as administrative. However, the inventories that could be present in the ICDF Complex were evaluated under the DOE-STD-1027-92 process. The result was the classification of the ICDF Complex as a "radiological, low hazard facility" (i.e., less than Category 3 ). This information was used in the development of the design and operational requirements and used in support of the design basis for the ICDF Complex. This requirement was not identified as an ARAR or TBC in the OU 3-13 ROD. In Section 9, this requirement is addressed and shows the associated ARARs and CERCLA documents addressing this requirement.

5.1.5.9 Life-Cycle Asset Management (I.1.E.9.). In DOE Manual 435.1, the requirement for life-cycle asset management is as follows:

Planning, acquisition, operation, maintenance, and disposition of radioactive waste management facilities shall be in accordance with DOE O 430.1A, Life-Cycle Asset Management, and DOE 4330.4B, Maintenance Management Program, including a configuration management process to ensure the integrity of physical assets and systems. Corporate physical asset databases shall be maintained as complete, current inventories of physical assets and systems to allow reliable analysis of existing and potential hazards to the public and workers.

This requirement is administrative in nature. However, the ICDF Complex is being designed and constructed to meet the requirements of DOE Order 430.1A and DOE N 251.38 and DOE O 433.1 (which cancel DOE 4330.4B, Chapters 1 and 2, respectively). Also, the operations and closure components for the ICDF Complex are being considered in the development of the design. The ICDF Complex, with the exception of the ICDF landfill, is being designed and constructed with "clean closure" concepts. This will allow for these components of the ICDF Complex to be closed and removed without having to have a long-term monitoring and maintenance requirement. In the case of the ICDF landfill, the landfill is being designed and constructed for an operational period of 15 years.

Following the operational period, the landfill will be closed with an engineered barrier with an expected design life of 1,000 years. This engineered barrier design incorporates features to minimize the monitoring and maintenance requirements for the long-term. Also, the ICDF Complex is under configure management for the design, construction, operation, and closure to ensure that accurate and up to date information on the facilities is available. Following construction, ICDF Complex "as-built drawings and specifications" will be prepared and maintained.

This section of DOE Manual 435.1 was not directly cited as an ARAR in the OU 3-13 ROD. In Section 9, this requirement is addressed and shows the associated ARARs and CERCLA documents addressing this requirement. 
5.1.5.10 Mixed Waste (I.1.E.10.). In DOE Manual 435.1, the requirement for mixed waste is as follows:

Radioactive waste that contains both source, special nuclear, or by-product material subject to the Atomic Energy Act of 1954, as amended, and a hazardous component is also subject to the Resource Conservation and Recovery Act (RCRA), as amended.

This requirement is classified as substantive. As the ICDF Complex is a CERCLA project, RCRA is not the controlling authority and the ICDF Complex is not required to obtain a RCRA permit. However, the ICDF Complex is being designed and constructed to meet the requirements of DOE Order 435.1, RCRA Subtitle C minimum technology requirements, and TSCA PCB design and construction requirements. The ICDF Complex, based on these design and construction requirements, is able to manage mixed waste as defined under RCRA and TSCA. This section of DOE Manual 435.1 was not directly cited as an ARAR in the OU 3-13 ROD. However, there are several ARARs for the ICDF Complex addressing characterization, storage, treatment, and requirements for mixed waste. In Section 9, this requirement is addressed and shows the associated ARARs and CERCLA documents addressing this requirement.

5.1.5.11 Packaging and Transportation (I.1.E.11.). In DOE Manual 435.1, the requirement for packaging and transportation is as follows:

Radioactive waste shall be packaged and transported in accordance with DOE O 460.1A, Packaging and Transportation Safety, and DOE O 460.2, Departmental Materials Transportation and Packaging Management.

This requirement is classified as administrative. The ICDF Complex is being designed, constructed, and will be operated in compliance with DOE Order and DOE Directives along with the ARARs and TBCs identified in the OU 3-13 ROD. Packaging and transportation of waste on the INL is required to follow the Department of Transportation regulation and requirements. However, once the waste arrives at the ICDF Complex, the transportation and packaging requirements are not as stringent. Transportation within the ICDF Complex is considered an intra-facility transfer and not subject to the same requirements as transportation across a public highway. As such, this requirement is not applicable within the ICDF Complex. This specific requirement was not identified as an ARAR or TBC in the OU 3-13 ROD. In Section 9, this requirement is addressed and shows the associated ARARs and CERCLA documents addressing this requirement.

5.1.5.12 Quality Assurance Program (I.1.E.12.). In DOE Manual 435.1, the requirement for quality assurance program is as follows:

Radioactive waste management facilities, operations, and activities shall develop and maintain a quality assurance program that meets the requirements of 10 CFR 830.120, Quality Assurance Requirements, and DOE O 414.1, Quality Assurance, as applicable.

This requirement is classified as substantive. The ICDF Complex is being designed, constructed, and will be operated in compliance with DOE Order and DOE Directives along with the ARARs and TBCs identified in the OU 3-13 ROD. Quality assurance requirement are part of the CERCLA process. Design, construction, operation, and closure activities associated with the ICDF Complex are considered and use quality assurance concepts and requirements. This specific requirement was not identified as an 
ARAR or TBC in the OU 3-13 ROD. In Section 9, this requirement is addressed and shows the associated ARARs and CERCLA documents addressing this requirement.

5.1.5.13 Radiation Protection (I.1.E.13.). In DOE Manual 435.1, the requirement for radiation protection is as follows:

Radioactive waste management facilities, operations, and activities shall meet the requirements of 10 CFR Part 835, Occupational Radiation Protection, and DOE 5400.5, Radiation Protection of the Public and the Environment.

This requirement is classified as substantive. The ICDF Complex is being designed to protect the public and workers from unacceptable exposures. For the operations of the ICDF Complex, the exposures will be kept ALARA. To accomplish this exposure requirement, ALARA concepts are integrated into the planning of operational activities and several types of monitoring that will be conducted. These monitoring requirements are necessary to demonstrate that the facility is being operated safely and not adversely impacting the public, workers, or the environment. The monitoring required at the ICDF Complex consists of air monitoring, leachate monitoring, and groundwater monitoring in addition to the routine monitoring for radiation exposure at a operating radiological facility. While this section of DOE Manual 435.1 was not directly cited as an ARAR, DOE Order 5400.5 was cited as a TBC for exposure to the public will be kept ALARA in the OU 3-13 ROD. In Section 9, this requirement is addressed and shows the associated ARARs and CERCLA documents addressing this requirement.

5.1.5.14 Records Management (I.1.E.14.). In DOE Manual 435.1, the requirement for records management is as follows:

Radioactive waste management facilities, operations, and activities shall develop and maintain a record-keeping system, as required by DOE O 200.1, Information Management Program, and DOE O 414.1, Quality Assurance. Records shall be established and maintained for radioactive waste generated, treated, stored, transported, or disposed. To the extent possible, records prepared in response to other requirements may be used to satisfy the documentation requirements of this Manual. Additional records may be required to satisfy the regulations applicable to the hazardous waste components of mixed waste.

This requirement is classified as administrative. However, the ICDF Complex is being constructed and will be operated in compliance with DOE orders and DOE directives along with the ARARs and TBCs identified in the OU 3-13 ROD. Records management is an important activity for the design, construction, operation, and closure of the ICDF Complex. There are established processes and procedures at the INL dealing with records management. These established processes and procedures will be used for the ICDF Complex. This specific requirement was not identified as an ARAR or TBC in the OU 3-13 ROD. In Section 9, this requirement is addressed and shows the associated ARARs and CERCLA documents addressing this requirement.

5.1.5.15 Release of Waste Containing Residual Radioactive Materials (I.1.E.15.). In DOE Manual 435.1, the requirement for release of waste containing residual radioactive materials is as follows:

The process for determining and documenting that waste is suitable to be released and managed without regard to its radioactive content shall be in accordance with the criteria and requirements in DOE 5400.5, Radiation Protection of the Public and the Environment. 
This requirement is classified as substantive. The ICDF Complex is being designed to protect the public and workers from unacceptable exposures. For the construction, operations, and closure of the ICDF Complex, materials will not be released without having been determined to meet the release limits in DOE Order 5400.5 as implemented by the Radiological Control Manual. While this section of DOE Manual 435.1 was not directly cited as an ARAR, DOE Order 5400.5 was cited as a TBC for exposure to the public will be kept ALARA in the OU 3-13 ROD. In Section 9, this requirement is addressed and shows the associated ARARs and CERCLA documents dealing with this requirement.

5.1.5.16 Safeguards and Security (I.1.E.16.). In DOE Manual 435.1, the requirement for safeguards and security is as follows:

Appropriate features shall be incorporated into the design and operation of radioactive waste management facilities, operations, and activities to prevent unauthorized access and operations, and for purposes of nuclear material control and accountability, where applicable; and shall be consistent with DOE O 470.1, Safeguards and Security Program.

This requirement is classified as substantive. Safeguards and security issues have been considered in the design, construction, operations, and closure phases of the ICDF Complex. While this section of DOE Manual 435.1 was not directly cited as an ARAR, security at a hazardous waste facility was selected as an ARAR in the OU 3-13 ROD. In Section 9, this requirement is addressed and shows the associated ARARs and CERCLA documents addressing this requirement.

5.1.5.17 Safety Management System (I.1.E.17.). In DOE Manual 435.1, the requirement for safety management system is as follows:

Radioactive waste management facilities, operations, and activities shall incorporate the principles of safety management as described in DOE P 450.5, Line Environment, Safety and Health Oversight, and meet the requirements of the safety management systems sections of 48 CFR Chapter 9, Department of Energy Acquisition Regulations and DOE M 411.1-1, Manual of Safety Management Functions, Responsibilities, and Authorities.

This requirement is classified as administrative. However, the ICP has adopted and is implementing the Integrated Safety Management System (ISMS). The ICDF Complex is being designed, constructed, and will be operated in compliance with DOE Order and DOE Directives along with the ARARs and TBCs identified in the OU 3-13 ROD. All work activities for the ICDF Complex construction, operations, and closure are using the ISMS in the work planning and implementation. This specific requirement was not identified as an ARAR or TBC in the OU 3-13. In Section 9, this requirement is addressed and shows the associated ARARs and CERCLA documents addressing this requirement.

5.1.5.18 Site-Evaluation and Facility Design (I.1.E.18.). In DOE Manual 435.1, the requirement for site evaluation and facility design is as follows:

New radioactive waste management facilities, operations, and activities shall be sited and designed in accordance with DOE O 420.1, Facility Safety, and DOE O 430.1A, Life-Cycle Asset Management.

This requirement is classified as substantive. Site evaluation and facility design are significant issues for the ICDF Complex. The site for the ICDF Complex was selected based on many criteria. These 
criteria were presented in the OU 3-13 ROD and consisted of general criteria of (1) public health and safety, (2) natural environment, (3) technical, (4) social economic environment, (5) cultural environment, and (6) community acceptance. The most significant major criteria from a design and siting issues are the subcriteria for public health and safety (effect on surface design, effects on surface water, effects on groundwater, proximity to fire, ambulance, and emergency services, elevation above flood plain, and transportation difficulty) and for technical (depth to bedrock, geological fault proximity, underlying soil permeability and attenuation capacity, earthquake epicenter proximity, perched water proximity, ease of monitoring, and soil suitability for engineered structures). Many of the criteria that were used are also used by the NRC in the site suitability and selection criteria for commercial LLW disposal facilities. Based on these criteria, an area southwest of INTEC was selected for the ICDF Complex. A geophysical and geotechnical study was conducted in the selected area, which resulted in the selected site for the ICDF Complex. For the design issues, the ICDF Complex is being designed and constructed to meet the requirements of DOE Order 435.1, RCRA, Subtitle C minimum technology requirements, and TSCA PCB design and construction requirements, including an engineered barrier with an expected design life of 1,000 years. This specific requirement was not identified as an ARAR or TBC in the OU 3-13 ROD. In Section 9, this requirement is addressed and shows the associated ARARs and CERCLA documents addressing this requirement.

5.1.5.19 Training and Qualification (I.1.E.19.). In DOE Manual 435.1, the requirement for training and qualifications is as follows:

A training and qualification program shall be implemented for radioactive waste management program personnel, and shall meet the requirements of DOE O 360.1, Training, and DOE 5480.20A, Personnel Selection, Qualification, and Training Requirements for DOE Nuclear Facilities.

This requirement is classified as administrative. However, training and qualification issues have been considered in the construction, operations, and closure phases of the ICDF Complex. While this section of DOE Manual 435.1 was not directly cited as an ARAR, personnel training at a hazardous waste facility was selected as an ARAR in the OU 3-13 ROD. In Section 9, this requirement is addressed and shows the associated ARARs and CERCLA documents addressing this requirement.

5.1.5.20 Waste Minimization and Pollution Prevention (I.1.E.20.). In DOE Manual 435.1, the requirement for waste minimization and pollution prevention is as follows:

Waste minimization and pollution prevention shall be implemented for radioactive waste management facilities, operations, and activities to meet the requirements of Executive Order 12856, Federal Compliance with Right-to-Know Laws and Pollution Prevention Requirements, and Executive Order 13101, Greening the Government through Waste Prevention, Recycling, and Federal Acquisition, and DOE 5400.1, General Environmental Protection Program.

This requirement is classified as administrative. However, the ICDF Complex is being constructed and will be operated in compliance with DOE Order and DOE Directives along with the ARARs and TBCs identified in the OU 3-13 ROD. Waste minimization and pollution prevention at facilities on the INL are required to implement waste minimization and pollution prevention processes as part of the normal operating environment. In Section 9, this requirement is addressed and shows the associated ARARs and CERCLA documents dealing with this requirement. 
5.1.5.21 Worker Protection (I.1.E.21.). In DOE Manual 435.1, the requirement for worker protection is as follows:

Radioactive waste management facilities, operations, and activities shall meet the requirements of DOE O 440.1A, Worker Protection Management for DOE

Federal and Contractor Employees.

This requirement is classified as substantive. The ICDF Complex is being designed to protect the workers from unacceptable risks and exposures. For the construction, operations, and closure of the ICDF Complex, worker protection is used in the planning and implementation of the work. While this section of DOE Manual 435.1 was not directly cited as an ARAR, DOE Order 435.1 was cited as a TBC for worker protection in the OU 3-13 ROD. In Section 9, this requirement is addressed and shows the associated ARARs and CERCLA documents addressing this requirement.

\subsection{Responsibilities (I.2.)}

Chapter I.2 of DOE Manual contains the general responsibilities for management of radioactive waste. Within Chapter I.2 of DOE Manual, seven major subsections dealing with responsibilities for management of radioactive waste. These major subsections are (1) Program Secretarial Officers (I.2.A), (2) Assistant Secretary for Environmental Management (I.2.B.), (3) Assistant Secretary for Environment, Safety, and Health (I.2.C.), (4) Deputy Assistant Secretary for Waste Management (I.2.D.), (5) Deputy Assistant Secretaries for Waste Management and Environmental Restoration (I.2.E.), (6) Field Element Managers, and (7) All Personnel. The evaluations are information for the ICDF Complex concerning these sections is presented in Sections 5.2.1 through 5.2.7.

\subsubsection{Program Secretarial Officers (I.2.A.)}

In DOE Manual 435.1, the responsibility of the program secretarial officers is as follows:

Program Secretarial Officers with radioactive waste management facilities, operations, or activities are responsible within their respective programs for ensuring that the Field Element Managers meet the requirements of DOE O 435.1, Radioactive Waste Management, and the Manual.

This responsibility is classified as administrative. In the Implementation Guide for use with DOE Manual 435.1, the objective of this responsibility is stated as dealing with DOE-HQ management and oversight of DOE field management for radioactive waste. As such, this responsibility is not directly or substantively related to the design, construction, operation, and closure of the ICDF Complex. No additional information concerning this responsibility is included in this compliance demonstration. This specific responsibility was not identified as an ARAR or TBC in the OU 3-13 ROD and is not specifically addressed in other CERCLA documents for the ICDF Complex.

\subsubsection{Assistant Secretary for Environmental Management (I.2.B.)}

In DOE Manual 435.1, the responsibilities of the Assistant Secretary for Environmental Management include (1) complex-wide radioactive waste management and (2) changes to regulations and DOE directives. These responsibilities are discussed in Sections 5.2.2.1 and 5.2.2.2. 
5.2.2.1 Complex-Wide Radioactive Waste Management (I.2.B.1.). In DOE Manual 435.1, the responsibility of the assistant secretary for Environmental Management concerning complex-wide radioactive waste management is as follows:

Establishing and maintaining integrated Complex-Wide Radioactive Waste Management Programs for high-level, transuranic, low-level, and MLLW. These programs shall use a systematic approach to planning, execution, and evaluation to ensure that waste generation, storage, treatment, and disposal needs are met and coordinated across the DOE complex.

This responsibility is classified as administrative. In the Implementation Guide for use with DOE Manual 435.1, the objective of this responsibility is stated as to ensure that coordination exists and is implemented among the DOE-HQ and field office programs for high-level, TRU, low-level, and MLLW. The ICDF Complex is specifically limited to INL CERCLA waste. As such, this responsibility is not directly or substantively related to the design, construction, operation, and closure of the ICDF Complex. No additional information concerning this responsibility is included in this compliance demonstration. This specific responsibility was not identified as an ARAR or TBC in the OU 3-13 ROD and is not specifically addressed in other CERCLA documents for the ICDF Complex.

5.2.2.2 Changes to Regulations and DOE Directives (I.2.B.2.). In DOE Manual 435.1, the responsibility of the assistant secretary for Environmental Management concerning changes to regulations and DOE directives is as follows:

Ensuring changes to regulations and DOE directives are reviewed and, when necessary, incorporated into revisions of DOE Manual 435.1 to ensure the basis for safe radioactive waste management facilities, operations, and activities is maintained.

This responsibility is classified as administrative. In the Implementation Guide for use with DOE Manual 435.1, the objective of this requirement is to ensure that changes to pertinent regulations and other DOE directives are evaluated and incorporated into revisions to radioactive waste management directives to keep current with new information and practices.

When the OU 3-13 ROD was signed by DOE-ID, EPA, and IDEQ, the regulations that must be complied with were set as the ARARs. This not only set the ARARs that must be complied with but the ARARs as written of a specific date (October 7, 1999). However, the ICDF Complex project is implementing the DOE order and directives. If there are changes to the DOE orders and directives that affect the ICDF Complex, these changes will be evaluated and incorporated as practical and necessary to ensure the continued safe and efficient operation of the ICDF Complex. No additional information concerning this responsibility is included in this compliance demonstration. This specific responsibility was not identified as an ARAR or TBC in the OU 3-13 ROD and is not specifically addressed in other CERCLA documents for the ICDF Complex.

\subsubsection{Assistant Secretary for Environment, Safety, and Health (I.2.C.)}

In DOE Manual 435.1, the responsibility of the assistant secretary for environment, safety, and health is as follows:

Providing an independent overview of DOE radioactive waste management and decommissioning programs to determine compliance with DOE environment, 
safety, and health requirements and applicable Environmental Protection Agency (EPA) and state regulations, including:

(1) Advising the Secretary of the status of Departmental compliance with the requirements of DOE Order/Manual 435.1 and applicable provisions of other DOE Orders.

(2) Conducting independent appraisals and audits of DOE waste management programs.

(3) Reviewing site Waste Management Plans with regard to compliance with DOE environment, safety, and health requirements.

This responsibility is classified as administrative. In the Implementation Guide for use with DOE Manual 435.1, the objective of this responsibility is stated as ensuring that the existing role of the Office of Environment, Safety, and Health for providing independent oversight is maintained and understood. As such, this responsibility is not directly or substantively related to the design, construction, operation, and closure of the ICDF Complex. No additional information concerning this responsibility is included in this compliance demonstration. This specific responsibility was not identified as an ARAR or TBC in the OU 3-13 ROD and is not specifically addressed in other CERCLA documents for the ICDF Complex.

\subsubsection{Deputy Assistant Secretary for Waste Management (I.2.D.)}

In DOE Manual 435.1, the responsibilities of the deputy assistant secretary for Waste Management include (1) complex-wide radioactive waste management and (2) waste management data systems. These responsibilities are discussed in Sections 5.2.4.1 through 5.2.4.2.

\subsubsection{Complex-Wide Radioactive Waste Management Program Plans (I.2.D.1). In DOE} Manual 435.1, the responsibility of the deputy assistant secretary for Waste Management concerning complex-wide radioactive waste management program plans is as follows:

Developing, implementing, and maintaining integrated Complex-Wide Radioactive Waste Management Program Plans for high-level, transuranic, low-level, and MLLW. Each plan shall, at the DOE complex-wide level, describe the functional elements, organizations, responsibilities, and activities that comprise the system needed to store, treat, and dispose of radioactive waste in a manner that is protective of the public, workers, and the environment.

In addition, the plans shall:

(a) Present a waste management strategy that integrates waste projections and life-cycle waste management planning into complex-wide facility configuration decisions; and

(b) Describe the approach to research and technology development being pursued to improve safety and/or efficiency in managing radioactive waste.

This responsibility is classified as administrative. In the Implementation Guide for use with DOE Manual 435.1, the objective of this responsibility is stated as to ensure that complex-wide plans provide an overarching strategy for making and implementing waste management decisions. The ICDF Complex 
is specifically limited to INL CERCLA waste. As such, this responsibility is not directly or substantively related to the design, construction, operation, and closure of the ICDF Complex. No additional information concerning this responsibility is included in this compliance demonstration. This specific responsibility was not identified as an ARAR or TBC in the OU 3-13 ROD and is not specifically addressed in other CERCLA documents for the ICDF Complex.

5.2.4.2 Waste Management Data System (I.2.D.2.). In DOE Manual 435.1, the responsibility of the deputy assistant secretary for waste management concerning waste management data system is as follows:

Establishing and maintaining a system to compile waste generation projection data and other information concerning radioactive waste management facilities, operations, and activities across the complex.

This responsibility is classified as administrative. In the Implementation Guide for use with DOE Manual 435.1, the objective of this responsibility is stated as to ensure information and data concerning the management of radioactive waste is collected and complied at the DOE complex level. The ICDF Complex is specifically limited to INL CERCLA waste. As such, this responsibility is not directly or substantively related to the design, construction, operation, and closure of the ICDF Complex. However, information concerning the operation of the ICDF Complex will be collected and disseminated in various reports including an annual summary of the ICDF Complex operations. No additional information concerning this responsibility is included in this compliance demonstration. This specific responsibility was not identified as an ARAR or TBC in the OU 3-13 ROD and is not specifically addressed in other CERCLA documents for the ICDF Complex.

\subsubsection{Deputy Assistance Secretaries for Waste Management and Environmental Restoration (I.2.E.)}

In DOE Manual 435.1, the responsibilities of the deputy assistant secretaries for waste management and environmental restoration include (1) disposal and (2) site closure plans. This responsibility is discussed in Sections 5.2.5.1 and 5.2.5.2.

5.2.5.1 Disposal (I.2.E.1.). In DOE Manual 435.1, the responsibilities of the deputy assistant secretaries for waste management and environmental restoration concerning disposal are as follows:

Reviewing and approving, along with EH-1, transuranic waste disposal facility performance assessments and other disposal documents as required in waste specific chapters for which DOE is responsible for making compliance determinations. Reviewing and approving performance assessments and composite analyses, or appropriate CERCLA documentation, for low-level waste disposal facilities, and issuing disposal authorization statements.

(a) The Deputy Assistant Secretaries shall establish a review panel consisting of DOE personnel to review low-level waste disposal facility performance assessments and composite analyses, review appropriate CERCLA documentation, recommend low-level waste disposal facility compliance determinations to the Deputy Assistant Secretaries, and develop disposal authorization statements.

(b) The Deputy Assistant Secretaries shall issue disposal authorization statements containing conditions that low-level waste disposal facilities 
must meet in order to operate with an approved radioactive waste management basis.

This responsibility is classified as administrative. In the Implementation Guide for use with DOE Manual 435.1, the objective of this responsibility is stated as DOE-HQ to ensure that the evaluations conducted in the performance assessment (or appropriate CERCLA documentation) and composite analysis (or appropriate CERCLA documentation) for a LLW disposal facility are found by DOE to be technically adequate, logical, complete, and defensible for establishing the controls on disposal of waste for protection of the public and the environment

During the development of the design and operational planning document, DOE was involved in the review and comment incorporation. Following the internal review of DOE-ID and BBWI, the documents were submitted to DOE-HQ, EPA, and IDEQ for review and comment. The comments were resolved and incorporated into the documents. This comment resolution and incorporation activity demonstrates that the documents are technically adequate, logical, complete, and defensible. As such, this responsibility does not directly or substantively alter the design and operational planning for the ICDF Complex.

However, as part of the requirements for operations of the ICDF Complex, a disposal authorization statement will be obtained during the startup activities. This specific responsibility was not identified as an ARAR or TBC in the OU 3-13 ROD and is not specifically addressed in other CERCLA documents for the ICDF Complex.

5.2.5.2 Site Closure Plans (I.2.E.2.). In DOE Manual 435.1, the responsibility of the deputy assistant secretaries for waste management and environmental restoration concerning site closure plans is as follows:

Reviewing and approving closure plans and other closure documentation for deactivated high-level waste facilities/sites and issuing authorization for closure activities to proceed.

This responsibility is classified as administrative. In the Implementation Guide for use with DOE Manual 435.1, the objective of this responsibility is stated as to ensure that closure activities for deactivated high-level waste facilities/sites do not proceed prior to review/approval of the site closure plans. The ICDF Complex WAC specifically excludes high-level waste from being received into any of the facilities within the ICDF Complex. As such, this responsibility is not directly or substantively related to the design, construction, operation, and closure of the ICDF Complex. No additional information concerning this responsibility is included in this compliance demonstration. This specific responsibility was not identified as an ARAR or TBC in the OU 3-13 ROD and is not specifically addressed in other CERCLA documents for the ICDF Complex.

\subsubsection{Field Element Managers (I.2.F.)}

In DOE Manual 435.1, there are 20 responsibilities of the field element managers which include the topics of closure plans, storage, treatment, disposal, monitoring, and corrective actions. These responsibilities are discussed in Sections 5.2.6.1 through 5.2.6.20. 


\subsubsection{Site-Wide Radioactive Waste Management Programs (I.2.F.1.). In DOE}

Manual 435.1, the responsibility under Site-wide radioactive waste management programs is as follows:

Developing, documenting, implementing, and maintaining a Site-Wide

Radioactive Waste Management Program. The Program shall use a systematic approach for planning, executing, and evaluating the site-wide management of radioactive waste in a manner that supports the Complex-Wide Radioactive Waste Management Programs and ensures that the requirements of DOE Order/Manual 435.1, Radioactive Waste Management.

This responsibility is classified as administrative. In the Implementation Guide for use with DOE Manual 435.1, the objective of this responsibility is stated as to ensure that radioactive waste is managed in a safe, effective, and efficient manner; radioactive waste management activities are integrated, coordinated, and support Site-wide and complex-wide goals and objectives; and progress towards goals and objectives are measured and evaluated, and feedback is provided for continued improvement of the management of radioactive waste. Additionally, the responsibility is to ensure there are mechanisms in place for providing input to and receiving direction from the complex-wide programs.

The ICDF Complex is specifically limited to INL CERCLA waste. However, the process and procedures being developed to support the operations of the ICDF Complex will allow for CERCLA waste from across the INL to be accepted into the ICDF Complex for staging, storage, treatment, and disposal. For waste that will be disposed at facilities other than the ICDF landfill or evaporation pond, the waste disposal will be coordinated with the other existing INL programs dealing with waste disposal, both on-site and off-site. As such, this responsibility is not directly or substantively related to the design, construction, operation, and closure of the ICDF Complex.

No additional information concerning this responsibility is included in this compliance demonstration. This specific responsibility was not identified as an ARAR or TBC in the OU 3-13 ROD and is not specifically addressed in other CERCLA documents for the ICDF Complex.

5.2.6.2 Radioactive Waste Management Basis (I.2.F.2.). In DOE Manual 435.1, the responsibility under radioactive waste management basis is as follows:

Ensuring a radioactive waste management basis is developed and maintained for each DOE radioactive waste management facility, operation, and activity; and ensuring review and approval of the basis before operations begin. The Radioactive Waste Management Basis shall:

(a) Reference or define the conditions under which the facility may operate based on the radioactive waste management documentation;

(b) Include the applicable elements identified in the specific waste-type chapters of DOE Manual 435.1; and

(c) Be developed using the graded approach process.

This responsibility is classified as administrative. In the Implementation Guide for use with DOE Manual 435.1, the objective of this responsibility is stated as to ensure that the hazards associated with radioactive waste management facilities, operations, and activities have been identified, their potential impacts analyzed, and appropriate controls documented, implemented, and maintained for the protection of workers, the public, and the environment. 
In developing the designs and operation plans for the ICDF Complex, the hazards associated with the activities were analyzed and the impacts on the workers, public, and environment calculated. As a result of these calculations, the required controls were identified. Also, as part of the requirements for operations of the ICDF Complex, a radioactive waste management basis will be developed and approved during the startup activities. This specific responsibility was not identified as an ARAR or TBC in the OU 3-13 ROD and is not specifically addressed in other CERCLA documents for the ICDF Complex. Also, Section 8 discusses the requirements associated with radioactive waste management basis along with how the requirements are being met.

5.2.6.3 Waste Minimization and Pollution Prevention (I.2.F.3.). In DOE Manual 435.1, the responsibility under waste minimization and pollution prevention is as follows:

Ensuring implementation of waste minimization and pollution prevention programs.

This responsibility is classified as administrative. In the Implementation Guide for use with DOE Manual 435.1, the objective of this responsibility is stated as to ensure that emphasis is placed on minimizing the amount of radioactive waste generated and on the implementation of minimization programs at radioactive waste management facilities. Waste minimization and pollution prevention at facilities on the INL are required to implement waste minimization and pollution prevention processes as part of the normal operating environment. This specific responsibility was not identified as an ARAR or TBC in the OU 3-13 ROD and is not specifically addressed in other CERCLA documents for the ICDF Complex.

\subsubsection{Approval of Exemptions for Use of Non-DOE Facilities (I.2.F.4.). In DOE}

Manual 435.1, the responsibilities under approval of exemptions for use of non-DOE facilities are as follows:

DOE radioactive waste shall be treated, stored, and in the case of low-level waste, disposed of at the site where the waste is generated, if practical; or at another DOE facility. If DOE capabilities are not practical or cost effective, exemptions may be approved to allow use of non-DOE facilities for the storage, treatment, or disposal of DOE radioactive waste based on the following requirements:

(a) Such non-DOE facilities shall:

1. Comply with applicable Federal, State, and local requirements;

2. Have the necessary permit(s), license(s), and approval(s) for the specific waste(s); and

3. Be determined by the Field Element Manager to be acceptable based on a review conducted annually by DOE.

(b) Exemptions for the use of non-DOE facilities shall be documented to be cost effective and in the best interest of DOE, including consideration of alternatives for on-site disposal, an alternative DOE site, and available non-DOE facilities; consideration of life-cycle cost and potential liability; and protection of public health and the environment. 
(c) DOE waste shall be sufficiently characterized and certified to meet the facility's waste acceptance criteria.

(d) Appropriate National Environmental Policy Act (NEPA) review must be completed. For actions taken under the Comprehensive Environmental Response, Compensation and Liability Act (CERCLA), it is DOE's policy to incorporate NEPA values into the CERCLA documentation.

(e) Headquarters shall be notified of any exemption allowing use of a nonDOE facility and the Office of the Assistant Secretary for Environment, Safety and Health (EH-1) shall be consulted prior to the exemption being executed.

(f) Host States and State Compacts where non-DOE facilities are located shall be consulted prior to approval of an exemption to use such facilities and notified prior to shipments being made.

This responsibility is classified as administrative. In the Implementation Guide for use with DOE Manual 435.1, the objective of this responsibility is indicate a clear preference for use of DOE facilities and to ensure that when it is determined to be necessary to use non-DOE facilities for the treatment, storage, and disposal of DOE radioactive waste only when such use is in the best interest of the Department and protective of the public, workers, and the environment. In developing the OU 3-13 ROD, an analysis of on-Site versus off-Site disposal was conducted. From this analysis it was determined that it was more cost effective to design, construct, operate, and close a landfill for the INL CERCLA waste than to use off-Site disposal. In addition, the use of an on-Site facility has less impact on the public than an off-Site disposal facility due to transportation and other issues. As a result, the OU 3-13 ROD selected design, construction, operation, and closure of a new on-Site disposal facility as the remedy for dealing with INL CERCLA waste.

A recent cost study, Idaho CERCLA Disposal Facility Complex On-Site Versus Off-Site Cost Comparison (EDF-2385) again showed that, based on the design of the ICDF Complex, the cost of on-Site disposal is much less costly than for off-Site disposal. In addition, contained in the OU 3-13 ROD is the requirement to evaluate the life-cycle on-Site versus off-Site cost effectiveness and comply with the DOE Policy concerning disposal of radioactive waste. Based on this, the current planning is to use the ICDF landfill and evaporation pond for disposal of INL CERCLA waste streams provided the waste meets the applicable WAC. If the waste does not meet the WAC for disposal, then the waste will be treated on-Site at the ICDF Complex and then disposed in the landfill or evaporation pond. However, if the required treatment is not available at the ICDF Complex or can not be made available cost effectively, the waste will be packaged, as necessary, for off-Site disposal at another DOE or commercial disposal facility using the existing other waste management programs and procedures.

This specific responsibility was not identified as an ARAR or TBC in the OU 3-13 ROD. However, in Section 9, this responsibility is addressed and shows the associated CERCLA document dealing with this responsibility.

\subsubsection{Environmental Restoration, Decommissioning, and Other Cleanup Waste}

(I.2.F.5.). In DOE Manual 435.1, the responsibilities under Environmental Restoration, Decommissioning, and Other Cleanup Waste are as follows:

Ensuring the management and disposal of radioactive waste resulting from environmental restoration activities, including decommissioning, meet the 
substantive requirements of DOE Order/Manual 435.1, Radioactive Waste Management. Environmental restoration activities using the CERCLA process (in accordance with Executive Order 12580) may demonstrate compliance with the substantive requirements of DOE Order/Manual 435.1, Radioactive Waste Management (including the Performance Assessment and performance objectives, as well as the Composite Analysis) through the CERCLA process. However, compliance with all substantive requirements of DOE Order/Manual 435.1 not met through the CERCLA process must be demonstrated. Environmental restoration activities which will result in the off-site management and disposal of radioactive waste must meet the applicable requirements of DOE Order/Manual 435.1, Radioactive Waste Management for the management and disposal of those off-site wastes. Field Elements performing environmental restoration activities involving development and management of radioactive waste disposal facilities under the CERCLA process shall:

(a) Submit certification to the Deputy Assistant Secretary for Environmental Restoration that compliance with the substantive requirements of DOE Order/Manual 435.1 have been met through application of the CERCLA process; and

(b) Submit the decision document, such as the Record of Decision, or any other document that serves as the authorization to dispose, to the Deputy Assistant Secretary for Environmental Restoration for approval.

This responsibility is classified as administrative. In the Implementation Guide for use with DOE Manual 435.1, the objective of this responsibility is stated as to ensure that radioactive waste generated as a result of environmental restoration, decommissioning, or other cleanup is managed in a manner that meets the requirements of DOE O 435.1, Radioactive Waste Management, and DOE M 435.1-1, Radioactive Waste Management Manual. The ICDF Complex is being designed and constructed to meet the requirement of DOE Order 435.1 and DOE Manual 435.1.

Demonstration of compliance with the substantive requirements of DOE Order 435.1 is presented in this compliance demonstration document. As such, this responsibility does not directly or substantively change the design, construction, operation, or closure of the ICDF Complex. This document will be submitted to DOE-HQ, which meets the "certification" responsibility under DOE Order 435.1 for the disposal facility.

During the development of the OU 3-13 ROD (DOE-ID 1999), DOE-HQ was briefed on the document. This briefing along with the resolution of issues was used as the "approval" by DOE-HQ for the OU 3-13 ROD, including the portion discussing the ICDF Complex. As the OU 3-13 ROD was previously submitted to DOE-HQ and was approved in October 1999, no additional approval of the OU 3-13 ROD is required.

This specific responsibility was not identified as an ARAR or TBC in the OU 3-13 ROD. However, in Section 9, this responsibility is addressed and shows the associated CERCLA document addressing this responsibility. 
5.2.6.6 Radioactive Waste Acceptance Requirements (I.2.F.6.). In DOE Manual 435.1, the responsibility under radioactive waste acceptance requirements is as follows:

Ensuring development, review, approval, and implementation of the radioactive waste acceptance requirements for facilities that receive waste for storage, treatment, or disposal. Radioactive waste acceptance requirements shall establish the facility's requirements for the receipt, evaluation, and acceptance of waste.

This requirement is classified as administrative. In the Implementation Guide for use with DOE Manual 435.1, the objective of these requirements is to establish limits and technical criteria which waste and/or waste containers must meet, based on the hazards of the waste, to ensure that waste is manageable at receipt and can subsequently be safely stored, treated, or disposed, as applicable. The ICDF Complex is being designed and constructed to protect the workers, public, and the environment. For protection of the public and environment, analysis and modeling was conducted to establish WAC limit of chemical and radiological constituents.

This specific responsibility was not identified as an ARAR or TBC in the OU 3-13 ROD and is not specifically addressed in other CERCLA documents for the ICDF Complex. Also, Section 8 discusses the requirements associated with radioactive waste acceptance along with how the requirements are being met.

5.2.6.7 Radioactive Waste Generator Requirements (I.2.F.7.). In DOE Manual 435.1, the responsibility under radioactive waste generator requirements is as follows:

Ensuring development, review, approval, and implementation of a program for waste generation planning, characterization, certification, and transfer. This program shall address characterization of waste, preparation of waste for transfer, certification that the waste meets the receiving facility's radioactive waste acceptance requirements, and transfer of waste.

This responsibility is classified as administrative. In the Implementation Guide for use with DOE Manual 435.1, the objective of radioactive waste generator requirements is to promote the development of effective programs for managing the front end of radioactive waste management cycles. Front end activities consist of those activities performed by waste generators in preparation for turning over waste for management in systems intended to lead to disposal. The field element manager is assigned responsibility for ensuring that effective programs are developed and implemented for managing radioactive wastes in a manner that promotes their eventual disposal.

In developing the WAC for the ICDF Complex, the waste generation planning, characterization, certification, and transfer issues were evaluated and considered. Each of these requirements is addressed in the WAC for the ICDF Complex facilities. For the ICDF Complex, there are processes and procedures that control how the waste is characterized for disposal and transferred into the ICDF Complex. Also, the planning for waste generation along with other requirements for the generating project are considered by the ICDF Complex.

While not specifically identified as a waste generator program, the implementation of the ICDF Complex operations will use the requirements and principle discussed in the Implementation Guide for use with DOE Manual 435.1 concerning radioactive waste generator requirements. This specific responsibility was not identified as an ARAR or TBC in the OU 3-13 ROD and is not specifically addressed in other CERCLA documents for the ICDF Complex. Also, Section 8 discusses the requirements associated with radioactive waste acceptance along with how the requirements are being met. 
5.2.6.8 Closure Plans (I.2.F.8.). In DOE Manual 435.1, the responsibility under closure plans is as follows:

Ensuring development, review, approval, and implementation of closure plans for radioactive waste management facilities in accordance with the applicable requirements in the waste-type chapters of DOE Manual 435.1.

This responsibility is classified as administrative. In the Implementation Guide for use with DOE Manual 435.1, the objective of this requirement is to ensure closure plans for radioactive waste facilities reflect the engineered and administrative controls established by the facility's radioactive waste management basis and that the closure plans and other documentation include sufficient technical specifications of the final closure of the facility to justify the bases for evaluating the protection of the public and the environment that are presented in the performance assessment and composite analysis of the facility, or similar prospective assessments.

In developing the designs and implementing work plans for the ICDF Complex, the issue of facility closure was evaluated. For all of the ICDF Complex facilities, with the exception of the landfill and evaporation pond, the closure approach is to completely remove the facilities and disposal accordingly (clean closure). Closure of the ICDF evaporation ponds is expected to be risk based closure. An engineered barrier (cap) with a 1,000-year design life will be the closure approach for the ICDF landfill. When the facilities are ready to be closed, a review of the closure approach and designs will be conducted to determine if the approach remains the most cost effective while providing sufficient protection to the public and environment.

While the DOE Order 435.1 closure plan requirements for the ICDF Complex were not identified as an ARAR, the implementation of the ICDF Complex operations will use the requirements and principle discussed in the Implementation Guide for use with DOE Manual 435.1 concerning closure requirements. Also, Section 8 discusses the requirements associated with closure plans along with how the requirements are being met.

5.2.6.9 Defense-In-Depth (I.2.F.9.). In DOE Manual 435.1, the responsibility under defense-in-depth is as follows:

Ensuring that defense-in-depth principles are incorporated where potential uncertainties or vulnerabilities warrant their use when reviewing and approving radioactive waste management activities and documents. These principles advocate the use of multiple levels of engineered and administrative controls to provide protection to the public, workers, and the environment.

This responsibility is classified as administrative. In the Implementation Guide for use with DOE Manual 435.1, the objective of this requirement is to ensure that defense-in-depth principles are appropriately evaluated and applied to the management of radioactive waste where uncertainties or vulnerabilities warrant multiple levels of controls to provide protection to the public, workers, and the environment.

In developing the designs and implementing work plans for the ICDF Complex, the issue of risk to the workers, public, and environment were evaluated. There are no systems identified in the ICDF Complex that are critical to the operation and that would significantly affect the environment, workers, or the public if shutdown. 
The risk to both the environment and public receptors were found to be acceptable without the need for additional controls. For workers in the landfill, the additional controls on dose are necessary in an unmitigated and uncontrolled operation. Operations of the ICDF landfill will be implemented to minimize the dose to the workers, while still maintaining the maximum flexibility for operations. Minimal use of clean soil as cover materials will be used, when necessary to reduce the dose rate and minimize the spread of contamination.

While the DOE Order 435.1 defense in depth requirement for the ICDF Complex was not identified as an ARAR, the implementation of the ICDF Complex operations will use the requirements and principle discussed in the Implementation Guide for use with DOE Manual 435.1 concerning defense in depth principles. Section 8 discusses the requirements associated with the ICDF Complex design and associated limits.

5.2.6.10 Oversight (I.2.F.10.). In DOE Manual 435.1, the responsibility under oversight is as follows:

Ensuring oversight of radioactive waste management facilities, operations, and activities is conducted. Oversight shall ensure radioactive waste management program activities are conducted in accordance with a radioactive waste management basis and meet the requirements of DOE Order/Manual 435.1, Radioactive Waste Management.

This responsibility is classified as administrative. In the Implementation Guide for use with DOE Manual 435.1, the objective of this requirement is to ensure field element oversight of radioactive waste, management facilities, operations, and activities is carried out.

However, the ICDF Complex project is within the line management organizational structure and is subject to oversight. As an example, the ICDF Complex (during construction) was part of the DOE-ID oversight audit of field activities at INTEC to determine if the activities were being conducted in a safe manner. This approach will continue to be implemented during operations and closure. Also, the ICP has adopted and is implementing the Integrated Safety Management System (ISMS). The ICDF Complex is being designed, constructed, and will be operated in compliance with DOE Order and DOE Directives along with the ARARs and TBCs identified in the OU 3-13 ROD. All work activities for the ICDF Complex construction, operations, and closure are using the ISMS in the work planning and implementation. This specific requirement was not identified as an ARAR or TBC in the OU 3-13 ROD. In Section 9, the associated CERCLA documents with oversight are presented.

5.2.6.11 Training and Qualification (I.2.F.11.). In DOE Manual 435.1, the responsibility under training and qualifications is as follows:

Ensuring that a training and qualification program is implemented for designated radioactive waste management program personnel, and the training is commensurate with job duties and responsibilities. Only those personnel who have been trained and qualified shall design or operate safety (safety class and safety significant) structures, systems, and components.

This responsibility is classified as administrative. In the Implementation Guide for use with DOE Manual 435.1, the objective of this requirement is to ensure that field element managers establish the process and criteria for designating personnel that should be trained on the management of radioactive waste and establishing the appropriate level of training for those individuals. 
However, training and qualification issues have been considered in the construction, operations, and closure phases of the ICDF Complex. While this section of DOE Manual 435.1 was not directly cited as an ARAR, personnel training at a hazardous waste facility was selected as an ARAR in the OU 3-13 ROD. In Section 9, training and qualification are addressed and shows the associated ARARs and CERCLA documents dealing with this requirement.

5.2.6.12 As Low As Reasonably Achievable (ALARA) (I.2.F.12.). In DOE Manual 435.1, the responsibility under ALARA is as follows:

Ensuring ALARA principles for radiation protection are incorporated when reviewing and approving radioactive waste management activities.

This responsibility is classified as substantive. In the Implementation Guide for use with DOE Manual 435.1, the objective of this requirement is to emphasize implementation of the ALARA process in the management of radioactive waste.

The ICDF Complex has been designed to protect the public and workers from unacceptable exposures. For the operations of the ICDF Complex, the exposures will be kept ALARA. To accomplish this exposure requirement, ALARA concepts are integrated into the planning of operational activities and several types of monitoring that will be conducted. These monitoring requirements are necessary to demonstrate that the facility is being operated safely and not adversely impacting the public, workers, or the environment. The monitoring required at the ICDF Complex consists of air monitoring, leachate monitoring, and groundwater monitoring in addition to the routine monitoring for radiation exposure at a operating radiological facility. In addition, activities with the expectation of increased dose will be evaluated during operations for methods to cost-effectively reduce the dose exposure to workers without adversely effecting the operations of the ICDF Complex. While this section of DOE Manual 435.1 was not directly cited as an ARAR, DOE Order 5400.5 was cited as a TBC for exposure to the public will be kept ALARA in the OU 3-13 ROD. In Section 9, ALARA is addressed and shows the associated ARARs and CERCLA documents addressing this ALARA.

5.2.6.13 Storage (I.2.F.13.). In DOE Manual 435.1, the responsibility under storage is as follows:

Ensuring all radioactive waste is stored in a manner that protects the public, workers, and the environment in accordance with a radioactive waste management basis, and that the integrity of waste storage is maintained for the expected time of storage and does not compromise meeting the disposal performance objectives for protection of the public and the environment when the waste is disposed.

This responsibility is classified as substantive. In the Implementation Guide for use with DOE Manual 435.1, the objective of this requirement is to properly store radioactive waste by providing for containment of the waste during storage, protecting the ability of packages to maintain containment, and ensuring waste is handled in storage in a way that facilitates proper disposal and contributes to the long-term performance of the disposal facility.

The ICDF Complex has been designed to protect the public and workers from unacceptable exposures. There are staging and storage areas associated with the ICDF Complex that are design and constructed to protect the workers, public, and the environment. Depending on the type of material being staged or stored at the ICDF Complex, different containers or storage requirements apply. These staging and storage areas are discussed in Section 3.6 along with the design and operational requirements. This section of DOE Manual 435.1 was not directly cited as an ARAR for the ICDF Complex in the OU 3-13 
ROD. In Section 9, storage of waste is addressed and shows the associated ARARs and CERCLA documents dealing with waste storage. Also, Sections 7 and 8 further discuss the storage of waste at the ICDF Complex.

5.2.6.14 Treatment (I.2.F.14.). In DOE Manual 435.1, the responsibility under treatment is as follows:

Ensuring all radioactive waste requiring treatment is treated in a manner that protects the public, workers, and the environment and in accordance with a radioactive waste management basis.

This responsibility is classified as administrative. In the Implementation Guide for use with DOE Manual 435.1, the objective of this requirement is to ensure that when radioactive waste treatment technologies are utilized, they provide the necessary protection to the public, workers and the environment from treatment operations and from the resulting treated waste.

The ICDF Complex has been designed to protect the public and workers from unacceptable exposures. There are treatment systems associated with the ICDF Complex that are design and constructed to protect the workers, public, and the environment. Depending on the type of material being treated at the ICDF Complex, treatment equipment will be used. The design of these treatment systems is discussed in Section 3.5. While this section of DOE Manual 435.1 was not directly cited as an ARAR for the ICDF Complex in the OU 3-13 ROD. In Section 9, storage of waste is addressed and shows the associated ARARs and CERCLA documents dealing with waste storage. Also, Sections 7 and 8 further discuss the storage of waste at the ICDF Complex.

5.2.6.15 Disposal (I.2.F.15.). In DOE Manual 435.1, the responsibility under disposal is as follows:

Ensuring radioactive waste is disposed in a manner that protects the public, workers, and the environment and in accordance with a radioactive waste management basis. Reviewing specific transuranic or low-level waste documentation including the performance assessment and composite analysis, or appropriate CERCLA documentation, prior to forwarding them to Headquarters for approval, and obtaining and ensuring the facility is operated in accordance with the disposal authorization statement. Conducting performance assessment and composite analysis maintenance.

This responsibility is classified as substantive. In the Implementation Guide for use with DOE Manual 435.1, the objective of this requirement as pertains to ICDF Complex is to ensure that LLW is disposed so that there is a reasonable expectation that the performance objectives of Chapter IV of DOE Manual 435.1-1 will be met. The objectives are also to ensure that the performance assessment and composite analysis for a LLW disposal facility are technically adequate, logical, complete, and defensible for establishing the controls on disposal of waste for protection of the public, and the environment into the future. Lastly, the objectives are to ensure that data are collected and studies conducted to verify these analyses and that they are updated whenever necessary.

During the development of the design and operational planning document, DOE was involved in the review and comment incorporation. Following the internal review of DOE-ID and BBWI, the documents were submitted to DOE-HQ, EPA and IDEQ for review and comment. The comments were resolved and incorporated into the documents. This comment resolution and incorporation activity demonstrates that the documents are technically adequate, logical, complete, and defensible. As such, this responsibility is not directly or substantively related to the design, construction, operation, and closure of the ICDF Complex. 
However, during the design process, the design and associated analysis was extensively reviewed by DOE-ID, EPA, and IDEQ to ensure that the design would protect the public and environment along with workers. In addition, DOE-HQ was supplied with a copy of the design and remedial action work plan during development for review. All relevant comments dealing wit the design or implementation at the ICDF Complex were resolved and incorporated accordingly. Also, as part of the requirements for operations of the ICDF Complex, a disposal authorization statement will be obtained during the startup activities.

No additional information concerning this responsibility is included in this compliance demonstration. While this section of DOE Manual 435.1 was not directly cited as an ARAR for the ICDF Complex in the OU 3-13 ROD. In Section 9, disposal of waste is addressed and shows the associated ARARs and CERCLA documents dealing with waste disposal. Also, Sections 7 and 8 further discuss the disposal of waste at the ICDF Complex.

5.2.6.16 Monitoring (I.2.F.16.). In DOE Manual 435.1, the requirement for monitoring is as follows:

Ensuring monitoring is conducted for all radioactive waste management facilities as required. Ensuring that disposal facilities are monitored, as appropriate, for compliance with conditions of the disposal authorization statement.

This responsibility is classified as substantive. In the Implementation Guide for use with DOE Manual 435.1, the objective of this requirement is to ensure that all monitoring is conducted as required, including monitoring of storage, treatment, and disposal facilities with respect to key parameters and conditions of their authorization statements.

The ICDF Complex has been designed to protect the public and workers from unacceptable exposures. There are treatment systems associated with the ICDF Complex that are designed and constructed to protect the workers, public, and the environment. Depending on the component of the ICDF Complex and type of waste, there are different monitoring requirements, processes, and procedures. The groundwater monitoring system is discussed in Section 3.8. There are many additional sampling and monitoring requirements for the ICDF Complex dealing with the storage, treatment, and disposal operations.

While this section of DOE Manual 435.1 was not directly cited as an ARAR for the ICDF Complex in the OU 3-13 ROD. In Section 9, monitoring is addressed and shows the associated ARARs and CERCLA documents dealing with monitoring. Also, Sections 7 and 8 further discuss the monitoring activities at the ICDF Complex.

\subsubsection{Material and Waste Declassification for Waste Management (I.2.F.17.). In DOE} Manual 435.1, the responsibility under waste declassification is as follows:

Ensuring, to the extent practical, radioactive material and waste generated under a program that is classified for national security reasons is declassified or rendered suitable for unclassified radioactive waste management.

This responsibility is classified as administrative. In the Implementation Guide for use with DOE Manual 435.1, the objective of this requirement is to reduce unnecessary management costs and maintain national security by ensuring that radioactive material and waste is, as practical, declassified and managed as unclassified waste. 
There are no identified or anticipated waste streams for the ICDF Complex that would have classification issues associated with the waste. As such this responsibility does not effect the ICDF Complex. This specific responsibility was not identified as an ARAR or TBC in the OU 3-13 ROD and is not specifically addressed in other CERCLA documents for the ICDF Complex

5.2.6.18 Waste Incidental to Reprocessing (I.2.F.18.). In DOE Manual 435.1, the responsibility under waste incidental to reprocessing is as follows:

Ensuring that waste incidental to reprocessing determinations are made by either the "citation" or "evaluation" process as described in Chapter II of this Manual. Ensuring consultation and coordination with the Office of Environmental Management for waste determined to be incidental to reprocessing through the "evaluation" process.

This responsibility is classified as administrative. In the Implementation Guide for use with DOE Manual 435.1, the objective of this requirement is to ensure that the processes and responsibilities for making waste incidental to reprocessing determinations are understood and implemented.

There are no waste streams identified or anticipated for the ICDF Complex that would require a "waste incidental to reprocessing" determination. As such this responsibility does not effect the ICDF Complex. This specific responsibility was not identified as an ARAR or TBC in the OU 3-13 ROD and is not specifically addressed in other CERCLA documents for the ICDF Complex. Also, Section 6 discusses why the waste streams that could be received into the ICDF Complex for staging/storage, treatment, and/or disposal are not high-level waste even though the contaminating media may have been high-level waste (liquid or solid).

5.2.6.19 Waste with No Identified Path to Disposal (I.2.F.19.). In DOE Manual 435.1, the responsibility under waste with no identified path to disposal is as follows:

Ensuring a process is developed and implemented for identifying the generation of radioactive waste with no identified path to disposal, and reviewing and approving conditions under which radioactive waste with no identified path to disposal may be generated. Headquarters shall be notified of the decisions to generate a waste with no path to disposal.

This responsibility is classified as substantive. In the Implementation Guide for use with DOE Manual 435.1, the objective of this requirement is to bring issues associated with generating waste with no identified path to disposal to the attention of appropriate DOE managers before the waste is generated to resolve the problems that will prevent it from being disposed, to ensure that the waste has appropriate long-term safe storage until it can be disposed, and to minimize the generation of waste with no path to disposal.

The ICDF Complex has been designed to protect the public and workers from unacceptable exposures. There are staging and storage areas associated with the ICDF Complex that are design and constructed to protect the workers, public, and the environment. Currently, there are no identified waste stream destined for the ICDF Complex that will not be able to be eventually disposed in either the ICDF landfill or at an offsite DOE facility. It may be necessary to stage/store the waste until the disposal facility can accept the waste for disposal. If the waste would require treatment and the required treatment and characteristics of the waste are not compatible with the ICDF treatment systems, then other treatment options will be explored including modification to the ICDF treatment systems or procedures to treat the waste for final disposal. However, treatment of waste classified as TRU waste (rad only or mixed) when received at the ICDF Complex will not be conducted at the ICDF Complex and if necessary will be sent to another DOE facility for treatment. 
This specific responsibility was not identified as an ARAR or TBC in the OU 3-13 ROD and is not specifically addressed in other CERCLA documents for the ICDF Complex.

5.2.6.20 Corrective Actions (I.2.F.20.). In DOE Manual 435.1, the responsibility under corrective actions is as follows:

Ensuring a process exists for proposing, reviewing, approving, and implementing corrective actions when necessary to ensure that the requirements of DOE Order/Manual 435.1, Radioactive Waste Management are met, and to address conditions that are not protective of the public, workers, or the environment. The process shall allow workers, through the appropriate level of management, to stop or curtail work when they discover conditions that pose an imminent danger or other serious hazard to workers or the public, or are not protective of the environment.

This responsibility is classified as substantive. In the Implementation Guide for use with DOE Manual 435.1, the objective of this requirement is to ensure that processes to identify, manage, and resolve radioactive waste management deficiencies in complying with DOE O 435.1 and address conditions that are not protective of the public, workers or the environment are established and implemented.

This responsibility is classified as substantive. The ICP has adopted and is implementing the ISMS. The ICDF Complex is being designed, constructed, and will be operated in compliance with DOE Orders and DOE Directives along with the ARARs and TBCs identified in the OU 3-13 ROD. All work activities for the ICDF Complex construction, operations, and closure are using the ISMS in the work planning and implementation. Part of a success safety management system is for the identification of problems and the associated corrective actions. In addition, all ICP personnel have "stop work" authority if they identify conditions that are an imminent danger or other serious hazard to workers or the public, or are not protective of the environment. This specific requirement was not identified as an ARAR or TBC in the OU 3-13 ROD.

\subsubsection{All Personnel (I.2.G.)}

In DOE Manual 435.1, all personnel have two major responsibilities related to radioactive management facilities, operations, and activities. Both of these responsibilities are discussed below in Sections 5.2.7.1 and 5.2.7.2.

5.2.7.1 Problem Identification (I.2.G.1.). In DOE Manual 435.1, the responsibility under problem identification is as follows:

Identifying and reporting radioactive waste management facilities, operations, or activities that do not meet the requirements of DOE Order/Manual 435.1, Radioactive Waste Management, or pose a threat to the safety of the public, workers, or the environment.

This responsibility is classified as administrative. In the Implementation Guide for use with DOE Manual 435.1, the objective of this requirement is to clearly state the responsibility and right of each individual to identify and report unsafe conditions so that action can be taken to ensure protection of workers, the public, and the environment. 
However, the ICP has adopted and is implementing the ISMS. The ICDF Complex is being designed, constructed, and will be operated in compliance with DOE Order and DOE Directives along with the ARARs and TBCs identified in the OU 3-13 ROD. All work activities for the ICDF Complex construction, operations, and closure are using the ISMS in the work planning and implementation. Part of a successful safety management system is for the identification of problems and the associated corrective actions. In addition, all ICP personnel have "stop work" authority if they identify conditions that are an imminent danger or other serious hazard to workers or the public, or are not protective of the environment. This specific requirement was not identified as an ARAR or TBC in the OU 3-13 ROD.

5.2.7.2 Shutdown or Curtailment of Activities (I.2.G.2.). In DOE Manual 435.1, the responsibility under shutdown or curtailment of activities is as follows:

Stopping or curtailing work, through the appropriate level of management, to prohibit continuation of conditions or activities which pose an imminent danger or other serious hazard to workers or the public, or are not protective of the environment.

This responsibility is classified as administrative. In the Implementation Guide for use with DOE Manual 435.1, the objective of this requirement is to ensure that the operation of radioactive waste management facilities or the performance of radioactive waste management activities is discontinued or controls put in place if it poses an imminent danger or serious hazard to the public, workers, or the environment.

However, the ICP has adopted and is implementing the ISMS. The ICDF Complex is being designed, constructed, and will be operated in compliance with DOE Order and DOE Directives along with the ARARs and TBCs identified in the Operable Unit 3-13 Record of Decision. All work activities for the ICDF Complex construction, operations, and closure are using the ISMS in the work planning and implementation. Part of a successful safety management system is for the identification of problems and the associated corrective actions. In addition, all ICP personnel have "stop work" authority if they identify conditions that are an imminent danger or other serious hazard to workers or the public, or are not protective of the environment. This specific requirement was not identified as an ARAR or TBC in the OU 3-13 ROD. 


\section{HIGH-LEVEL WASTE REQUIREMENTS (DOE ORDER 435.1, CHAPTER II)}

Chapter II of DOE Manual 435.1 deals with the specific requirement associated with the generation, storage, treatment, handling, and disposal of HLW. This section of the ICDF Complex compliance demonstration discusses why the HLW, contained in DOE Manual 435.1, requirements are not applicable to the ICDF Complex. An evaluation is presented to demonstrate why the requirements of Chapter II of DOE Manual 435.1 are not applicable to the ICDF Complex. Also, within this compliance demonstration document, additional information is presented on (1) how the requirement or responsibility is being satisfied, (2) if the requirement or responsibility was identified as an ARARs or TBCs, and (3) references to Section 9 discussing the CERCLA documents that provide supplemental and/or supporting information regarding the how the requirement or responsibility is met.

Within Chapter II, the requirements are organized into 22 major sections. However, as HLW will not be received into the ICDF Complex, only the first section (definition of HLW) of HLW requirements in DOE Manual 435.1 will be discussed in this compliance demonstration document. The evaluation and information for the ICDF Complex concerning this Chapter II of DOE Manual 435.1 are presented in Section 6.1.

\subsection{Definition of High-Level Waste}

In DOE Manual 435.1, the definition of HLW is as follows:

High-level waste is the highly radioactive waste material resulting from the reprocessing of spent nuclear fuel, including liquid waste produced directly in reprocessing and any solid material derived from such liquid waste that contains fission products in sufficient concentrations; and other highly radioactive material that is determined, consistent with existing law, to require permanent isolation.

This requirement is classified as substantive. In the Implementation Guide for use with DOE Manual 435.1, the objective of this requirement is to provide the criteria for determining which DOE radioactive wastes are to be managed as high-level waste, and therefore, in accordance with DOE Manual 435.1-1, Chapter II, High-Level Waste Requirements, and Chapter I, General Requirements and Responsibilities.

The discussion and background information presented in the implementation guide is focused on the primary waste streams resulting from the reprocessing of spent nuclear fuel when defining what is HLW. However, the ICDF Complex is not intended to accept these primary waste streams. The ICDF Complex is not designed for, constructed, nor envisioned to be operated to accept spent nuclear fuel, which is explicitly excluded from receipt into the ICDF Complex by the ICDF Complex WAC (DOE-ID 2005). Also, the ICDF Complex is not designed for, constructed, nor envisioned to be operated to accept "liquid waste produced directly in reprocessing." "Solid material derived from such liquid waste" is also not within the design and operation of the ICDF Complex and facilities within the ICDF Complex are not being constructed to receive these waste streams.

Each of these wastes as described as presented above are primary waste streams. However, there are secondary waste streams that can be generated as a result of conducting INL CERCLA investigative, remedial, and removal actions in areas that contained these primary waste streams. Within and surrounding the INTEC tank farm, there are known spills of liquid wastes from the piping systems that 
have had HLW and other aqueous waste streams. Also, there is a known spill of calcine material from Bin Set \#3 (release site CPP-13) in which the calcine was removed, but residual contamination still exists. These liquid spills and solid wastes have contaminated the underlying soils and structures.

To determine if HLW requirements apply to contaminated soils and debris, it is necessary to define contamination. Contamination is defined as unwanted radioactive and/or hazardous material that is disbursed on or in equipment, structures, objects, soil or water. Contamination may be either surface or volumetric (i.e., contamination incorporated within a solid material) (DOE 1997a, and 1997b).

This definition as it applies to radioactive materials is similar to that used by the DOE, NRC and EPA for radiological criteria for unrestricted use of the material (DOE O 5400.5; EPA 1997). The source of contamination is not considered in determining acceptable levels of residual radioactivity. The levels are based strictly on concentration and subsequent dose impacts. This is consistent with the guidance in DOE G 435.1-1, Implementation Guide for use with DOE M 435.1-1, that states that components, equipment, and other materials contaminated with HLW can be managed as non-HLW if management of the contaminated material can be shown not to jeopardize the health and safety of the public, workers, and the environment.

This definition of contamination as it applies to hazardous materials is consistent with the "contained-in" policy used by the EPA. The EPA does not consider groundwater and environmental media (such as soils) to be solid waste (EPA 1989). Therefore, environmental media contaminated with hazardous waste are not listed hazardous wastes and the "mixture" and "derived from" rules are not appropriate. Instead, EPA views that the environmental media contains the hazardous waste; this is referred to as the "contained-in" policy. Implementation of the "contained-in" policy considers contaminated soil characteristics such as hazardous constituent concentrations, risk to human health or the environment, and the potential for exposure in determining whether the contaminated soils no longer contain any hazardous waste. The same logic applies to contaminated debris materials.

If soil contaminated with hazardous waste is mixed with noncontaminated soil, the resulting waste is a diluted waste not a mixture. Under the EPA rules, dilution is not an acceptable waste treatment procedure to reduce the concentrations of the contaminants. If a soil contaminated with a characteristic waste is treated to remove the characteristic, then the soil is eligible for disposal.

There are cases where treatment of characteristic waste is not necessary to be acceptable for disposal. This possibility exists at WAG 3, of which the ICDF Complex is a part, due to the establishment of an area of contamination in the OU 3-13 ROD. Under specific conditions, waste streams for OU 3-13 can be excavated and disposed in the landfill even if the waste is characteristic for RCRA constituents. However, should the excavated waste stream be "stored" or "treated" prior to disposal, then the waste must be treated to meet the LDR requirements.

Within the implementation guide for DOE Order 435.1, there is no discussion of "mixture," "derived from," or "contained-in" requirements related to radionuclide contamination. Based on this and the regulatory definition of contamination (discussed above), there is no requirement to classify contaminated soil or debris as HLW even though the source of soil or debris contamination may have been a release of HLW. The contaminated soil or debris must be managed in accordance with its radiological hazards based on radioactive concentrations of the soil or debris and in accordance with CERCLA and/or RCRA requirements for treatment, as necessary, and disposal of the hazardous constituents. Therefore, contaminated soils and debris waste streams are not HLW.

Based on this, there are no HLW streams being considered for disposal in the ICDF. As a result, no additional analysis on HLW is contained in this compliance demonstration document. This section of 
DOE Manual 435.1 was not directly cited as an ARAR for the ICDF Complex in the OU 3-13 ROD. In Section 9, HLW is addressed and shows the associated ARARs and CERCLA documents dealing with HLW for the ICDF Complex. Also, Sections 7 and 8 further discuss the management associated with the TRU and LLW at the ICDF Complex.

The ICDF Complex is not intended for the management of HLW streams as discussed above. However, waste streams evaluated under the "waste incidental to reprocessing" process may be considered for management within the ICDF Complex. The results of the evaluation would have to be that the waste is "not HLW" and therefore can be managed in other facilities. These waste streams would be considered on a case-by-case basis for management at the ICDF Complex. If the waste met the landfill Waste Acceptance Criteria, disposal in the ICDF landfill would then be considered for the waste stream. 
6-4 


\section{TRANSURANIC WASTE (DOE ORDER 435.1, CHAPTER III)}

Chapter III of DOE Manual 435.1 deals with the management of TRU waste. This section of the ICDF Complex compliance demonstration discusses the requirements for the management of TRU waste contained in DOE Manual 435.1. An evaluation is presented to determine whether requirements for management of TRU waste in Chapter III of DOE Manual 435.1 are administrative or substantive (see Section 1.1) in function.

If the requirement for TRU waste management is administrative, minimal additional discussion is presented. For the substantive requirements and responsibilities under DOE Manual 435.1, additional information is presented on (1) how the requirement or responsibility is being satisfied, (2) if the requirement or responsibility was identified as an ARARs or TBCs, and (3) references to Section 9 discussing the CERCLA documents that provide supplemental and/or supporting information regarding the how the requirement or responsibility is met.

Within Chapter III, the requirements for management of TRU waste are organized into 17 major sections. The 17 major sections include the topics of site evaluation, facility design, storage, treatment, disposal, monitoring, and waste acceptance. These responsibilities are discussed in Sections 7.1 through 7.17.

\subsection{Definition of Transuranic Waste (III.A.)}

In DOE Manual 435.1, the definition of TRU waste is as follows:

Transuranic waste is radioactive waste containing more than 100 nanocuries (3700 becquerels) of alpha-emitting transuranic isotopes per gram of waste, with half-lives greater than 20 years, except for:

(1) High-level radioactive waste;

(2) Waste that the Secretary of Energy has determined, with the concurrence of the Administrator of the Environmental Protection Agency, does not need the degree of isolation required by the 40 CFR Part 191 disposal regulations; or

(3) Waste that the Nuclear Regulatory Commission has approved for disposal on a case-by-case basis in accordance with 10 CFR Part 61.

This requirement is classified as substantive. In the Implementation Guide for use with DOE Manual 435.1, the objective of this requirement is to provide the criteria for determining if a waste is to be managed in accordance with DOE M 435.1-1, Chapter III, TRU Waste Requirements. Additionally, it is necessary to determine if a waste meets the definition of TRU waste to enable the Department of Energy to comply with provisions in the Waste Isolation Pilot Plant Land Withdrawal Act of 1992, as amended.

The definition provided above is the definition that is being used for the ICDF Complex. This section of DOE Manual 435.1 was not directly cited as an ARAR for the ICDF Complex in the OU 3-13 ROD. In Section 9, TRU waste is addressed and shows the associated ARARs and CERCLA documents dealing with TRU waste for the ICDF Complex. 


\subsection{Management of Specific Waste (III.B.)}

In DOE Manual 435.1, the requirement for management of specific waste is as follows:

There are three requirements in DOE Manual 435.1 for the management of specific wastes are presented in Section 7.2.1, 7.2.2, and 7.2.3.

\subsubsection{Mixed Transuranic Waste (III.B.1.)}

In DOE Manual 435.1, the requirements for mixed TRU waste are as follows:

Transuranic waste determined to contain both a hazardous component subject to the Resource Conservation and Recovery Act (RCRA), as amended, and a radioactive component subject to the Atomic Energy Act of 1954, as amended, shall be managed in accordance with the requirements of RCRA and DOE Order/Manual 435.1, Radioactive Waste Management.

This requirement is classified as substantive. In the Implementation Guide for use with DOE Manual 435.1, the objective of this requirement is to ensure that DOE TRU waste is managed in accordance with the applicable requirements of external regulations, specifically those of the RCRA, that address nonradiological hazards, in addition to being managed in accordance with the requirements of DOE O 435.1 and the Radioactive Waste Management Manual, DOE M 435.1-1.

The ICDF Complex has been designed and is being constructed to deal with hazardous waste constituents. Management of the various waste streams at the ICDF Complex consider all of the constituents in the waste including the RCRA and radionuclide constituents. This section of DOE Manual 435.1 was not directly cited as an ARAR for the ICDF Complex in the OU 3-13 ROD. In Section 9, mixed TRU waste is addressed and shows the associated ARARs and CERCLA documents dealing with the mixed TRU waste for the ICDF Complex.

\subsubsection{TSCA-Regulated Waste (III.B.2.)}

In DOE Manual 435.1, the requirement for TSCA-regulated waste is as follows:

Transuranic waste containing polychlorinated biphenyls, asbestos, or other such regulated toxic components shall be managed in accordance with requirements derived from the Toxic Substances Control Act, as amended, DOE Order/Manual 435.1, Radioactive Waste Management.

This requirement is classified as substantive. In the Implementation Guide for use with DOE Manual 435.1, the objective of this requirement is to ensure that DOE TRU waste is managed in accordance with the applicable requirements of external regulations, specifically those of the TSCA, that address nonradiological hazards, in addition to being managed in accordance with the requirements of DOE O 435.1 and the Radioactive Waste Management Manual, DOE M 435.1-1.

The ICDF Complex has been designed and is being constructed to deal with hazardous waste constituents. Management of the various waste streams at the ICDF Complex consider all of the constituents in the waste including the TSCA and radionuclide constituents. This section of DOE Manual 435.1 was not directly cited as an ARAR for the ICDF Complex in the OU 3-13 ROD. In Section 9, mixed TRU waste is addressed and shows the associated ARARs and CERCLA documents dealing with the mixed TRU waste for the ICDF Complex. 


\subsubsection{Pre-1970 Transuranic Waste (III.B.3.)}

In DOE Manual 435.1, the requirement for pre-1970 TRU waste is as follows:

Transuranic waste disposed of prior to implementation of the 1970 Atomic Energy Commission Immediate Action Directive regarding retrievable storage of transuranic waste is not subject to the requirements of DOE Order/Manual 435.1, Radioactive Waste Management.

This requirement is classified as administrative. In the Implementation Guide for use with DOE Manual 435.1, the objective of this requirement is to ensure that DOE TRU waste is managed in accordance with the requirements of DOE O 435.1 and the Radioactive Waste Management Manual, DOE M 435.1-1.

The ICDF Complex is not expected to deal with pre-1970 TRU waste streams. There is the possibility during the operations of the ICDF Complex that TRU waste will be received. This waste would be managed as if it is new TRU waste, which eliminates the pre-1970 TRU waste issue. This specific responsibility was not identified as an ARAR or TBC in the OU 3-13 ROD and is not specifically addressed in other CERCLA documents for the ICDF Complex.

\subsection{Complex-Wide Transuranic Waste Management Program (III.C.)} follows:

In DOE Manual 435.1, the requirement for complex-wide TRU waste management program is as

A complex-wide program and plan shall be developed as described under Responsibilities, 2.B and 2.D, in Chapter I of DOE Manual 435.1.

This requirement is classified as administrative. In the Implementation Guide for use with DOE Manual 435.1, the objective of this requirement is to ensure the development, documentation, and implementation of a complex-wide TRU waste management program. The complex-wide program and plan establishes the framework within which individual site programs operate. The ICDF Complex is specifically limited to INL CERCLA waste. As such, this responsibility is not directly or substantively related to the design, construction, operation, and closure of the ICDF Complex. No additional information concerning this responsibility is included in this compliance demonstration. This specific responsibility was not identified as an ARAR or TBC in the OU 3-13 ROD and is not specifically addressed in other CERCLA documents for the ICDF Complex.

\subsection{Radioactive Waste Management Basis (III.D.)}

In DOE Manual 435.1, the requirement for radioactive waste management basis is as follows:

Transuranic waste facilities, operations, and activities shall have a radioactive waste management basis consisting of physical and administrative controls to ensure the protection of workers, the public, and the environment.

There are four areas of requirements in DOE Manual 435.1 for the radioactive waste management basis presented in Sections 7.4.1, 7.4.2, 7.4.3, and 7.4.4. 


\subsubsection{Generators (III.D.1.)}

In DOE Manual 435.1, the requirement for radioactive waste management basis dealing with specific waste management controls for radioactive waste management basis:

Generators - The waste certification program.

This requirement is classified as substantive. In the Implementation Guide for use with DOE Manual 435.1, the objective of this requirement is to ensure that the hazards associated with TRU waste management facilities, operations, and activities have been identified, their potential impacts analyzed, and appropriate controls documented, implemented, and maintained for the protection of workers, the public, and the environment.

The ICDF Complex has been designed and is being constructed to safely manage radioactive waste. Impacts from the management of radioactive waste constituents and other constituents have analyzed. These impacts were determined to be acceptable. However, operations at the ICDF Complex are not expected to produce TRU waste. Limited quantities of TRU waste may be received into the ICDF Complex for temporary storage. Some limited sampling and analysis of the waste being received into the ICDF Complex will be conducted. Certification of these TRU waste streams would be conducted by the existing INL facilities and programs dealing with the TRU waste. This section of DOE Manual 435.1 was not directly cited as an ARAR for the ICDF Complex in the OU 3-13 ROD. In Section 9, TRU waste is addressed and shows the associated ARARs and CERCLA documents dealing with the TRU waste for the ICDF Complex.

\subsubsection{Treatment Facilities (III.D.2.)}

In DOE Manual 435.1, the requirement for radioactive waste management basis dealing with specific waste management controls for radioactive waste management basis is as follows:

Treatment Facilities - The waste acceptance requirements and the waste certification program.

This requirement is classified as substantive. In the Implementation Guide for use with DOE Manual 435.1, the objective of this requirement is to ensure that the hazards associated with TRU waste management facilities, operations, and activities have been identified, their potential impacts analyzed, and appropriate controls documented, implemented, and maintained for the protection of workers, the public, and the environment.

The ICDF Complex has been designed and is being constructed to safely manage radioactive waste. Impacts from the management of radioactive waste constituents and other constituents have analyzed. These impacts were determined to be acceptable. However, the ICDF Complex currently has not been designed to treat TRU waste. If the ICDF Complex receives TRU waste requiring treatment, the waste stream will be transferred to the existing INL facilities and programs dealing with the treatment of TRU waste. This section of DOE Manual 435.1 was not directly cited as an ARAR for the ICDF Complex in the OU 3-13 ROD. Therefore, this requirement is not specifically addressed in other CERCLA documents for the ICDF Complex. 


\subsubsection{Storage Facilities (III.D.3.)}

In DOE Manual 435.1, the requirement for radioactive waste management basis dealing with specific waste management controls for radioactive waste management basis is as follows:

Storage Facilities - The waste acceptance requirements and the waste certification program.

This requirement is classified as substantive. In the Implementation Guide for use with DOE Manual 435.1, the objective of this requirement is to ensure that the hazards associated with TRU waste management facilities, operations, and activities have been identified, their potential impacts analyzed, and appropriate controls documented, implemented, and maintained for the protection of workers, the public, and the environment.

The ICDF Complex has been designed and is being constructed to safely manage radioactive waste. Impacts from the management of radioactive waste constituents and other constituents have analyzed. These impacts were determined to be acceptable. One of the operations that will be conducted at the ICDF Complex is the staging and storage of waste streams. The existing design of the ICDF Complex is sufficient to allow for the storage of "limited quantities" of TRU waste. These waste streams will be temporarily stored and then transferred to the existing INL facilities and program for the disposition of the waste stream. This section of DOE Manual 435.1 was not directly cited as an ARAR for the ICDF Complex in the OU 3-13 ROD. In Section 9, TRU waste is addressed and shows the associated ARARs and CERCLA documents dealing with the TRU waste for the ICDF Complex.

\subsubsection{Disposal Facilities (III.D.4.)}

In DOE Manual 435.1, the requirement for radioactive waste management basis dealing with specific waste management controls for radioactive waste management basis is as follows:

Disposal Facilities - The performance assessment, disposal authorization statement, waste acceptance requirements, and monitoring plan.

This requirement is classified as substantive. In the Implementation Guide for use with DOE Manual 435.1, the objective of this requirement is to ensure that the hazards associated with TRU waste management facilities, operations, and activities have been identified, their potential impacts analyzed, and appropriate controls documented, implemented, and maintained for the protection of workers, the public, and the environment.

The ICDF Complex has been designed and is being constructed to safely manage radioactive waste. Impacts from the management of radioactive waste constituents and other constituents have analyzed. These impacts were determined to be acceptable. The ICDF Complex is not designed to dispose TRU waste. Should TRU waste be received into the ICDF Complex requiring disposal, the waste stream will be transferred to the existing INL facilities and programs that deal with the disposal of TRU waste. This section of DOE Manual 435.1 was not directly cited as an ARAR for the ICDF Complex in the OU 3-13 ROD. Therefore, this requirement is not specifically addressed in other CERCLA documents for the ICDF Complex.

\subsection{Contingency Actions (III.E.)}

In DOE Manual 435.1, the requirement for contingency actions is found in Sections 7.5.1 and 7.5.2. 


\subsubsection{Contingency Storage (III.E.1.)}

In DOE Manual 435.1, the requirements for contingency storage are as follows:

Contingency storage - For off-normal or emergency situation involving liquid transuranic waste storage or treatment, spare capacity with adequate capabilities shall be maintained to receive the largest volume of liquid contained in any one storage tank or treatment facility. Tanks or other facilities that are designated transuranic waste contingency storage shall be maintained in an operational condition at all times when waste is present and shall meet the requirements of DOE Order 435.1 and DOE Manual 435.1.

This requirement is classified as substantive. In the Implementation Guide for use with DOE Manual 435.1, the objective of this requirement is to ensure the impacts on the public, workers, or environment are mitigated in the event that a leak develops in a tank storing TRU waste or in a facility processing TRU waste. The mitigation is provided by ensuring spare waste storage capacity is a required part of a site's emergency management program. To meet this objective, there needs to be both capacity to handle the largest volume of any single storage tank or liquid waste in process, and the capability to transfer the waste.

The ICDF Complex has been designed and is being constructed to safely manage liquid radioactive waste. The ICDF Complex has tanks to store liquid waste. Also, there are sumps and other areas that can collect liquid waste. Each of these systems has secondary containment to catch leaks from the primary tank or structure. There is additional tank capacity that will be available at the ICDF Complex for the liquid waste in case a tank or other structure springs a leak. However, operations at the ICDF Complex are not expected to produce TRU waste. Limited quantities of TRU waste may be received into the ICDF Complex for temporary storage. This section of DOE Manual 435.1 was not directly cited as an ARAR for the ICDF Complex in the OU 3-13 ROD. In Section 9, contingency storage is addressed and shows the associated ARARs and CERCLA documents for the ICDF Complex.

\subsubsection{Transfer Equipment (III.E.2.)}

In DOE Manual 435.1, the requirement for transfer equipment is as follows:

Transfer equipment - Pipelines and auxiliary facilities necessary for the transfer of liquid waste to contingency storage shall be maintained in an operational condition at all times when waste is present and shall meet the requirements of DOE Order 435.1 and DOE Manual 435.1.

This requirement is classified as substantive. In the Implementation Guide for use with DOE Manual 435.1, the objective of this requirement is to ensure the impacts on the public, workers, or environment are mitigated in the event that a leak develops in a tank storing TRU waste or in a facility processing TRU waste. The mitigation is provided by ensuring spare waste storage capacity is a required part of a site's emergency management program. To meet this objective, there needs to be both capacity to handle the largest volume of any single storage tank or liquid waste in process, and the capability to transfer the waste.

The ICDF Complex has been designed and is being constructed to safely manage liquid radioactive waste. The ICDF Complex has transfer equipment to move liquid waste between the various tanks and other structures at the ICDF Complex. However, operations at the ICDF Complex are not expected to produce TRU waste. Limited quantities of TRU waste may be received into the ICDF Complex for 
temporary storage. This section of DOE Manual 435.1 was not directly cited as an ARAR for the ICDF Complex in the OU 3-13 ROD. In Section 9, transfer equipment is addressed and shows the associated ARARs and CERCLA documents for the ICDF Complex.

\subsection{Corrective Actions (III.F.)}

In DOE Manual 435.1, there are two major corrective action requirements related to TRU waste. Both of these requirements are discussed below in Sections 7.6.1 and 7.6.2.

\subsubsection{Order Compliance (III.F.1.)}

In DOE Manual 435.1, the requirement for order compliance is as follows:

Order Compliance - Corrective actions shall be implemented whenever necessary to ensure the requirements of DOE Order 435.1 and DOE Manual 435.1 are met.

This requirement is classified as substantive. In the Implementation Guide for use with DOE Manual 435.1, the objective of this requirement is to ensure that actions will be taken to preclude, minimize, or mitigate hazards whenever a situation arises at a TRU waste management facility that could threaten worker or public safety, or the environment.

The ICDF Complex has been designed and is being constructed to safely manage radioactive waste materials. There are existing processes and procedures at the INL for corrective actions identification and implementation. Also, specific procedures are being developed for the ICDF Complex to deal with emergency issues and resolution of those issues.

This section of DOE Manual 435.1 was not directly cited as an ARAR for the ICDF Complex in the OU 3-13 ROD. In Section 9, corrective actions are addressed and shows the associated ARARs and CERCLA documents for the ICDF Complex.

\subsubsection{Operations Curtailment (III.F.2.)}

In DOE Manual 435.1, the requirement for operations curtailment is as follows:

Operations Curtailment - Operations shall be curtailed or facilities shut down for failure to establish, maintain, or operate consistent with an approved radioactive waste management basis.

This requirement is classified as substantive. In the Implementation Guide for use with DOE Manual 435.1, the objective of this requirement is to limit the operation of waste management activities and facilities as necessary to avoid creation of near- or long-term safety or environmental hazards.

The ICDF Complex has been designed and is being constructed to safely manage radioactive waste materials. The waste materials at the ICDF Complex will be tracked for inventory control, which is necessary to remain within the radioactive waste management basis. This waste tracking can be used to identify when the operations of the ICDF Complex are approaching the operating limits. The necessary operations and actions can then be taken to remain within the operating limits. In addition, there will be periodic surveillances conducted at the ICDF Complex to determine/verify that the operations are remaining within the operating limits. If the ICDF Complex exceeds the operating limits, the necessary actions, including curtailment/shutdown of facilities/operations, will be conducted to bring the ICDF Complex back within the operating limits. 
This section of DOE Manual 435.1 was not directly cited as an ARAR for the ICDF Complex in the OU 3-13 ROD. In Section 9, operations curtailment are addressed and shows the associated ARARs and CERCLA documents for the ICDF Complex.

\subsection{Waste Acceptance (III.G.)}

In DOE Manual 435.1, there are two major waste acceptance requirements related to TRU waste. Both of these requirements are discussed below in Sections 7.7.1 and 7.7.2.

\subsubsection{Technical and Administrative (III.G.1.)}

In DOE Manual 435.1, the technical and administrative requirements are as follows:

Technical and Administrative - Waste acceptance requirements for all transuranic waste storage, treatment, or disposal facilities, operations, and activities shall specify, at a minimum, the following:

- Allowable activities and/or concentrations of specific radionuclides;

- $\quad$ Acceptable waste form and/or container requirements that ensure the chemical and physical stability of waste under conditions that might be encountered during transportation, storage, treatment, or disposal;

- $\quad$ Restrictions or prohibitions on waste, materials, or containers that may adversely affect waste handlers or compromise facility or waste container performance;

- $\quad$ Requirement to identify transuranic waste as defense or non-defense, and limitations on acceptance; and

- $\quad$ The basis, procedures, and level of authority required for granting exceptions to the waste acceptance requirements, which shall be contained in each facility's waste acceptance documentation. Each exception request shall be documented, including its disposition as approved or not approved.

This requirement is classified as substantive. In the Implementation Guide for use with DOE Manual 435.1, the objective of the waste acceptance requirements are to ensure that TRU waste which is received at a facility contains only the radionuclides that the facility can safely manage, and only in concentrations and/or total activities which are compatible with the work to be undertaken in the facility; ensure that TRU waste which is to be received at a facility is in a form or package that will maintain its integrity and retain acceptable configuration under the conditions that are expected to be encountered during the management steps the waste will undergo; ensure that no TRU waste received at a facility contains materials that will compromise the safety or integrity of the facility under the expected operating conditions; and ensure that formal procedures exist and a decision process is clear concerning the granting of exceptions to waste acceptance requirements.

The WAC for the ICDF Complex was designed to be protective. The impacts associated with radionuclides were evaluated in evaluating the hazards associated with the ICDF Complex. The WAC

does not set specific limits on concentrations of specific radionuclides, but the total activities are limited by the limits imposed by the hazard analysis document. The inventory is tracked and maintained to 
demonstrate that the ICDF Complex is remaining within the acceptable limits. However, the WAC does set limits on containers, chemical/physical requirements, and allowable waste forms. There are no specific requirements in the WAC related to defense versus nondefense waste. When it is time for the waste, that has been received into the ICDF Complex, to be disposed, the appropriate determination will be made and the waste sent to the applicable disposal facility. Changing the WAC at the ICDF Complex would require a modification to a primary document under the FFA/CO. This modification process is a structured and methodical process that is fully documented with either the changes being accepted or rejected.

This section of DOE Manual 435.1 was not directly cited as an ARAR for the ICDF Complex in the OU 3-13 ROD. In Section 9, waste acceptance is addressed and shows the associated ARARs and CERCLA documents for the ICDF Complex.

\subsubsection{Evaluation and Acceptance (III.G.2.)}

In DOE Manual 435.1, the evaluation and acceptance requirement is as follows:

Evaluation and Acceptance - The receiving facility shall evaluate waste for acceptance, including confirmation that technical and administrative requirements have been met. A process for the disposition of non-conforming wastes shall be established.

This requirement is classified as substantive. In the Implementation Guide for use with DOE Manual 435.1, the objective of this requirement is to establish a process by which personnel at a facility receiving TRU waste for storage, treatment, or disposal determine that the waste being transferred is acceptable in accordance with the waste acceptance requirements, and for that process to specifically address management of waste that does not conform with all of the requirements when it is received at the facility.

The ICDF Complex has a process for the acceptance of waste into the facility. This process includes the sampling and analysis that is conducted to verify the waste is as expected and that the waste is within the WAC limits. There are specific steps in the acceptance and tracking process which are contained in the waste tracking plan. Also, there are process and procedures for the ICDF Complex that deal with (resolve) waste streams that do not meet the WAC or are not as expected for the available information when received.

This section of DOE Manual 435.1 was not directly cited as an ARAR for the ICDF Complex in the OU 3-13 ROD. In Section 9, waste acceptance is addressed and shows the associated ARARs and CERCLA documents for the ICDF Complex.

\subsection{Waste Generation Planning (III.H.)}

In DOE Manual 435.1, there are 2 major waste generation planning requirements related to TRU waste. Both of these requirements are discussed below in Sections 7.8.1 and 7.8.2.

\subsubsection{Life-Cycle Planning (III.H.1.)}

In DOE Manual 435.1, the life-cycle planning requirement is as follows:

Life-Cycle Planning - Prior to waste generation, planning shall be preformed to address the entire life-cycle for all transuranic waste streams. 
This requirement is classified as administrative. In the Implementation Guide for use with DOE Manual 435.1, the objective of this requirement is to provide for the disposal of all TRU waste that is generated in the future by ensuring that prior to generating a new TRU waste stream, the specific waste management facilities necessary for safe management of the waste from the time it is generated up to and including its disposal are identified; plans are developed for resolving issues that prevent disposal, and for safe, long-term storage for TRU waste with no path to disposal; and sites are discouraged from generating TRU waste that does not have an identified path to disposal.

There is a documented process for evaluating all waste streams that are destined for ICDF Complex. This evaluation involves knowing what waste stream would be generated and the characteristics of the waste. This process of evaluating the potential waste streams includes looking at all required destinations/facilities that the waste stream will be managed. There may be waste streams that the final destination is not known and will require storage until the disposal facility is identified. The ICDF Complex has waste storage capabilities and will continue to evaluate disposal options for the waste that is in storage.

This section of DOE Manual 435.1 was not directly cited as an ARAR for the ICDF Complex in the OU 3-13 ROD. In Section 9, waste generation is addressed and shows the associated ARARs and CERCLA documents for the ICDF Complex.

\subsubsection{Waste with No Identified Path to Disposal (III.H.2.)}

In DOE Manual 435.1, the waste with no identified path to disposal requirements are as follows:

Waste With No Identified Path to Disposal - Transuranic waste streams with no identified path to disposal shall be generated only in accordance with approved conditions which, at a minimum, shall address:

- $\quad$ Programmatic need to generate the waste;

- Characterization and issues preventing the disposal of the waste;

- $\quad$ Safe storage of the waste until disposal can be achieved; and

- $\quad$ Activities and plans for achieving final disposal of the waste.

This requirement is classified as administrative. In the Implementation Guide for use with DOE Manual 435.1, the objective of this requirement is to ensure that prior to generation of a new TRU waste streams with no path to disposal, the need to generate the waste is carefully considered and plans for safe long-term storage and for resolving issues that prevent disposal of the wastes are developed.

There is a documented process for evaluating all waste streams that are destined for ICDF Complex. Part of this evaluation is knowing the rationale for why the waste stream needs to be generated. All wastes destined for the ICDF Complex are required to be associated with an INL CERCLA response action. These CERCLA projects evaluate various alternatives for the remediation, including generation and disposal of waste. Once it is determined that a waste stream will be received at the ICDF Complex, the waste stream evaluation involves knowing what waste streams would be generated and the characteristics of the waste. This process of evaluating the potential waste streams includes looking at all required destinations/facilities that the waste stream will be managed. There may be a waste streams that the final destination is not known and will require storage until the disposal facility is identified. The 
ICDF Complex has waste storage capabilities and will continue to evaluate disposal options for the waste that is in storage.

This section of DOE Manual 435.1 was not directly cited as an ARAR for the ICDF Complex in the OU 3-13 ROD. In Section 9, waste generation is addressed and shows the associated ARARs and CERCLA documents for the ICDF Complex.

\subsection{Waste Characterization (III.I.)}

In DOE Manual 435.1, the waste characterization requirement is as follows:

Transuranic waste shall be characterized using direct or indirect methods, and the characterization documented in sufficient detail to ensure safe management and compliance with the waste acceptance requirements of the facility receiving the waste.

This requirement is classified as substantive. In the Implementation Guide for use with DOE Manual 435.1, the objective of this requirement is to ensure that sufficient knowledge of TRU waste's characteristics (e.g., chemical, physical, radiological) is available to protect workers handling the waste and to support effective decision-making for its management. This information is to be maintained from generation, through storage and treatment in sufficient detail to ensure that the requirements of subsequent treatment and storage facilities, transportation regulations, and the disposal requirements for TRU waste will be met.

For the ICDF Complex, there is a defined process of verification of the waste stream received into the various facilities. These characterization processes include both direct and indirect methods of characterization, which are used in the development of the Material Profile. The Material Profile information is compared against the applicable WAC to determine if the waste is within the acceptable limits. Additional characterization, including direct methods, may be used to complete the Material Profile. For receipt and disposal at the ICDF Complex, additional verification sampling and analysis is conducted to verify compliance with the WAC.

This section of DOE Manual 435.1 was not directly cited as an ARAR for the ICDF Complex in the OU 3-13 ROD. In Section 9, waste characterization is addressed and shows the associated ARARs and CERCLA documents for the ICDF Complex.

Also, there are two major waste characterization requirements related to TRU waste. Both of these requirements are discussed below in Sections 7.9.1 and 7.9.2.

\subsubsection{Data Quality Objectives (III.I.1.)}

In DOE Manual 435.1, the data quality objectives requirement is as follows:

Data Quality Objectives - The data quality objectives process, or a comparable process, shall be used for identifying characterization parameters and acceptable uncertainty in characterization data

This requirement is classified as substantive. In the Implementation Guide for use with DOE Manual 435.1, the objective of this requirement is to invoke a process for determining the type, quantity, and quality of characterization data needed to support the safe management of TRU waste so as to ensure 
that needed data are acquired, the data meet the objectives they are being collected for, and resources are not wasted on unnecessary, incomplete or unusable data collection efforts.

When developing a Sampling and Analysis Plan (SAP) for an INL CERCLA project, data quality objectives are developed and documented. This same process was followed for the development of the verification SAP for the ICDF Complex. For the ICDF Complex verification SAP, the data quality objectives were focused on what information (contaminant concentrations) was necessary to ensure that the waste would remain within the WAC. Because, the data quality objectives were developed for the ICDF Complex related to the WAC limits it is not necessary to develop individual waste stream data quality objectives. Also, data quality objectives are discussed in the WAC for the ICDF Complex.

This section of DOE Manual 435.1 was not directly cited as an ARAR for the ICDF Complex in the OU 3-13 ROD. In Section 9, waste characterization is addressed and shows the associated ARARs and CERCLA documents for the ICDF Complex.

\subsubsection{Minimum Waste Characterization (III.I.2.)}

In DOE Manual 435.1, the minimum waste characterization requirements are as follows:

Minimum Waste Characterization - Characterization data shall, at a minimum, include the following:

- $\quad$ Physical and chemical characteristics;

- Volume, including the waste and any stabilization or absorbent media;

- Weight of the container and contents;

- Identities, activities, and concentrations of major radionuclides;

- $\quad$ Characterization date;

- $\quad$ Generating source;

- $\quad$ Packaging date; and

- $\quad$ Any other information which may be needed to prepare and maintain the disposal facility performance assessment or demonstrate compliance with applicable performance objectives.

This requirement is classified as substantive. In the Implementation Guide for use with DOE Manual 435.1, the objective of this requirement is to establish minimum TRU waste data that have been determined to be necessary for safe and effective management during the life cycle of the waste.

For the ICDF Complex, waste streams undergo a waste profiling process prior to generation or receipt into the facility. Within this waste profiling process, the available information on the waste stream characteristics is input into the waste tracking system. The waste tracking system includes the physical/chemical characteristics, volume, weights, constituents, and other relevant data. During the waste profiling process, it is occasionally necessary to further characterize the waste stream. This additional information is added into the waste profile contained in the waste tracking system. When the waste is received into the ICDF Complex, additional verification sampling and analysis may be conducted to 
verify that the waste stream is as stated on the Material Profile form. All the information in the waste tracking system is maintained as a record and updated as the waste stream is moved between the various facilities. All of the Material Profile information can be used by the disposal facility to evaluate compliance with the disposal facilities WAC, which is determined by the performance assessment and performance objectives.

This section of DOE Manual 435.1 was not directly cited as an ARAR for the ICDF Complex in the OU 3-13 ROD. In Section 9, waste characterization is addressed and shows the associated ARARs and CERCLA documents for the ICDF Complex.

\subsection{Waste Certification (III.J.)}

In DOE Manual 435.1, the waste certification requirement is as follows:

A waste certification program shall be developed, documented, and implemented to ensure that the waste acceptance requirements of facilities receiving transuranic waste for storage, treatment, or disposal are met.

This requirement is classified as administrative. In the Implementation Guide for use with DOE Manual 435.1, the objective of this requirement is to ensure that waste transferred to a facility for storage, treatment, or disposal meets the receiving facility's waste acceptance requirements, to reduce the likelihood that transferred wastes contain unacceptable materials or characteristics, and to avoid hazards that would occur from the transportation and handling of waste packages which do not meet acceptance requirements. Certification also ensures that the storage, treatment, or disposal facilities receiving the waste operate within limits established through safety analyses and/or performance assessments.

The ICDF Complex will operate using an integrated waste tracking system. Within the waste tracking system, there are various steps for approval and certification of the waste streams. One of the checks in the system is to verify that the Material Profile for the waste stream is within the WAC limits for the facility. The WAC limits for the ICDF Complex considered the hazard classification and analysis of the various facilities in the ICDF Complex and the operations that could occur in the ICDF Complex facilities. The waste tracking system includes all of the operational limits and generates a flag for waste streams that are destined for a facility in the ICDF Complex if the waste exceeds the facility WAC.

This section of DOE Manual 435.1 was not directly cited as an ARAR for the ICDF Complex in the OU 3-13 ROD. In Section 9, waste certification is addressed and shows the associated ARARs and CERCLA documents for the ICDF Complex.

Also, there are three major waste certification requirements related to TRU waste. The three requirements are discussed below in Sections 7.10.1, 7.10.2, and 7.10.3.

\subsubsection{Certification Program (III.J.1.)}

In DOE Manual 435.1, the certification program requirements are as follows:

Certification Program - The waste certification program shall designate the officials who have the authority to certify and release waste for shipment; and specify what documentation is required for waste generation, characterization, shipment, and certification. The program shall provide requirements for auditability, retrievability, and storage of required documentation and specify the records retention period. 
This requirement is classified as administrative. In the Implementation Guide for use with DOE Manual 435.1, the objective of this requirement is to ensure waste certification programs are developed that clearly identify the documentation required for certifying waste, specify personnel with the authority to make the certification, and provide a traceable and verifiable record of and basis for certification.

The ICDF Complex will operate using an integrated waste tracking system. Within the waste tracking system, there are various steps for approval and certification of the waste streams. Operation of the waste tracking system will involve selected personnel with the access to approve waste transfers and certification of the Material Profile for the waste stream. Also, the waste tracking system maintains a record of the various changes to the Material Profile, approvals, and other information, including characterization data, related to the waste stream.

This section of DOE Manual 435.1 was not directly cited as an ARAR for the ICDF Complex in the OU 3-13 ROD. In Section 9, waste certification is addressed and shows the associated ARARs and CERCLA documents for the ICDF Complex.

\subsubsection{Certification Before Transfer (III.J.2.)}

In DOE Manual 435.1, the certification before transfer requirement is as follows:

Certification Before Transfer - Transuranic waste shall be certified as meeting waste acceptance requirements before it is transferred to the facility receiving the waste.

This requirement is classified as administrative. In the Implementation Guide for use with DOE Manual 435.1, the objective of this requirement is to ensure that waste meets the acceptance requirements of the storage, treatment, or disposal facility before it is transferred to prevent transferring waste that could endanger receiving facility personnel, and to avoid the delay and potential hazards associated with corrective actions taken to remedy noncompliant conditions.

The ICDF Complex will operate using an integrated waste tracking system. Within the waste tracking system, there are various steps for approval and certification of the waste streams. One of the checks in the system is to verify that the waste profile for the waste stream is within the WAC limits for the facility. The waste tracking system includes all of the operational limits and generates a flag for waste streams that are destined for a facility in the ICDF Complex if that waste exceeds the facility WAC. If a flag is generated, the waste stream can not be received until the issues that resulted in the flag being generated is resolved. This is intended to reduce the possibility of a noncompliant condition developing at the ICDF Complex.

This section of DOE Manual 435.1 was not directly cited as an ARAR for the ICDF Complex in the OU 3-13 ROD. In Section 9, waste certification is addressed and shows the associated ARARs and CERCLA documents for the ICDF Complex.

\subsubsection{Maintaining Certification (III.J.3.)}

In DOE Manual 435.1, the maintaining certification requirement is as follows:

Transuranic waste that has been certified as meeting the waste acceptance requirements for transfer to a storage, treatment, or disposal facility shall be managed in a manner that maintains its certification status. 
This requirement is classified as administrative. In the Implementation Guide for use with DOE Manual 435.1, the objective of this requirement is to ensure that certified waste is managed to maintain the certification status and avoid the unnecessary handling of waste containers that would be necessary for recertifying waste.

The ICDF Complex will operate using an integrated waste tracking system. Within the waste tracking system, there are various steps for approval and certification of the waste streams. One of the checks in the system is to verify that the waste profile for the waste stream is within the WAC limits for the facility. The waste tracking system includes all of the operational limits and generates a flags for waste stream that are destined for a facility in the ICDF Complex if that waste exceeds the facility WAC. Movement within the ICDF Complex will be tracked in the waste tracking system to maintain the certification of the waste stream within the ICDF Complex. If the waste stream will be sent to another facility after being at the ICDF Complex, the Material Profile for that waste stream will be compared against the receiving facilities requirements. At that time all Material Profile information for the waste streams will be turned over to an existing INL facility and program dealing with treatment and disposal of TRU waste. This turnover will ensure that the waste stream remains certified for the ICDF Complex and potentially be certified for the treatment and disposal facilities.

This section of DOE Manual 435.1 was not directly cited as an ARAR for the ICDF Complex in the OU 3-13 ROD. In Section 9, waste certification is addressed and shows the associated ARARs and CERCLA documents for the ICDF Complex.

\subsection{Waste Transfer (III.K.)}

In DOE Manual 435.1, the waste transfer requirement is as follows:

A documented process shall be established and implemented for transferring responsibility for management of transuranic waste and for ensuring availability of relevant data.

This requirement is classified as administrative. In the Implementation Guide for use with DOE Manual 435.1, the objective of this requirement is to ensure that the responsibility for TRU waste containers is established, maintained, properly transferred, and adequately documented so that ownership, and therefore responsibility for safe management, of waste is clear. This responsibility includes maintaining the waste characterization information, the container information, and information about the treatment, storage, transportation and disposal status of containers of waste. This responsibility also includes an assurance that the container of waste has not been altered in a manner that affects its certification status or the ability of the waste to be properly managed.

The ICDF Complex will operate using an integrated waste tracking system. Within the waste tracking system, there are various steps for approval and certification of the waste streams. The waste tracking system also includes the information on transfer of responsibility of the waste stream. The waste tracking system also includes all of the characterization data along with the container information. Movement within the ICDF Complex will be tracked in the waste tracking system to maintain the record of waste transfers and changes in responsibility. If the waste stream will be sent to another facility after being at the ICDF Complex, all of the information along with the waste stream will be transferred to an existing INL facility and program dealing with treatment and disposal of TRU waste. This transfer will ensure that the waste stream remains certified for the ICDF Complex and potentially be certified for the treatment and disposal facilities. 
This section of DOE Manual 435.1 was not directly cited as an ARAR for the ICDF Complex in the OU 3-13 ROD. In Section 9, waste transfer is addressed and shows the associated ARARs and CERCLA documents for the ICDF Complex.

Also, there are two major waste certification requirements related to TRU waste. The two requirements are discussed below in Sections 7.11.1 and 7.11.2.

\subsubsection{Authorization (III.K.1.)}

In DOE Manual 435.1, the authorization requirement is as follows:

Authorization - Transuranic waste shall not be transferred to a storage, treatment, or disposal facility until personnel responsible for the facility receiving the waste authorize the transfer.

This requirement is classified as administrative. In the Implementation Guide for use with DOE Manual 435.1, the objective of this requirement is to ensure that shipments or transfers of TRU waste are made only with the cognizance and approval of personnel at the facility receiving waste so that preparations can be assured for its safe management.

The ICDF Complex will operate using an integrated waste tracking system. Within the waste tracking system, there are various steps for approval and certification of the waste streams. Waste can not be received or transferred in the ICDF Complex without the approval process contained in the waste tracking system. Only certain personnel have the authority in the waste tracking system to approve of the waste transfers. This allows for maintaining control of the various waste streams and management of transfers to maintain the ICDF Complex is a safe manner. Movement within the ICDF Complex will be tracked in the waste tracking system to maintain the record of waste transfers and changes in responsibility. If the waste stream will be sent to another facility after being at the ICDF Complex, all of the information along with the waste stream will be transferred to an existing INL facility and program dealing with treatment and disposal of TRU waste. This transfer will ensure that the responsibility for the waste stream is documented and managed in a safe manner.

This section of DOE Manual 435.1 was not directly cited as an ARAR for the ICDF Complex in the OU 3-13 ROD. In Section 9, waste transfer is addressed and shows the associated ARARs and CERCLA documents for the ICDF Complex.

\subsubsection{Data (III.K.2.)}

In DOE Manual 435.1, the data requirement is as follows:

Data - Waste characterization data, container information, and generation, storage, treatment, and transportation information for transuranic waste shall be transferred with or be traceable to the waste.

This requirement is classified as administrative. In the Implementation Guide for use with DOE Manual 435.1, the objective of this requirement is to ensure establishment and maintenance of information about the characteristics of waste and the waste containers to ensure that sufficient information to support management of waste in a manner that is protective of workers, the public, and the environment is always available. 
For the ICDF Complex, waste streams undergo a waste profiling process prior to generation or receipt into the facility. Within this waste profiling process, the available information on the waste stream characteristics is input into the waste tracking system. The waste tracking system includes the physical/chemical characteristics, volume, weights, constituents, and other relevant data. During the waste profiling process, it is occasionally necessary to further characterize the waste stream. This additional information is added into the waste profile contained in the waste tracking system. When the waste is received into the ICDF Complex, additional verification sampling and analysis may be conducted to verify that the waste stream is as stated on the waste profile form. All the information in the waste tracking system is maintained as a record and updated as the waste stream is moved between the various facilities.

This section of DOE Manual 435.1 was not directly cited as an ARAR for the ICDF Complex in the OU 3-13 ROD. In Section 9, waste transfer is addressed and shows the associated ARARs and CERCLA documents for the ICDF Complex.

\subsection{Packaging and Transportation (III.L.)}

In DOE Manual 435.1, there are 2 major packaging and transportation requirements related to TRU waste. Both of these requirements are discussed below in Sections 7.12.1 and 7.12.2.

\subsubsection{Packaging (III.L.1.)}

In DOE Manual 435.1, the packaging requirements are as follows:

Transuranic waste shall be packaged in a manner that provides containment and protection for the duration of the anticipated storage period and until disposal is achieved or until the waste is removed from the container.

Vents or other mechanisms to prevent pressurization of containers or generation of flammable or explosive concentrations of gases shall be installed on containers of newly-generated waste at the time the waste is packaged. Containers of currently stored waste shall meet this requirement as soon as practical unless analyses demonstrate that the waste can otherwise be managed safely.

When transuranic waste is packaged, defense waste shall be packaged separately from non-defense waste, if feasible.

Containers of transuranic waste shall be marked such that their contents can be identified.

This requirement is classified as administrative. In the Implementation Guide for use with DOE Manual 435.1, the objective of these requirements is to ensure that when waste is packaged, the container selected is adequate to contain the waste and limit radiation exposure for the entire time the waste is in storage, to reduce future exposure by segregating defense and nondefense wastes, and to ensure that the container can be correlated to necessary information on its contents. The first subrequirement is to ensure the selection of a container for waste based on the life cycle of the waste so that there will not be unnecessary repackaging of waste. The second subrequirement is to prevent the build-up of pressure or concentrations of gases that could cause a loss of waste confinement. The third subrequirement is to ensure the segregation of defense waste that can be accepted for disposal at Waste Isolation Pilot Plant (WIPP) from other waste in order to facilitate compliance with the Waste Isolation Pilot Plant Land Withdrawal Act of 1992, as amended. The last subrequirement is to ensure that it is possible to identify 
the contents of the container of waste during storage and when the waste is removed from storage for treatment or disposal without having to open the container.

Waste can be received into the ICDF in a variety of container or transport vessels. The shipments into the ICDF Complex may result in bulk material being delivered without a containment container. However, for waste streams that are classified as TRU waste, the waste stream will be received in containers designed for containment of the waste material. These containers will be sufficiently robust to remain protective for the duration of the storage and until the anticipated disposal period. When the waste is ready for disposal, the waste stream will be transferred to an existing INL facility and program dealing with the disposal of TRU waste.

For storage of waste at the ICDF Complex, the constituents in the waste stream will be evaluated for the possibility of generating pressure in the container. If there is the possibility of generating pressure, then the containers will appropriately vented. For waste streams that do not have the possibility of generating pressures of the time period through disposal, then vents will not be required.

There are no specific requirements in the ICDF Complex WAC related to defense versus nondefense waste. When it is time for the waste that has been received into the ICDF Complex to be disposed, the appropriate determination will be made and the waste sent to the applicable disposal facility.

Appropriate markings will be placed on the containers of waste that is classified as TRU waste. These markings will be visible and used to ensure that the TRU waste is managed appropriately.

This section of DOE Manual 435.1 was not directly cited as an ARAR for the ICDF Complex in the OU 3-13 ROD. In Section 9, packaging is addressed and shows the associated ARARs and CERCLA documents for the ICDF Complex.

\subsubsection{Transportation (III.L.2.)}

In DOE Manual 435.1, the packaging requirement is as follows:

To the extent practical, the volume of waste and number of transuranic waste shipments shall be minimized.

This requirement is classified as administrative. In the Implementation Guide for use with DOE Manual 435.1, the objective of this requirement is to reduce the risk associated with TRU waste management by reducing the number of miles traveled transporting waste. This is to be done by the efficient use of waste containers, minimizing the volume of waste which requires shipment, and optimizing shipping plans and schedules.

The ICDF Complex is not intended to generate TRU waste, but to serve as an temporary storage facility for INL CERCLA TRU waste that is generated as a result of implementing remediation (remedial and removal) projects. A part of the planning for generating a waste stream, the use of containers is considered and the number of containers is minimized as practical. When it is time to dispose of TRU waste in temporary storage at the ICDF Complex, the waste will be transferred to the existing INL facilities and program dealing with the disposal of TRU waste. These existing facilities and programs work to minimize the transportation issues associated with TRU waste.

This section of DOE Manual 435.1 was not directly cited as an ARAR for the ICDF Complex in the OU 3-13 ROD. In Section 9, transportation is addressed and shows the associated ARARs and CERCLA documents for the ICDF Complex. 


\subsection{Site Evaluation and Facility Design (III.M.)}

In DOE Manual 435.1, there are two major site evaluation and facility design requirements related to TRU waste. Both of these requirements are discussed below in Sections 7.13.1 and 7.13.2.

\subsubsection{Site Evaluation (III.M.1.)}

In DOE Manual 435.1, the site evaluation requirements are as follows:

Site Evaluation - Proposed locations for transuranic waste facilities shall be evaluated to identify relevant features that should be avoided or must be considered in facility design and analyses.

Each site proposed for a new transuranic waste facility or expansion of an existing transuranic waste facility shall be evaluated considering environmental characteristics, geotechnical characteristics, and human activities.

Proposed sites with environmental characteristics, geotechnical characteristics, and human activities for which adequate protection cannot be provided through facility design shall be deemed unsuitable for the location of the facility.

This requirement is classified as substantive. In the Implementation Guide for use with DOE Manual 435.1, the objective of this requirement is to ensure that natural and human environmental factors and geotechnical characteristics of proposed sites are accounted for in selecting the location and design features of new TRU waste management facilities or significant modifications of existing facilities, and that locations are avoided if facility design cannot compensate for negative site characteristics or environmental conditions.

This requirement is classified as substantive. Site evaluation was a significant issue for the ICDF Complex. The site for the ICDF Complex was selected based on many criteria. These criteria were presented in the OU 3-13 ROD and consisted of general criteria of (1) public health and safety, (2) natural environment, (3) technical, (4) social economic environment, (5) cultural environment, and (6) community acceptance. The most significant major criteria from a design and siting issues are the subcriteria for public health and safety (effect on surface design, effects on surface water, effects on groundwater, proximity to fire, ambulance, and emergency services, elevation above flood plain, and transportation difficulty) and for technical (depth to bedrock, geological fault proximity, underlying soil permeability and attenuation capacity, earthquake epicenter proximity, perched water proximity, ease of monitoring, and soil suitability for engineered structures). Many of the criteria that were used are also used by the NRC in the site suitability and selection criteria for commercial LLW disposal facilities. Based on these criteria, an area southwest of INTEC was selected for the ICDF Complex. A geophysical and geotechnical study was conducted in the selected area, which resulted in the selected site for the ICDF Complex.

This section of DOE Manual 435.1 was not directly cited as an ARAR for the ICDF Complex in the OU 3-13 ROD. In Section 9, facility evaluation is addressed and shows the associated ARARs and CERCLA documents for the ICDF Complex.

\subsubsection{Facility Design (III.M.2.)}

In DOE Manual 435.1, the facility requirements and general design criteria, at a minimum, are as follows:

Confinement - Transuranic waste systems and components shall be designed to maintain waste confinement. 
Ventilation - Design of transuranic waste treatment and storage facilities shall include ventilation through an appropriate filtration system to maintain the release of radioactive material in airborne effluents within the requirements and guidelines specified in applicable regulations and DOE Orders.

When conditions exist for generating gases in flammable or explosive concentrations in treatment or storage facilities, ventilation or other measures shall be provided to keep the gases in a non-flammable and non-explosive condition. When concentrations of explosive and flammable gases are expected to approach the lower flammability limit, measures shall be taken to prevent deflagration or detonation.

Consideration of Decontamination and Decommissioning - Areas in new and modifications to existing transuranic waste management facilities that are subject to contamination with radioactive or other hazardous materials shall be designed to facilitate decontamination. For other facilities a proposed decommissioning method or a conversion method leading to reuse shall be described.

Instrumentation and Control Systems - Engineering controls shall be incorporated in the design and engineering of transuranic waste treatment and storage facilities to provide volume inventory data and to prevent spills, leaks, and overflows from tanks or confinement systems.

Monitoring - Monitoring and/or leak detection capabilities shall be incorporated in the design and engineering of transuranic waste storage, treatment, and disposal facilities to provide rapid identification of failed confinement and/or other abnormal conditions.

This requirement is classified as substantive. In the Implementation Guide for use with DOE Manual 435.1, the objectives of this requirement are to ensure that a minimum set of facility requirements and general design requirements determined from hazards analyses or policy considerations are applied to TRU waste management facilities; ensure that the design of TRU waste management facilities and equipment include features necessary to prevent the uncontrolled releases of radioactive materials; ensure that airborne effluents released from TRU waste management facilities are in accordance with applicable DOE Orders and external regulations, and to preclude or mitigate the accumulation of flammable or explosive gases which could lead to fire or explosion and the uncontrolled release of radioactive material; ensure the incorporation of the concept of life-cycle waste management into the design and construction of radioactive waste management facilities to minimize the amount of radioactive waste that must be managed in the future from D\&D\&D activities, and to reduce the number of facilities that must be dismantled due to contamination rather than reused for another beneficial purpose; ensure that engineered controls are included in the design of TRU waste storage and treatment facilities to minimize the likelihood of release of radionuclides that could lead to exposures or contamination of the environment; and ensure the design and installation of equipment capable of identifying failures in containing TRU waste and other conditions that could result in exposure of the public, workers or releases to the environment.

The ICDF Complex is only intended to take limited quantities of TRU waste for temporary storage. This temporary storage is intended to last until another INL facility can accept the TRU waste for disposition. The TRU waste will be required to be contained in appropriate containers (e.g., drums). Bulk receipt of TRU waste is not acceptable for the ICDF Complex. There are no facilities within the ICDF Complex to package bulk TRU into appropriate containers. 
The containers of TRU waste at the ICDF Complex will be stored at the SSA (CPP-1789). This is a fenced paved storage facility under INL CERCLA control. The containers are periodically inspected for a variety of criteria including container condition. If the containers are degrading, the containers are repaired or overpacked. These requirements will also apply to TRU waste in storage at the ICDF Complex. This will ensure that adequate confinement for the TRU waste is maintained.

The containers of TRU waste will be vented if necessary. This determination will be based on the waste constituents in the container. If the waste will generate a gaseous phase during storage, the container will include vents designed to control the release of radioactive and other material to acceptable levels. This will ensure that adequate ventilation, if necessary, is available for the stored TRU waste.

The ICDF Complex is not intended to accept waste that can result in explosive or flammable concentration of gases. If the waste material is expected to generate concentrations of gases that would be capable of creating a fire or explosion, additional requirements would be imposed on the container of waste. These additional requirements could include forced ventilation or other methods to control the concentrations of gases in the waste container to levels below concern. Information on the makeup of the waste is included on the waste profile, which must be accepted before the waste can be received into the ICDF Complex. Storage of waste which may generate these concentrations of gases would be strictly limited and controlled at the ICDF Complex to remain within the hazard analysis for the ICDF Complex.

Storage of TRU waste at the ICDF Complex will only occur in containers. This minimizes the amount of D\&D\&D necessary at the ICDF Complex in relation to TRU waste. In the unlikely event that a spill of TRU waste occurs during the storage, the spill will be immediately cleaned up when discovered.

The volume of waste, including TRU waste, at the ICDF Complex will be known at all times. A running inventory of the waste in the various ICDF Complex facilities is maintained in the waste tracking system. The ICDF Complex is not intended to deal with TRU waste except in a storage capacity. The use of properly designed containers at the ICDF Complex reduces the likelihood of a spill of TRU waste.

At the ICDF Complex, inspections are conducted periodically. These inspections look for signs of container deterioration, bulging, and other indicators. These indications are used to identify abnormal conditions that could result in the release of waste materials to the environment. When an abnormal or deteriorating condition is identified for a container, the container is repaired or overpacked as necessary to prevent the release of waste materials.

This section of DOE Manual 435.1 was not directly cited as an ARAR for the ICDF Complex in the OU 3-13 ROD. In Section 9, facility design is addressed and shows the associated ARARs and CERCLA documents for the ICDF Complex.

\subsection{Storage (III.N.)}

In DOE Manual 435.1, there are four major site evaluation and facility design requirements related to TRU waste. Both of these requirements are discussed below in Sections 7.14.1 through 7.14.4.

\subsubsection{Storage Prohibitions (III.N.1.)}

In DOE Manual 435.1, the storage prohibitions requirements are as follows:

Storage Prohibitions - Transuranic waste in storage shall not be readily capable of detonation, explosive decomposition, reaction at anticipated pressures and 
temperatures, or explosive reaction with water. Prior to storage, pyrophoric materials shall be treated, prepared, and packaged to be nonflammable.

This requirement is classified as substantive. In the Implementation Guide for use with DOE Manual 435.1, the objective of this requirement is to promote safe storage of TRU waste by eliminating from storage materials which could result in fires or explosions due to their reactivity or ignitability.

Limited quantities of TRU waste may be received into the ICDF Complex for temporary storage. The ICDF Complex is not intended to accept waste that can result in explosive or flammable concentration of gases. If the waste material is expected to generate concentrations of gases that would be capable of creating a fire or explosion, additional requirements would be imposed on the container of waste. These additional requirements could include forced ventilation or other methods to control the concentrations of gases in the waste container to levels below concern. Information on the makeup of the waste is included on the waste profile, which must be accepted before the waste can be received into the ICDF Complex. Storage of waste which may generate these concentrations of gases would be strictly limited and controlled at the ICDF Complex to remain within the hazard analysis for the ICDF Complex. Waste materials with a pyrophoric nature are restricted from receipt at the ICDF Complex as they are capable of reacting violently with water. If waste material with pyrophoric constituents are to be received into the ICDF Complex, the waste material must be rendered no reactive prior to receipt to remain within the hazard analysis.

This section of DOE Manual 435.1 was not directly cited as an ARAR for the ICDF Complex in the OU 3-13 ROD. In Section 9, storage is addressed and shows the associated ARARs and CERCLA documents for the ICDF Complex.

\subsubsection{Storage Integrity (III.N.2.)}

In DOE Manual 435.1, the storage integrity requirement is as follows:

Storage Integrity - Transuranic waste shall be stored in a location and manner that protects the integrity of waste for the expected time of storage and minimizes worker exposure.

This requirement is classified as substantive. In the Implementation Guide for use with DOE Manual 435.1, the objective of this requirement is to ensure that the selection of the location and method for storing TRU waste is made so that both workers and the containers of waste are provided with adequate protection.

The ICDF Complex is only intended to take limited quantities of TRU waste for temporary storage. This temporary storage is intended to last until another INL facility can accept the TRU waste for disposition. The TRU waste will be required to be contained in appropriate containers (e.g., drums). Bulk receipt of TRU waste is not acceptable for the ICDF Complex. There are no facilities within the ICDF Complex to package bulk TRU into appropriate containers.

The containers of TRU waste at the ICDF Complex will be stored at the SSA (CPP-1789). This is a fenced paved storage facility under INL CERCLA control. The containers are periodically inspected for a variety of criteria including container condition. If the containers are degrading, the containers are repaired or overpacked. These requirements will also apply to TRU waste in storage at the ICDF Complex. This will ensure that the container integrity is maintained and the workers are provided with adequate protection for exposure to TRU waste materials. 
This section of DOE Manual 435.1 was not directly cited as an ARAR for the ICDF Complex in the OU 3-13 ROD. In Section 9, storage is addressed and shows the associated ARARs and CERCLA documents for the ICDF Complex.

\subsubsection{Container Inspection (III.N.3.)}

In DOE Manual 435.1, the container inspection requirement is as follows:

Container Inspection - A process shall be developed and implemented for inspecting and maintaining containers of transuranic waste to ensure container integrity is not compromised.

This requirement is classified as substantive. In the Implementation Guide for use with DOE Manual 435.1, the objective of this requirement is to prevent or minimize the potential exposure of workers and release of radioactive contamination to the environment that could result from allowing TRU waste containers to degrade. The requirement is intended to ensure that the confinement abilities of containers is routinely evaluated and action taken to ensure the waste remains contained.

The ICDF Complex is only intended to take limited quantities of TRU waste for temporary storage. This temporary storage is intended to last until another INL facility can accept the TRU waste for disposition. The TRU waste will be required to be contained in appropriate containers (e.g., drums). Bulk receipt of TRU waste is not acceptable for the ICDF Complex. There are no facilities within the ICDF Complex to package bulk TRU into appropriate containers.

At the ICDF Complex, inspections are conducted periodically. These inspections look for signs of container deterioration, bulging, and other indicators. These indications are used to identify abnormal conditions that could result in the release of waste materials to the environment. When an abnormal or deteriorating condition is identified for a container, the container is repaired or overpacked as necessary to prevent the release of waste materials.

This section of DOE Manual 435.1 was not directly cited as an ARAR for the ICDF Complex in the OU 3-13 ROD. In Section 9, storage is addressed and shows the associated ARARs and CERCLA documents for the ICDF Complex.

\subsubsection{Retrievable Earthen-Covered Storage (III.N.4.)}

In DOE Manual 435.1, the retrievable earthen-covered storage requirements are as follows:

Retrievable Earthen-Covered Storage - Plans for the removal of transuranic waste from retrievable earthen-covered storage facilities shall be established and maintained. Prior to commencing waste retrieval activities, each waste storage site shall be evaluated to determine relevant information on types, quantities, and location of radioactive and hazardous chemicals as necessary to protect workers during the retrieval process.

This requirement is classified as substantive. In the Implementation Guide for use with DOE Manual 435.1, the objective of this requirement is to promote the removal of retrievably-stored TRU waste from earthen-covered storage and its transfer to subsequent waste management facilities where there is less potential of release to the environment. Additionally, the purpose of the requirement is to ensure that, to the extent practical, information about the waste is collected and analyzed so hazards associated with the waste can be mitigated through selection of equipment, development of procedures, and implementation of work practices. 
This requirement is classified as administrative. There are no earthen covered storage facilities at the ICDF Complex. This specific requirement was not identified as an ARAR or TBC in the OU 3-13 ROD and is not specifically addressed in other CERCLA documents for the ICDF Complex.

\subsection{Treatment (III.O.)}

In DOE Manual 435.1, the treatment requirement is as follows:

Transuranic waste shall be treated as necessary to meet the waste acceptance requirements of the facility receiving the waste for storage or disposal.

This requirement is classified as substantive. In the Implementation Guide for use with DOE Manual 435.1, the objective of this requirement is to emphasize that TRU waste must be treated as necessary to meet the waste acceptance requirements of the storage, or disposal facility or facilities to which it will be transferred.

The ICDF Complex is only intended to take limited quantities of TRU waste for temporary storage. This temporary storage is intended to last until another INL facility can accept the TRU waste for disposition. Only TRU waste meeting the ICDF Complex WAC will allowed to be received into the ICDF Complex. If treatment is necessary for to meet the ICDF Complex WAC, the treatment will occur prior to receipt. For disposition (disposal) of the waste, the waste will be transferred to an existing INL facility and program that deals with the treatment, as necessary, and disposal of the TRU waste.

This section of DOE Manual 435.1 was not directly cited as an ARAR for the ICDF Complex in the OU 3-13 ROD. In Section 9, treatment is addressed and shows the associated ARARs and CERCLA documents for the ICDF Complex.

\subsection{Disposal (III.P.)}

In DOE Manual 435.1, the disposal requirement is as follows:

Transuranic waste shall be disposed in accordance with the requirements of 40 CFR Part 191, Environmental Radiation Protection Standard for Management and Disposal of Spent Nuclear Fuel, High-Level and Transuranic Wastes.

This requirement is classified as substantive. In the Implementation Guide for use with DOE Manual 435.1, the objective of this requirement is to ensure TRU waste is disposed of in a facility that meets the appropriate regulatory requirements and to establish Headquarters as the DOE authority for making compliance determinations for TRU waste disposal facilities other than WIPP.

The ICDF Complex is only intended to take limited quantities of TRU waste for temporary storage. This temporary storage is intended to last until another INL facility can accept the TRU waste for disposition. For disposition (disposal) of the waste, the waste will be transferred to an existing INL facility and program that deals with the treatment, as necessary, and disposal of the TRU waste.

This section of DOE Manual 435.1 was not directly cited as an ARAR for the ICDF Complex in the OU 3-13 ROD. In Section 9, disposal is addressed and shows the associated ARARs and CERCLA documents for the ICDF Complex. 


\subsection{Monitoring (III.Q.)}

In DOE Manual 435.1, there are three major monitoring requirements related to TRU waste. Both of these requirements are discussed below in Sections 7.17.1 through 7.17.3.

\subsubsection{All Waste Facilities (III.Q.1.)}

In DOE Manual 435.1, the all facilities requirements are as follows:

All Waste Facilities - Parameters that shall be sampled or monitored, at a minimum, include: temperature, pressure (for closed systems), radioactivity in ventilation exhaust and liquid effluent streams, and flammable or explosive mixtures of gases. Facility monitoring programs shall include verification that passive and active control systems have not failed.

This requirement is classified as substantive. In the Implementation Guide for use with DOE Manual 435.1, the objective of this requirement is to specify minimum parameters for which information will be routinely collected and analyzed for the purpose of anticipating or identifying undesirable conditions in the management of TRU waste.

The ICDF Complex is only intended to take limited quantities of TRU waste for temporary storage. This temporary storage is intended to last until another INL facility can accept the TRU waste for disposition. Waste being received into the ICDF Complex undergoes characterization to support the waste profile. This characterization includes both process knowledge and physical sampling and analysis as necessary. Further sampling and analysis may be conducted for verification of the waste profile. This information is used to assess whether the waste meets the WAC. TRU waste will only be stored within the ICDF Complex at the SSA (CPP-1789). This is a fenced and paved storage area. The temperature of the stored waste will assume ambient conditions and there is no possibility of building pressure in the storage facility nor is there a ventilation system. The ventilation will occur on the waste containers. Routine monitoring will be conducted as part of the periodic inspection of the containers in the storage areas at the ICDF Complex. These inspections will look for signs of damage, deterioration, and other indicators of problems. If issues are identified, appropriate actions will be taken to mitigate the risks.

This section of DOE Manual 435.1 was not directly cited as an ARAR for the ICDF Complex in the OU 3-13 ROD. In Section 9, monitoring is addressed and shows the associated ARARs and CERCLA documents for the ICDF Complex.

\subsubsection{Stored Waste (III.Q.2.)}

In DOE Manual 435.1, the stored waste requirement is as follows:

Stored Wastes - All transuranic waste in storage shall be monitored, as prescribed by the appropriate facility safety analysis, to ensure the waste are maintained in safe conditions.

This requirement is classified as substantive. In the Implementation Guide for use with DOE Manual 435.1, the objective of this requirement is to ensure that the results of safety analyses performed as part of the authorization of TRU waste facility operations are appropriately translated into monitoring requirements for waste storage so conditions that could lead to exposure of the public or workers, or releases to the environment are detected and mitigated. 
The ICDF Complex is only intended to take limited quantities of TRU waste for temporary storage. This temporary storage is intended to last until another INL facility can accept the TRU waste for disposition. The hazard analysis performed for the ICDF Complex evaluated the materials that could be at risk for each facility in the ICDF Complex. This hazard analysis considered the impacts on the materials at risk on the worker, public, and the environment. While, the hazard analysis did not result in specific monitoring requirements, the control of the inventories is a limit. Each of these individual facilities have limits on what can be in the inventory at any one time. The waste tracking system at the ICDF Complex contains the limits for the acceptable inventories. Exceeding the inventories will trigger a flag in the waste tracking system requiring action to be taken to get the facility back within the acceptable limits.

This section of DOE Manual 435.1 was not directly cited as an ARAR for the ICDF Complex in the OU 3-13 ROD. In Section 9, monitoring is addressed and shows the associated ARARs and CERCLA documents for the ICDF Complex.

\subsubsection{Liquid Waste Storage Facilities (III.Q.3.)}

In DOE Manual 435.1, the liquid waste storage facilities requirement is as follows:

Liquid Waste Storage Facilities - For facilities storing liquid transuranic waste, the following shall also be monitored: liquid level and/or waste volume, and significant waste chemistry parameters.

This requirement is classified as substantive. In the Implementation Guide for use with DOE Manual 435.1, the objective of this requirement is to ensure monitoring of parameters that indicate the quantity of liquid TRU waste stored in tanks so that changes can be promptly checked to determine if they indicate leakage, overfilling, or other problems. The objective of this requirement also includes tracking of the chemical characteristics of the waste to anticipate and avert undesirable storage conditions.

The ICDF Complex is only intended to take limited quantities of TRU waste for temporary storage. This temporary storage is intended to last until another INL facility can accept the TRU waste for disposition. Waste being received into the ICDF Complex must undergo characterization to support the waste profile. This characterization includes both process knowledge and physical sampling and analysis as necessary. Further sampling and analysis may be conducted for verification of the waste profile. For liquid waste, the chemistry of the waste is sampled to for a variety of parameters to ensure that the waste is compatible with the expected waste containers. This information is used to assess whether the waste meets the WAC. TRU waste will only be stored within the ICDF Complex at the SSA. This is a fenced and paved storage area. The tanks used to store liquid waste in the ICDF Complex are double contained. The outer container is monitored to detect leakage of the primary container. If the primary container is leaking the waste would be transferred to another tank.

This section of DOE Manual 435.1 was not directly cited as an ARAR for the ICDF Complex in the OU 3-13 ROD. In Section 9, monitoring is addressed and shows the associated ARARs and CERCLA documents for the ICDF Complex. 


\section{LOW-LEVEL WASTE (DOE ORDER 435.1, CHAPTER IV)}

Chapter IV of DOE Manual 435.1 deals with the management of LLW. This section of the ICDF Complex compliance demonstration discusses the requirements for the management of LLW contained in DOE Manual 435.1. An evaluation is presented to determine whether requirements for management of LLW in Chapter IV of DOE Manual 435.1 are administrative or substantive (see Section 1.1) in function. If the requirements for LLW management is administrative, minimal additional discussion is presented. For the substantive requirements and responsibilities under DOE Manual 435.1, additional information is presented on (1) how the requirement or responsibility is being satisfied, (2) if the requirement or responsibility was identified as an ARARs or TBCs, and (3) references to Section 9 discussing the CERCLA documents that provide supplemental and/or supporting information regarding the how the requirement or responsibility is met.

Within Chapter IV, the requirements for management of are organized into 18 major sections. The 18 major sections include the topics of site evaluation, facility design, storage, treatment, disposal, monitoring, and waste acceptance. These responsibilities are discussed in Sections 8.1 through 8.18.

\subsection{Definition of Low-Level Waste (IV.A.)}

In DOE Manual 435.1, the definition of LLW is as follows:

Low-level radioactive waste is radioactive waste that is not high-level radioactive waste, spent nuclear fuel, transuranic waste, byproduct material (as defined in Section 11e.(2) of the Atomic Energy Act of 1954, as amended), or naturally occurring radioactive material.

This requirement is classified as substantive. In the Implementation Guide for use with DOE Manual 435.1, the objective of this requirement is to provide the criteria for determining which DOE radioactive wastes are to be managed as LLW in accordance with DOE M 435.1, Chapter IV, Low-Level Waste Requirements.

The definition provided above is the definition that is being used for the ICDF Complex. This section of DOE Manual 435.1 was not directly cited as an ARAR for the ICDF Complex in the OU 3-13 ROD. In Section 9, LLW is addressed and shows the associated ARARs and CERCLA documents dealing with LLW for the ICDF Complex.

\subsection{Management of Specific Wastes (IV.B.)}

In DOE Manual 435.1, there are four major management of specific waste requirements related to LLW. Both of these requirements are discussed below in Sections 8.2.1 through 8.2.4.

\subsubsection{Mixed Low-Level Waste (IV.B.1.)}

In DOE Manual 435.1, the management of MLLW requirements are as follows:

Mixed Low-Level Waste. Low-level waste determined to contain both source, special nuclear, or byproduct material subject to the Atomic Energy Act of 1954, as amended, and a hazardous component subject to the Resource Conservation and Recovery Act (RCRA), as amended, shall be managed in accordance with the requirements of RCRA and DOE O 435.1, Radioactive Waste Management, and Manual. 
This requirement is classified as substantive. In the Implementation Guide for use with DOE Manual 435.1, the purpose of this requirement is to ensure that DOE LLW is managed in accordance with the applicable requirements of external regulations, specifically those of the RCRA, that address nonradiological hazards, in addition to being managed in accordance with the requirements of DOE O 435.1 and the Radioactive Waste Management Manual, DOE M 435.1-1

The ICDF Complex has been designed and is being constructed to deal with hazardous waste constituents. Management of the various waste streams at the ICDF Complex consider all of the constituents in the waste including the RCRA and radionuclide constituents. This section of DOE Manual 435.1 was not directly cited as an ARAR for the ICDF Complex in the OU 3-13 ROD. In Section 9, MLLW is addressed and shows the associated ARARs and CERCLA documents dealing with the MLLW for the ICDF Complex.

\subsubsection{TSCA-Regulated Waste (IV.B.2.)}

In DOE Manual 435.1, the management of TSCA-regulated waste requirement is as follows:

TSCA-Regulated Waste. Low-level waste containing polychlorinated biphenyls, asbestos, or other such regulated toxic components shall be managed in accordance with requirements derived from the Toxic Substances Control Act, as amended, DOE O 435.1, Radioactive Waste Management, and Manual.

This requirement is classified as substantive. In the Implementation Guide for use with DOE Manual 435.1, the purpose of this requirement is to ensure that DOE LLW is managed in accordance with the applicable requirements of external regulations, specifically those of the TSCA, that address nonradiological hazards, in addition to being managed in accordance with the requirements of DOE O 435.1 and the Radioactive Waste Management Manual, DOE M 435.1-1.

The ICDF Complex has been designed and is being constructed to deal with hazardous waste constituents. Management of the various waste streams at the ICDF Complex consider all of the constituents in the waste including the TSCA and radionuclide constituents. This section of DOE Manual 435.1 was not directly cited as an ARAR for the ICDF Complex in the OU 3-13 ROD. In Section 9, MLLW is addressed and shows the associated ARARs and CERCLA documents dealing with the MLLW for the ICDF Complex.

\subsubsection{Accelerator-Produced Waste (IV.B.3.)}

In DOE Manual 435.1, the management of accelerator-produced waste requirement is as follows:

Accelerator-Produced Waste. Radioactive waste produced as a result of operations of DOE accelerators is low-level waste and shall be managed in accordance with DOE O 435.1, Radioactive Waste Management, and Manual, and all applicable Federal or State requirements.

This requirement is classified as substantive. In the Implementation Guide for use with DOE Manual 435.1, the purpose of this requirement is to allow for the management of certain other radioactive wastes as LLW that are the responsibility of the department under the Atomic Energy Act of 1954, as amended. 
The ICDF Complex is not expected to deal with accelerator produced waste streams. This specific responsibility was not identified as an ARAR or TBC in the OU 3-13 ROD and is not specifically addressed in other CERCLA documents for the ICDF Complex.

\subsubsection{1e.(2) and Naturally Occurring Radioactive Material (IV.B.4.)}

In DOE Manual 435.1, the management 11e.(2) and naturally occurring radioactive material requirement is as follows:

11e.(2) and Naturally Occurring Radioactive Material. Small quantities of

11e.(2) byproduct material and naturally occurring radioactive material may be managed as low- level waste provided they can be managed to meet the requirements for low-level waste disposal in Section IV.P of the Manual.

This requirement is classified as substantive. In the Implementation Guide for use with DOE Manual 435.1, the purpose of this requirement is to allow for the management of certain other radioactive wastes as LLW that are the responsibility of the department under the Atomic Energy Act of 1954, as amended.

The ICDF Complex is not expected to deal with naturally occurring radioactive material waste streams. This specific responsibility was not identified as an ARAR or TBC in the OU 3-13 ROD and is not specifically addressed in other CERCLA documents for the ICDF Complex.

\subsection{Complex-Wide Low-Level Waste Management Program (IV.C.)}

In DOE Manual 435.1, the complex-wide LLW management program requirement is as follows:

A complex-wide program and plan shall be developed as described under Responsibilities, 2.B and 2.C, in Chapter I of DOE Manual 435.1.

This requirement is classified as substantive. In the Implementation Guide for use with DOE Manual 435.1, the objective of this requirement is to ensure the development, documentation, and implementation of a complex-wide LLW management program to provide for cost efficient and integrated management of LLW throughout the complex and within individual site radioactive waste management programs. MLLW is, as appropriate, reflected in LLW plans and through its own program plan.

The ICDF Complex is specifically limited to INL CERCLA waste. As such, this responsibility is not directly or substantively related to the design, construction, operation, and closure of the ICDF Complex. No additional information concerning this responsibility is included in this compliance demonstration. This specific responsibility was not identified as an ARAR or TBC in the OU 3-13 ROD and is not specifically addressed in other CERCLA documents for the ICDF Complex.

\subsection{Radioactive Waste Management Basis (IV.D.)}

In DOE Manual 435.1, the radioactive waste management basis requirement is as follows:

Low-level waste facilities, operations, and activities shall have a radioactive waste management basis consisting of physical and administrative controls to ensure the protection of workers, the public, and the environment. 
In DOE Manual 435.1, there are 4 additional specific controls required for the radioactive waste management basis for LLW. These requirements are discussed below in Sections 8.4.1 through 8.4.4.

\subsubsection{Generators (IV.D.1.)}

In DOE Manual 435.1, the generator requirement is as follows:

Generators. The waste certification program.

This requirement is classified as substantive. In the Implementation Guide for use with DOE Manual 435.1, the objective of this requirement is to ensure that the hazards associated with LLW management facilities, operations, and activities have been identified, their potential impacts analyzed, and appropriate controls documented, implemented, and maintained for the protection of workers, the public, and the environment.

The ICDF Complex has been designed and is being constructed to safely manage radioactive waste. Impacts from the management of radioactive waste constituents and other constituents have analyzed. These impacts were determined to be acceptable. Some limited sampling and analysis of the waste being received into the ICDF Complex will be conducted. Certification of these LLW streams occurs during the waste profiling and approval processes. This section of DOE Manual 435.1 was not directly cited as an ARAR for the ICDF Complex in the OU 3-13 ROD. In Section 9, LLW is addressed and shows the associated ARARs and CERCLA documents dealing with the LLW for the ICDF Complex.

\subsubsection{Treatment Facilities (IV.D.2.)}

In DOE Manual 435.1, the generator requirement is as follows:

Treatment Facilities. The waste acceptance requirements and the waste certification program.

This requirement is classified as substantive. In the Implementation Guide for use with DOE Manual 435.1, the objective of this requirement is to ensure that the hazards associated with LLW management facilities, operations, and activities have been identified, their potential impacts analyzed, and appropriate controls documented, implemented, and maintained for the protection of workers, the public, and the environment.

The ICDF Complex has been designed and is being constructed to safely manage radioactive waste. Impacts from the management of radioactive waste constituents and other constituents have analyzed. These impacts were determined to be acceptable. One of the operations that will be conducted at the ICDF Complex is the treatment of LLW streams. The existing design of the ICDF Complex is sufficient to allow for the treatment of LLW. Following treatment, the waste will be sampled to ensure that the waste meets the WAC requirements. This section of DOE Manual 435.1 was not directly cited as an ARAR for the ICDF Complex in the OU 3-13 ROD. In Section 9, LLW is addressed and shows the associated ARARs and CERCLA documents dealing with the LLW for the ICDF Complex. 


\subsubsection{Storage Facilities (IV.D.3.)}

In DOE Manual 435.1, the storage facilities requirement is as follows:

Storage Facilities. The waste acceptance requirements and the waste certification program.

This requirement is classified as substantive. In the Implementation Guide for use with DOE Manual 435.1, the objective of this requirement is to ensure that the hazards associated with LLW management facilities, operations, and activities have been identified, their potential impacts analyzed, and appropriate controls documented, implemented, and maintained for the protection of workers, the public, and the environment.

The ICDF Complex has been designed and is being constructed to safely manage radioactive waste. Impacts from the management of radioactive waste constituents and other constituents have analyzed. These impacts were determined to be acceptable. One of the operations that will be conducted at the ICDF Complex is the staging and storage of waste streams. The existing design of the ICDF Complex is sufficient to allow for the storage of LLW. This section of DOE Manual 435.1 was not directly cited as an ARAR for the ICDF Complex in the OU 3-13 ROD. In Section 9, LLW is addressed and shows the associated ARARs and CERCLA documents dealing with the LLW for the ICDF Complex.

\subsubsection{Disposal Facilities (IV.D.4.)}

In DOE Manual 435.1, the disposal facilities requirement is as follows:

Disposal Facilities. The performance assessment, composite analysis, disposal authorization statement, closure plan, waste acceptance requirements, and monitoring plan.

This requirement is classified as substantive. In the Implementation Guide for use with DOE Manual 435.1, the objective of this requirement is to ensure that the hazards associated with LLW management facilities, operations, and activities have been identified, their potential impacts analyzed, and appropriate controls documented, implemented, and maintained for the protection of workers, the public, and the environment.

The ICDF Complex has been designed and is being constructed to safely manage radioactive waste. Impacts from the management of radioactive waste constituents and other constituents have analyzed. These impacts were determined to be acceptable. All pathways for potential exposure were analyzed for impacts with the results all being acceptable. One of the operations that will be conducted at the ICDF Complex is the disposal of LLW streams. The existing design of the ICDF Complex is sufficient to allow for the safe disposal of LLW. This section of DOE Manual 435.1 was not directly cited as an ARAR for the ICDF Complex in the OU 3-13 ROD. In Section 9, LLW is addressed and shows the associated ARARs and CERCLA documents dealing with the LLW for the ICDF Complex.

\subsection{Contingency Actions (IV.E.)}

In DOE Manual 435.1, there are two major contingency action requirements in addition to the requirements in Chapter I of DOE Manual 435.1. These additional requirements are presented in Sections 8.5.1 and 8.5.2. 


\subsubsection{Contingency Storage (IV.E.1.)}

In DOE Manual 435.1, the additional contingency storage requirements are as follows:

Contingency Storage. For off-normal or emergency situations involving high activity or high hazard liquid low-level waste storage or treatment, spare capacity with adequate capabilities shall be maintained to receive the largest volume of liquid contained in any one storage tank or treatment facility. Tanks or other facilities that are designated low-level waste contingency storage shall be maintained in an operational condition when waste is present and shall meet the requirements of DOE O 435.1, Radioactive Waste Management, and Manual.

This requirement is classified as substantive. In the Implementation Guide for use with DOE Manual 435.1, the objective of this requirement is to mitigate the impacts on the public, workers, or environment in the event that a leak develops in a tank storing high activity or high hazard liquid LLW or in a facility processing such waste. The mitigation is provided by ensuring spare waste storage capacity is a required part of a site's emergency management program. To meet this objective, there needs to be both capacity to handle the largest volume of any single storage tank or liquid waste in process and the capability to transfer the waste.

The ICDF Complex has been designed and is being constructed to safely manage liquid radioactive waste. The ICDF Complex has tanks to store liquid waste. Also, there are sumps and other areas that can collect liquid waste. Each of these systems has secondary containment to catch leaks from the primary tank or structure. There is additional tank capacity that will be available at the ICDF Complex for the liquid waste in case a tank or other structure springs a leak. This section of DOE Manual 435.1 was not directly cited as an ARAR for the ICDF Complex in the OU 3-13 ROD. In Section 9, contingency storage is addressed and shows the associated ARARs and CERCLA documents for the ICDF Complex.

\subsubsection{Transfer Equipment (IV.E.2.)}

In DOE Manual 435.1, the transfer equipment requirements are as follows:

Transfer Equipment. Pipelines and auxiliary facilities necessary for the transfer of high activity or high hazard liquid low-level waste to contingency storage shall be maintained in an operational condition when waste is present and shall meet the requirements of DOE O 435.1, Radioactive Waste Management, and Manual.

This requirement is classified as substantive. In the Implementation Guide for use with DOE Manual 435.1, the objective of this requirement is to mitigate the impacts on the public, workers, or environment in the event that a leak develops in a tank storing high activity or high hazard liquid LLW or in a facility processing such waste. The mitigation is provided by ensuring spare waste storage capacity is a required part of a site's emergency management program. To meet this objective, there needs to be both capacity to handle the largest volume of any single storage tank or liquid waste in process and the capability to transfer the waste.

The ICDF Complex has been designed and is being constructed to safely manage liquid radioactive waste. The ICDF Complex has transfer equipment to move liquid waste between the various tanks and other structures at the ICDF Complex. This section of DOE Manual 435.1 was not directly cited as an ARAR for the ICDF Complex in the OU 3-13 ROD. In Section 9, transfer equipment is addressed and shows the associated ARARs and CERCLA documents for the ICDF Complex. 


\subsection{Corrective Actions (IV.F.)}

In DOE Manual 435.1, there are two additional corrective action requirements for LLW. These additional requirements are presented in Sections 8.6.1 and 8.6.2.

\subsubsection{Order Compliance (IV.F.1.)}

In DOE Manual 435.1, the order compliance requirement is as follows:

Order Compliance. Corrective actions shall be implemented whenever necessary to ensure the requirements of DOE O 435.1, Radioactive Waste Management, and Manual are met.

This requirement is classified as substantive. In the Implementation Guide for use with DOE Manual 435.1, the objective of this requirement is to ensure that actions will be taken to preclude, minimize, or mitigate hazards whenever a situation arises at a LLW management facility that could threaten the safety of the worker, public, or environment.

The ICDF Complex has been designed and is being constructed to safely manage radioactive waste materials. There are existing processes and procedures at the ICP for corrective actions identification and implementation. Also, specific procedures are being developed for the ICDF Complex to deal with emergency issues and resolution of those issues.

This section of DOE Manual 435.1 was not directly cited as an ARAR for the ICDF Complex in the OU 3-13 ROD. In Section 9, corrective actions are addressed and shows the associated ARARs and CERCLA documents for the ICDF Complex.

\subsubsection{Operations Curtailment (IV.F.2.)}

In DOE Manual 435.1, the operations curtailments requirement is as follows:

Operations Curtailment. Operations shall be curtailed or facilities shut down for failure to establish, maintain, or operate consistent with an approved radioactive waste management basis.

This requirement is classified as substantive. In the Implementation Guide for use with DOE Manual 435.1, the objective of this requirement is to limit the operation of waste management activities and facilities as necessary to avoid creation of near- or long-term safety or environmental hazards.

The ICDF Complex has been designed and is being constructed to safely manage radioactive waste materials. The waste materials at the ICDF Complex will be tracked for inventory control, which is necessary to remain within the radioactive waste management basis. This waste tracking can be used to identify when the operations of the ICDF Complex are approaching the operating limits. The necessary operations and actions can then be taken to remain within the operating limits. In addition, there will be periodic surveillances conducted at the ICDF Complex to determine/verify that the operations are remaining within the operating limits. If the ICDF Complex exceeds the operating limits, the necessary actions, including curtailment/shutdown of facilities/operations, will be conducted to bring the ICDF Complex back within the operating limits. 
This section of DOE Manual 435.1 was not directly cited as an ARAR for the ICDF Complex in the OU 3-13 ROD. In Section 9, operations curtailment is addressed and shows the associated ARARs and CERCLA documents for the ICDF Complex.

\subsection{Waste Acceptance (IV.G.)}

In DOE Manual 435.1, there are two additional waste acceptance requirements for LLW. These additional requirements are presented in Sections 8.7.1 and 8.7.2.

\subsubsection{Technical and Administrative (IV.G.1.)}

In DOE Manual 435.1, the technical and administrative requirements are as follows:

Technical and Administrative. Waste acceptance requirements for all low level waste storage, treatment, or disposal facilities, operations, and activities shall specify, at a minimum, the following:

- $\quad$ Allowable activities and/or concentrations of specific radionuclides.

- Acceptable waste form and/or container requirements that ensure the chemical and physical stability of waste under conditions that might be encountered during transportation, storage, treatment, or disposal.

- $\quad$ Restrictions or prohibitions on waste, materials, or containers that may adversely affect waste handlers or compromise facility or waste container performance.

- $\quad$ The following are additional waste acceptance requirements that shall be specified in low-level waste disposal facility waste acceptance requirements:

Low-level waste must contribute to and not detract from achieving long- term stability of the facility, minimizing the need for long-term active maintenance, minimizing subsidence, and minimizing contact of water with waste. Void spaces within the waste and, if containers are used, between the waste and its container shall be reduced to the extent practical.

- $\quad$ Liquid low-level waste or low-level waste containing free liquid must be converted into a form that contains as little freestanding liquid as is reasonably achievable, but in no case shall the liquid exceed 1 percent of the waste volume when the low-level waste is in a disposal container, or 0.5 percent of the waste volume after it is processed to a stable form.

- Low-level waste must not be readily capable of detonation or of explosive decomposition or reaction at anticipated pressures and temperatures, or of explosive reaction with water. Pyrophoric materials contained in waste shall be treated, prepared, and packaged to be nonflammable. 
- $\quad$ Low-level waste must not contain, or be capable of generating by radiolysis or biodegradation, quantities of toxic gases, vapors, or fumes harmful to the public or workers or disposal facility personnel, or harmful to the long-term structural stability of the disposal site.

- Low-level waste in a gaseous form must be packaged such that the pressure does not exceed 1.5 atmospheres absolute at $20 \mathrm{C}$.

- $\quad$ The basis, procedures, and levels of authority required for granting exceptions to the waste acceptance requirements, which shall be contained in each facility's waste acceptance documentation. Each exception request shall be documented, including its disposition as approved or not approved.

This requirement is classified as substantive. In the Implementation Guide for use with DOE Manual 435.1, the objective of the waste acceptance requirements are to ensure that LLW which is received at a facility contains only the radionuclides that the facility can safely manage and only in concentrations and/or total activities which are compatible with the work to be undertaken in the facility; ensure that LLW which is to be received at a facility is in a form or container that will maintain its integrity and retain acceptable configuration under the conditions that are expected to be encountered during the management steps the waste will undergo; and ensure that no LLW received at a facility contains materials that will compromise the safety or integrity of the facility under the expected operating conditions. Also, an objective of the technical and administrative requirements for LLW disposal is to ensure that LLW disposed in DOE waste disposal facilities are in a form and/or packaged so that the waste contributes to the facility meeting the performance objectives for disposal of LLW. The final objective of this requirement is to ensure that formal procedures exist and a decision process is clear concerning the granting of exceptions to waste acceptance requirements.

The WAC for the ICDF Complex was designed to be protective. The impacts associated with radionuclides were evaluated in evaluating the hazards associated with the ICDF Complex. The WAC does not set specific limits on concentrations of specific radionuclides but the total activities are limited by the limits imposed by the hazard analysis document. The inventory is tracked and maintained to demonstrate that the ICDF Complex is remaining within the acceptable limits. However, the WAC does set limits on containers, chemical/physical requirements, and allowable waste forms. Also, there are specific requirements and limits on the placement of waste to maintain a long term stable closed facility. This includes void space limits and compaction requirements. There are additional requirements and restrictions on the acceptable waste streams for disposal concerning pyrophoric/reactive materials, material capable of generating gases, containers of pressurized gases.

However, the ICDF Complex has both a landfill and evaporation pond for disposal. Wastes destined for disposal in the landfill are restricted on the amount of free liquid that is allowed. This includes waste streams that have undergone treatment prior to disposal in the landfill. Waste streams destined for disposal in the evaporation pond are liquid in form and are not subject to the free liquid issue.

Changing the WAC at the ICDF Complex would require a modification to a primary document under the FFA/CO. This modification process is a structured and methodical process that is fully documented with either the changes being accepted or rejected.

This section of DOE Manual 435.1 was not directly cited as an ARAR for the ICDF Complex in the OU 3-13 ROD. In Section 9, waste acceptance is addressed and shows the associated ARARs and CERCLA documents for the ICDF Complex. 


\subsubsection{Evaluation and Acceptance (IV.G.2.)}

In DOE Manual 435.1, the evaluation and acceptance requirements are as follows:

Evaluation and Acceptance. The receiving facility shall evaluate waste for acceptance, including confirmation that the technical and administrative requirements have been met. A process for the disposition of non-conforming wastes shall be established.

This requirement is classified as substantive. In the Implementation Guide for use with DOE Manual 435.1, the objective of this requirement is to establish a process by which personnel at a facility receiving LLW for storage, treatment, or disposal determine that the waste being transferred is acceptable in accordance with the waste acceptance requirements and for that process to specifically address the management of waste that does not conform with all of the requirements when it is received at the facility.

The ICDF Complex has a process for the acceptance of waste into the facility. This process includes the sampling and analysis that is conducted to verify the waste is as expected and that the waste is within the WAC limits. There are specific steps in the acceptance and tracking process which are contained in the waste tracking plan. Also, there are process procedures for the ICDF Complex that deal with (resolve) waste streams that do not meet the WAC or are not as expected for the available information when received.

This section of DOE Manual 435.1 was not directly cited as an ARAR for the ICDF Complex in the OU 3-13 ROD. In Section 9, waste acceptance is addressed and shows the associated ARARs and CERCLA documents for the ICDF Complex.

\subsection{Waste Generation Planning (IV.H.)}

In DOE Manual 435.1, there are two additional waste generation planning requirements for LLW. These additional requirements are presented in Sections 8.8.1 and 8.8.2.

\subsubsection{Life-Cycle Planning (IV.H.1.)}

In DOE Manual 435.1, the life-cycle planning requirement is as follows:

Life-Cycle Planning - Prior to waste generation, planning shall be preformed to address the entire life-cycle for all low level waste streams.

This requirement is classified as administrative. In the Implementation Guide for use with DOE Manual 435.1, the objective of this requirement is to provide for the disposal of all LLW that is generated in the future by ensuring that prior to generating a new LLW stream, the specific waste management facilities necessary for safe management of the waste from the time it is generated up to and including its disposal are identified and sites are discouraged from generating LLW that does not have an identified path to disposal.

There is a documented process for evaluating all waste streams that are destined for ICDF Complex. This evaluation involves knowing what waste stream would be generated and the characteristics of the waste. This process of evaluating the potential waste streams includes looking at all required destinations/facilities that the waste stream will be managed. There may be waste stream that the final destination is not known and will require storage until the disposal facility is identified. The ICDF Complex has process for the storage of waste streams and will continue to evaluate disposal and treatment options for the waste that is in storage. 
This section of DOE Manual 435.1 was not directly cited as an ARAR for the ICDF Complex in the OU 3-13 ROD. In Section 9, waste generation is addressed and shows the associated ARARs and CERCLA documents for the ICDF Complex.

\subsubsection{Waste With No Identified Path to Disposal (IV.H.2.)}

In DOE Manual 435.1, the waste with no identified path to disposal requirements are as follows:

Waste With No Identified Path to Disposal - Low level waste streams with no identified path to disposal shall be generated only in accordance with approved conditions which, at a minimum, shall address:

- $\quad$ Programmatic need to generate the waste;

- Characterization and issues preventing the disposal of the waste;

- $\quad$ Safe storage of the waste until disposal can be achieved; and

- $\quad$ Activities and plans for achieving final disposal of the waste.

This requirement is classified as administrative. In the Implementation Guide for use with DOE Manual 435.1, the objective of this requirement is to ensure that prior to generation of a new LLW streams with no path to disposal, the need to generate the waste is carefully considered, and plans for safe long-term storage and for resolving issues that prevent disposal of the wastes are developed.

There is a documented process for evaluating all waste streams that are destined for ICDF Complex. Part of this evaluating is knowing the rationale for why the waste stream needs to be generated. All wastes destined for the ICDF Complex are required to be associated with an INL CERCLA remediation (remedial or removal) action. These CERCLA project evaluate various alternatives for the remediation, including generation and disposal of waste. Once it is determined that a waste stream will be received at the ICDF Complex, the waste stream evaluation involve knowing what waste stream would be generated and the characteristics of the waste. This process of evaluating the potential waste streams includes looking at all required destinations/facilities that the waste stream will be managed. There may be a waste stream that the final destination is not known and will require storage until the disposal facility is identified. The ICDF Complex has process for the storage of waste streams and will continue to evaluate treatment and/or disposal options for the waste that is in storage.

This section of DOE Manual 435.1 was not directly cited as an ARAR for the ICDF Complex in the OU 3-13 ROD. In Section 9, waste generation is addressed and shows the associated ARARs and CERCLA documents for the ICDF Complex.

\subsection{Waste Characterization (IV.I.)}

In DOE Manual 435.1, the waste characterization requirement is as follows:

Low-level waste shall be characterized using direct or indirect methods, and the characterization documented in sufficient detail to ensure safe management and compliance with the waste acceptance requirements of the facility receiving the waste. 
This requirement is classified as substantive. In the Implementation Guide for use with DOE Manual 435.1, the objective of this requirement is to ensure that sufficient knowledge of LLW's characteristics (e.g., chemical, physical, radiological) is available to protect workers handling the waste and to support effective decision-making for its management. This information is to be maintained from generation, through storage and treatment in sufficient detail to ensure that the requirements of subsequent treatment and storage facilities, transportation regulations, and the disposal requirements for LLW will be met.

For the ICDF Complex, there is a defined process of verification of the waste stream received into the various facilities. These characterization processes include both direct and indirect methods of characterization, which are used in the development of the Material Profile. The Material Profile information is compared against the applicable WAC to determine if the waste is within the acceptable limits. Additional characterization, including direct methods, may be used to complete the Material Profile. For receipt and disposal at the ICDF Complex, additional verification sampling and analysis is conducted to verify compliance with the WAC.

This section of DOE Manual 435.1 was not directly cited as an ARAR for the ICDF Complex in the OU 3-13 ROD. In Section 9, waste characterization is addressed and shows the associated ARARs and CERCLA documents for the ICDF Complex.

In DOE Manual 435.1, there are two additional waste characterization requirements for LLW. These additional requirements are presented in Sections 8.9.1 and 8.9.2.

\subsubsection{Data Quality Objectives (IV.I.1.)}

In DOE Manual 435.1, the data quality objectives requirement is as follows:

Data Quality Objectives. The data quality objectives process, or a comparable process, shall be used for identifying characterization parameters and acceptable uncertainty in characterization data.

This requirement is classified as substantive. In the Implementation Guide for use with DOE Manual 435.1, the objective of this requirement is to invoke a process for determining the type, quantity, and quality of characterization data needed to support the safe management of LLW so as to ensure that needed data are acquired, the data meet the objectives they are being collected for, and resources are not wasted on unnecessary, incomplete, or unusable data collection efforts.

When developing a SAP for an INL CERCLA project, data quality objectives are developed and documented. This same process was followed for the development of the verification sampling and analysis plan for the ICDF Complex. For the ICDF Complex verification SAP, the data quality objectives were focused on what information (contaminant concentrations) was necessary to ensure that the waste would remain within the WAC. Because the data quality objectives developed for the ICDF Complex were related to the WAC limits, it is not necessary to develop individual waste stream data quality objectives. Also, data quality objectives are discussed in the WAC for the ICDF Complex.

This section of DOE Manual 435.1 was not directly cited as an ARAR for the ICDF Complex in the OU 3-13 ROD. In Section 9, waste characterization is addressed and shows the associated ARARs and CERCLA documents for the ICDF Complex. 


\subsubsection{Minimum Waste Characterization Requirements (IV.I.2.)}

In DOE Manual 435.1, the minimum waste characterization requirements are as follows:

Minimum Waste Characterization. Characterization data shall, at a minimum, include the following information relevant to the management of the waste:

- $\quad$ Physical and chemical characteristics;

- $\quad$ Volume, including the waste and any stabilization or absorbent media;

- Weight of the container and contents;

- Identities, activities, and concentrations of major radionuclides;

- $\quad$ Characterization date;

- $\quad$ Generating source; and

- $\quad$ Any other information which may be needed to prepare and maintain the disposal facility performance assessment, or demonstrate compliance with applicable performance objectives.

This requirement is classified as substantive. In the Implementation Guide for use with DOE Manual 435.1, the objective of this requirement is to establish MLLW data that have been determined to be necessary for safe and effective management during the life cycle of the waste.

For the ICDF Complex, a waste stream undergoes a waste profiling process prior to generation or receipt into the facility. Within this waste profiling process, the available information on the waste stream characteristics is input into the waste tracking system. The waste tracking system includes the physical/chemical characteristics, volume, weights, constituents, and other relevant data. During the waste profiling process, it is occasionally necessary to further characterize the waste stream. This additional information is added into the waste profile contained in the waste tracking system. When the waste is received into the ICDF Complex, additional verification sampling and analysis may be conducted to verify that the waste stream is as stated on the waste profile form. All the information in the waste tracking system is maintained as a record and updated as the waste stream is moved between the various facilities. All of the waste profile information can be used by the disposal facility to evaluate compliance with the disposal facilities WAC, which is determined by the performance assessment and performance objectives.

This section of DOE Manual 435.1 was not directly cited as an ARAR for the ICDF Complex in the OU 3-13 ROD. In Section 9, waste characterization is addressed and shows the associated ARARs and CERCLA documents for the ICDF Complex.

\subsection{Waste Certification (IV.J.)}

In DOE Manual 435.1, the waste certification requirement is as follows:

A waste certification program shall be developed, documented, and implemented to ensure that the waste acceptance requirements of facilities receiving low-level waste for storage, treatment, and disposal are met. 
This requirement is classified as administrative. In the Implementation Guide for use with DOE Manual 435.1, the objective of this requirement is to ensure that LLW transferred to a facility for storage, treatment, or disposal meets the receiving facility's waste acceptance requirements to reduce the likelihood that transferred wastes contain unacceptable materials or characteristics, and to avoid hazards that would occur from the transportation and handling of waste packages which do not meet acceptance requirements. Certification also ensures that the storage, treatment, or disposal facilities receiving the LLW operate within limits established through safety analyses and/or performance assessments.

The ICDF Complex will operate using an integrated waste tracking system. Within the waste tracking system, there are various steps for approval and certification of the waste streams. One of the checks in the system is to verify that the waste profile for the waste stream is within the WAC limits for the facility. The WAC limits for the ICDF Complex considered the hazard classification and analysis of the various facilities in the ICDF Complex and the operations that could occur in the ICDF Complex facilities. The waste tracking system includes all of the operational limits and generates flags for waste streams that are destined for a facility in the ICDF Complex if that waste exceeds the facility WAC.

This section of DOE Manual 435.1 was not directly cited as an ARAR for the ICDF Complex in the OU 3-13 ROD. In Section 9, waste certification is addressed and shows the associated ARARs and CERCLA documents for the ICDF Complex.

In DOE Manual 435.1, there are three additional waste certification requirements for LLW. These additional requirements are presented in Sections 8.10.1, 8.10.2, and 8.10.3.

\subsubsection{Certification Program (IV.J.1.)}

In DOE Manual 435.1, the certification program requirements are as follows:

Certification Program. The waste certification program shall designate the officials who have the authority to certify and release waste for shipment; and specify what documentation is required for waste generation, characterization, shipment, and certification. The program shall provide requirements for auditability, retrievability, and storage of required documentation and specify the records retention period.

This requirement is classified as administrative. In the Implementation Guide for use with DOE Manual 435.1, the objective of this requirement is to ensure waste certification programs are developed that clearly identify the documentation required for certifying LLW, specify personnel with the authority to make the certification, and provide a traceable and verifiable record of and basis for certification.

The ICDF Complex will operate using an integrated waste tracking system. Within the waste tracking system, there are various steps for approval and certification of the waste streams. Operation of the waste tracking system involves selected personnel with the access to approve waste transfers and certification of the waste profile for the waste stream. Also, the waste tracking system maintains a record of the various changes to the waste profiles, approvals, and other information, including characterization data, related to the waste stream.

This section of DOE Manual 435.1 was not directly cited as an ARAR for the ICDF Complex in the OU 3-13 ROD. In Section 9, waste certification is addressed and shows the associated ARARs and CERCLA documents for the ICDF Complex. 


\subsubsection{Certification Before Transfer (IV.J.2.)}

In DOE Manual 435.1, the certification before transfer requirement is as follows:

Certification Before Transfer. Low-level waste shall be certified as meeting waste acceptance requirements before it is transferred to the facility receiving the waste.

This requirement is classified as administrative. In the Implementation Guide for use with DOE Manual 435.1, the objective of this requirement is to certify that LLW meets the acceptance requirements of the storage, treatment, or disposal facility before it is transferred to prevent transferring waste that could endanger receiving facility personnel, and to avoid the delay and potential hazards associated with corrective actions taken to remedy noncompliant conditions.

The ICDF Complex will operate using an integrated waste tracking system. Within the waste tracking system, there are various steps for approval and certification of the waste streams. One of the checks in the system is to verify that the Material Profile for the waste stream is within the WAC limits for the facility. The waste tracking system includes all of the operational limits and generates a flag for waste stream that are destined for a facility in the ICDF Complex if that waste exceeds the facility WAC. If a flag is generated, the waste stream can not be received until the issues that resulted in the flag being generated is resolved. This is intended to reduce the possibility of a noncompliant condition developing at the ICDF Complex.

This section of DOE Manual 435.1 was not directly cited as an ARAR for the ICDF Complex in the OU 3-13 ROD. In Section 9, waste certification is addressed and shows the associated ARARs and CERCLA documents for the ICDF Complex.

\subsubsection{Maintaining Certification (IV.J.3.)}

In DOE Manual 435.1, the maintaining certification requirement is as follows:

Maintaining Certification. Low-level waste that has been certified as meeting the waste acceptance requirements for transfer to a storage, treatment, or disposal facility shall be managed in a manner that maintains its certification status.

This requirement is classified as administrative. In the Implementation Guide for use with DOE Manual 435.1, the objective of this requirement is to ensure that certified LLW is managed to maintain the certification status and avoid the unnecessary handling of waste containers that would be necessary for recertifying waste.

The ICDF Complex will operate using the waste tracking system. Within the waste tracking system, there are various steps for approval and certification of the waste streams. One of the checks in the system is to verify that the waste profile for the waste stream is within the WAC limits for the facility. The waste tracking system includes all of the limits and generates a flags for waste stream that are destined for a facility in the ICDF Complex that exceed the facility WAC. Movement within the ICDF Complex will be tracked in the waste tracking system to maintain the certification of the waste stream within the ICDF Complex. If the waste stream will be sent to another facility after being at the ICDF Complex, the waste profile for that waste stream will be compared against the receiving facilities requirements. At that time all waste profile information for the waste stream will be turned over to an existing INL facility and program dealing with treatment and disposal of TRU waste. This turnover will ensure that the waste stream remains certified for the ICDF Complex and potentially be certified for the treatment and disposal facilities. 
This section of DOE Manual 435.1 was not directly cited as an ARAR for the ICDF Complex in the OU 3-13 ROD. In Section 9, waste certification is addressed and shows the associated ARARs and CERCLA documents for the ICDF Complex.

\subsection{Waste Transfer (IV.K.)}

In DOE Manual 435.1, the waste transfer requirement is as follows:

A documented process shall be established and implemented for transferring responsibility for management of low-level waste and for ensuring availability of relevant data. The following requirements are in addition to those in Chapter I of the Manual.

This requirement is classified as administrative. In the Implementation Guide for use with DOE Manual 435.1, the objective of this requirement is to ensure that the responsibility for LLW containers is established, maintained, properly transferred, and adequately documented so that ownership, and therefore responsibility for safe management, of waste is clear. This responsibility includes maintaining the waste characterization information, the container information, and information about the treatment, storage, transportation, and disposal status of containers of waste. This responsibility also includes an assurance that the container of waste has not been altered in a manner that affects its certification status or the ability of the waste to be properly managed.

The ICDF Complex will operate using the waste tracking system. Within the waste tracking system, there are various steps for approval and certification of the waste streams. The waste tracking system also includes the information on transfer of responsibility of the waste stream. The waste tracking system also includes all of the characterization data along with the container information. Movement within the ICDF Complex will be tracked in the waste tracking system to maintain the record of waste transfers and changes in responsibility. If the waste stream will be sent to another facility after being at the ICDF Complex, all of the information along with the waste stream will be transferred to an existing INL facility and program dealing with treatment and disposal of TRU waste. This transfer will ensure that the waste stream remains certified for the ICDF Complex and potentially be certified for the treatment and disposal facilities.

This section of DOE Manual 435.1 was not directly cited as an ARAR for the ICDF Complex in the OU 3-13 ROD. In Section 9, waste transfer is addressed and shows the associated ARARs and CERCLA documents for the ICDF Complex.

In DOE Manual 435.1, there are two additional waste transfer requirements for LLW. These additional requirements are presented in Sections 8.11.1 and 8.11.2.

\subsubsection{Authorization (IV.K.1.)}

In DOE Manual 435.1, the authorization requirement is as follows:

Authorization. Low-level waste shall not be transferred to a storage, treatment, or disposal facility until personnel responsible for the facility receiving the waste authorize the transfer.

This requirement is classified as administrative. In the Implementation Guide for use with DOE Manual 435.1, the objective of this requirement is to ensure that shipments or transfers of LLW are made only with the cognizance and approval of personnel at the facility receiving LLW so that preparations can be assured for its safe management. 
The ICDF Complex will operate using the waste tracking system. Within the waste tracking system, there are various steps for approval and certification of the waste streams. Waste can not be received or transferred in the ICDF Complex without the approval process contained in the waste tracking system. Only certain personnel have the authority in the waste tracking system to approve of the waste transfers. This allows for maintaining control of the various waste stream and management of transfers to maintain the ICDF Complex is a safe manner. Movement within the ICDF Complex will be tracked in the waste tracking system to maintain the record of waste transfers and changes in responsibility. If the waste stream will be sent to another facility after being at the ICDF Complex, all of the information along with the waste stream will be transferred to an existing INL facility and program dealing with treatment and disposal of TRU waste. This transfer will ensure that the responsibility for the waste stream is documented and managed in a safe manner.

This section of DOE Manual 435.1 was not directly cited as an ARAR for the ICDF Complex in the OU 3-13 ROD. In Section 9, waste transfer is addressed and shows the associated ARARs and CERCLA documents for the ICDF Complex.

\subsubsection{Data (IV.K.2.)}

In DOE Manual 435.1, the data requirement is as follows:

Data. Waste characterization data, container information, and generation, storage, treatment, and transportation information for low-level waste shall be transferred with or be traceable to the waste.

This requirement is classified as administrative. In the Implementation Guide for use with DOE Manual 435.1, the objective of this requirement is to establish and maintain information about the characteristics of LLW and the waste containers to ensure that sufficient information to support management of waste in a manner that is protective of workers, the public, and the environment is always available.

For the ICDF Complex, waste streams must undergo a waste profiling process prior to generation or receipt into the facility. Within this waste profiling process, the available information on the waste stream characteristics is input into the waste tracking system. The waste tracking system includes the physical/chemical characteristics, volume, weights, constituents, and other relevant data. During the waste profiling process, it is occasionally necessary to further characterize the waste stream. This additional information is added into the waste profile contained in the waste tracking system. When the waste is received into the ICDF Complex, additional verification sampling and analysis may be conducted to verify that the waste stream is as stated on the waste profile form. All the information in the waste tracking system is maintained as a record and updated as the waste stream is moved between the various facilities.

This section of DOE Manual 435.1 was not directly cited as an ARAR for the ICDF Complex in the OU 3-13 ROD. In Section 9, waste transfer is addressed and shows the associated ARARs and CERCLA documents for the ICDF Complex. 


\subsection{Packaging and Transportation (IV.L.)}

In DOE Manual 435.1, there are two packaging and transportation requirements for LLW. These additional requirements are presented in Sections 8.12.1 and 8.12.2.

\subsubsection{Packaging (IV.L.1.)}

In DOE Manual 435.1, the packaging requirements are as follows:

Packaging. If containers are used:

- $\quad$ Low-level waste shall be packaged in a manner that provides containment and protection for the duration of the anticipated storage period and until disposal is achieved or until the waste has been removed from the container.

- When waste is packaged, vents or other measures shall be provided if the potential exists for pressurizing or generating flammable or explosive concentrations of gases within the waste container.

- $\quad$ Containers of low-level waste shall be marked such that their contents can be identified.

This requirement is classified as administrative. In the Implementation Guide for use with DOE Manual 435.1, the objective of these requirements is to ensure that when LLW is packaged, the container selected is adequate to contain the waste and limit radiation exposure for the entire time the waste is in storage, and to ensure that the container can be correlated to necessary information on its contents. The first subrequirement is to ensure the selection of a container for waste based on the life-cycle of the waste so that there will not be unnecessary repackaging of waste. The second subrequirement is to prevent the build up of pressure or concentrations of gases that could cause a loss of waste confinement. The third subrequirement is to ensure that it is possible to identify the contents of the container of waste during storage and when the waste is removed from storage for treatment or disposal without having to open the container.

Waste can be received into the ICDF in a variety of containers or transport vessels. The shipments into the ICDF Complex may result in bulk material being delivered without a containment container. When waste streams are received at the ICDF Complex for direct disposal, the container is only used for shipment. Other waste streams will be received into the ICDF Complex for treatment and the same type of container may be used as a shipping container.

For storage of waste at the ICDF Complex, the constituents in the waste stream will be evaluated for the possibility of generating pressure in the container. If there is the possibility of generating pressure, then the containers will be appropriately vented. For waste streams that do not have the possibility of generating pressures of the time period through disposal, then vents will not be required.

Appropriate markings will be placed on the containers of waste that is classified as LLW. These markings will be visible and used to ensure that the LLW is managed appropriately.

This section of DOE Manual 435.1 was not directly cited as an ARAR for the ICDF Complex in the OU 3-13 ROD. In Section 9, packaging is addressed and shows the associated ARARs and CERCLA documents for the ICDF Complex. 


\subsubsection{Transportation (IV.L.2.)}

In DOE Manual 435.1, the transportation requirement is as follows:

Transportation. To the extent practical, the volume of waste and number of lowlevel waste shipments shall be minimized.

This requirement is classified as administrative. In the Implementation Guide for use with DOE Manual 435.1, the objective of this requirement is to reduce the risk associated with LLW management by reducing the number of miles traveled in transporting waste. This is to be done by efficiently using waste containers, minimizing the volume of waste which requires shipment, and optimizing shipping plans and schedules.

The ICDF Complex will deal with a variety of waste streams. Shipments of the various waste streams can occur in different type of containers. As part of the planning for generating a waste stream, the use of containers is considered and the number of containers is minimized as practical.

This section of DOE Manual 435.1 was not directly cited as an ARAR for the ICDF Complex in the OU 3-13 ROD. In Section 9, transportation is addressed and shows the associated ARARs and CERCLA documents for the ICDF Complex.

\subsection{Site Evaluation and Facility Design (IV.M.)}

In DOE Manual 435.1, there are three site evaluation and facility design requirements for LLW. These additional requirements are presented in Sections 8.13.1, 8.13.2, and 8.13.3.

\subsubsection{Site Evaluation (IV.M.1.)}

In DOE Manual 435.1, the site evaluation requirements are as follows:

Site Evaluation. Proposed locations for low-level waste facilities shall be evaluated to identify relevant features that should be avoided or must be considered in facility design and analyses.

Each site proposed for a new low-level waste facility or expansion of an existing low-level waste facility shall be evaluated considering environmental characteristics, geotechnical characteristics, and human activities, including for a low-level waste disposal facility, the capability of the site to demonstrate, at a minimum, whether it is:

- $\quad$ Located to accommodate the projected volume of waste to be received;

- $\quad$ Located in a flood plain, a tectonically active area, or in the zone of water table fluctuation; and

- $\quad$ Located where radionuclide migration pathways are predictable and erosion and surface runoff can be controlled.

Proposed sites with environmental characteristics, geotechnical characteristics, and human activities for which adequate protection cannot be provided through facility design shall be deemed unsuitable for the location of the facility. 
Low-level waste disposal facilities shall be sited to achieve long-term stability and to minimize, to the extent practical, the need for active maintenance following final closure.

This requirement is classified as substantive. In the Implementation Guide for use with DOE Manual 435.1, the objectives of these requirements are

1. To ensure that a suitable site location is selected and relevant features of the proposed site that should be included in the design of a LLW management facility are evaluated so the facility can be appropriately designed to provide protection to the public, workers, and the environment, and to identify features of the site that would be detrimental to this goal so they can be avoided.

2. To ensure that specific evaluations are performed as part of the evaluation of a site for a LLW management facility and that the evaluations are appropriately considered in the final site selection and layout, and the design and construction of the facility, in particular, for LLW disposal facilities, the objective of this requirement includes ensuring that particularly important site attributes have been evaluated.

3. To avoid sites for which postulated severe natural events cannot be protected from adequately through design and construction and to continue to have assurance that the public safety and health will be protected and the impacts on the environment will continue to be minimized.

4. To ensure the selection of proposed low-level disposal sites within DOE reservations that have positive attributes toward meeting the disposal performance objectives of DOE Manual 435.1-1, and to the extent practical, ensure that new LLW disposal facilities are not sited in locations which will inherently require long-term active maintenance to achieve disposal performance objectives.

Site evaluation was a significant issue for the ICDF Complex. The site for the ICDF Complex was selected based on many criteria. These criteria were presented in the OU 3-13 ROD and consisted of general criteria of (1) public health and safety, (2) natural environment, (3) technical, (4) social economic environment, (5) cultural environment, and (6) community acceptance. The most significant major criteria from a design and siting issues are the subcriteria for public health and safety (effect on surface design, effects on surface water, effects on groundwater, proximity to fire, ambulance, and emergency services, elevation above flood plain, and transportation difficulty) and for technical (depth to bedrock, geological fault proximity, underlying soil permeability and attenuation capacity, earthquake epicenter proximity, perched water proximity, ease of monitoring, and soil suitability for engineered structures). Many of the criteria that were used are also used by the NRC in the site suitability and selection criteria for commercial LLW disposal facilities. Based on these criteria, an area southwest of INTEC was selected for the ICDF Complex. A geophysical and geotechnical study was conducted in the selected area, which resulted in the selected site for the ICDF Complex. Also, during the design of the ICDF Complex, the criteria and objectives of this requirement were evaluated. The ICDF Complex, including the landfill meet the requirements. The design and closure approach ensure that the ICDF Complex will be able to meet the performance criteria and not require extensive active long term maintenance to achieve the disposal performance objectives.

This section of DOE Manual 435.1 was not directly cited as an ARAR for the ICDF Complex in the OU 3-13 ROD. In Section 9, facility evaluation is addressed and shows the associated ARARs and CERCLA documents for the ICDF Complex. 


\subsubsection{Low-Level Waste Treatment and Storage Facility Design (IV.M.2.)}

In DOE Manual 435.1, the LLW treatment and storage facility design requirements are as follows:

Low-Level Waste Treatment and Storage Facility Design. The following facility requirements and general design criteria, at a minimum, apply:

- $\quad$ Confinement. Low-level waste systems and components shall be designed to maintain waste confinement.

- Ventilation.

- $\quad$ Design of low-level waste treatment and storage facilities shall include ventilation, if applicable, through an appropriate filtration system to maintain the release of radioactive material in airborne effluents within the requirements and guidelines specified in applicable requirements.

- When conditions exist for generating gases in flammable or explosive concentrations, ventilation systems or other measures shall be provided to keep the gases in a nonflammable and non-explosive condition. Where concentrations of explosive or flammable gases are expected to approach the lower flammability limit, measures shall be taken to prevent deflagration or detonation.

- Consideration of Decontamination and Decommissioning. Areas in new and modifications to existing low-level waste management facilities that are subject to contamination with radioactive or other hazardous materials shall be designed to facilitate decontamination. For such facilities a proposed decommissioning method or a conversion method leading to reuse shall be described.

- Instrumentation and Control Systems. Engineering controls shall be incorporated in the design and engineering of low-level waste treatment and storage facilities to provide volume inventory and to prevent spills, leaks, and overflows from tanks or confinement systems.

- $\quad$ Monitoring. Monitoring and/or leak detection capabilities shall be incorporated in the design and engineering of low-level waste treatment and storage facilities to provide rapid identification of failed confinement and/or other abnormal conditions.

This requirement is classified as substantive. In the Implementation Guide for use with DOE Manual 435.1, the objectives are

1. To ensure that a minimum set of facility requirements and general design requirements determined from hazards analyses or policy considerations are applied to LLW treatment and storage facilities.

2. To ensure the design of LLW storage and treatment facilities includes the installation of equipment capable of containing LLW so that releases that could result in exposures to workers or the public or that could contaminate the environment are minimized. 
3. To ensure that the design of LLW treatment and storage facilities includes features to remove radioactive materials from airborne effluents that could endanger worker or public safety and/or the environment to levels allowed in regulations before they are released, and to preclude or mitigate the accumulation of flammable or explosive gases in the facilities which could lead to uncontrolled releases of radioactive materials.

4. To ensure the incorporation of the concept of life-cycle waste management into the operations of radioactive waste management facilities to result in the minimization of radioactive waste that must be managed in the future from decontamination and decommissioning activities, and the reduction of facilities that must be dismantled due to contamination rather than reused for another beneficial purpose. The objective of this requirement is to ensure that engineering controls are included in the design of LLW management facilities to minimize the likelihood of release of radionuclides that could lead to exposures or contamination of the environment.

5. To ensure the design of LLW management facilities includes the installation of equipment capable of identifying failures in containing LLW and other conditions that could result in exposures of workers or the public to radioactivity or contamination of the environment.

The containers of waste at the ICDF Complex will be stored at the SSA (CPP-1789). This is a fenced paved storage facility under INL CERCLA control. The containers are periodically inspected for a variety of criteria including container condition. If the containers are degrading, the containers are repaired or overpacked. These requirements will also apply to waste in storage at the ICDF Complex. This will ensure that adequate confinement for the waste is maintained. Bulk storage of waste in waste staging piles will also have inspections and repairs as necessary to ensure that adequate confinement is maintained.

The containers of waste will be vented if necessary. This determination will be based on the waste constituents in the container. If the waste will generate a gaseous phase during storage, the container will include vents designed to control the release of radioactive and other material to acceptable levels. This will ensure that adequate ventilation, if necessary, is available for the stored waste.

The ICDF Complex is not intended to accept waste that can result in explosive or flammable concentration of gases. If the waste material is expected to generate concentrations of gases that would be capable of creating a fire or explosion, additional requirements would be imposed on the container of waste. These additional requirements could include forced ventilation or other methods to control the concentrations of gases in the waste container to levels below concern. Information on the makeup of the waste is included on the waste profile, which must be accepted before the waste can be received into the ICDF Complex. Storage of waste which may generate these concentrations of gases would be strictly limited and controlled at the ICDF Complex to remain within the hazard analysis for the ICDF Complex.

Storage of waste at the ICDF Complex will occur in containers and waste staging piles. This minimizes the amount of D\&D\&D necessary at the ICDF Complex in relation to waste. When the containers are removed from the ICDF Complex, there will no D\&D\&D required to deal with the storage of waste. In the unlikely event that a spill of waste occurs during the storage, the spill will be immediately cleaned up when discovered.

The volume of waste at the ICDF Complex will be know at all times. A running inventory of the waste in the various ICDF Complex facilities is maintained in the waste tracking system. The use of properly designed containers at the ICDF Complex reduces the likelihood of a spill of waste. 
At the ICDF Complex, inspections are conducted periodically. These inspections look for signs of container deterioration, bulging, and other indicators. These indications are used to identify abnormal conditions that could result in the release of waste materials to the environment. When an abnormal or deteriorating condition is identified for a container, the container is repaired or overpacked as necessary to prevent the release of waste materials.

In addition to storage at the ICDF Complex, there are treatment systems for LLW. These treatment system deal with soils and debris. The requirements and criteria discussed above were considered in the design of the treatment systems. This ensures that the treatment systems for the ICDF Complex will meet the facility design requirements for dealing with radionuclide contaminated waste streams.

This section of DOE Manual 435.1 was not directly cited as an ARAR for the ICDF Complex in the OU 3-13 ROD. In Section 9, facility design is addressed and shows the associated ARARs and CERCLA documents for the ICDF Complex.

\subsubsection{Low-Level Waste Disposal Facility Design (IV.M.3.)}

In DOE Manual 435.1, the LLW disposal facility design requirements are as follows:

Low-Level Waste Disposal Facility Design. The following facility requirements and general design criteria, at a minimum, apply:

- $\quad$ Confinement. Low-level waste systems and components shall be designed to maintain waste confinement.

- Ventilation.

- $\quad$ Design of low-level waste disposal facilities shall include ventilation, if applicable, through an appropriate filtration system to maintain the release of radioactive material in airborne effluents within the requirements and guidelines specified in applicable requirements.

- When conditions exist for generating gases in flammable or explosive concentrations, ventilation systems or other measures shall be provided to keep the gases in a non-flammable and non-explosive condition. Where concentrations of explosive or flammable gases are expected to approach the lower flammability limit, measures shall be taken to prevent deflagration or detonation.

- $\quad$ Stability. Low-level waste disposal facilities shall be designed to achieve long-term stability and to minimize to the extent practical, the need for active maintenance following final closure.

- $\quad$ Control of Water. Low-level waste disposal facilities shall be designed to minimize to the extent practical, the contact of waste with water during and after disposal. 
This requirement is classified as substantive. In the Implementation Guide for use with DOE Manual 435.1, the objectives are

1. To ensure the design of LLW disposal facilities includes features and/or equipment capable of containing LLW so that releases that could result in exposures to workers or the public or that could contaminate the environment are minimized.

2. To ensure that the design of LLW disposal facilities includes features to remove radioactive materials from airborne effluents that could endanger worker or public safety and/or the environment to levels allowed in applicable requirements before they are released, and to preclude or mitigate the accumulation of explosive and oxidizer gases in the facilities which could lead to uncontrolled releases of radioactive materials.

3. To ensure that the design features of LLW disposal facilities provide for three basic objectives of safe and environmentally protective radioactive waste disposal: that the facilities will be stable for a long time, that little or no active maintenance is needed to maintain this desired stability after the facility is closed, and that contact of waste and water that could degrade waste forms or transport radionuclides is minimized.

The ICDF landfill was design to be compliant with RCRA Subtitle C, TSCA PCB, and DOE Order 435.1 performance criteria. The design was evaluated for impacts on worker, the public, and the environment. The WAC was set at limits to remain protective of these potential receptors. This ensures that adequate confinement of the waste is maintained during operations and following closure. As the disposal facility is an open air landfill during operations, there is no need for ventilation.

The ICDF Complex is not intended to accept waste that can result in explosive or flammable concentration of gases. If the waste material is expected to generate concentrations of gases that would be capable of creating a fire or explosion, additional requirements would be imposed on the container of waste. The additional requirements must be addressed before the waste stream would be acceptable for disposal in the ICDF landfill. This ensures that there is not a fire or explosion issue within the landfill from the waste being disposed.

The volume of waste, including TRU waste, at the ICDF Complex will be known at all times. A running inventory of the waste in the various ICDF Complex facilities is maintained in the waste tracking system.

There are specific requirements concerning void space and compaction for the ICDF landfill. These are presented in the WAC. The design evaluated the stability issue and the limits were set based on the design. This ensures that the closed facility will remain in a stable configuration that does not requirement significant maintenance to maintain performance.

During operations, water leaching through the waste is controlled by the leachate collection and recovery systems. These systems remove the leachate generated by water passing through the waste prior to migration into the vadose zone. The engineered containment structure (cap) that was designed for the ICDF landfill at closure had control of water as the major criteria. The cap as designed reduces the expected infiltration to very low levels following closure. The cap design was evaluated as it would look like in 1,000 years with the applicable erosion and settlement. Prior to the 1,000-year period, additional protection is afforded by the increased thickness of the cap, which reduces the infiltration further. The WAC limits were set assuming the cap following the 1,000 years of degradation. This ensures that the ICDF landfill remains protective. 
This section of DOE Manual 435.1 was not directly cited as an ARAR for the ICDF Complex in the OU 3-13 ROD. In Section 9, facility design is addressed and shows the associated ARARs and CERCLA documents for the ICDF Complex.

\subsection{Storage and Staging (IV.N.)}

In DOE Manual 435.1, there are seven storage and staging requirements for LLW. These additional requirements are presented in Sections 8.14.1 through 8.14.7.

\subsubsection{Storage Prohibitions (IV.N.1.)}

In DOE Manual 435.1, the storage prohibitions requirements are as follows:

Storage Prohibitions. Low-level waste in storage shall not be readily capable of detonation, explosive decomposition, reaction at anticipated pressures and temperatures, or explosive reaction with water. Prior to storage, pyrophoric materials shall be treated, prepared, and packaged to be nonflammable.

This requirement is classified as substantive. In the Implementation Guide for use with DOE Manual 435.1, the objective of this requirement is to promote safe storage of LLW by eliminating from storage materials which could result in fires or explosions due to their reactivity or ignitability.

The ICDF Complex is not intended to accept waste that can result in explosive or flammable concentration of gases. If the waste material is expected to generate concentrations of gases that would be capable of creating a fire or explosion, additional requirements would be imposed on the container of waste. These additional requirements could include forced ventilation or other methods to control the concentrations of gases in the waste container to levels below concern. Information on the makeup of the waste is included on the waste profile, which must be accepted before the waste can be received into the ICDF Complex. Storage of waste which may generate these concentrations of gases would be strictly limited and controlled at the ICDF Complex to remain within the hazard analysis for the ICDF Complex. Waste materials with a pyrophoric nature are restricted from receipt at the ICDF Complex as they are capable of reacting violently with water. If waste material with pyrophoric constituents are to be received into the ICDF Complex, the waste material must be rendered no reactive prior to receipt to remain within the hazard analysis.

This section of DOE Manual 435.1 was not directly cited as an ARAR for the ICDF Complex in the OU 3-13 ROD. In Section 9, storage is addressed and shows the associated ARARs and CERCLA documents for the ICDF Complex.

\subsubsection{Storage Limit (IV.N.2.)}

In DOE Manual 435.1, the storage limit requirement is as follows:

Storage Limit. Low-level waste that has an identified path to disposal shall not be stored longer than one year prior to disposal, except for storage for decay, or as otherwise authorized by the Field Element Manager.

This requirement is classified as administrative. In the Implementation Guide for use with DOE Manual 435.1, the objective of this requirement is to limit LLW in storage, provide for the timely disposal of LLW, and to limit waste from being stored for indefinite periods of time. LLW is to be actively managed so that final disposition can be achieved with a minimum of storage time during its life cycle. 
Within the ICDF Complex there are various storage and staging areas. These areas are not intended to be used as a long-term storage facility. However, it may be necessary to store waste until the disposal facility is ready to accept the waste or until an appropriate other disposal facility is found that can take the waste depending on compliance with the WAC. The ICDF Complex staging, for waste staging piles, is defined with a time limit of two years. After this amount of time, the waste is considered to be in storage. However, the intent the ICDF Complex operations is to minimize the amount of waste in storage. All waste streams in storage or staging will be inspected to maintain the ICDF Complex is a safe and protective manner.

This section of DOE Manual 435.1 was not directly cited as an ARAR for the ICDF Complex in the OU 3-13 ROD. In Section 9, storage is addressed and shows the associated ARARs and CERCLA documents for the ICDF Complex.

\subsubsection{Storage Integrity (IV.N.3.)}

In DOE Manual 435.1, the storage integrity requirement is as follows:

Storage Integrity. Low-level waste shall be stored in a location and manner that protects the integrity of waste for the expected time of storage and minimizes worker exposure.

This requirement is classified as substantive. In the Implementation Guide for use with DOE Manual 435.1, the objective of this requirement is to ensure that the selection of the location and method for storing LLW is made so that both workers and the containers of waste are provided with adequate protection.

Some containerized waste at the ICDF Complex will be stored at the SSA. This is a fenced paved storage facility under INL CERCLA control. The containers are periodically inspected for a variety of criteria including container condition. If the containers are degrading, the containers are repaired or overpacked. These requirements will also apply to waste in storage at the ICDF Complex. This will ensure that the container integrity is maintained and the workers are provided with adequate protection for exposure to TRU waste materials.

Also, bulk storage of contaminated soils and debris will occur at the ICDF Complex. This storage will also include inspection and repair requirements. However, the containers in this case is a membrane beneath the waste with a membrane above the waste. The upper membrane is removed for transfers into and out of the waste storage area.

This section of DOE Manual 435.1 was not directly cited as an ARAR for the ICDF Complex in the OU 3-13 ROD. In Section 9, storage is addressed and shows the associated ARARs and CERCLA documents for the ICDF Complex.

\subsubsection{Storage Waste Characterization (IV.N.4.)}

In DOE Manual 435.1, the storage waste characterization requirements are as follows:

Low-level waste that does not have an identified path to disposal shall be characterized as necessary to meet the data quality objectives and minimum characterization requirements of this Chapter, to ensure safe storage, and to facilitate disposal. 
Characterization information for all low-level waste in storage shall be maintained as a record in accordance with the requirements for Records Management in Chapter I of the Manual.

This requirement is classified as substantive. In the Implementation Guide for use with DOE Manual 435.1, there are two requirements. The first requirement is to establish, document, and maintain minimum characterization information for LLW that does not have an identified path to disposal. Minimum characterization information will facilitate future disposal because the historical knowledge of the waste is preserved. Characterizing LLW with no identified path to disposal will enable it to be stored safely and for disposal options to be evaluated. When a disposal option is ultimately identified the nominal characterization information necessary for it to be acceptable for disposal will be available. The second requirement is to ensure that characterization information on waste in storage is maintained as a federal record, providing a traceable path if future actions require knowledge of the original characterization information.

When developing a SAP for an INL CERCLA project, data quality objectives are developed and documented. This same process was followed for the development of the verification SAP for the ICDF Complex. For the ICDF Complex verification SAP, the data quality objectives were focused on what information (contaminant concentrations) was necessary to ensure that the waste would remain within the WAC. Because, the data quality objectives were developed for the ICDF Complex related to the WAC limits it is not necessary to develop individual waste stream data quality objectives. Also, data quality objectives are discussed in the WAC for the ICDF Complex. The information collected during the characterization and/or verification activities is maintained as records in the appropriate storage configuration.

This section of DOE Manual 435.1 was not directly cited as an ARAR for the ICDF Complex in the OU 3-13 ROD. In Section 9, waste characterization is addressed and shows the associated ARARs and CERCLA documents for the ICDF Complex.

\subsubsection{Container Inspection (IV.N.5.)}

In DOE Manual 435.1, the container inspection requirement is as follows:

Container Inspection. A process shall be developed and implemented for inspecting and maintaining containers of low-level waste to ensure container integrity is not compromised.

This requirement is classified as substantive. In the Implementation Guide for use with DOE Manual 435.1, the objective of this requirement is to prevent or minimize the potential exposure of workers and release of radioactive contamination to the environment that could result from allowing LLW containers to degrade. The requirement is intended to ensure that the containment function of the waste containers is routinely evaluated and action taken to ensure the waste remains contained.

At the ICDF Complex, inspections are conducted periodically. These inspections look for signs of container deterioration, bulging, and other indicators. These indications are used to identify abnormal conditions that could result in the release of waste materials to the environment. When an abnormal or deteriorating condition is identified for a container, the container is repaired or overpacked as necessary to prevent the release of waste materials.

This section of DOE Manual 435.1 was not directly cited as an ARAR for the ICDF Complex in the OU 3-13 ROD. In Section 9, storage is addressed and shows the associated ARARs and CERCLA documents for the ICDF Complex. 


\subsubsection{Storage Management (IV.N.6.)}

In DOE Manual 435.1, the storage management requirement is as follows:

Storage Management. Low-level waste storage shall be managed to identify and segregate low-level waste from mixed low-level waste.

This requirement is classified as administrative. In the Implementation Guide for use with DOE Manual 435.1, the objective of this requirement is to prevent the commingling of LLW with MLLW.

Waste can be received into the ICDF in a variety of container or transport vessels. The shipments into the ICDF Complex may result in bulk material being delivered without a containment container. When waste streams are received at the ICDF Complex for direct disposal, the container is only used for shipment. Other waste streams will be received into the ICDF Complex for treatment and the same type of container may be used as a shipping container.

Appropriate markings will be placed on the containers of waste that is classified as LLW. These markings will be visible and used to ensure that the LLW and MLLW are managed appropriately. However, there are not separate areas for the storage/staging of LLW and MLLW streams. All waste streams will be staged and stored in the same areas. The marking and labeling of areas along with the waste tracking system will be used to know what waste stream has what characteristics.

This section of DOE Manual 435.1 was not directly cited as an ARAR for the ICDF Complex in the OU 3-13 ROD. In Section 9, packaging is addressed and shows the associated ARARs and CERCLA documents for the ICDF Complex.

\subsubsection{Staging (IV.N.7.)}

In DOE Manual 435.1, the staging requirement is as follows:

Staging. Staging of low-level waste shall be for the purpose of the accumulation of such quantities of waste as necessary to facilitate transportation, treatment, and disposal. Staging longer than 90 days shall meet the requirements for storage above and in Chapter I of the Manual.

This requirement is classified as administrative. In the Implementation Guide for use with DOE Manual 435.1, the objective of this requirement is to allow for the safe temporary accumulation of LLW to facilitate its management without the accumulation being considered storage and thus bound by the associated requirements for storage.

Within the ICDF Complex there are various storage and staging areas. These areas are not intended to be used as a long-term storage facility. However, it may be necessary to stage waste until the disposal facility is ready to accept the waste or until an appropriate other disposal facility is found that can take the waste depending on compliance with the WAC. The ICDF Complex staging, for waste staging piles, is defined with a time limit of two years. After this amount of time, the waste is considered to be in storage. However, the intent the ICDF Complex operations is to minimize the amount of waste in staging and storage. All waste streams in storage or staging will be inspected to maintain the ICDF Complex is a safe and protective manner.

This section of DOE Manual 435.1 was not directly cited as an ARAR for the ICDF Complex in the OU 3-13 ROD. In Section 9, storage is addressed and shows the associated ARARs and CERCLA documents for the ICDF Complex. 


\subsection{Treatment (IV.O.)}

In DOE Manual 435.1, the treatment requirement is as follows:

Low-level waste treatment to provide more stable waste forms and to improve the long- term performance of a low-level waste disposal facility shall be implemented as necessary to meet the performance objectives of the disposal facility.

This requirement is classified as substantive. In the Implementation Guide for use with DOE Manual 435.1, the objective of this requirement is to ensure LLW is treated to meet disposal facility WAC, to achieve greater stability of the disposal site, and for a greater level of assurance that the disposal performance objectives are met.

The treatment systems at the ICDF Complex are designed to be simple and reliable. These treatment systems are designed to treat the waste to meet the ICDF landfill disposal WAC. For the treatment of debris, grout will be pumped into the waste container to fill the void spaces. Soil will be treated by mixing reagents (cement, fly ash, etc.) with the contaminated soil using limited water, which will produce a treated waste form resembling soil. These treatment system comply with the requirements of dealing with hazardous waste components under RCRA. These treatment systems ensure that the treated waste meet the performance standard and requirements for disposal in the ICDF landfill according to the WAC.

This section of DOE Manual 435.1 was not directly cited as an ARAR for the ICDF Complex in the OU 3-13 ROD. In Section 9, facility design is addressed and shows the associated ARARs and CERCLA documents for the ICDF Complex.

\subsection{Disposal (IV.P.)}

In DOE Manual 435.1, there are seven disposal requirements for LLW. These additional requirements are presented in Sections 8.16.1 through 8.16.7.

\subsubsection{Performance Objectives (IV.P.1.)}

In DOE Manual 435.1, the performance objectives requirements are as follows:

Performance Objectives. Low-level waste disposal facilities shall be sited, designed, operated, maintained, and closed so that a reasonable expectation exists that the following performance objectives will be met for waste disposed of after September 26, 1988:

- Dose to representative members of the public shall not exceed $25 \mathrm{mrem}$ $(0.25 \mathrm{mSv})$ in a year total effective dose equivalent from all exposure pathways, excluding the dose from radon and its progeny in air.

- Dose to representative members of the public via the air pathway shall not exceed $10 \mathrm{mrem}(0.10 \mathrm{mSv})$ in a year total effective dose equivalent, excluding the dose from radon and its progeny.

- Release of radon shall be less than an average flux of $20 \mathrm{pCi} / \mathrm{m}^{2} / \mathrm{s}$ $\left(0.74 \mathrm{~Bq} / \mathrm{m}^{2} / \mathrm{s}\right)$ at the surface of the disposal facility. Alternatively, a limit 
of $0.5 \mathrm{pCi} / 1(0.0185 \mathrm{~Bq} / \mathrm{l})$ of air may be applied at the boundary of the facility.

This requirement is classified as substantive. In the Implementation Guide for use with DOE Manual 435.1, the objective of these requirements is to ensure that all phases of LLW disposal (i.e., facility siting and design, operations, maintenance, and closure) are conducted in a manner that will result in a reasonable expectation that the disposal performance objectives will be met. The performance objectives are specific objectives that quantify, where possible, the desired protection of the public and the environment from disposed LLW.

The ICDF Complex has been designed and is being constructed to safely manage radioactive waste. Impacts from the management of radioactive waste constituents and other constituents have analyzed. All pathways were analyzed during the development of the design and establishment of the WAC. These impacts were determined to be acceptable and less than the performance criteria stated above.

This section of DOE Manual 435.1 was not directly cited as an ARAR for the ICDF Complex in the OU 3-13 ROD. In Section 9, facility design is addressed and shows the associated ARARs and CERCLA documents for the ICDF Complex.

\subsubsection{Performance Assessment (IV.P.2.)}

In DOE Manual 435.1, the performance assessment requirements are as follows:

Performance Assessment. A site-specific radiological performance assessment shall be prepared and maintained for DOE low-level waste disposed of after September 26, 1988. The performance assessment shall include calculations for a 1,000 year period after closure of potential doses to representative future members of the public and potential releases from the facility to provide a reasonable expectation that the performance objectives identified in Chapter IV are not exceeded as a result of operation and closure of the facility.

Analyses performed to demonstrate compliance with the performance objectives in Chapter IV, and to establish limits on concentrations of radionuclides for disposal based on the performance measures for inadvertent intruders in Chapter IV shall be based on reasonable activities in the critical group of exposed individuals. Unless otherwise specified, the assumption of average living habits and exposure conditions in representative critical groups of individuals projected to receive the highest doses is appropriate. The likelihood of inadvertent intruder scenarios may be considered in interpreting the results of the analyses and establishing radionuclide concentrations, if adequate justification is provided.

The point of compliance shall correspond to the point of highest projected dose or concentration beyond a 100 meter buffer zone surrounding the disposed waste. A larger or smaller buffer zone may be used if adequate justification is provided.

Performance assessments shall address reasonably foreseeable natural processes that might disrupt barriers against release and transport of radioactive materials.

Performance assessments shall use DOE-approved dose coefficients (dose conversion factors) for internal and external exposure of reference adults. 
The performance assessment shall include a sensitivity/uncertainty analysis.

Performance assessments shall include a demonstration that projected releases of radionuclides to the environment shall be maintained as low as reasonably achievable (ALARA).

For purposes of establishing limits on radionuclides that may be disposed of near- surface, the performance assessment shall include an assessment of impacts to water resources.

For purposes of establishing limits on the concentration of radionuclides that may be disposed of near-surface, the performance assessment shall include an assessment of impacts calculated for a hypothetical person assumed to inadvertently intrude for a temporary period into the low-level waste disposal facility. For intruder analyses, institutional controls shall be assumed to be effective in deterring intrusion for at least 100 years following closure. The intruder analyses shall use performance measures for chronic and acute exposure scenarios, respectively, of $100 \mathrm{mrem}(1 \mathrm{mSv})$ in a year and $500 \mathrm{mrem}(5 \mathrm{mSv})$ total effective dose equivalent excluding radon in air.

This requirement is classified as administrative. In the Implementation Guide for use with DOE Manual 435.1, the objective of these requirements is to ensure that all aspects of LLW disposal (i.e., facility siting and design, operations, maintenance, and eventual closure) are analyzed in a performance assessment to provide a reasonable expectation that the disposal performance objectives will be met.

A performance assessment has been developed for the ICDF landfill. This performance assessment followed the standard layout of the analysis. Included within the performance assessment are all of the criteria and requirements discussed above. The result of the performance assessment is that the ICDF landfill meets all of the criteria and requirements for disposal of LLW.

This section of DOE Manual 435.1 was not directly cited as an ARAR for the ICDF Complex in the OU 3-13 ROD. In Section 9, facility design is addressed and shows the associated ARARs and CERCLA documents for the ICDF Complex.

\subsubsection{Composite Analysis (IV.P.3.)}

In DOE Manual 435.1, the composite analysis requirements are as follows:

Composite Analysis. For disposal facilities which received waste after September 26, 1988, a site-specific radiological composite analysis shall be prepared and maintained that accounts for all sources of radioactive material that may be left at the DOE site and may interact with the low-level waste disposal facility, contributing to the dose projected to a hypothetical member of the public from the existing or future disposal facilities. Performance measures shall be consistent with DOE requirements for protection of the public and environment and evaluated for a 1,000 year period following disposal facility closure. The composite analysis results shall be used for planning, radiation protection activities, and future use commitments to minimize the likelihood that current low-level waste disposal activities will result in the need for future corrective or remedial actions to adequately protect the public and the environment. 
This requirement is classified as administrative. In the Implementation Guide for use with DOE Manual 435.1, the objective of this requirement is to ensure that a prospective assessment be conducted to assess potential dose to hypothetical members of the public from the aggregate of residual radioactive material that is likely to remain on a DOE site and that is likely to add to the dose from an active or planned LLW disposal facility.

A composite analysis has been developed for the ICDF landfill that includes all interacting sources. This composite analysis followed the standard layout of the analysis. Included within the composite analysis are all of the criteria and requirements discussed above. The result of the composite analysis is that the ICDF landfill meets all of the criteria and requirements for disposal of LLW. The cumulative impacts are considerably less than the standards as stated in DOE Manual 435.1.

This section of DOE Manual 435.1 was not directly cited as an ARAR for the ICDF Complex in the OU 3-13 ROD. In Section 9, facility design is addressed and shows the associated ARARs and CERCLA documents for the ICDF Complex.

\subsubsection{Performance Assessment and Composite Analysis Maintenance (IV.P.4.)}

In DOE Manual 435.1, the performance assessment and composite analysis maintenance requirements are as follows:

Performance Assessment and Composite Analysis Maintenance. The performance assessment and composite analysis shall be maintained to evaluate changes that could affect the performance, design, and operating bases for the facility. Performance assessment and composite analysis maintenance shall include the conduct of research, field studies, and monitoring needed to address uncertainties or gaps in existing data. The performance assessment shall be updated to support the final facility closure. Additional iterations of the performance assessment and composite analysis shall be conducted as necessary during the post-closure period.

Performance assessments and composite analyses shall be reviewed and revised when changes in waste forms or containers, radionuclide inventories, facility design and operations, closure concepts, or the improved understanding of the performance of the waste disposal facility in combination with the features of the site on which it is located alter the conclusions or the conceptual model(s) of the existing performance assessment or composite analysis.

A determination of the continued adequacy of the performance assessment and composite analysis shall be made on an annual basis, and shall consider the results of data collection and analysis from research, field studies, and monitoring.

Annual summaries of low-level waste disposal operations shall be prepared with respect to the conclusions and recommendations of the performance assessment and composite analysis and a determination of the need to revise the performance assessment or composite analysis.

This requirement is classified as administrative. In the Implementation Guide for use with DOE Manual 435.1, the objectives of these requirements are (1) to ensure that performance assessments and composite analyses are updated as appropriate, whenever changes in their bases (assumptions, 
parameters, etc.) are contemplated or effected in order to maintain the validity and effectiveness of the controls which are based on the performance assessment and composite analysis and (2) to ensure that the bases of the performance assessment and composite analysis (e.g., assumptions, parameters, waste inventory) remain valid and to ensure that results of testing, research, and development, and monitoring are considered in this determination and summary.

Both a performance assessment and composite analysis for the ICDF landfill have been developed. These reports along with the associated analysis will be update/revised as necessary. These changes will only be done if impacts or changes are expected to result in significant changes in the results of the analysis. Other information that is developed from other activities will be considered for impacts on the existing analysis and incorporated as appropriate.

The performance assessment and composite analysis will be evaluated annually to determine the need to update/revise the analysis. This evaluation will be documented and maintained in the project file. Also, an annual summary of the waste operations at the ICDF landfill will be prepared, which will include the inventories disposed and other relevant operating information.

This section of DOE Manual 435.1 was not directly cited as an ARAR for the ICDF Complex in the OU 3-13 ROD. In Section 9, facility design is addressed and shows the associated ARARs and CERCLA documents for the ICDF Complex.

\subsubsection{Disposal Authorization (IV.P.5.)}

In DOE Manual 435.1, the disposal authorization requirements are as follows:

Disposal Authorization. A disposal authorization statement shall be obtained prior to construction of a new low-level waste disposal facility. Field Elements with existing low-level waste disposal facilities shall obtain a disposal authorization statement in accordance with the schedule in the Complex-Wide Low-Level Waste Management Program Plan. The disposal authorization statement shall be issued based on a review of the facility's performance assessment, composite analysis, performance assessment and composite analysis maintenance, preliminary closure plan, and preliminary monitoring plan. The disposal authorization statement shall specify the limits and conditions on construction, design, operations, and closure of the low level waste facility based on these reviews. A disposal authorization statement is a part of the radioactive waste management basis for a disposal facility. Failure to obtain a disposal authorization statement by the implementation date of this Order shall result in shutdown of the disposal facility.

This requirement is classified as administrative. In the Implementation Guide for use with DOE Manual 435.1, the objectives of this requirement is to ensure that any conditions or limitations that are required on the operations of a LLW disposal facility or waste accepted at the facility that result from the review and approval of the performance assessment and composite analysis maintenance plans, monitoring plans, and closure plans are included in the radioactive waste management basis for the facility.

The performance assessment, composite analysis, preliminary closure plan, and monitoring plans have all been developed. The development of the performance assessment and composite analysis were based on the results and design studies conducted to develop the WAC. The planned operations of the ICDF Complex are within the limits set by the various studies. This ensures that the ICDF Complex can 
and will be operated in a safe manner based on the limited developed in the design, construction, and implementation documents.

It is expected that the review of this compliance demonstration document along with the performance assessment and composite analysis will result in the issuance of the disposal authorization statement. However, the disposal authorization statement is not a document prepared by the ICDF Complex project. Delays in obtaining the disposal authorization statement could delay the start of operations for the ICDF Complex. Following receipt of the disposal authorization statement, the plans will be revised, as determined to be necessary, to include the additional requirements for the disposal facility radioactive waste management basis.

This section of DOE Manual 435.1 was not directly cited as an ARAR for the ICDF Complex in the OU 3-13 ROD. In Section 9, facility design is addressed and shows the associated ARARs and CERCLA documents for the ICDF Complex.

\subsubsection{Disposal Facility Operations (IV.P.6.)}

In DOE Manual 435.1, the disposal facility operations requirements are as follows:

Disposal Facility Operations. The disposal facility design and operation must be consistent with the disposal facility closure plan and lead to disposal facility closure that provides a reasonable expectation that performance objectives will be met. Low-level waste shall be disposed in such a manner that achieves the performance objectives stated in Chapter IV, consistent with the disposal facility radiological performance assessment. Additional requirements include:

- $\quad$ Operating procedures shall be developed and implemented for low-level waste disposal facilities that protect the public, workers, and the environment; ensure the security of the facility; minimize subsidence during and after waste emplacement; achieve long-term stability and minimize the need for long-term active maintenance; and meet the requirements of the closure/post-closure plan.

- $\quad$ Permanent identification markers for disposal excavations and monitoring wells shall be emplaced.

- $\quad$ Low-level waste placement into disposal units shall minimize voids between waste containers. Voids within disposal units shall be filled to the extent practical. Uncontainerized bulk waste shall also be placed in a manner that minimizes voids and subsidence.

- Operations are to be conducted so that active waste disposal operations will not have an adverse effect on any other disposal units.

- $\quad$ Operations shall include a process for tracking and documenting low-level waste placement in the facility by generating source. 
This requirement is classified as substantive. In the Implementation Guide for use with DOE Manual 435.1, the objectives of this requirement are

1. To ensure that the low-level disposal facility is operated in a manner that adheres to the requirements and limitations contained in and derived from the closure plan and performance assessment and the critical documents related to design and operational functions that provide reasonable assurance the disposal performance objectives will be met at the facility.

2. To ensure that operating procedures are developed, documented, and implemented for the critical functions listed in the requirement that are important to meeting the performance objectives for LLW disposal over the long term. The objective of this requirement is to ensure that physical identification markers are placed to locate trenches and monitoring wells so they will be able to be located in the future as an additional measure against inadvertent intrusion.

3. To enhance the integrity of the disposed waste and the disposal unit to the maximum extent practicable by elimination of voids between waste packages within the disposal unit.

4. To enhance the integrity of the disposed waste and the disposal unit to the maximum extent practicable by ensuring that ongoing operations do not adversely affect disposal units that are already filled.

5. To preserve the knowledge of the location of specific wastes in the disposal unit and the detailed characterization information about the waste in the event corrective actions are necessary.

The ICDF Complex will have detailed operating procedure that are based on the design, construction, and implementing documents. The design, construction, and implementing documents were developed to analyze the impacts on human health and the environment. The limits imposed by these documents ensures that the ICDF Complex, including the disposal facility, will be protective. Also, the design document analyzed the subsidence issues and established limits for void space and compaction requirements. This analysis along with the implementation will ensure that the postclosure activities for maintenance are minimized and the long-term performance is as expected. After closure, permanent markers will be installed at the location of the four corners of the disposal facility and around monitoring wells.

There are no other disposal units in close proximity to this disposal facility. This minimizes the impacts on the operations at the ICDF Complex disposal unit and the other disposal units on the INL. However, the impacts of closure of INTEC facilities were evaluated in the composite analysis to determine the total impacts and risks. The INTEC facilities are not located within the area of operations for the ICDF disposal facility.

The waste tracking system has a variety of functions. The tracking system will maintain the inventory disposed in the disposal facility, including the radionuclide and nonradionuclide constituents and volumes. Also, the location of the disposal within the cell will be maintained in the waste tracking system along with the source of the waste disposed.

This section of DOE Manual 435.1 was not directly cited as an ARAR for the ICDF Complex in the OU 3-13 ROD. In Section 9, facility design is addressed and shows the associated ARARs and CERCLA documents for the ICDF Complex. 


\subsubsection{Alternate Requirements for Low-Level Waste Disposal Facility Design and Operation (IV.P.7.)}

In DOE Manual 435.1, the alternate requirements for LLW disposal facility design and operation requirements are as follows:
Alternate Requirements for Low-Level Waste Disposal Facility Design and Operation. Requirements other than those set forth in this section for the design and operation of a low-level waste disposal facility may be approved on a specific basis if a reasonable expectation is demonstrated that the disposal performance objectives will be met.

This requirement is classified as administrative. In the Implementation Guide for use with DOE Manual 435.1, the objective of this requirement is to allow for site-specific approval of alternative methodologies for establishing the design and operation of a LLW disposal facility other than use of the performance assessment and composite analysis as long as the disposal performance objectives for protection of the public and the environment in the future are met.

In developing the design for the ICDF landfill, a different approach was used to determine the impacts on human health and the environment than is used in a performance assessment. These methodologies were used to establish the limits and other operating criteria, include the WAC. However, the analysis done for design did not consider the impacts from other facilities that is included in a composite analysis or certain intruder scenarios that are normally evaluated in a performance assessment. To deal with these issues, both a performance assessment (using standard methodology) and composite analysis were developed following the development of the design for the disposal facility. The result of the performance assessment was that the impacts were less than predicted from the design analysis and within the acceptable limits. The composite analysis also shows that the impacts are within the acceptable range.

This section of DOE Manual 435.1 was not directly cited as an ARAR for the ICDF Complex in the OU 3-13 ROD. In Section 9, facility design is addressed and shows the associated ARARs and CERCLA documents for the ICDF Complex.

\subsection{Closure (IV.Q.)}

In DOE Manual 435.1, there are two closure requirements for LLW. These additional requirements are presented in Sections 8.17.1 and 8.17.2.

\subsubsection{Disposal Facility Closure Plans (IV.Q.1.)}

In DOE Manual 435.1, the disposal facility closure plans requirements are as follows:

Disposal Facility Closure Plans. A preliminary closure plan shall be developed and submitted to Headquarters for review with the performance assessment and composite analysis. The closure plan shall be updated following issuance of the disposal authorization statement to incorporate conditions specified in the disposal authorization statement.

Be updated as required during the operational life of the facility. 
Include a description of how the disposal facility will be closed to achieve long-term stability and minimize the need for active maintenance following closure and to ensure compliance with the requirements of DOE 5400.5, Radiation Protection of the Public and the Environment.

Include the total expected inventory of wastes to be disposed of at the facility over the operational life of the facility.

This requirement is classified as administrative. In the Implementation Guide for use with DOE Manual 435.1, the objectives of these requirements are

1. To ensure that critical information on LLW disposal facility closure analyzed in the performance assessments and composite analyses is documented in a preliminary plan that is submitted along with performance assessment and composite analysis for review and to ensure that any changes to the facility closure plan that is part of a condition of the disposal authorization statement is formally incorporated into the closure plan.

2. To ensure that conditions encountered or developed during the operation of a LLW disposal facility that will impact long-term safety and environmental considerations when the facility is closed are incorporated into the closure plan in a timely fashion.

3. To ensure that the primary public health and environmental protection requirements are addressed in the closure plan, as well as the principal goals of achieving long-term stability and minimizing maintenance after closure.

4. To ensure that the closure plan is updated throughout the operation of the facility to accurately reflect and consider all of the long-term hazards associated with the actual inventory of LLW disposed at the facility over its operational lifetime.

A preliminary closure plan has been developed for the closure of the entire ICDF Complex. Within this preliminary closure plan, the closure of the disposal facility (landfill) is included and includes the engineered barrier (cap) design and specifications. This preliminary closure plan was included in the ICDF Complex remedial action work plan. The performance assessment and composite analysis used the information from the preliminary closure plan approach and design documents in the assessment of impacts. The preliminary closure plan also discussed postclosure activities. This closure plan will not likely be updated during the operation of the facility, but will be revised and updated prior to closure to specify the details and specifications that will be used during the closure activities and to refine the postclosure monitoring/maintenance activities.

Protection of human health and the environment were key criteria that had to be met during the development of the WAC. Development of the WAC stated with an expected inventory. The resulting WAC resulted in an acceptable inventory greatly exceeding the expected inventory. This ensures that the disposal facility will remain protective. This information was used in the development of the preliminary closure plan. The inventory disposed in the facility will be tracked and maintained. However, with the acceptable inventory being much greater than the expected inventory, the closure plan will not be updated during operations unless there are significant changes that would impact the protectiveness of the facility. The closure plan will be updated and expanded in detail prior to closure.

This section of DOE Manual 435.1 was not directly cited as an ARAR for the ICDF Complex in the OU 3-13 ROD. In Section 9, facility design is addressed and shows the associated ARARs and CERCLA documents for the ICDF Complex. 


\subsubsection{Disposal Facility Closure (IV.Q.2.)}

In DOE Manual 435.1, the disposal facility closure requirements are as follows:

Disposal Facility Closure. Closure of a disposal facility shall occur within a five-year period after it is filled to capacity, or after the facility is otherwise determined to be no longer needed.

Prior to facility closure, the final inventory of the low-level waste disposed in the facility shall be prepared and incorporated in the performance assessment and composite analysis which shall be updated to support the closure of the facility.

A final closure plan shall be prepared based on the final inventory of waste disposed in the facility, the plan implemented, and the updated performance assessment and composite analysis prepared in support of the facility closure.

Institutional control measures shall be integrated into land use and stewardship plans and programs, and shall continue until the facility can be released pursuant to DOE 5400.5, Radiation Protection of the Public and the Environment.

The location and use of the facility shall be filed with the local authorities responsible for land use and zoning.

This requirement is classified as administrative. In the Implementation Guide for use with DOE Manual 435.1, the objectives of these requirements are

1. To ensure that the disposal facility does not remain in an unmaintained state, leading to compromise of the ability of the disposal units to contribute to long-term stability and protection of the public, workers, and the environment.

2. To ensure that necessary information associated with the final inventory of LLW disposed at the facility over its operational lifetime is incorporated into the performance assessment and composite analysis in support of the final closure of the facility, and then incorporated into the closure plan to provide protection of the workers, public, and environment from the long-term hazards posed by the disposal waste.

3. To ensure that institutional control will continue until the LLW disposal facility can be released for unrestricted use and that local land use records appropriately record the previous use of the land as a radioactive waste disposal facility to provide additional protection again misuse of the land and the possibility of an inadvertent intrusion.

The preliminary closure plan that has been developed for the ICDF Complex remedial action work plan will be revised and updated at the time of closure. Information that will be considered in the revised/updated closure plan will include the final inventory disposed in the facility, types of waste, locations of waste streams, and other relevant information. The performance assessment and composite analysis will be updated, as necessary, at the time of closure to incorporate the final inventory and other relevant information.

The institutional controls are specified in the preliminary closure plan. These institutional controls will be updated as necessary at the time of closure and included in the revised closure plan. Also, the necessary and required notifications will be filed and maintained for the closed disposal facility. 
This section of DOE Manual 435.1 was not directly cited as an ARAR for the ICDF Complex in the OU 3-13 ROD. In Section 9, facility design is addressed and shows the associated ARARs and CERCLA documents for the ICDF Complex.

\subsection{Monitoring (IV.R.)}

In DOE Manual 435.1, there are three monitoring requirements for LLW. These additional requirements are presented in Sections 8.18.1, 8.18.2, and 8.18.3.

\subsubsection{All Facilities (IV.R.1.)}

In DOE Manual 435.1, all facilities requirements are as follows:

All Waste Facilities. Parameters that shall be sampled or monitored, at a minimum, include: temperature, pressure (for closed systems), radioactivity in ventilation exhaust and liquid effluent streams, and flammable or explosive mixtures of gases. Facility monitoring programs shall include verification that passive and active control systems have not failed.

This requirement is classified as substantive. In the Implementation Guide for use with DOE Manual 435.1, the objective of this requirement is to specify minimum parameters for which information will be routinely collected and analyzed for the purpose of anticipating or identifying undesirable conditions in the management of LLW.

Waste being received into the ICDF Complex undergo characterization to support the waste profile. This characterization includes both process knowledge and physical sampling and analysis as necessary. Further sampling and analysis may be conducted for verification of the waste profile. This information is used to assess whether the waste meets the WAC. Some waste streams may be stored within the ICDF Complex at the SSA. This is a fenced and paved storage area. The temperature of the stored waste will assume ambient conditions and there is no possibility of building pressure in the storage facility nor is there a ventilation system. The ventilation will occur on the waste containers. Routine monitoring will be conducted as part of the periodic inspection of the containers in the storage areas at the ICDF Complex. These inspection will look for signs of damage, deterioration, and other indicators of problems. If issues are identified, appropriate actions will be taken to mitigate the risks.

This section of DOE Manual 435.1 was not directly cited as an ARAR for the ICDF Complex in the OU 3-13 ROD. In Section 9, monitoring is addressed and shows the associated ARARs and CERCLA documents for the ICDF Complex.

\subsubsection{Liquid Waste Storage Facilities (IV.R.2.)}

In DOE Manual 435.1, the liquid waste storage facilities requirement is as follows:

Liquid Waste Storage Facilities. For facilities storing liquid low-level waste, the following shall also be monitored: liquid level and/or waste volume, and significant waste chemistry parameters.

This requirement is classified as substantive. In the Implementation Guide for use with DOE Manual 435.1, the objective of this requirement is to ensure monitoring of parameters that indicate the quantity of liquid TRU waste stored in tanks so that changes can be promptly checked to determine if they indicate leakage, overfilling, or other problems. The objective of this requirement also includes tracking of the chemical characteristics of the waste to anticipate and avert undesirable storage conditions. 
The objective of this requirement is to mandate regular observation of parameters that indicate the quantity of liquid LLW stored in tanks (1) so that unexpected changes in quantity indications can be promptly checked to determine if they are a reflection of leakage or other problems; and (2) so that liquid LLW input to storage tanks will be monitored to avoid overfilling. The objective of this requirement also includes tracking of the chemical characteristics of the waste to anticipate and avert undesirable storage conditions.

Waste being received into the ICDF Complex undergo characterization to support the waste profile. This characterization includes both process knowledge and physical sampling and analysis as necessary. Further sampling and analysis may be conducted for verification of the waste profile. For liquid waste, the chemistry of the waste is sampled to for a variety of parameters to ensure that the waste is compatible with the expected waste containers. This information is used to assess whether the waste meets the WAC. The tanks used to store liquid waste in the ICDF Complex are double contained. The outer container is monitored to detect leakage of the primary container. If the primary container is leaking the waste would be transferred to another tank.

This section of DOE Manual 435.1 was not directly cited as an ARAR for the ICDF Complex in the OU 3-13 ROD. In Section 9, monitoring is addressed and shows the associated ARARs and CERCLA documents for the ICDF Complex.

\subsubsection{Disposal Facilities (IV.R.3.)}

In DOE Manual 435.1, the disposal facilities requirements are as follows:

Disposal Facilities. A preliminary monitoring plan for a low-level waste disposal facility shall be prepared and submitted to Headquarters for review with the performance assessment and composite analysis. The monitoring plan shall be updated within one year following issuance of the disposal authorization statement to incorporate and implement conditions specified in the disposal authorization statement.

The site-specific performance assessment and composite analysis shall be used to determine the media, locations, radionuclides, and other substances to be monitored.

The environmental monitoring program shall be designed to include measuring and evaluating releases, migration of radionuclides, disposal unit subsidence, and changes in disposal facility and disposal site parameters which may affect long-term performance.

The environmental monitoring programs shall be capable of detecting changing trends in performance to allow application of any necessary corrective action prior to exceeding the performance objectives in Chapter IV.

This requirement is classified as substantive. In the Implementation Guide for use with DOE Manual 435.1, the objectives of these requirements are

1. To ensure that the monitoring program is appropriately designed and administered in a way that supports the analysis and evaluations conducted in the performance assessment and composite analysis and the conditions under which the disposal facility may operate based on the review and approval of these assessments. 
2. To specify the minimum parameters that must be monitored at all LLW disposal facilities. Monitoring of these parameters can alert operators of changing conditions that could be caused by problems associated with the disposal of LLW at the facility. This requirement adds the specific monitoring for disposal facility performance for the long-term in addition to the monitoring requirements that are required in Chapter I.

3. To ensure that if data collected from the monitoring program indicates the facility is not performing as expected, that corrective actions will be initiated quickly to minimize potential impacts to the environment and the public health, and to maintain the reasonable assurance that the performance objectives will continue to be met.

For the ICDF landfill, a monitoring system has been designed and installed. This monitoring system includes monitoring of the leachate generated in the disposal facility and groundwater (perched water and the SRPA). The groundwater monitoring plan was included in the remedial design and construction work plan for the ICDF landfill and evaporation pond and the leachate monitoring plan was included in the ICDF Remedial Action Work Plan. These monitoring systems have been developed to specify the media to be sampled, locations and frequency for samples to be collected from, and the constituents (radionuclides and nonradionuclides) to be monitored. These monitoring systems are capable of detecting and evaluating releases from the disposal facility, including the migration of radionuclides. Other parameters that may impact the long-term performance of the disposal facility such as compaction will be periodically monitored to ensure that the disposal facility will meet the long-term performance objectives. The information collected will be capable of being used for trending purposes to detect changes and develop corrective actions as necessary. These monitoring plans will be updated as necessary, but not necessarily within one year of obtaining the disposal authorization statement, to incorporated new information from the monitoring activities. Also, the monitoring programs and other information that will be collected during operations is sufficient and appropriate to maintain/update the performance assessment and composite analysis as necessary.

This section of DOE Manual 435.1 was not directly cited as an ARAR for the ICDF Complex in the OU 3-13 ROD. In Section 9, facility design is addressed and shows the associated ARARs and CERCLA documents for the ICDF Complex. 


\section{CROSSWALK WITH 435.1 REQUIREMENTS}

This section presents a crosswalk of how the ICDF Complex complies with the various requirements in DOE Manual 435.1. This crosswalk information is presented in tabular form for ease of understanding and presentation. The requirements and/or responsibilities for each of the four chapters in DOE Manual 435.1 are presented along with whether the requirement was classified as substantive or administrative. Also, the ARARs from the OU 3-13 ROD or other driving CERCLA requirements are presented in this tabular presentation. Next, the CERCLA document prepared for the ICDF Complex project that provide additional information are presented. Finally, the whether the requirement is satisfied or not is presented in the tabular presentation.

The general requirements and responsibilities from Chapter I of DOE Manual 435.1 are presented in Table 9-1. Many of the responsibilities are for DOE-HQ organizations or particular personnel. Within the evaluation of the general requirement and responsibilities, all of requirements/responsibilities from Chapter I are presented regardless of whether classified as substantive or administrative.

Table 9-2 deals with Chapter II of DOE Manual 435.1. Chapter II deals with HLW. As the ICDF Complex will not be accepting HLW into the facility for any reason, only the definition of HLW was evaluated and presented in Table 9-2. However, the definition of HLW is classified as substantive.

Table 9-3 deals with Chapter III of DOE Manual 435.1. Chapter III deals with TRU waste. Management of TRU waste at the ICDF Complex will only consist of temporary storage. Within the evaluation of the TRU waste requirement, all of requirements from Chapter III are presented regardless of whether classified as substantive or administrative.

Table 9-4 deals with Chapter IV of DOE Manual 435.1. Chapter IV deals with LLW. Management of LLW at the ICDF Complex will include storage, treatment, and disposal. Within the evaluation of the LLW requirement, all of requirements from Chapter IV are presented regardless of whether classified as substantive or administrative. 
Requirement/Responsibility

Substantive or

Relevant or equivalent ARARs cited in the OU 3-13 ROD

CERCLA documents providing supporting information regarding compliance with requirement

Requirement

Administrative Relevant or equ

CHAPTER I - GEN

I.1.A. Delegation of Authority

I.1.B. Use of Guidance

I.1.C. Radioactive Waste

Management

Administrative • None

Administrative - None

Substantive - DOE Order 435.1; Radioactive waste management performance objectives to protect workers (TBC)

- None

- None

- Waste Acceptance Criteria for ICDF Complex, DOE/ID-10881 (DOE-ID 2005)

- INEEL CERCLA Disposal Facility Construction Waste Management Plan, DOE/ID-10958 (DOE-ID 2002d)

- Staging, Storage, Sizing, and Treatment Facility Construction Waste Management Plan, DOE/ID-10873 (DOE-ID 2002e)

- ICDF Complex Operations Waste Management Plan, DOE/ID-10886 (DOE-ID 2003d)
I.1.D. Analysis of Environmental Impacts
Substantive

The DOE NEPA/CERCLA integration policy, issued on June 13,1994, establishes that DOE will integrate NEPA values into CERCLA documents. The CERCLA Final Record of Decision for the Idaho Nuclear Technology and Engineering Center, Operable Unit 3-13 at the INEEL (DOE/ID-199) integrated NEPA values to the extent practical.
- Comprehensive RI/FS for the Idaho Chemical Processing Plant OU 3-13 at the INEEL, Part B FS Supplement Report, DOE/ID-10619 (DOE-ID 1998)

- $\quad$ Final Record of Decision for the Idaho Nuclear Technology and Engineering Center, Operable Unit 3-13 at the INEEL, DOE/ID-10660 (DOE-ID 1999)

- "Environmental Checklist for ICDF Complex," INEL-00-018, R1 (INEEL 2001a)

- "NESHAP Compliance Demonstration for the ICDF Complex" (EDF-2236)

- "IDAPA Air Compliance Demonstration for the ICDF Complex" (EDF-2237)

- "NESHAP Modeling for the ICDF Complex" (EDF-ER-290)

- "INEEL CERCLA Disposal Facility Short-Term Risk Assessment" (EDF-ER-327) (This document also evaluates the impacts on both public receptors and non-ICDF workers.)

- $\quad$ "Screening Level Ecological Risk Assessment for the INEEL CERCLA Disposal Facility Complex" (EDF-ER-311)

- $\quad$ None

Regulations and DOE Directives

Administrative $\quad \bullet \quad$ None

E(1) Analysis (

Administrative

- $\quad$ None

- INEEL CERCLA Disposal Facility Complex Remedial Action Work Plan, DOE/ID-10984

Information (DOE-ID 2003a)

- ICDF Complex Operations and Maintenance Plan, DOE/ID-11000 (DOE-ID 2003b)

- "ICDF Complex Waste Tracking Plan" (PLN-914)

- ICDF Complex Operational and Monitoring Sampling and Analysis Plan, DOE/ID-11005 (DOE-ID 2003e)

- ICDF Complex Groundwater Monitoring Plan, DOE/ID-10955 (DOE-ID 2002c)

- $\quad$ Sampling and Analysis Plan for SSSTF Waste Stabilization Operations, DOE/ID-10924 (DOE-ID 2003f)

- ICDF Complex Waste Verification Sampling and Analysis Plan, DOE/ID-10985 (DOE-ID 2003g) 
Requirement/Responsibility Substantive or
Administrative

I.1.E.(2) Classified Waste

I.1.E.(3) Conduct of Operations

Administrative

- None

Substantive

- None

I.1.E.(4) Critically Safety

I.1.E.(5) Emergency Management Program

I.1.E.(6) Environmental and

Occurrence Reporting

I.1.E.(7) Environmental Monitoring
Substantive

- $\quad$ None

Substantive

IDAPA 16.01.05.008 [40 CFR 264.16(a)(1),(c)] Personnel training

Administrative

Substantive
- $\quad$ None

DOE Order 5400.5; Exposures to the public will be kept ALARA (TBC)

- $\quad 40$ CFR 61.92, 40 CFR 61.93; NESHAP for radionuclides from DOE facilities, emission monitoring and emission compliance

- IDAPA 16.01.01.585, IDAPA 16.01.01.586; Rules for the control of air pollution in Idaho

- IDAPA 16.01.05.008 (40 CFR 264.92); Groundwater protection standard

- IDAPA 16.01.05.008 (40 CFR 264.301); Landfill design and operating requirements
CERCLA documents providing supporting information regarding compliance with requirement

INEEL CERCLA Disposal Facility Groundwater Detection Monitoring Program: Data Analysis Plan, DOE/ID-10998 (DOE-ID 2003h)

- None

- INEEL CERCLA Disposal Facility Complex Remedial Action Work Plan, DOE/ID-10984 (DOE-ID 2003a)

- ICDF Complex Operations and Maintenance Plan, DOE/ID-11000 (DOE-ID 2003b)

- Health and Safety Plan for Construction of the INEEL CERCLA Disposal Facility and Evaporation Pond, INEEL/EXT-2000-01424 (INEEL 2001b)

- Health and Safety Plan for Construction of Staging, Storage, Sizing, and Treatment Facility, INEEL/EXT-01-00271 (INEEL 2002a)

- Health and Safety Plan for INEEL CERCLA Disposal Facility Operations, INEEL/EXT-01-01318 (INEEL 2003)

- $\quad$ "Hazard Assessment Document, ICDF Complex Hazard Classification" (HAD-136)

- "INEEL CERCLA Disposal Facility Short-Term Risk Assessment" (EDF-ER-327)

- $\quad$ Also, detailed procedures are being developed for the various tasks that will be conducted at the ICDF Complex and these procedures will be included into the Operations and Maintenance Manual.

- Waste Acceptance Criteria for ICDF Complex, DOE/ID-10881 (DOE-ID 2005)

- Health and Safety Plan for Construction of the INEEL CERCLA Disposal Facility and Evaporation Pond, INEEL/EXT-2000-01424 (INEEL 2001b)

- Health and Safety Plan for Construction of Staging, Storage, Sizing, and Treatment Facility, INEEL/EXT-01-00271 (INEEL 2002a)

- Health and Safety Plan for INEEL CERCLA Disposal Facility Operations, INEEL/EXT-01-01318 (INEEL 2003)

- "Hazard Assessment Document, ICDF Complex Hazard Classification" (HAD-136)

- None

- INEEL CERCLA Disposal Facility Complex Remedial Action Work Plan, DOE/ID-10984 (DOE-ID 2003a)

- ICDF Complex Operations and Maintenance Plan, DOE/ID-11000 (DOE-ID 2003b)

- ICDF Complex Operational and Monitoring Sampling and Analysis Plan, DOE/ID-11005 (DOE-ID 2003e)

- ICDF Complex Groundwater Monitoring Plan, DOE/ID-10955 (DOE-ID 2002c) 

groundwater monitoring requirements

- IDAPA 16.01.05.008 (40 CFR 264.98); Detection monitoring program

- IDAPA 16.01.05.008 [40 CFR 264.310(b)(1)(4)(5)(6)]; Landfill postclosure requirements

- IDAPA 16.01.05.008 (40 CFR 264.302); Landfill action leakage rate

- IDAPA 16.01.05.008 (40 CFR 264, Subpart J); Tank Systems

- IDAPA 16.01.05.008 (40 CFR 264.554); Remediation waste staging piles

- IDAPA 16.01.05.008 (40 CFR 264.192); Design and installation of new tank systems or components

- IDAPA 16.01.05.008 (40 CFR 264.601); Miscellaneous units environmental performance standards

- IDAPA 16.01.05.008 (40 CFR 264, Subpart I); Use and management of containers

- IDAPA 16.01.05.008 (40 CFR 264, Subpart DD); Containment buildings

- IDAPA 16.01.05.008 (40 CFR 264.1052 through 1062); Air emissions standards for equipment leaks

- IDAPA 16.01.05.008 (40 CFR 264.1082 through 1088); Air emission standards for tanks, surface impoundments, and containers

- IDAPA 16.01.05.008 (40 CFR 264.221); Surface impoundment design and operating requirements

- IDAPA 16.01.05.008 (40 CFR 264.552); CAMUs

- $\quad$ IDAPA 16.01.05.008 (40 CFR 264, Subpart G); Closure and postclosure

- $\quad 40$ CFR 761.75(b)(1)(2); PCB landfill design requirements 


Requirement/Responsibility
I.1.E.(9) Life-Cycle Asset

Management
I.1.E.(10) Mixed Waste

I.1.E.(11) Packaging and Transportation

I.1.E.(12) Quality Assurance Program Substantive
Substantive

6 (40 CFR 262.11); Hazardous waste determination

- IDAPA 16.01.05.005 (40 CFR 261.20 through 24); Hazardous waste characteristics identification

- $\quad 40$ CFR 761.50(b)(7); PCB radioactive waste

- IDAPA 16.01.05.005 (40 CFR 261); Identification and listing of hazardous waste
Administrative

- $\quad$ None

- $\quad$ None
CERCLA documents providing supporting information regarding compliance with requirement Remedial Design/Construction Work Plan for the Waste Area Group 3 Staging, Storage, Sizing, and Treatment Facility, DOE/ID-10889 (DOE-ID 2002a)

- $\quad$ ICDF Remedial Design/Construction Work Plan, DOE/ID-10848 (DOE-ID 2002b)

- INEEL CERCLA Disposal Facility Complex Remedial Action Work Plan, DOE/ID-10984 (DOE-ID 2003a)

- "WAG 3 Staging, Storage, Sizing, and Treatment Facility" (TFR-17)

- "WAG 3 INEEL CERCLA Disposal Facility and Evaporation Pond" (TFR-71)

- $\quad$ "Technical and Functional Requirements for the INEEL CERCLA Disposal Facility (ICDF) Control and Integrated Waste Tracking System" (TFR-2520)

- " "SSA As-Built Drawings, Design Drawings, and Specifications," Appendix E of DOE/ID-10889 (DOE-ID 2002a)

- Following the construction of the facilities and startup, the facility drawing will be updated to the "as built" condition of the facilities. The "as built" conditions will be documented in the ICDF Complex Remedial Action Report. Also, following closure, the drawings will again be updated to show the "as built" conditions after closure.

- Waste Acceptance Criteria for ICDF Complex, DOE/ID-10881 (DOE-ID 2005)

- INEEL CERCLA Disposal Facility Construction Waste Management Plan, DOE/ID-10958 (DOE-ID 2002d)

- Staging, Storage, Sizing, and Treatment Facility Construction Waste Management Plan, DOE/ID-10873 (DOE-ID 2002e)

- ICDF Complex Operations Waste Management Plan, DOE/ID-10886 (DOE-ID 2003d)

- Waste Acceptance Criteria for ICDF Complex, DOE/ID-10881 (DOE-ID 2005)

- ICDF Complex Operations and Maintenance Plan, DOE/ID-11000 (DOE-ID 2003b)

- "Quality Program Plan for the INEEL CERCLA Disposal Facility Complex" (PLN-873)

- Preliminary Inspection Plan for SSSTF Construction Activities, INEEL/EXT-01-00777 (INEEL 2002b)

- INEEL CERCLA Disposal Facility Construction Quality Assurance Plan, DOE/ID-1085 (DOE-ID 2002f)

- Quality Assurance Project Plan for Waste Area Group 1, 2, 3, 4, 5, 6, 7, 10, and Inactive Sites, DOE/ID-10587 (DOE-ID 2000b)
Requiremen

Satisfied

$-$

$-$ 


\section{Requirement/Responsibility}

I.1.E.(13) Radiation Protection
Substantive or

Substantive
Relevant or equivalent ARARs cited in the OU 3-13 ROD DOE Order 5400.5; Exposures to the public will be kept ALARA (TBC)

- DOE Order 435.1; Radioactive waste management performance objectives to protect workers (TBC)
I.1.E.(14) Records Management

1.E.(15) Release of Waste

Containing Residual Radioactive

Materials

I.1.E.(16) Safeguards and Security

\section{Substantive}

Substantive

Substantive
- $\quad$ None

- None

IDAPA 16.01.05.008 [40 CFR 264.14(a), (b), (c)]
CERCLA documents providing supporting information regarding compliance with requirement INEEL CERCLA Disposal Facility Complex Remedial Action Work Plan, DOE/ID-10984 (DOE-ID 2003a)

- ICDF Complex Operations and Maintenance Plan, DOE/ID-11000 (DOE-ID 2003b)

- ICDF Complex Operational and Monitoring Sampling and Analysis Plan, DOE/ID-11005 (DOE-ID 2003e)

- ICDF Complex Groundwater Monitoring Plan, DOE/ID-10955 (DOE-ID 2002c)

- "NESHAP Compliance Demonstration for the ICDF Complex" (EDF-2236)

- " "IDAPA Air Compliance Demonstration for the ICDF Complex" (EDF-2237)

- "NESHAP Modeling for the ICDF Complex" (EDF-ER-290)

- "INEEL CERCLA Disposal Facility Short-Term Risk Assessment" (EDF-ER-327) (This document also evaluates the impacts on both public receptors and non-ICDF workers.)

- "SSSTF Design Radiological Control Analysis" (EDF-ER-302)

- $\quad$ Health and Safety Plan for Construction of the INEEL CERCLA Disposal Facility and Evaporation Pond, INEEL/EXT-2000-01424 (INEEL 2001b)

- Health and Safety Plan for Construction of Staging, Storage, Sizing, and Treatment Facility INEEL/EXT-01-00271 (INEEL 2002a)

- Health and Safety Plan for INEEL CERCLA Disposal Facility Operations, INEEL/EXT-01-01318 (INEEL 2003)

- INEEL CERCLA Disposal Facility Complex Remedial Action Work Plan, DOE/ID-10984 (DOE-ID 2003

- ICDF Complex Operations and Maintenance Plan, DOE/ID-11000 (DOE-ID 2003b)

- "ICDF Complex Waste Tracking Plan" (PLN-914)

- INEEL CERCLA Disposal Facility Construction Waste Management Plan, DOE/ID-10958 (DOE-ID 2002d)

- Staging, Storage, Sizing, and Treatment Facility Construction Waste Management Plan, DOE/ID-10873 (DOE-ID 2002e)

- ICDF Complex Operations Waste Management Plan, DOE/ID-10886 (DOE-ID 2003d)

- “ICDF Complex Waste Tracking Plan" (PLN-914)
Requirement 


\section{Requirement/Responsibility I.1.E.(17) Safety Management} System
Substantive or

Administrative
Relevant or equivalent ARARs cited in the OU 3-13 ROD
I.1.E.(18) Site-Evaluation and Facility Design
Substantive

\section{waste staging piles}

- 40 CFr 761.50(d)(4); Disposal requirements for PCBs 。

- IDAPA 16.01.05.008 (40 CFR 264.301); Landfill design and operating requirements

- IDAPA 16.01.05.008 [40 CFR 264.18(a) and (b)]; Landfill location standards

- IDAPA 16.01.05.008 (40 CFR 264, Subpart J); Tank Systems

- IDAPA 16.01.05.008 (40 CFR 264.554); Remediation waste staging piles

- $\quad 40$ CFR 761.75(b)(1)(2); PCB landfill design requirements

- IDAPA 16.01.05.008 (40 CFR 264.192); Design and installation of new tank systems or components

- $\quad$ IDAPA 16.01.05.008 (40 CFR 264.601);

Miscellaneous units environmental performance standards

- IDAPA 16.01.05.008 (40 CFR 264, Subpart I); Use and management of containers

- IDAPA 16.01.05.008 (40 CFR 264, Subpart DD); Containment buildings

- IDAPA 16.01.05.008 (40 CFR 264.221); Surface impoundment design and operating requirements

- $\quad$ IDAPA 16.01.05.008 (40 CFR 264.552); CAMUs

- 16 USC 469 et seq. 36 CFR 65; National Archeological and Historical Preservation Act

- 25 USC 3001; Native American Graves Protection and Repatriation Act
CERCLA documents providing supporting information regarding compliance with requirement INEEL CERCLA Disposal Facility Complex Remedial Action Work Plan, DOE/ID-10984 (DOE-ID 2003a)

- ICDF Complex Operations and Maintenance Plan, DOE/ID-11000 (DOE-ID 2003b)

- Health and Safety Plan for Construction of the INEEL CERCLA Disposal Facility and Evaporation Pond, INEEL/EXT-2000-01424 (INEEL 2001b)

- Health and Safety Plan for Construction of Staging, Storage, Sizing, and Treatment Facility INEEL/EXT-01-00271 (INEEL 2002a)

- Health and Safety Plan for INEEL CERCLA Disposal Facility Operations, INEEL/EXT-01-01318 (INEEL 2003)

- Also, detailed procedures are being developed for the various tasks that will be conducted at the ICDF Complex and these procedures will be included into the Operations and Maintenance Manual

- $\quad$ Final Record of Decision for the Idaho Technology and Engineering Center, Operable Unit 3-13 at the INEEL, DOE/ID-10660 (DOE-ID 1999)

- Geotechnical Report for the Conceptual Design of the INEEL CERCLA Disposal Facility at Waste Area Group 3, Operable Unit 3-13, DOE/ID-10812 (DOE-ID 2000a)

- $\quad$ "Staging, Storage, Sizing, and Treatment Facility (SSSTF) Siting Study" (EDF-1548)

- $\quad$ Remedial Design/Construction Work Plan for the Waste Area Group 3 Staging, Storage, Sizing, and Treatment Facility, DOE/ID-10889 (DOE-ID 2002a), along with the supporting drawings, specifications, and Engineering Design Files

- ICDF Remedial Design/Construction Work Plan, DOE/ID-10848 (DOE-ID 2002b), along with the supporting drawings, specifications, and Engineering Design Files

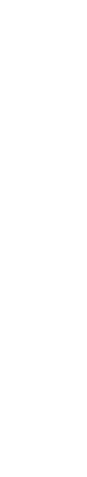

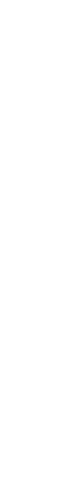

然 
CERCLA documents providing supporting information regarding compliance with requirement performance objectives to protect workers (TBC)

- DOE Order 5400.5; Exposures to the public will be kept ALARA (TBC) Administrative $\quad-\quad$ IDAPA 16.01.05.008 [40 CFR 264.16(a)(1),(c)]
Personnel training

- $\quad$ DOE Order 435.1; Radioactive waste management performance objectives to protect workers (TBC)

- DOE Order 5400.5; Exposures to the public will be kept ALARA (TBC)

- IDAPA 16.01.05.008 [40 CFR 264.16(a)(1)(c)]; Personnel training
- "Training Plan for the INEEL CERCLA Disposal Facility (Draft Title II)" (PLN-963)

- INEEL CERCLA Disposal Facility Complex Remedial Action Work Plan, DOE/ID-10984 (DOE-ID 2003a)

- ICDF Complex Operations and Maintenance Plan, DOE/ID-11000 (DOE-ID 2003b)

- Health and Safety Plan for Construction of the INEEL CERCLA Disposal Facility and Evaporation Pond, INEEL/EXT-2000-01424 (INEEL 2001b)

- Health and Safety Plan for Construction of Staging, Storage, Sizing, and Treatment Facility, INEEL/EXT-01-00271 (INEEL 2002a)

- Health and Safety Plan for INEEL CERCLA Disposal Facility Operations, INEEL/EXT-01-01318 (INEEL 2003)

- Also, detailed procedures are being developed for the various tasks that will be conducted at the ICDF Complex and these procedures will be included into the Operations and Maintenance Manual.

- INEEL CERCLA Disposal Facility Construction Waste Management Plan, DOE/ID-10958 (DOE-ID 2002d)

- Staging, Storage, Sizing, and Treatment Facility Construction Waste Management Plan, DOE/ID-10873 (DOE-ID 2002e)

- ICDF Complex Operations Waste Management Plan, DOE/ID-10886 (DOE-ID 2003d)

- Idaho National Engineering and Environmental Laboratory Reusable Property, Recyclable Materials, and Waste Acceptance Criteria (RRWAC), DOE/ID-10381 (DOE-ID 1994)

- INEEL Interim Pollution Prevention Plan, DOE/ID-10333 (DOE-ID 2000c)

- INEEL CERCLA Disposal Facility Complex Remedial Action Work Plan, DOE/ID-10984 (DOE-ID 2003a)

- ICDF Complex Operations and Maintenance Plan, DOE/ID-11000 (DOE-ID 2003b)

- Health and Safety Plan for Construction of the INEEL CERCLA Disposal Facility and Evaporation Pond, INEEL/EXT-2000-01424 (INEEL 2001b)

- Health and Safety Plan for Construction of Staging, Storage, Sizing, and Treatment Facility, INEEL/EXT-01-00271 (INEEL 2002a)

- Health and Safety Plan for INEEL CERCLA Disposal Facility Operations, INEEL/EXT-01-01318 (INEEL 2003)

- "INEEL CERCLA Disposal Facility Short-Term Risk Assessment" (EDF-ER-327) (This document also evaluates the impacts on both public receptors and non-ICDF workers.)

- $\quad$ "SSSTF Design Radiological Control Analysis" (EDF-ER-302)

- Also, detailed procedures are being developed for the various tasks that will be conducted at the ICDF Complex and these procedures will be included into the Operations and Maintenance Manual. 
I.2.A. Program Secretarial Officers Administrative

I.2.B. Assistant Secretary for Environmental Managemen

I.2.B.(1) Complex-Wide Radioactive Administrative Waste Management

I.2.B.(2) Changes to Regulations and Administrative DOE Directives

I.2.C. Assistant Secretary for

Environment, Safety, and Health

Adninistative

- None

- $\quad$ None

- $\quad$ None

- $\quad$ None

- None

$\mathrm{N} / \mathrm{A}$

None

Yes

1.2.D. Deputy Assistant Secretary for Waste Management

I.2.D.(1) Complex-Wide Radioactive Administrative

Waste Management Program Plans

I.2.D.(2) Waste Management Data

Administrative

- $\quad$ None

None

- None

N/A

None

.2.E. Deputy Assistance Secretaries for Waste Management and Environmental Restoration

I.2.E.(1) Disposal Administrative • None

I.1.E.(2) Site Closure Plans Administrative

- None

- $\quad$ None

I.2.F. Field Element Managers

I.2.F.(1) Site-Wide Radioactive

Administrative

- None

Waste Management Program

I.2.F.(2) Radioactive Waste

Administrative

- DOE Order 435.1; Radioactive waste management performance objectives to protect workers

- None

Waste Acceptance Criteria for ICDF Complex, DOE/ID-10881 (DOE-ID 2005)

"INEEL CERCLA Disposal Facility Short-Term Risk Assessment" (EDF-ER-327) (This document also evaluates the impacts on both public receptors and non-ICDF workers.)

- $\quad$ "Screening Level Ecological Risk Assessment for the INEEL CERCLA Disposal Facility Complex" (EDF-ER-311)

- $\quad$ "SSSTF Design Radiological Control Analysis" (EDF-ER-302)

- " "Hazard Assessment Document, ICDF Complex Hazard Classification" (HAD-136)

- $\quad$ "Fate and Transport Modeling Results and Summary Report" (EDF-ER-275)

- "NESHAP Compliance Demonstration for the ICDF Complex" (EDF-2236)

- " "IDAPA Air Compliance Demonstration for the ICDF Complex" (EDF-2237)

- "NESHAP Modeling for the ICDF Complex" (EDF-ER-290)

- Health and Safety Plan for INEEL CERCLA Disposal Facility Operations, INEEL/EXT-01-01318 (INEEL 2003)

- ICDF Complex Operations and Maintenance Plan, DOE/ID-11000 (DOE-ID 2003b)

- $\quad$ Also, detailed procedures are being developed for the various tasks that will be conducted at the ICDF Complex and these procedures will be included into the Operations and Maintenance Manual.

- None

Yes


Requirement/Responsibility

I.2.F.(4) Approval of Exemptions for

Use of Non-DOE Facilities

I.2.F.(5) Environmental Restoration,

Decommissioning, and Other

Cleanup Waste

I.2.F.(6) Radioactive Waste

Acceptance Requirements

I.2.F.(7) Radioactive Waste

Generator Requirements

I.2.F.(8) Closure Plans

I.2.F.(9) Defense-In-Depth

I.2.F.(10) Oversight

Administrative

Administrative

Administrative

Administrative

Administrative

Administrative

Administrative - None

None

None

- None

- None

- IDAPA 16.01.05.008 [40 CFR

264.310(a)(1)(2)(3)(4)(5)]; Landfill closure requirements

- IDAPA 16.01.05.008 (40 CFR 264, Subpart G) Closure and post-closure

- None

- None
CERCLA documents providing supporting information regarding compliance with requirement

"INEEL CERCLA Disposal Facility Complex On-Site Versus Off-Site Cost Comparison" (EDF-2385)

- $\quad$ Final Record of Decision for the Idaho Technology and Engineering Center, Operable Unit 3-13 at the INEEL, DOE/ID-10660 (DOE-ID 1999)

- None

- $\quad$ None

- $\quad$ None

Satified

Yes

Yes

Yes

- INEEL CERCLA Disposal Facility Complex Remedial Action Work Plan, DOE/ID-10984 (DOE-ID 2003a)

- ICDF Complex Operations and Maintenance Plan, DOE/ID-11000 (DOE-ID 2003b)

- Health and Safety Plan for Construction of the INEEL CERCLA Disposal Facility and Evaporation Pond, INEEL/EXT-2000-01424 (INEEL 2001b)

- Health and Safety Plan for Construction of Staging, Storage, Sizing, and Treatment Facility, INEEL/EXT-01-00271 (INEEL 2002a)

- Health and Safety Plan for INEEL CERCLA Disposal Facility Operations, INEEL/EXT-01-01318 (INEEL 2003)

- Also, detailed procedures are being developed for the various tasks that will be conducted at the ICDF Complex and these procedures will be included into the Operations and Maintenance Manual.

- “Training Plan for the INEEL CERCLA Disposal Facility (Draft Title II)” (PLN-963)

- INEEL CERCLA Disposal Facility Complex Remedial Action Work Plan, DOE/ID-10984 (DOE-ID 2003a)

- ICDF Complex Operations and Maintenance Plan, DOE/ID-11000 (DOE-ID 2003b)

- Health and Safety Plan for Construction of the INEEL CERCLA Disposal Facility and Evaporation Pond, INEEL/EXT-2000-01424 (INEEL 2001b)

- Health and Safety Plan for Construction of Staging, Storage, Sizing, and Treatment Facility, INEEL/EXT-01-00271 (INEEL 2002a)

- Health and Safety Plan for INEEL CERCLA Disposal Facility Operations, INEEL/EXT-01-01318 (INEEL 2003)

- Also, detailed procedures are being developed for the various tasks that will be conducted at the ICDF Complex and these procedures will be included into the Operations and Maintenance Manual. 
Requirement/Responsibility Achievable (ALARA)

Administrative

Substantive

Relevant or equivalent ARARs cited in the OU 3-13 ROD DOE Order 435.1; Radioactive waste management performance objectives to protect workers (TBC)

- DOE Order 5400.5; Exposures to the public will be kept ALARA (TBC)

CERCLA documents providing supporting information regarding compliance with requirement

INEEL CERCLA Disposal Facility Complex Remedial Action Work Plan, DOE/ID-10984

- ICDF Complex Operations and Maintenance Plan, DOE/ID-11000 (DOE-ID 2003b)

- ICDF Complex Operational and Monitoring Sampling and Analysis Plan, DOE/ID-11005 (DOE-ID 2003e)

- ICDF Complex Groundwater Monitoring Plan, DOE/ID-10955 (DOE-ID 2002c)

- "NESHAP Compliance Demonstration for the ICDF Complex" (EDF-2236)

- "IDAPA Air Compliance Demonstration for the ICDF Complex" (EDF-2237)

- "NESHAP Modeling for the ICDF Complex" (EDF-ER-290)

- "INEEL CERCLA Disposal Facility Short-Term Risk Assessment" (EDF-ER-327) (This document also evaluates the impacts on both public receptors and non-ICDF workers.)

- "SSSTF Design Radiological Control Analysis" (EDF-ER-302)

- Health and Safety Plan for Construction of the INEEL CERCLA Disposal Facility and Evaporation Pond, INEEL/EXT-2000-01424 (INEEL 2001b)

- Health and Safety Plan for Construction of Staging, Storage, Sizing, and Treatment Facility, INEEL/EXT-01-00271 (INEEL 2002a)

- Health and Safety Plan for INEEL CERCLA Disposal Facility Operations, INEEL/EXT-01-01318 (INEEL 2003)

IDAPA 16.01.05.008 (40 CFR 264.554); Remediation waste staging piles

- IDAPA 16.01.05.008 (40 CFR 264, Subpart J); Tank Systems

- IDAPA 16.01.05.008 (40 CFR 264.554); Remediation waste staging piles

- IDAPA 16.01.05.008 (40 CFR 264.192); Design and installation of new tank systems or components

- IDAPA 16.01.05.008 (40 CFR 264.601); Miscellaneous units environmental performance standards

- IDAPA 16.01.05.008 (40 CFR 264, Subpart I); Use and management of containers

- IDAPA 16.01.05.008 (40 CFR 264, Subpart DD); Containment buildings

- IDAPA 16.01.05.008 (40 CFR 264.221); Surface impoundment design and operating requirements

- IDAPA 16.01.05.008 (40 CFR 264.552); CAMUs

- DOE Order 435.1; Radioactive waste management performance objectives to protect workers (TBC)

- DOE Order 5400.5; Exposures to the public will be kept ALARA (TBC)

- INEEL CERCLA Disposal Facility Complex Remedial Action Work Plan, DOE/ID-10984 (DOE-ID 2003a)

- ICDF Complex Operations and Maintenance Plan, DOE/ID-11000 (DOE-ID 2003b)

- Waste Acceptance Criteria for ICDF Complex, DOE/ID-10881 (DOE-ID 2005)

- "NESHAP Compliance Demonstration for the ICDF Complex" (EDF-2236)

- "NESHAP Modeling for the ICDF Complex" (EDF-ER-290)

- "INEEL CERCLA Disposal Facility Short-Term Risk Assessment" (EDF-ER-327) (This document also evaluates the impacts on both public receptors and non-ICDF workers.)

- "Hazard Assessment Document, ICDF Complex Hazard Classification" (HAD-136) 
Requirement/Responsibility

I.2.F.(14) Treatmen

2.F.(15) Disposal

I.2.F.(16) Monitoring
Substantive or

Substantive

Relevant or equivalent ARARs cited in the OU 3-13 ROD

- IDAPA 16.01.05.008 (40 CFR 264.601); Miscellaneous units environmental performance standards

- IDAPA 16.01.05.008 (40 CFR 264, Subpart DD); Containment buildings

- IDAPA 16.01.05.008 (40 CFR 264.552); CAMUs

- DOE Order 435.1; Radioactive waste management performance objectives to protect workers (TBC)

- DOE Order 5400.5; Exposures to the public will be kept ALARA (TBC)

Substantive

- IDAPA 16.01.05.008 (40 CFR 264.301); Landfill design and operating requirements

- $\quad 40$ CFR 761.75(b)(1)(2); PCB landfill design requirements

- $\quad$ DOE Order 435.1; Radioactive waste management performance objectives to protect workers (TBC)

- DOE Order 5400.5; Exposures to the public will be kept ALARA (TBC)

40 CFR 61.92, 40 CFR 61.93; NESHAP for radionuclides from DOE facilities, emission monitoring and emission compliance

- IDAPA 16.01.01.585, IDAPA 16.01.01.586; Rules for the control of air pollution in Idaho

- IDAPA 16.01.05.008 (40 CFR 264.92); Groundwater protection standard

IDAPA 16.01.05.008 (40 CFR 264.301); Landfill design and operating requirements

IDAPA 16.01.05.008 (40 CFR 264.97); General groundwater monitoring requirements

- IDAPA 16.01.05.008 (40 CFR 264.98); Detection monitoring program
CERCLA documents providing supporting information regarding compliance with requirement INEEL CERCLA Disposal Facility Complex Remedial Action Work Plan, DOE/ID-10984 (DOE-ID 2003a)

- ICDF Complex Operations and Maintenance Plan, DOE/ID-11000 (DOE-ID 2003b)

- Waste Acceptance Criteria for ICDF Complex, DOE/ID-10881 (DOE-ID 2005)

- "NESHAP Compliance Demonstration for the ICDF Complex" (EDF-2236)

- "NESHAP Modeling for the ICDF Complex" (EDF-ER-290)

- "INEEL CERCLA Disposal Facility Short-Term Risk Assessment" (EDF-ER-327) (This document also evaluates the impacts on both public receptors and non-ICDF workers.)

- $\quad$ "SSSTF Design Radiological Control Analysis" (EDF-ER-302)

- " "Hazard Assessment Document, ICDF Complex Hazard Classification" (HAD-136)

- Remedial Design/Construction Work Plan for the Waste Area Group 3 Staging, Storage, Sizing, and Treatment Facility, DOE/ID-10889 (DOE-ID 2002a), along with the supporting drawings, specifications, and Engineering Design Files

- "Leachate Generation Study" (EDF-ER-269)

- "Leachate Contaminant Reduction Time Study" (EDF-ER-274)

- " "Fate and Transport Modeling Results and Summary Report" (EDF-ER-275)

- $\quad$ "Hydrologic Modeling of Final Cover" (EDF-ER-279)

- $\quad$ "Liner and Final Cover Long-Term Performance Evaluation and Final Cover Life Cycle Expectation" (EDF-ER-281)

- Performance Assessment for the INEEL CERCLA Disposal Facility, DOE/ID-10978 (DOE-ID 2003i)

- Composite Analysis for the INEEL CERCLA Disposal Facility Landfill, DOE/ID-10979 (DOE-ID 2003j)

- ICDF Remedial Design/Construction Work Plan, DOE/ID-10848 (DOE-ID 2002b), along with the supporting drawings, specifications, and Engineering Design Files

- INEEL CERCLA Disposal Facility Complex Remedial Action Work Plan, DOE/ID-10984 (DOE-ID 2003a)

- ICDF Complex Operations and Maintenance Plan, DOE/ID-11000 (DOE-ID 2003b) ICDF Complex Operational and Monitoring Sampling and Analysis Plan, DOE/ID-11005 (DOE-ID 2003e)

ICDF Complex Groundwater Monitoring Plan, DOE/ID-10955 (DOE-ID 2002c)

- $\quad$ Also, detailed procedures are being developed for the various tasks that will be conducted at the ICDF Complex and these procedures will be included into the Operations and Maintenance Manual. .

- 


\begin{tabular}{|c|c|c|c|c|}
\hline Requirement/Responsibility & $\begin{array}{l}\text { Substantive or } \\
\text { Administrative }\end{array}$ & Relevant or equivalent ARARs cited in the OU 3-13 ROD & CERCLA documents providing supporting information regarding compliance with requirement & $\begin{array}{l}\text { Requirement } \\
\text { Satisfied }\end{array}$ \\
\hline & & $\begin{array}{l}\text { 264.310(b)(1)(4)(5)(6)]; Landfill postclosure } \\
\text { requirements } \\
\text { - } \quad \text { IDAPA 16.01.05.008 (40 CFR 264.302); Landfill } \\
\text { action leakage rate } \\
\text { - } \quad \text { IDAPA 16.01.05.008 (40 CFR 264, Subpart J); Tank } \\
\text { Systems } \\
\text { - IDAPA 16.01.05.008 (40 CFR 264.554); Remediation } \\
\text { waste staging piles } \\
\text { - IDAPA 16.01.05.008 (40 CFR 264.192); Design and } \\
\text { installation of new tank systems or components } \\
\text { - } \quad \text { IDAPA 16.01.05.008 (40 CFR 264.601); } \\
\text { Miscellaneous units environmental performance } \\
\text { standards } \\
\text { - IDAPA 16.01.05.008 (40 CFR 264, Subpart I); Use } \\
\text { and management of containers } \\
\text { IDAPA 16.01.05.008 (40 CFR 264, Subpart DD); } \\
\text { Containment buildings } \\
\text { IDAPA 16.01.05.008 (40 CFR 264.1052 through } \\
\text { 1062); Air emissions standards for equipment leaks } \\
\text { IDAPA 16.01.05.008 (40 CFR 264.1082 through } \\
\text { 1088); Air emission standards for tanks, surface } \\
\text { impoundments, and containers } \\
\text { IDAPA 16.01.05.008 (40 CFR 264.221); Surface } \\
\text { impoundment design and operating requirements } \\
\text { IDAPA 16.01.05.008 (40 CFR 264.552); CAMUs } \\
\text { IDAPA 16.01.05.008 (40 CFR 264, Subpart G); } \\
\text { Closure and postclosure }\end{array}$ & & \\
\hline $\begin{array}{l}\text { I.2.F.(17) Material and Waste } \\
\text { Declassification for Waste } \\
\text { Management }\end{array}$ & Administrative & - $\quad$ None & - $\quad$ None & N/A \\
\hline $\begin{array}{l}\text { I.2.F.(18) Waste Incidental to } \\
\text { Reprocessing }\end{array}$ & Administrative & - $\quad$ None & None & N/A \\
\hline $\begin{array}{l}\text { I.2.F.(19) Waste With No Identified } \\
\text { Path to Disposal }\end{array}$ & Administrative & - $\quad$ None & - $\quad$ None & Yes \\
\hline I.2.F.(20) Corrective Actions & Administrative & None & None & Yes \\
\hline \multicolumn{5}{|l|}{ I.2.G. All Personnel } \\
\hline I.2.G.(1) Problem Identification & Administrative & - $\quad$ None & - $\quad$ None & Yes \\
\hline $\begin{array}{l}\text { I.2.G.(2) Shutdown or Curtailment of } \\
\text { Activities }\end{array}$ & Administrative & None & None & Yes \\
\hline
\end{tabular}




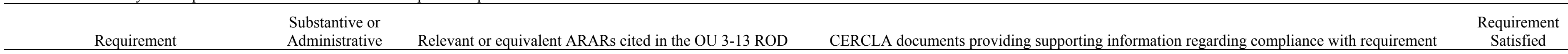
CHAPTER II - HLW REQUIREMENTS
II.A. Definition of HLW
Substantive
- DOE Order 435.1; Radioactive waste management performance objectives to protect workers (TBC)

- Waste Acceptance Criteria for ICDF Complex, DOE/ID-10881 (DOE-ID 2005)

- INEEL CERCLA Disposal Facility Construction Waste Management Plan, DOE/ID-10958 (DOE-ID 2002d)

- Staging, Storage, Sizing, and Treatment Facility Construction Waste Management Plan DOE/ID-10873 (DOE-ID 2002e)

- ICDF Complex Operations Waste Management Plan, DOE/ID-10886 (DOE-ID 2003d)

- ICDF Complex Waste Verification Sampling and Analysis Plan, DOE/ID-10985 (DOE-ID 2003g) 


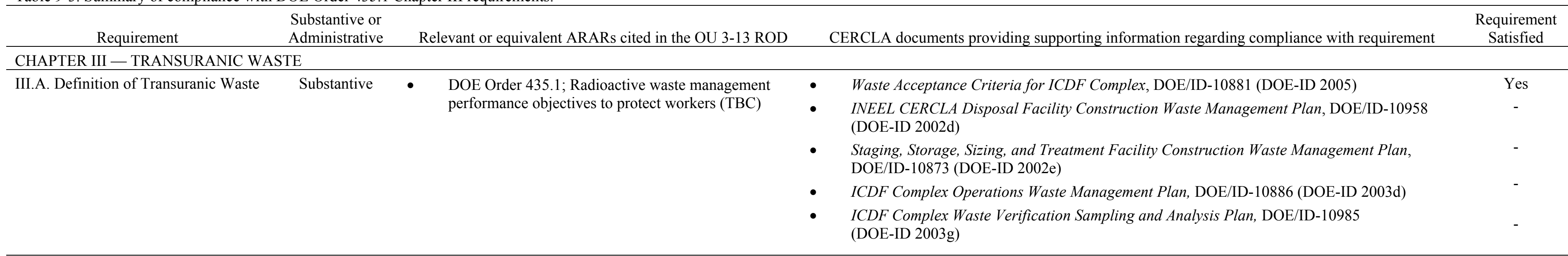

III.B. Management of Specific Waste III.B.(1) Mixed Transuranic Waste

Substantive

IDAPA 16.01.05.006 (40 CFR 262.11); Hazardous waste determination

- IDAPA 16.01.05.005 (40 CFR 261.20 through 24) Hazardous waste characteristics identification

- $\quad 40$ CFR 761.50(b)(7); PCB radioactive waste

- IDAPA 16.01.05.005 (40 CFR 261); Identification and listing of hazardous waste

III.B.(2) TSCA-Regulated Waste

IDAPA 16.01.05.006 (40 CFR 262.11); Hazardous waste determination

- $\quad 40$ CFR 761.50(b)(7); PCB radioactive waste

$\quad 40$ CFR 761.50(b)(8); Porous surfaces

40 CFR 761.50(d)(4); Disposal requirements for PCBs

- Waste Acceptance Criteria for ICDF Complex, DOE/ID-10881 (DOE-ID 2005)

- INEEL CERCLA Disposal Facility Complex Remedial Action Work Plan, DOE/ID-10984 (DOE-ID 2003a)

- ICDF Complex Operations and Maintenance Plan, DOE/ID-11000 (DOE-ID 2003b)

- INEEL CERCLA Disposal Facility Construction Waste Management Plan, DOE/ID-10958 (DOE-ID 2002d)

- Staging, Storage, Sizing, and Treatment Facility Construction Waste Management Plan, DOE/ID-10873 (DOE-ID 2002e)

- $\quad$ ICDF Complex Operations Waste Management Plan, DOE/ID-10886 (DOE-ID 2003d)

- ICDF Complex Waste Verification Sampling and Analysis Plan, DOE/ID-10985 (DOE-ID 2003g)

- Waste Acceptance Criteria for ICDF Complex, DOE/ID-10881 (DOE-ID 2005)

- INEEL CERCLA Disposal Facility Complex Remedial Action Work Plan, DOE/ID-10984 (DOE-ID 2003a)

- ICDF Complex Operations and Maintenance Plan, DOE/ID-11000 (DOE-ID 2003b)

- INEEL CERCLA Disposal Facility Construction Waste Management Plan, DOE/ID-10958 (DOE-ID 2002d)

- Staging, Storage, Sizing, and Treatment Facility Construction Waste Management Plan, DOE/ID-10873 (DOE-ID 2002e)

- $\quad$ ICDF Complex Operations Waste Management Plan, DOE/ID-10886 (DOE-ID 2003d)

- ICDF Complex Waste Verification Sampling and Analysis Plan, DOE/ID-10985 (DOE-ID 2003g) 
- $\quad$ DOE Order 435.1; Radioactive waste management performance objectives to protect workers

- IDAPA 16.01.05.006 (40 CFR 262.11); Hazardous waste determination

III.D.(2) Treatment Facilities III.D.(3) Storage Facilities
Substantive Substantive
N/A

IDAPA 16.01.05.008 (40 CFR 264, Subpart J); Tan Systems

- IDAPA 16.01.05.008 (40 CFR 264.192); Design and installation of new tank systems or components

- IDAPA 16.01.05.008 (40 CFR 264.601); Miscellaneous units environmental performance standards

- $\quad$ IDAPA 16.01.05.008 (40 CFR 264, Subpart I); Use and management of containers

- IDAPA 16.01.05.008 (40 CFR 264, Subpart DD); Containment buildings

- IDAPA 16.01.05.008 (40 CFR 264.221); Surface impoundment design and operating requirements

IDAPA 16.01.05.008 (40 CFR 264.552); CAMUs

DOE Order 435.1; Radioactive waste management performance objectives to protect workers (TBC)

- DOE Order 5400.5; Exposures to the public will be kept ALARA (TBC)
- $\quad$ "Hazard Assessment Document, ICDF Complex Hazard Classification" (HAD-136)

- Waste Acceptance Criteria for ICDF Complex, DOE/ID-10881 (DOE-ID 2005)

- "NESHAP Compliance Demonstration for the ICDF Complex" (EDF-2236)

- "NESHAP Modeling for the ICDF Complex" (EDF-ER-290)

- " "INEEL CERCLA Disposal Facility Short-Term Risk Assessment" (EDF-ER-327) (This document also evaluates the impacts on both public receptors and non-ICDF workers.)

- " "IDAPA Air Compliance Demonstration for the ICDF Complex" (EDF-2237)

- "SSSTF Design Radiological Control Analysis" (EDF-ER-302)

- Health and Safety Plan for INEEL CERCLA Disposal Facility Operations, INEEL/EXT-01-01318 (INEEL 2003)

- INEEL CERCLA Disposal Facility Complex Remedial Action Work Plan, DOE/ID-10984 (DOE-ID 2003a)

- ICDF Complex Waste Verification Sampling and Analysis Plan, DOE/ID-10985 (DOE-ID 2003g)

- N/A

- "Hazard Assessment Document, ICDF Complex Hazard Classification" (HAD-136)

- Waste Acceptance Criteria for ICDF Complex, DOE/ID-10881 (DOE-ID 2005)

- “NESHAP Compliance Demonstration for the ICDF Complex" (EDF-2236)

- "NESHAP Modeling for the ICDF Complex" (EDF-ER-290)

- "INEEL CERCLA Disposal Facility Short-Term Risk Assessment" (EDF-ER-327) (This document also evaluates the impacts on both public receptors and non-ICDF workers.)

- " "IDAPA Air Compliance Demonstration for the ICDF Complex" (EDF-2237)

- $\quad$ "SSSTF Design Radiological Control Analysis" (EDF-ER-302)

- Health and Safety Plan for INEEL CERCLA Disposal Facility Operations, INEEL/EXT-01-01318 (INEEL 2003)

- ICDF Complex Operations and Maintenance Plan, DOE/ID-11000 (DOE-ID 2003b) 
III.F. Corrective Actions

III.F.(1) Order Compliance

Substantive

\section{III.G. Waste Acceptance \\ III.G.(1) Technical and}

Administrative

Substantive

- DOE Order 5400.5; Exposures to the public will be kept ALARA (TBC)

- $\quad$ DOE Order 435.1; Radioactive waste management performance objectives to protect workers (TBC)

- IDAPA 16.01.05.006 (40 CFR 262.11); Hazardous waste determination

- IDAPA 16.01.05.005 (40 CFR 261.20 through 24); Hazardous waste characteristics identification

- $\quad 40$ CFR 761.50(b)(7); PCB radioactive waste
- INEEL CERCLA Disposal Facility Complex Remedial Action Work Plan, DOE/ID-10984

- ICDF Complex Operations and Maintenance Plan, DOE/ID-11000 (DOE-ID 2003b)

- Remedial Design/Construction Work Plan for the Waste Area Group 3 Staging, Storage, Sizing, and Treatment Facility, DOE/ID-10889 (DOE-ID 2002a), along with the supporting drawings, specifications, and Engineering Design Files

- Waste Acceptance Criteria for ICDF Complex, DOE/ID-10881 (DOE-ID 2005)

- INEEL CERCLA Disposal Facility Complex Remedial Action Work Plan, DOE/ID-10984 (DOE-ID 2003a)

- ICDF Complex Operations and Maintenance Plan, DOE/ID-11000 (DOE-ID 2003b)

- $\quad$ Remedial Design/Construction Work Plan for the Waste Area Group 3 Staging, Storage, Sizing, and Treatment Facility, DOE/ID-10889 (DOE-ID 2002a), along with the supporting drawings, specifications, and Engineering Design Files

- Waste Acceptance Criteria for ICDF Complex, DOE/ID-10881 (DOE-ID 2005)

- INEEL CERCLA Disposal Facility Complex Remedial Action Work Plan, DOE/ID-10984 (DOE-ID 2003a)

- ICDF Complex Operations and Maintenance Plan, DOE/ID-11000 (DOE-ID 2003b)

- $\quad$ Also, detailed procedures are being developed for the various tasks that will be conducted at the ICDF Complex and these procedures will be included into the Operations and Maintenance Manual.

- INEEL CERCLA Disposal Facility Complex Remedial Action Work Plan, DOE/ID-10984 (DOE-ID 2003a)

- ICDF Complex Operations and Maintenance Plan, DOE/ID-11000 (DOE-ID 2003b)

- “ICDF Complex Waste Tracking Plan” (PLN-914)

- "Hazard Assessment Document, ICDF Complex Hazard Classification" (HAD-136)

- $\quad$ Also, detailed procedures are being developed for the various tasks that will be conducted at the ICDF Complex and these procedures will be included into the Operations and Maintenance

- Waste Acceptance Criteria for ICDF Complex, DOE/ID-10881 (DOE-ID 2005)

- $\quad$ "Hazard Assessment Document, ICDF Complex Hazard Classification" (HAD-136)

Yes

$-$

"ICDF Complex Waste Tracking Plan" (PLN-914)

- ICDF Complex Waste Verification Sampling and Analysis Plan, DOE/ID-10985 (DOE-ID 2003g)

- INEEL CERCLA Disposal Facility Complex Remedial Action Work Plan, DOE/ID-10984 (DOE-ID 2003a)

- ICDF Complex Operations and Maintenance Plan, DOE/ID-11000 (DOE-ID 2003b)

- INEEL CERCLA Disposal Facility Construction Waste Management Plan, DOE/ID-10958 (DOE-ID 2002d) 

and listing of hazardous waste

- IDAPA 16.01.05.008 (40 CFR 264.554); Remediation waste staging piles

- $\quad 40$ CFR $761.50(d)(4)$; Disposal requirements for PCBs

- IDAPA 16.01.05.008 (40 CFR 264.301); Landfill design and operating requirements

- IDAPA 16.01.05.008 [40 CFR 264.18(a) and (b)]; Landfill location standards

- IDAPA 16.01.05.008 (40 CFR 264, Subpart J); Tank Systems

- IDAPA 16.01.05.008 (40 CFR 264.554); Remediation waste staging piles

- $\quad 40$ CFR 761.75(b)(1)(2); PCB landfill design requirements

- IDAPA 16.01.05.008 (40 CFR 264.192); Design and installation of new tank systems or components

- $\quad$ IDAPA 16.01.05.008 (40 CFR 264.601);

Miscellaneous units environmental performance standards

- IDAPA 16.01.05.008 (40 CFR 264, Subpart I); Use and management of containers

- IDAPA 16.01.05.008 (40 CFR 264, Subpart DD); Containment buildings

- IDAPA 16.01.05.008 (40 CFR 264.221); Surface impoundment design and operating requirements

- IDAPA 16.01.05.008 (40 CFR 264.552); CAMUs

- DOE Order 5400.5; Exposures to the public will be kept ALARA (TBC)

- DOE Order 435.1; Radioactive waste management performance objectives to protect workers (TBC)

- IDAPA 16.01.05.006 (40 CFR 262.11); Hazardous waste determination

- IDAPA 16.01.05.005 (40 CFR 261.20 through 24); Hazardous waste characteristics identification

- $\quad 40$ CFR 761.50(b)(7); PCB radioactive waste

- IDAPA 16.01.05.005 (40 CFR 261); Identification and listing of hazardous waste

- IDAPA 16.01.05.008 (40 CFR 264.554); Remediation waste staging piles

Waste Acceptance Criteria for ICDF Complex, DOE/ID-10881 (DOE-ID 2005)

- " “ICDF Complex Waste Tracking Plan" (PLN-914)

- ICDF Complex Waste Verification Sampling and Analysis Plan, DOE/ID-10985 (DOE-ID 2003g)

- INEEL CERCLA Disposal Facility Complex Remedial Action Work Plan, DOE/ID-10984 (DOE-ID 2003a)

- ICDF Complex Operations and Maintenance Plan, DOE/ID-11000 (DOE-ID 2003b)

- INEEL CERCLA Disposal Facility Construction Waste Management Plan, DOE/ID-10958 (DOE-ID 2002d)

- $\quad$ Staging, Storage, Sizing, and Treatment Facility Construction Waste Management Plan DOE/ID-10873 (DOE-ID 2002e)

- $\quad 40$ CFR 761.50(d)(4); Disposal requirements for PCBs 


\begin{tabular}{|c|c|c|c|c|}
\hline Requirement & $\begin{array}{l}\text { Substantive or } \\
\text { Administrative }\end{array}$ & Relevant or equivalent ARARs cited in the OU 3-13 ROD & CERCLA documents providing supporting information regarding compliance with requirement & $\begin{array}{l}\text { Requirement } \\
\text { Satisfied }\end{array}$ \\
\hline & & 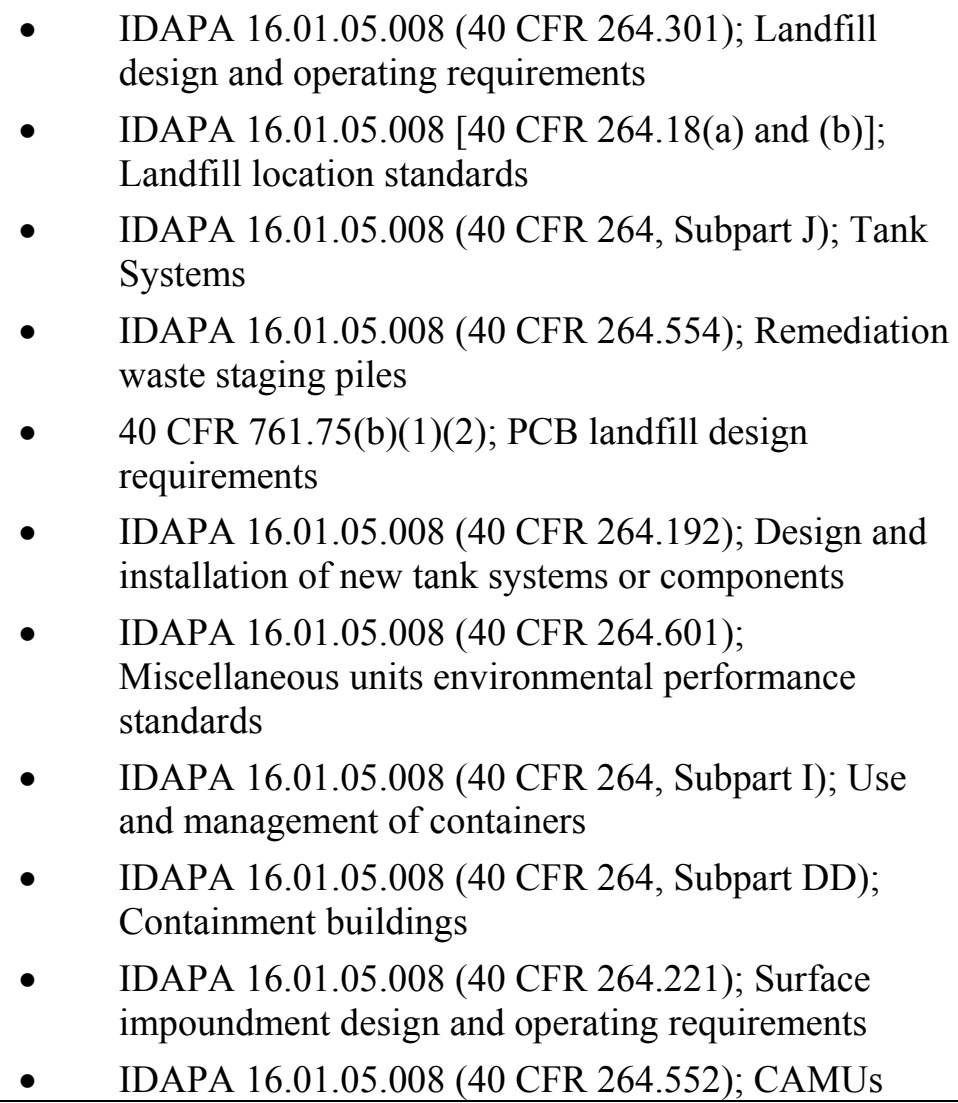 & & - \\
\hline III.H. Waste Generation Planning & & & & \\
\hline III.H.(1) Life-Cycle Planning & Administrative & - $\quad$ None & $\begin{array}{l}\text { - } \quad \text { Waste Acceptance Criteria for ICDF Complex, DOE/ID-10881 (DOE-ID 2005) } \\
\text { - INEEL CERCLA Disposal Facility Complex Remedial Action Work Plan, DOE/ID-10984 } \\
\text { (DOE-ID 2003a) } \\
\text { - ICDF Complex Operations and Maintenance Plan, DOE/ID-11000 (DOE-ID 2003b) }\end{array}$ & $\begin{array}{l}\text { Yes } \\
- \\
-\end{array}$ \\
\hline $\begin{array}{l}\text { III.H.(2) Waste With No Identified } \\
\text { Path to Disposal }\end{array}$ & Administrative & - $\quad$ None & $\begin{array}{l}\text { - } \quad \text { Waste Acceptance Criteria for ICDF Complex, DOE/ID-10881 (DOE-ID 2005) } \\
\text { - } \quad \text { "Hazard Assessment Document, ICDF Complex Hazard Classification" (HAD-136) } \\
\text { - } \quad \text { ICDF Complex Operations and Maintenance Plan, DOE/ID-11000 (DOE-ID 2003b) }\end{array}$ & $\begin{array}{c}\text { Yes } \\
- \\
-\end{array}$ \\
\hline III.I Waste Characterization & Substantive & $\begin{array}{l}\text { - IDAPA 16.01.05.006 (40 CFR 262.11); Hazardous } \\
\text { waste determination }\end{array}$ & $\begin{array}{l}\text { - } \quad \text { Waste Acceptance Criteria for ICDF Complex, DOE/ID-10881 (DOE-ID 2005) } \\
\text { INEEL CERCLA Disposal Facility Construction Waste Management Plan, DOE/ID-10958 } \\
\text { (DOE-ID 2002d) } \\
\text { - Staging, Storage, Sizing, and Treatment Facility Construction Waste Management Plan, } \\
\text { DOE/ID-10873 (DOE-ID 2002e) } \\
\text { - ICDF Complex Operations Waste Management Plan, DOE/ID-10886 (DOE-ID 2003d) } \\
\text { - ICDF Complex Waste Verification Sampling and Analysis Plan, DOE/ID-10985 } \\
\text { (DOE-ID 2003g) }\end{array}$ & $\begin{array}{l}\text { Yes } \\
- \\
- \\
- \\
-\end{array}$ \\
\hline
\end{tabular}




\begin{tabular}{ccc}
\hline Requirement & $\begin{array}{c}\text { Substantive or } \\
\text { Administrative }\end{array}$ & Relevant or equivalent ARARs cited in the OU 3-13 ROD \\
\hline III.I.(1) Data Quality Objectives & Substantive & - None
\end{tabular}

CERCLA documents providing supporting information regarding compliance with requirement

Requirement

- Waste Acceptance Criteria for ICDF Complex, DOE/ID-10881 (DOE-ID 2005)

- "ICDF Complex Waste Tracking Plan" (PLN-914)

- ICDF Complex Waste Verification Sampling and Analysis Plan, DOE/ID-10985 (DOE-ID 2003g)

III.I.(2) Minimum Waste

Substantive

Characterization

- IDAPA 16.01.05.006 (40 CFR 262.11); Hazardous waste determination

III.J. Waste Certification

Administrative

- $\quad$ None

III.J.(1) Certification Program

Administrative

III.J.(2) Certification Before Transfer

Administrative

- None

- None

\section{III.J.(3) Maintaining Certification}

III.K. Waste Transfer

Administrative

Administrative

Administrative

- None

- None

III.K.(1) Authorization

Administrative

- None
- ICDF Complex Operations and Maintenance Plan, DOE/ID-11000 (DOE-ID 2003b)

- $\quad$ "ICDF Complex Waste Tracking Plan" (PLN-914)

- ICDF Complex Waste Verification Sampling and Analysis Plan, DOE/ID-10985 (DOE-ID 2003g)

- "ICDF Complex Waste Tracking Plan" (PLN-914)

- $\quad$ "Hazard Assessment Document, ICDF Complex Hazard Classification" (HAD-136)

- " "ICDF Complex Waste Tracking Plan" (PLN-914)

- Waste Acceptance Criteria for ICDF Complex, DOE/ID-10881 (DOE-ID 2005)

- "ICDF Complex Waste Tracking Plan" (PLN-914)

- ICDF Complex Waste Verification Sampling and Analysis Plan. DOE/ID-10985 (DOE-ID 2003g)

- "ICDF Complex Waste Tracking Plan" (PLN-914)

- " "ICDF Complex Waste Tracking Plan" (PLN-914)

- $\quad$ "ICDF Complex Waste Tracking Plan" (PLN-914)

- Waste Acceptance Criteria for ICDF Complex, DOE/ID-10881 (DOE-ID 2005)

- "ICDF Complex Waste Tracking Plan" (PLN-914)

- Waste Acceptance Criteria for ICDF Complex, DOE/ID-10881 (DOE-ID 2005)

- ICDF Complex Waste Verification Sampling and Analysis Plan, DOE/ID-10985 (DOE-ID 2003g)

III.L. Packaging and Transportation

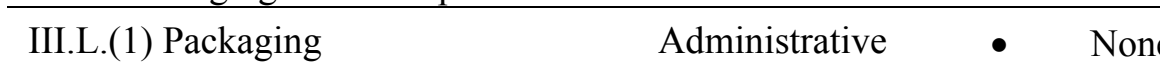

None

III.L.(2) Transportation

Administrative

- $\quad$ None

III.M. Site Evaluation and Facility Design

III.M.(1) Site Evaluation Substantive

- $\quad 16$ USC 469 et seq. 36 CFR 65; National Archeological and Historical Preservation Act

- 25 USC 3001; Native American Graves Protection and Repatriation Act

- DOE Order 435.1; Radioactive waste management performance objectives to protect workers (TBC)

- DOE Order 5400.5; Exposures to the public will be kept ALARA (TBC)
- Waste Acceptance Criteria for ICDF Complex, DOE/ID-10881 (DOE-ID 2005)

- ICDF Complex Operations and Maintenance Plan, DOE/ID-11000 (DOE-ID 2003b)

- Waste Acceptance Criteria for ICDF Complex, DOE/ID-10881 (DOE-ID 2005)

- $\quad$ Final Record of Decision for the Idaho Technology and Engineering Center, Operable Unit 3-13 at the INEEL, DOE/ID-10660 (DOE-ID 1999)

- Geotechnical Report for the Conceptual Design of the INEEL CERCLA Disposal Facility at Waste Area Group 3, Operable Unit 3-13, DOE/ID-10812 (DOE-ID 2000a)

- $\quad$ "Staging, Storage, Sizing, and Treatment Facility (SSSTF) Siting Study" (EDF-1548)

- Remedial Design/Construction Work Plan for the Waste Area Group 3 Staging, Storage, Sizing, and Treatment Facility, DOE/ID-10889 (DOE-ID 2002a), along with the supporting drawings, specifications, and Engineering Design Files

- $\quad$ ICDF Remedial Design/Construction Work Plan, DOE/ID-10848 (DOE-ID 2002b), along with the supporting drawings, specifications, and Engineering Design Files
- "ICDF Complex Waste Tracking Plan" (PLN-914) 


\begin{tabular}{ccc} 
Requirement & $\begin{array}{c}\text { Substantive or } \\
\text { Administrative }\end{array}$ & Relevant or equivalent ARARs cited in the OU 3-13 ROD \\
\hline III.M.(2) Facility Design & Substantive & IDAPA 16.01.05.008 (40 CFR 264, Subpart J); Tan \\
& & Systems
\end{tabular}
Systems

- $\quad$ IDAPA 16.01.05.008 (40 CFR 264.601);

Miscellaneous units environmental performance

$$
\begin{aligned}
& \text { Miscellaneourds } \\
& \text { standards }
\end{aligned}
$$

- IDAPA 16.01.05.008 (40 CFR 264, Subpart I); Use and management of containers

- IDAPA 16.01.05.008 (40 CFR 264, Subpart DD); Containment buildings

- $\quad$ DOE Order 435.1; Radioactive waste management performance objectives to protect workers (TBC)

- DOE Order 5400.5; Exposures to the public will be kept ALARA (TBC)
CERCLA documents providing supporting information regarding compliance with requirement Remedial Design/Construction Work Plan for the Waste Area Group 3 Staging, Storage, Sizing, and Treatment Facility, DOE/D-10889 (DOE-ID 2002a), along with the supporting drawings, specifications, and Engineering Design Files

- ICDF Remedial Design/Construction Work Plan, DOE/ID-10848 (DOE-ID 2002b), along with the supporting drawings, specifications, and Engineering Design Files

- INEEL CERCLA Disposal Facility Complex Remedial Action Work Plan, DOE/ID-10984 (DOE-ID 2003a)

- "WAG 3 Staging, Storage, Sizing, and Treatment Facility" (TFR-17)

- "WAG 3 INEEL CERCLA Disposal Facility and Evaporation Pond" (TFR-71)

- " "INEEL CERCLA Disposal Facility (ICDF) Control and Integrated Waste Tracking System" (TFR-2520)

- $\quad$ SSA As-Built Drawings, Design Drawings, and Specifications, Appendix E of DOE/ID-1088 (DOE-ID 2002a)

• "ICDF Complex Waste Tracking Plan" (PLN-914)

\section{III.N. Storage}

III.N.(1) Storage Prohibition

Substantive

III.N.(2) Storage Integrity

Substantive

III.N.(3) Container Inspection

Substantive

III.N.(4) Retrievable Earthen-Covered Administrative Storage
DOE Order 435.1; Radioactive waste management performance objectives to protect workers (TBC)

- DOE Order 5400.5; Exposures to the public will be kept ALARA (TBC)

- IDAPA 16.01.05.008 (40 CFR 264, Subpart J); Tank Systems

- $\quad$ IDAPA 16.01.05.008 (40 CFR 264.601); Miscellaneous units environmental performance standards

- IDAPA 16.01.05.008 (40 CFR 264, Subpart I); Use and management of containers

- IDAPA 16.01.05.008 (40 CFR 264, Subpart DD); Containment buildings

- DOE Order 435.1; Radioactive waste managemen performance objectives to protect workers (TBC)

- DOE Order 5400.5; Exposures to the public will be kept ALARA (TBC)

- IDAPA 16.01.05.008 (40 CFR 264, Subpart I); Use and management of containers

- IDAPA 16.01.05.008 (40 CFR 264, Subpart DD); Containment buildings

- $\quad$ DOE Order 435.1; Radioactive waste management performance objectives to protect workers (TBC)

- DOE Order 5400.5; Exposures to the public will be kept ALARA (TBC)

- N/A
- Waste Acceptance Criteria for ICDF Complex, DOE/ID-10881 (DOE-ID 2005)

- Waste Acceptance Criteria for ICDF Complex, DOE/ID-10881 (DOE-ID 2005)

- INEEL CERCLA Disposal Facility Complex Remedial Action Work Plan, DOE/ID-10984 (DOE-ID 2003a)

- ICDF Complex Operations and Maintenance Plan, DOE/ID-11000 (DOE-ID 2003b)

- INEEL CERCLA Disposal Facility Complex Remedial Action Work Plan, DOE/ID-10984 (DOE-ID 2003a)

- ICDF Complex Operations and Maintenance Plan, DOE/ID-11000 (DOE-ID 2003b)

- Also, detailed procedures are being developed for the various tasks that will be conducted at the ICDF Complex and these procedures will be included into the Operations and Maintenance Manual.

- $\quad$ N/A 


\begin{tabular}{|c|c|c|c|c|}
\hline Requirement & $\begin{array}{l}\text { Substantive or } \\
\text { Administrative }\end{array}$ & Relevant or equivalent ARARs cited in the OU 3-13 ROD & CERCLA documents providing supporting information regarding compliance with requirement & $\begin{array}{c}\text { Requirement } \\
\text { Satisfied }\end{array}$ \\
\hline III.O Treatment & Substantive & - $\mathrm{N} / \mathrm{A}$ & - N/A & N/A \\
\hline III.P. Disposal & Substantive & N/A & N/A & N/A \\
\hline \multicolumn{5}{|l|}{ III.Q. Monitoring } \\
\hline III.Q.(1) All Waste Facilities & Substantive & $\begin{array}{l}\text { - } \\
\text { DOE Order 435.1; Radioactive waste management } \\
\text { performance objectives to protect workers (TBC) } \\
\text { DOE Order 5400.5; Exposures to the public will be } \\
\text { kept ALARA (TBC) } \\
\text { - } \quad \text { 40 CFR 61.92, 40 CFR 61.93; NESHAP for } \\
\text { radionuclides from DOE facilities, emission } \\
\text { monitoring and emission compliance } \\
\text { - } \quad \text { IDAPA 16.01.01.585, IDAPA 16.01.01.586; Rules } \\
\text { for the control of air pollution in Idaho } \\
\text { - } \quad \text { IDAPA 16.01.05.008 (40 CFR 264, Subpart J); Tank } \\
\text { Systems } \\
\text { - } \\
\text { IDAPA 16.01.05.008 (40 CFR 264.192); Design and } \\
\text { installation of new tank systems or components } \\
\text { IDAPA 16.01.05.008 (40 CFR 264.601); } \\
\text { Miscellaneous units environmental performance } \\
\text { standards } \\
\text { IDAPA 16.01.05.008 (40 CFR 264, Subpart I); Use } \\
\text { and management of containers } \\
\text { IDAPA 16.01.05.008 (40 CFR 264, Subpart DD); } \\
\text { Containment buildings } \\
\text { IDAPA 16.01.05.008 (40 CFR 264.1052 through } \\
\text { 1062); Air emissions standards for equipment leaks }\end{array}$ & $\begin{array}{l}\text { - INEEL CERCLA Disposal Facility Complex Remedial Action Work Plan, DOE/ID-10984 } \\
\text { (DOE-ID 2003a) } \\
\text { - ICDF Complex Operations and Maintenance Plan, DOE/ID-11000 (DOE-ID 2003b) } \\
\text { - Also, detailed procedures are being developed for the various tasks that will be conducted at } \\
\text { the ICDF Complex and these procedures will be included into the Operations and } \\
\text { Maintenance Manual. } \\
\text { ICDF Complex Waste Verification Sampling and Analysis Plan, DOE/ID-10985 } \\
\text { (DOE-ID 2003g) } \\
\text { Health and Safety Plan for INEEL CERCLA Disposal Facility Operations, } \\
\text { INEEL/EXT-01-01318 (INEEL 2003) }\end{array}$ & $\begin{array}{l}\text { Yes } \\
- \\
- \\
-\end{array}$ \\
\hline III.Q.(2) Stored Waste & Substantive & $\begin{array}{l}\text { DOE Order 435.1; Radioactive waste management } \\
\text { performance objectives to protect workers (TBC) } \\
\text { DOE Order 5400.5; Exposures to the public will be } \\
\text { kept ALARA (TBC) } \\
\text { - } \quad \text { 40 CFR 61.92, 40 CFR 61.93; NESHAP for } \\
\text { radionuclides from DOE facilities, emission } \\
\text { monitoring and emission compliance } \\
\text { - IDAPA 16.01.01.585, IDAPA 16.01.01.586; Rules } \\
\text { for the control of air pollution in Idaho } \\
\text { - IDAPA 16.01.05.008 (40 CFR 264, Subpart J); Tank } \\
\text { - Systems } \\
\text { IDAPA 16.01.05.008 (40 CFR 264.192); Design and } \\
\text { installation of new tank systems or components } \\
\text { IDAPA 16.01.05.008 (40 CFR 264.601); } \\
\text { Miscellaneous units environmental performance } \\
\text { standards }\end{array}$ & $\begin{array}{l}\text { - } \quad \text { "Hazard Assessment Document, ICDF Complex Hazard Classification" (HAD-136) } \\
\text { - } \quad \text { "ICDF Complex Waste Tracking Plan" (PLN-914) } \\
\text { - Health and Safety Plan for INEEL CERCLA Disposal Facility Operations, } \\
\text { INEEL/EXT-01-01318 (INEEL 2003) }\end{array}$ & $\begin{array}{c}\text { Yes } \\
- \\
-\end{array}$ \\
\hline
\end{tabular}


Requirement

II.Q.(3) Liquid Waste Storage Facilities

$\mathrm{C}$

IDAPA 16.01.05.008 ( $40 \mathrm{CFR}$
and management of containers

- $\quad$ IDAPA 16.01.05.008 (40 CFR 264, Subpart DD);

Containment buildings

- IDAPA 16.01.05.008 (40 CFR 264.1052 through

1062); Air emissions standards for equipment leaks

- $\quad$ DOE Order 435.1; Radioactive waste management performance objectives to protect workers (TBC)

- DOE Order 5400.5; Exposures to the public will be kept ALARA (TBC)

- $\quad 40$ CFR 61.92, 40 CFR 61.93; NESHAP for radionuclides from DOE facilities, emission monitoring and emission compliance

- IDAPA 16.01.01.585, IDAPA 16.01.01.586; Rules for the control of air pollution in Idaho

- IDAPA 16.01.05.008 (40 CFR 264, Subpart J); Tank Systems

- IDAPA 16.01.05.008 (40 CFR 264.192); Design and installation of new tank systems or components

- $\quad$ IDAPA 16.01.05.008 (40 CFR 264.601);

Miscellaneous units environmental performance standards

- IDAPA 16.01.05.008 (40 CFR 264, Subpart I); Use and management of containers

- IDAPA 16.01.05.008 (40 CFR 264, Subpart DD); Containment buildings

- IDAPA 16.01.05.008 (40 CFR 264.1052 through 1062); Air emissions standards for equipment leak

- INEEL CERCLA Disposal Facility Complex Remedial Action Work Plan, DOE/ID-10984 (DOE-ID 2003a)

- ICDF Complex Operations and Maintenance Plan, DOE/ID-11000 (DOE-ID 2003b)

- Also, detailed procedures are being developed for the various tasks that will be conducted at the ICDF Complex and these procedures will be included into the Operations and Maintenance Manual

- ICDF Complex Waste Verification Sampling and Analysis Plan, DOE/ID-10985 (DOE-ID 2003g)

- Health and Safety Plan for INEEL CERCLA Disposal Facility Operations, INEEL/EXT-01-01318 (INEEL 2003) 


\begin{tabular}{|c|c|c|c|c|}
\hline Requirement & $\begin{array}{l}\text { Substantive or } \\
\text { Administrative }\end{array}$ & Relevant or equivalent ARARs cited in the OU 3-13 ROD & CERCLA documents providing supporting information regarding compliance with requirement & $\begin{array}{l}\text { Requirement } \\
\text { Satisfied }\end{array}$ \\
\hline
\end{tabular}
IV.A. Definition of Low-Level Waste $\quad$ Substantive $\quad-\quad$ DOE Order 435.1; Radioactive waste management

- Waste Acceptance Criteria for ICDF Complex, DOE/ID-10881 (DOE-ID 2005)

- INEEL CERCLA Disposal Facility Construction Waste Management Plan, DOE/ID-10958 (DOE-ID 2002d)

- Staging, Storage, Sizing, and Treatment Facility Construction Waste Management Plan, DOE/ID-10873 (DOE-ID 2002e)

- ICDF Complex Operations Waste Management Plan, DOE/ID-10886 (DOE-ID 2003d)

IV.B. Management of Specific Wastes

IV.B.(1) Mixed Low-Level Waste

- $\quad$ IDAPA 16.01.05.006 (40 CFR 262.11); Hazardous waste determination

- IDAPA 16.01.05.005 (40 CFR 261.20 through 24); Hazardous waste characteristics identification

- $\quad 40$ CFR 761.50(b)(7); PCB radioactive waste

IDAPA 16.01.05.005 (40 CFR 261); Identification and listing of hazardous waste

IDAPA 16.01.05.006 (40 CFR 262.11); Hazardous waste determination

- $\quad 40$ CFR 761.50(b)(7); PCB radioactive waste

- $\quad 40$ CFR $761.50(\mathrm{~b})(8)$; Porous surfaces

- $\quad 40$ CFR 761.50(d)(4); Disposal requirements for $\mathrm{PCBs}$
- $\quad$ Waste Acceptance Criteria for ICDF Complex, DOE/ID-10881 (DOE-ID 2005)

- INEEL CERCLA Disposal Facility Complex Remedial Action Work Plan, DOE/ID-10984 (DOE-ID 2003a)

- ICDF Complex Operations and Maintenance Plan, DOE/ID-11000 (DOE-ID 2003b)

- INEEL CERCLA Disposal Facility Construction Waste Management Plan, DOE/ID-10958 (DOE-ID 2002d)

- Staging, Storage, Sizing, and Treatment Facility Construction Waste Management Plan DOE/ID-10873 (DOE-ID 2002e)

- $\quad$ ICDF Complex Operations Waste Management Plan, DOE/ID-10886 (DOE-ID 2003d)

- ICDF Complex Waste Verification Sampling and Analysis Plan, DOE/ID-10985 (DOE-ID 2003g)

- Waste Acceptance Criteria for ICDF Complex, DOE/ID-10881 (DOE-ID 2005)

- INEEL CERCLA Disposal Facility Complex Remedial Action Work Plan, DOE/ID-10984 (DOE-ID 2003a)

- ICDF Complex Operations and Maintenance Plan, DOE/ID-11000 (DOE-ID 2003b)

- INEEL CERCLA Disposal Facility Construction Waste Management Plan, DOE/ID-10958 (DOE-ID 2002d)

- $\quad$ Staging, Storage, Sizing, and Treatment Facility Construction Waste Management Plan, DOE/ID-10873 (DOE-ID 2002e)

- ICDF Complex Operations Waste Management Plan, DOE/ID-10886 (DOE-ID 2003d)

- ICDF Complex Waste Verification Sampling and Analysis Plan, DOE/ID-10985 (DOE-ID 2003g) 


\begin{tabular}{|c|c|c|c|c|}
\hline Requirement & $\begin{array}{l}\text { Substantive or } \\
\text { Administrative }\end{array}$ & Relevant or equivalent ARARs cited in the OU 3-13 ROD & CERCLA documents providing supporting information regarding compliance with requirement & $\begin{array}{l}\text { Requirement } \\
\text { Satisfied }\end{array}$ \\
\hline IV.B.(3) Accelerator-Produced Waste & Substantive & N/A & N/A & N/A \\
\hline $\begin{array}{l}\text { IV.B.(4) 11e.(2) and Naturally } \\
\text { Occurring Radioactive Material }\end{array}$ & Substantive & N/A & $\cdot$ & N/A \\
\hline $\begin{array}{l}\text { IV.C. Complex-Wide Low-Level } \\
\text { Waste Management Program }\end{array}$ & Administrative & - $\quad$ None & - $\quad$ None & N/A \\
\hline
\end{tabular}

Waste Management Program

Substantive $\quad$ D DOE Order 435.1; Radioactive waste management performance objectives to protect workers

IV.D.(1) Generators

- IDAPA 16.01.05.006

IV.D.(2) Treatment Facilities

Substantive

IDAPA 16.01.05.008 (40 CFR 264.601);

Miscellaneous units environmental performance standards

- IDAPA 16.01.05.008 (40 CFR 264, Subpart DD) Containment buildings

- IDAPA 16.01.05.008 (40 CFR 264.552); CAMUs

- DOE Order 435.1; Radioactive waste management performance objectives to protect workers (TBC)

- DOE Order 5400.5; Exposures to the public will be kept ALARA (TBC)
" cHazard Assessment Document, ICDF Complex Hazard Classification" (HAD-136)

- Waste Acceptance Criteria for ICDF Complex, DOE/ID-10881 (DOE-ID 2005)

- "NESHAP Compliance Demonstration for the ICDF Complex" (EDF-2236)

- "NESHAP Modeling for the ICDF Complex" (EDF-ER-290)

- "INEEL CERCL A Disposal Facility Short-Term Risk Assessment" (EDF-ER-327) (This document also evaluates the impacts on both public receptors and non-ICDF workers.)

- "IDAPA Air Compliance Demonstration for the ICDF Complex" (EDF-2237)

- "SSSTF Design Radiological Control Analysis" (EDF-ER-302)

- Health and Safety Plan for INEEL CERCLA Disposal Facility Operations, INEEL/EXT-01-01318 (INEEL 2003)

- ICDF Complex Operations and Maintenance Plan, DOE/ID-11000 (DOE-ID 2003b)

- ICDF Complex Waste Verification Sampling and Analysis Plan, DOE/ID-10985 (DOE-ID 2003g)

- "Hazard Assessment Document, ICDF Complex Hazard Classification” (HAD-136)

- Waste Acceptance Criteria for ICDF Complex, DOE/ID-10881 (DOE-ID 2005)

- "NESHAP Compliance Demonstration for the ICDF Complex" (EDF-2236)

- "NESHAP Modeling for the ICDF Complex" (EDF-ER-290)

- "INEEL CERCLA Disposal Facility Short-Term Risk Assessment" (EDF-ER-327) (This document also evaluates the impacts on both public receptors and non-ICDF workers.)

- "IDAPA Air Compliance Demonstration for the ICDF Complex" (EDF-2237)

- $\quad$ "SSSTF Design Radiological Control Analysis" (EDF-ER-302)

- Health and Safety Plan for INEEL CERCLA Disposal Facility Operations, INEEL/EXT-01-01318 (INEEL 2003)

- ICDF Complex Operations and Maintenance Plan, DOE/ID-11000 (DOE-ID 2003b) 


\begin{tabular}{|c|c|c|c|c|}
\hline Requirement & $\begin{array}{l}\text { Substantive or } \\
\text { Administrative }\end{array}$ & Relevant or equivalent ARARs cited in the OU 3-13 ROD & CERCLA documents providing supporting information regarding compliance with requirement & $\begin{array}{l}\text { Requirement } \\
\text { Satisfied }\end{array}$ \\
\hline IV.D.(3) Storage Facilities & Substantive & 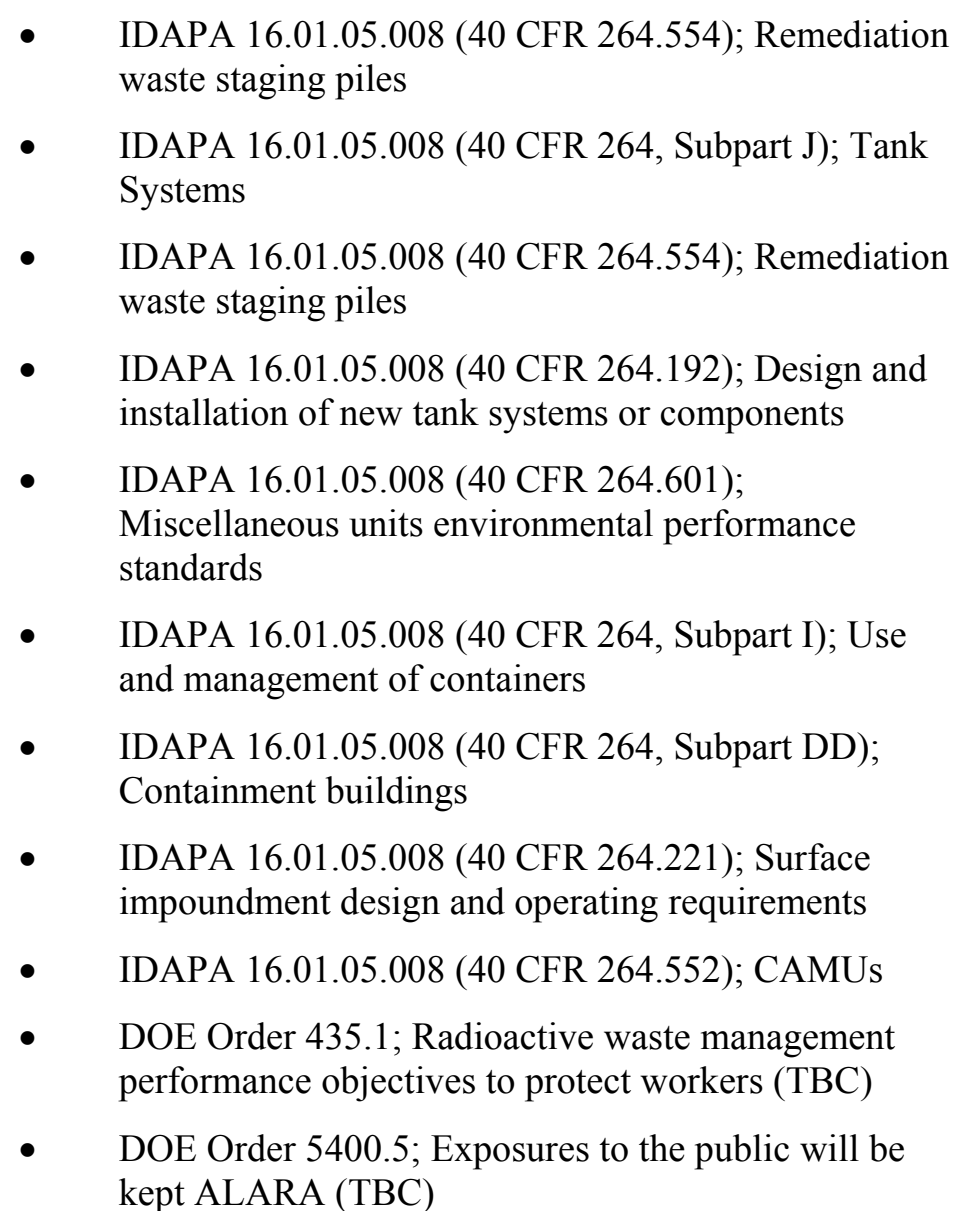 & $\begin{array}{l}\text { - } \quad \text { "Hazard Assessment Document, ICDF Complex Hazard Classification" (HAD-136) } \\
\text { - Waste Acceptance Criteria for ICDF Complex, DOE/ID-10881 (DOE-ID 2005) } \\
\text { - } \quad \text { "NESHAP Compliance Demonstration for the ICDF Complex" (EDF-2236) } \\
\text { - } \quad \text { NESHAP Modeling for the ICDF Complex" (EDF-ER-290) } \\
\text { - } \quad \text { "INEEL CERCLA Disposal Facility Short-Term Risk Assessment" (EDF-ER-327) (This } \\
\text { - } \text { document also evaluates the impacts on both public receptors and non-ICDF workers.) } \\
\text { - } \quad \text { "SDAPA Air Compliance Demonstration for the ICDF Complex" (EDF-2237) } \\
\text { - Health and Safety Plan for INEEL CERCLA Disposal Facility Operations, INEEL/EXT-01-01318 } \\
\text { (INEEL 2003) } \\
\text { ICDF Complex Operations and Maintenance Plan, DOE/ID-11000 (DOE-ID 2003b) }\end{array}$ & $\begin{array}{c}\text { Yes } \\
- \\
- \\
- \\
- \\
- \\
- \\
-\end{array}$ \\
\hline IV.D.(4) Disposal Facilities & Substantive & $\begin{array}{l}\text { - IDAPA 16.01.05.008 (40 CFR 264.301); Landfill } \\
\text { design and operating requirements } \\
\text { - } 40 \text { CFR 761.75(b)(1)(2); PCB landfill design } \\
\text { requirements } \\
\text { - } \quad \begin{array}{l}\text { DOE Order 435.1; Radioactive waste management } \\
\text { performance objectives to protect workers (TBC) }\end{array} \\
\text { - DOE Order 5400.5; Exposures to the public will be } \\
\text { kept ALARA (TBC) }\end{array}$ & 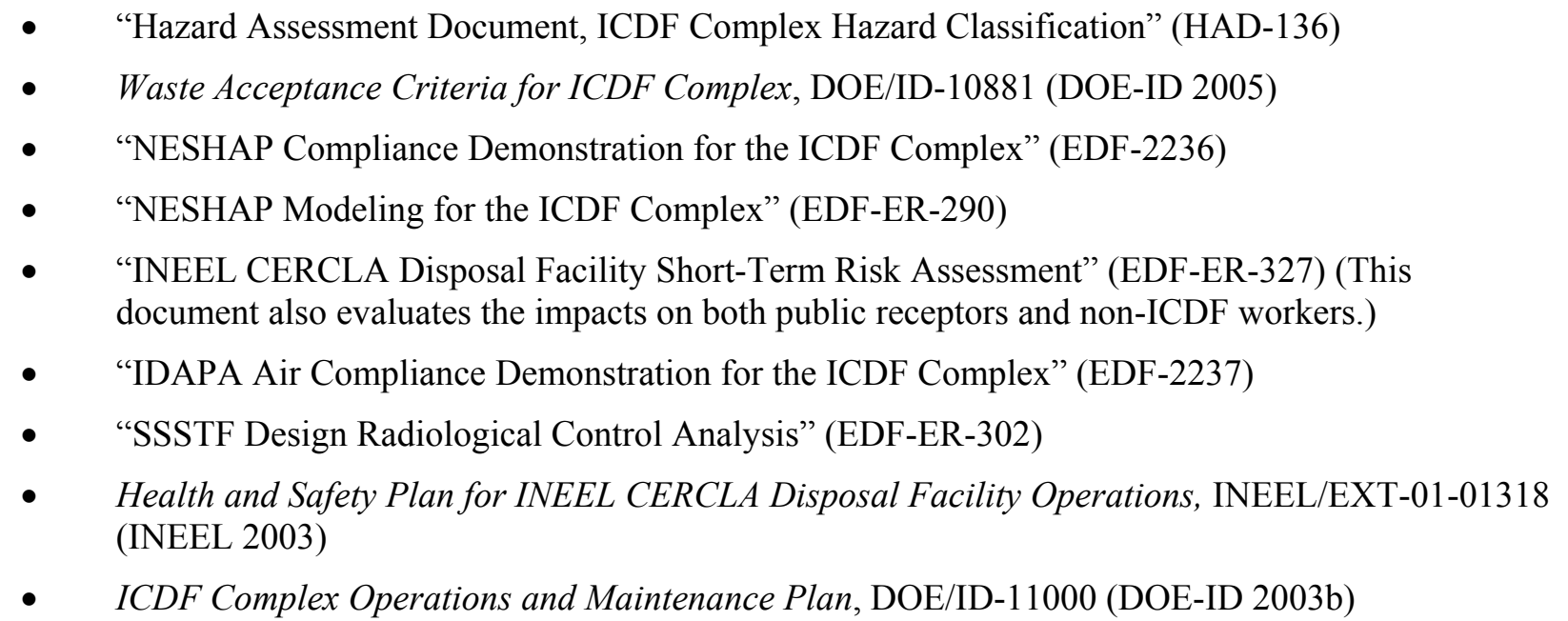 & $\begin{array}{c}\text { Yes } \\
- \\
- \\
- \\
- \\
- \\
- \\
-\end{array}$ \\
\hline
\end{tabular}




\section{Requirement}

Requirement

IV.E. Contingency Actions

IV.E.(1) Contingency Storage Substantive or

Substantive

Relevant or equivalent ARARs cited in the OU 3-13 ROD

CERCLA documents providing supporting information regarding compliance with requirement

Requirement Satisfied

- INEEL CERCLA Disposal Facility Complex Remedial Action Work Plan, DOE/ID-10984 (DOE-ID 2003a)

- ICDF Complex Operations and Maintenance Plan, DOE/ID-11000 (DOE-ID 2003b)

- $\quad$ Remedial Design/Construction Work Plan for the Waste Area Group 3 Staging, Storage, Sizing, and Treatment Facility, DOE/ID-10889 (DOE-ID 2002a), along with the supporting drawings, specifications, and Engineering Design Files

IV.E.(2) Transfer Equipment $\quad$ Substantive $\quad$ None

- Waste Acceptance Criteria for ICDF Complex, DOE/ID-10881 (DOE-ID 2005)

- INEEL CERCLA Disposal Facility Complex Remedial Action Work Plan, DOE/ID-10984 (DOE-ID 2003a)

- ICDF Complex Operations and Maintenance Plan, DOE/ID-11000 (DOE-ID 2003b)

- Remedial Design/Construction Work Plan for the Waste Area Group 3 Staging, Storage, Sizing, and Treatment Facility, DOE/ID-10889 (DOE-ID 2002a), along with the supporting drawings, specifications, and Engineering Design Files

- Waste Acceptance Criteria for ICDF Complex, DOE/ID-10881 (DOE-ID 2005)

IV.F. Corrective Actions

IV.F.(1) Order Compliance Substantive • None

IV.F.(2) Operations Curtailment

Substantive

None

- INEEL CERCLA Disposal Facility Complex Remedial Action Work Plan. DOE/ID-10984 (DOE-ID 2003a)

- ICDF Complex Operations and Maintenance Plan, DOE/ID-11000 (DOE-ID 2003b)

- Also, detailed procedures are being developed for the various tasks that will be conducted at the ICDF Complex and these procedures will be included into the Operations and Maintenance ICDF Co
Manual.

- INEEL CERCLA Disposal Facility Complex Remedial Action Work Plan, DOE/ID-10984 (DOE-ID 2003a)

- ICDF Complex Operations and Maintenance Plan, DOE/ID-11000 (DOE-ID 2003b)

- "ICDF Complex Waste Tracking Plan" (PLN-914)

- "Hazard Assessment Document, ICDF Complex Hazard Classification" (HAD-136)

- Also, detailed procedures are being developed for the various tasks that will be conducted at the ICDF Complex and these procedures will be included into the Operations and Maintenance Manual.
Yes

$-$ 


\begin{tabular}{|c|c|c|c|c|}
\hline Requirement & $\begin{array}{l}\text { Substantive or } \\
\text { Administrative }\end{array}$ & Relevant or equivalent ARARs cited in the OU 3-13 ROD & CERCLA documents providing supporting information regarding compliance with requirement & $\begin{array}{l}\text { Requirement } \\
\text { Satisfied }\end{array}$ \\
\hline \multicolumn{5}{|l|}{ IV.G. Waste Acceptance } \\
\hline $\begin{array}{l}\text { IV.G.(1) Technical and } \\
\text { Administrative }\end{array}$ & Substantive & 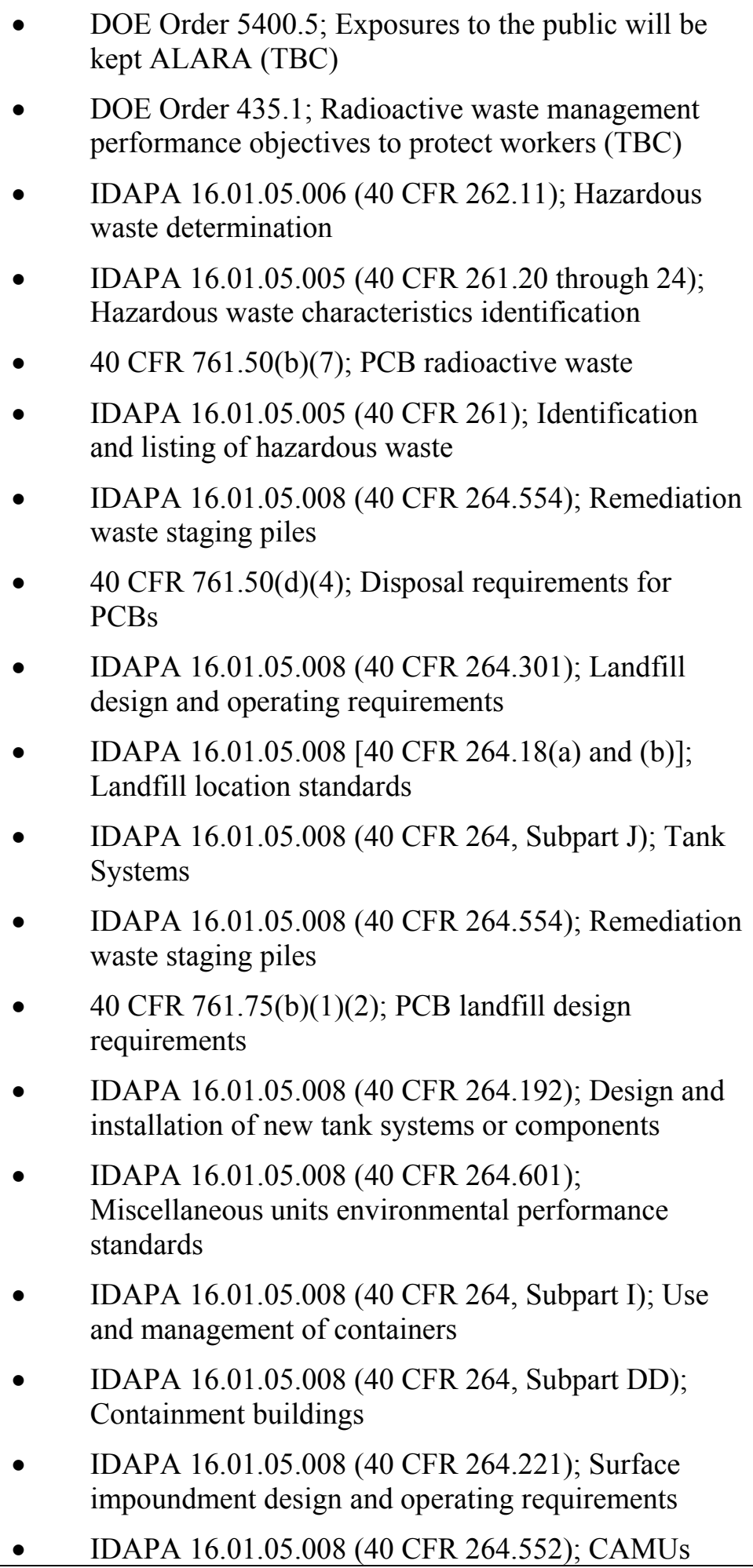 & $\begin{array}{ll}\text { - } & \text { Waste Acceptance Criteria for ICDF Complex, DOE/ID-10881 (DOE-ID 2005) } \\
\text { - } & \text { "Hazard Assessment Document, ICDF Complex Hazard Classification" (HAD-136) } \\
\text { - } & \text { "ICDF Complex Waste Tracking Plan" (PLN-914) } \\
\text { - } & \text { ICDF Complex Waste Verification Sampling and Analysis Plan, DOE/ID-10985 (DOE-ID 2003g) } \\
\text { - } & \text { ICDF Complex Operations and Maintenance Plan, DOE/ID-11000 (DOE-ID 2003b) } \\
\text { - } & \text { INEEL CERCLA Disposal Facility Complex Remedial Action Work Plan, DOE/ID-10984 } \\
\text { - (DOE-ID 2003a) } & \text { "Waste Placement Plan" (EDF-ER-286) } \\
\text { - } & \text { "Subsurface Consolidation Calculations" (EDF-ER-266) } \\
\text { - } & \text { "Landfill Compaction/Subsidence Study" (EDF-ER-267) }\end{array}$ & $\begin{array}{c}\text { Yes } \\
- \\
- \\
- \\
- \\
- \\
- \\
- \\
- \\
- \\
-\end{array}$ \\
\hline
\end{tabular}




\begin{tabular}{|c|c|c|c|c|}
\hline Requirement & $\begin{array}{l}\text { Substantive or } \\
\text { Administrative }\end{array}$ & Relevant or equivalent ARARs cited in the OU 3-13 ROD & CERCLA documents providing supporting information regarding compliance with requirement & $\begin{array}{l}\text { Requirement } \\
\text { Satisfied }\end{array}$ \\
\hline IV.G.(2) Evaluation and Acceptance & Substantive & 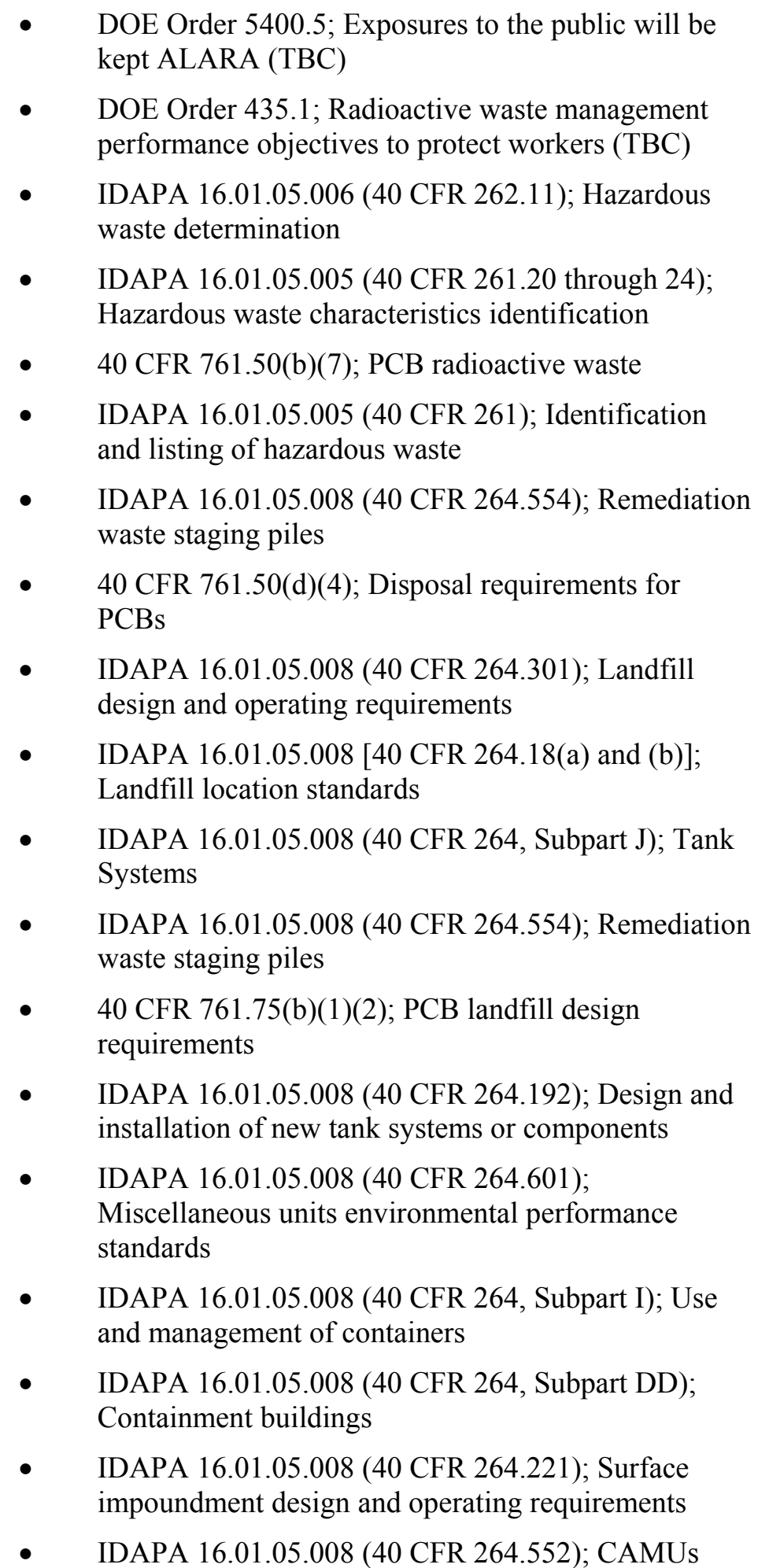 & $\begin{array}{l}\text { - } \quad \text { ICDF Complex Waste Acceptance Criteria, DOE/ID-10881 (DOE-ID 2005) } \\
\text { - } \\
\text { - ICDF Complex Waste Tracking Plan" (PLN-914) } \\
\text { - } \quad \text { ICDF Complex Waste Verification Sampling and Analysis Plan, DOE/ID-10985 (DOE-ID 2003g) } \\
\text { INEEL CERCLA Disposal Facility Complex Remedial Action Work Plan, DOE/ID-10984 } \\
\text { (DOE-ID 2003a) } \\
\text { - ICDF Complex Operations and Maintenance Plan, DOE/ID-11000 (DOE-ID 2003b) }\end{array}$ & $\begin{array}{c}\text { Yes } \\
- \\
- \\
-\end{array}$ \\
\hline
\end{tabular}




\section{Table 9-4. (continued). \\ Requirement \\ IV.H. Waste Generation Planning}

IV.H.(1) Life-Cycle Planning Substantive or

Relevant or equivalent ARARs cited in the OU 3-13 ROD

Administrative $\quad$ None

CERCLA documents providing supporting information regarding compliance with requirement

Administrative

None

IV.H.(2) Waste With No Identified Path to Disposal

IV.I. Waste Characterization

IV.I.(1) Data Quality Objectives

IV.I.(2) Minimum Waste

Characterization Requirements

IV.J. Waste Certification

IV.J.(1) Certification Program

IV.J.(2) Certification Before Transfer
Substantive • IDAPA 16.01.05.006 (40 CFR 262.11); Hazardous waste determination

Substantive • None

Substantive

IDAPA 16.01.05.006 (40 CFR 262.11); Hazardous waste determination

Administrative

- None

Administrative • None

Administrative - None
- INEEL CERCLA Disposal Facility Construction Waste Management Plan, DOE/ID-10958 (DOE-ID 2002d)

- Staging, Storage, Sizing, and Treatment Facility Construction Waste Management Plan, DOE/ID-10873 (DOE-ID 2002e)

- ICDF Complex Operations Waste Management Plan, DOE/ID-10886 (DOE-ID 2003d)

- Idaho National Engineering and Environmental Laboratory Reusable Property, Recyclable Materials, and Waste Acceptance Criteria (RRWAC), DOE/ID-10381 (DOE-ID 1994)

- INEEL Interim Pollution Prevention Plan, DOE/ID-10333 (DOE-ID 2000c)

- INEEL CERCLA Disposal Facility Complex Remedial Action Work Plan, DOE/ID-10984 (DOE-ID 2003a)

- ICDF Complex Operations and Maintenance Plan, DOE/ID-11000 (DOE-ID 2003b)

- Health and Safety Plan for Construction of the INEEL CERCLA Disposal Facility and Evaporation Pond, INEEL/EXT-2000-01424 (INEEL 2001b)

- Health and Safety Plan for Construction of Staging, Storage, Sizing, and Treatment Facility, INEEL/EXT-01-00271 (INEEL 2002a)

- Health and Safety Plan for INEEL CERCLA Disposal Facility Operations, INEEL/EXT-01-01318 (INEEL 2003)

- $\quad$ Also, detailed procedures are being developed for the various tasks that will be conducted at the ICDF Complex and these procedures will be included into the Operations and Maintenance Manual.

- $\quad$ Waste Acceptance Criteria for ICDF Complex, DOE/ID-10881 (DOE-ID 2005)

- ICDF Complex Waste Verification Sampling and Analysis Plan, DOE/ID-10985 (DOE-ID 2003g)

- $\quad$ Waste Acceptance Criteria for ICDF Complex, DOE/ID-10881 (DOE-ID 2005)

- "ICDF Complex Waste Tracking Plan" (PLN-914)

- ICDF Complex Waste Verification Sampling and Analysis Plan, DOE/ID-10985 (DOE-ID 2003g)

- ICDF Complex Operations and Maintenance Plan, DOE/ID-11000 (DOE-ID 2003b)

- “ "ICDF Complex Waste Tracking Plan" (PLN-914)

- ICDF Complex Waste Verification Sampling and Analysis Plan, DOE/ID-10985 (DOE-ID 2003g)

- "ICDF Complex Waste Tracking Plan" (PLN-914)

- "Hazard Assessment Document, ICDF Complex Hazard Classification" (HAD-136)

- "ICDF Complex Waste Tracking Plan" (PLN-914)

- Waste Acceptance Criteria for ICDF Complex, DOE/ID-10881 (DOE-ID 2005)

- ICDF Complex Waste Tracking Plan" (PLN-914)

- ICDF Complex Waste Verification Sampling and Analysis Plan, DOE/ID-10985 (DOE-ID 2003g) 


\begin{tabular}{|c|c|c|c|c|}
\hline Requirement & $\begin{array}{l}\text { Substantive or } \\
\text { Administrative }\end{array}$ & Relevant or equivalent ARARs cited in the OU 3-13 ROD & CERCLA documents providing supporting information regarding compliance with requirement & $\begin{array}{c}\text { Requirement } \\
\text { Satisfied }\end{array}$ \\
\hline IV.J.(3) Maintaining Certification & Administrative & - $\quad$ None & - $\quad$ "ICDF Complex Waste Tracking Plan" (PLN-914) & Yes \\
\hline IV.K. Waste Transfer & Administrative & None & "ICDF Complex Waste Tracking Plan" (PLN-914) & Yes \\
\hline \multirow[t]{2}{*}{ IV.K.(1) Authorization } & \multirow[t]{2}{*}{ Administrative } & \multirow[t]{2}{*}{ - None } & • " “ICDF Complex Waste Tracking Plan" (PLN-914) & Yes \\
\hline & & & - $\quad$ ICDF Complex Waste Acceptance Criteria, DOE/ID-10881 (DOE-ID 2005) & - \\
\hline \multirow[t]{3}{*}{ IV.K.(2) Data } & \multirow[t]{3}{*}{ Administrative } & \multirow[t]{3}{*}{ - $\quad$ None } & • “ICDF Complex Waste Tracking Plan" (PLN-914) & Yes \\
\hline & & & - $\quad$ Waste Acceptance Criteria for ICDF Complex, DOE/ID-10881 (DOE-ID 2005) & - \\
\hline & & & - ICDF Complex Waste Verification Sampling and Analysis Plan, DOE/ID-10985 (DOE-ID 2003g) & - \\
\hline \multicolumn{5}{|l|}{ IV.L. Packaging and Transportation } \\
\hline \multirow[t]{3}{*}{ IV.L.(1) Packaging } & \multirow[t]{3}{*}{ Administrative } & \multirow[t]{3}{*}{ - $\quad$ None } & - Waste Acceptance Criteria for ICDF Complex, DOE/ID-10881 (DOE-ID 2005) & Yes \\
\hline & & & - ICDF Complex Operations and Maintenance Plan, DOE/ID-11000 (DOE-ID 2003b) & - \\
\hline & & & • $\quad$ “ICDF Complex Waste Tracking Plan” (PLN-914) & - \\
\hline IV.L.(2) Transportation & Administrative & None & Waste Acceptance Criteria for ICDF Complex, DOE/ID-10881 (DOE-ID 2005) & Yes \\
\hline \multicolumn{5}{|c|}{ IV.M. Site Evaluation and Facility Design } \\
\hline IV.M.(1) Site Evaluation & Substantive & $\begin{array}{ll}\text { - } & \text { IDAPA 16.01.05.008 (40 CFR 264.554); Remediation } \\
& \text { waste staging piles } \\
\text { - } & \text { 40 CFR 761.50(d)(4); Disposal requirements for } \\
& \text { PCBs } \\
\text { - } & \text { IDAPA 16.01.05.008 (40 CFR 264.301); Landfill } \\
& \text { design and operating requirements } \\
\text { - } & \text { IDAPA 16.01.05.008 [40 CFR 264.18(a) and (b)]; } \\
\text { - Landfill location standards } \\
\text { - } \quad \text { IDAPA 16.01.05.008 (40 CFR 264, Subpart J); Tank } \\
\text { Systems } \\
\text { - } \quad \text { IDAPA 16.01.05.008 (40 CFR 264.554); Remediation } \\
\text { - } \quad \text { waste staging piles } \\
\text { 40 CFR 761.75(b)(1)(2); PCB landfill design } \\
\text { requirements } \\
\text { - IDAPA 16.01.05.008 (40 CFR 264.192); Design and } \\
\text { installation of new tank systems or components } \\
\text { - IDAPA 16.01.05.008 (40 CFR 264.601); } \\
\text { Miscellaneous units environmental performance } \\
\text { standards } \\
\text { IDAPA 16.01.05.008 (40 CFR 264, Subpart I); Use } \\
\text { and management of containers } \\
\text { - IDAPA 16.01.05.008 (40 CFR 264, Subpart DD); }\end{array}$ & $\begin{array}{l}\text { - Final Record of Decision for the Idaho Technology and Engineering Center, Operable Unit 3-13 } \\
\text { at the INEEL, DOE/ID-10660 (DOE-ID 1999) } \\
\text { - Geotechnical Report for the Conceptual Design of the INEEL CERCLA Disposal Facility at Waste } \\
\text { Area Group 3, Operable Unit 3-13, DOE/ID-10812 (DOE-ID 2000a) } \\
\text { - "Staging, Storage, Sizing, and Treatment Facility (SSSTF) Siting Study" (EDF-1548) } \\
\text { - } \quad \text { Remedial Design/Construction Work Plan for the Waste Area Group 3 Staging, Storage, Sizing, } \\
\text { and Treatment Facility, DOE/ID-10889 (DOE-ID 2002a), along with the supporting drawings, } \\
\text { specifications, and Engineering Design Files } \\
\text { - ICDF Remedial Design/Construction Work Plan, DOE/ID-10848 (DOE-ID 2002b), along with the } \\
\text { supporting drawings, specifications, and Engineering Design Files }\end{array}$ & $\begin{array}{l}\text { Yes } \\
- \\
- \\
-\end{array}$ \\
\hline
\end{tabular}


- IDAPA 16.01.05.008 (40 CFR 264.221); Surface impoundment design and operating requirements

- IDAPA 16.01.05.008 (40 CFR 264.552); CAMUs

- $\quad 16$ USC 469 et seq. 36 CFR 65; National

Archeological and Historical Preservation Act

- 25 USC 3001; Native American Graves Protection and Repatriation Act

- DOE Order 435.1; Radioactive waste management performance objectives to protect workers (TBC)

- DOE Order 5400.5; Exposures to the public will be

IV.M.(2) Low-Level Waste Treatment and Storage Facility Design kept ALARA (TBC)

IDAPA 16.01.05.008 (40 CFR 264.554); Remediation waste staging piles

- IDAPA 16.01.05.008 (40 CFR 264, Subpart J); Tan Systems

- IDAPA 16.01.05.008 (40 CFR 264.192); Design an installation of new tank systems or components

- IDAPA 16.01.05.008 (40 CFR 264.601);

Miscellaneous units environmental performance standards

- IDAPA 16.01.05.008 (40 CFR 264, Subpart I); Use and management of containers

- $\quad$ IDAPA 16.01.05.008 (40 CFR 264, Subpart DD); Containment buildings

- IDAPA 16.01.05.008 (40 CFR 264.221); Surface impoundment design and operating requirements

- $\quad$ IDAPA 16.01.05.008 (40 CFR 264.552); CAMUs

- DOE Order 435.1; Radioactive waste management performance objectives to protect workers (TBC)

- DOE Order 5400.5; Exposures to the public will be kept ALARA (TBC)

IV.M.(3) Low-Level Waste Disposal Facility Design
Substantive

IDAPA 16.01.05.008 (40 CFR 264.301); Landfill design and operating requirements

- $\quad 40$ CFR 761.75(b)(1)(2); PCB landfill design requirements

- DOE Order 435.1; Radioactive waste management performance objectives to protect workers (TBC)
Remedial Design/Construction Work Plan for the Waste Area Group 3 Staging, Storage, Sizing, and Treatment Facility, DOE/ID-10889 (DOE-ID 2002a), along with the supporting drawings, specifications, and Engineering Design Files

- INEEL CERCLA Disposal Facility Complex Remedial Action Work Plan, DOE/ID-10984 (DOE-ID 2003a)

- ICDF Complex Operations and Maintenance Plan, DOE/ID-11000 (DOE-ID 2003b)

- "INEEL CERCLA Disposal Facility Short-Term Risk Assessment" (EDF-ER-327) (This document also evaluates the impacts on both public receptors and non-ICDF workers.)

- " $\quad$ SSA As-Built Drawings, Design Drawings, and Specifications," Appendix E of DOE/ID-10889 (DOE ID 2002a)

- “SSSTF Design Radiological Control Analysis” (EDF-ER-302)

- "Hazard Assessment Document, ICDF Complex Hazard Classification” (HAD-136)

- ICDF Remedial Design/Construction Work Plan, DOE/ID-10848 (DOE-ID 2002b), along with the supporting drawings, specifications, and Engineering Design Files

- INEEL CERCLA Disposal Facility Complex Remedial Action Work Plan, DOE/ID-10984 (DOE-ID 2003a)

- " "WAG 3 INEEL CERCLA Disposal Facility and Evaporation Pond" (TFR-71)

- " "INEEL CERCLA Disposal Facility (ICDF) Control and Integrated Waste Tracking System" (TFR-2520) 


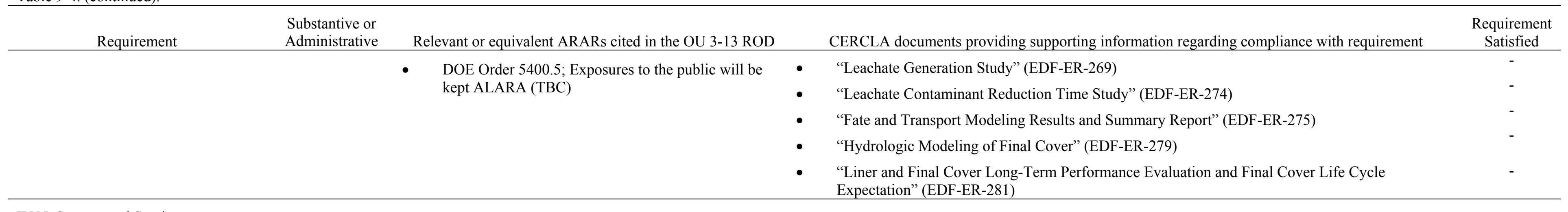

IV.N. Storage and Staging

IV N.(1) Storage Prohibition

Substantive

IDAPA 16.01.05.008 (40 CFR 264.554); Remediation

- Waste Acceptance Criteria for ICDF Complex, DOE/ID-10881 (DOE-ID 2005)

IDAPA 16.01.05.008 (40 CFR 264, Subpart J); Tank Systems

- IDAPA 16.01.05.008 (40 CFR 264.192); Design and installation of new tank systems or components

- IDAPA 16.01.05.008 (40 CFR 264.601);

Miscellaneous units environmental performance standards

- IDAPA 16.01.05.008 (40 CFR 264, Subpart I); Use and management of containers

- $\quad$ IDAPA 16.01.05.008 (40 CFR 264, Subpart DD); Containment buildings

- IDAPA 16.01.05.008 (40 CFR 264.221); Surface impoundment design and operating requirements

IDAPA 16.01.05.008 (40 CFR 264.552); CAMUs

- DOE Order 435.1; Radioactive waste management performance objectives to protect workers (TBC)

- DOE Order 5400.5; Exposures to the public will be kept ALARA (TBC)

- "Hazard Assessment Document, ICDF Complex Hazard Classification" (HAD-136)

- "INEEL CERCLA Disposal Facility Short-Term Risk Assessment" (EDF-ER-327) (This document also evaluates the impacts on both public receptors and non-ICDF workers.)

- INEEL CERCLA Disposal Facility Complex Remedial Action Work Plan, DOE/ID-10984 (DOE-ID 2003a)

- ICDF Complex Operations and Maintenance Plan, DOE/ID-11000 (DOE-ID 2003b)

- $\quad$ Also, detailed procedures are being developed for the various tasks that will be conducted at the ICDF Complex and these procedures will be included into the Operations and Maintenance Manual. 


\section{Requirement}

IV.N.(3) Storage Integrity

IV.N.(4) Storage Waste

Characterization

IV.N.(5) Container Inspection

IV.N.(6) Storage Management
Substantive or Administrative

Substantive

IDAPA 16.01.05.008 (40 CFR 264.554); Remediation waste staging piles

- IDAPA 16.01.05.008 (40 CFR 264, Subpart J); Tank Systems

- IDAPA 16.01.05.008 (40 CFR 264.192); Design and installation of new tank systems or components

- IDAPA 16.01.05.008 (40 CFR 264.601); Miscellaneous units environmental performance standards

- IDAPA 16.01.05.008 (40 CFR 264, Subpart I); Use and management of containers

- IDAPA 16.01.05.008 (40 CFR 264, Subpart DD); Containment buildings

- IDAPA 16.01.05.008 (40 CFR 264.221); Surface impoundment design and operating requirements

- IDAPA 16.01.05.008 (40 CFR 264.552); CAMUs

- DOE Order 435.1; Radioactive waste management Performance objectives to protect workers (TBC)

- DOE Order 5400.5; Exposures to the public will be kept ALARA (TBC)

Substantive • IDAPA 16.01.05.006 (40 CFR 262.11); Hazardous waste determination

Substantive - IDAPA 16.01.05.008 (40 CFR 264, Subpart I); Use and management of containers

- IDAPA 16.01.05.008 (40 CFR 264, Subpart DD); Containment buildings

- IDAPA 16.01.05.008 (40 CFR 264.552); CAMUs

- DOE Order 435.1; Radioactive waste management performance objectives to protect workers (TBC)

- DOE Order 5400.5; Exposures to the public will be kept ALARA (TBC)

Substantive - IDAPA 16.01.05.008 (40 CFR 264.554); Remediation waste staging piles

- IDAPA 16.01.05.008 (40 CFR 264, Subpart J); Tank Systems

- IDAPA 16.01.05.008 (40 CFR 264.192); Design and installation of new tank systems or components
CERCLA documents providing supporting information regarding compliance with requirement

Waste Acceptance Criteria for ICDF Complex, DOE/ID-10881 (DOE-ID 2005)

- INEEL CERCLA Disposal Facility Complex Remedial Action Work Plan, DOE/ID-10984 (DOE-ID 2003a)

- ICDF Complex Operations and Maintenance Plan, DOE/ID-11000 (DOE-ID 2003b)

- Waste Acceptance Criteria for ICDF Complex, DOE/ID-10881 (DOE-ID 2005)

- “ICDF Complex Waste Tracking Plan" (PLN-914)

- ICDF Complex Waste Verification Sampling and Analysis Plan, DOE/ID-10985 (DOE-ID 2003g)

- ICDF Complex Operations and Maintenance Plan, DOE/ID-11000 (DOE-ID 2003b)

- INEEL CERCLA Disposal Facility Complex Remedial Action Work Plan, DOE/ID-10984 (DOE-ID 2003a)

- ICDF Complex Operations and Maintenance Plan, DOE/ID-11000 (DOE-ID 2003b)

- Also, detailed procedures are being developed for the various tasks that will be conducted at the ICDF Complex and these procedures will be included into the Operations and Maintenance Manual.

INEEL CERCLA Disposal Facility Complex Remedial Action Work Plan, DOE/ID-10984 (DOE-ID 2003a)

- ICDF Complex Operations and Maintenance Plan, DOE/ID-11000 (DOE-ID 2003b)

- "ICDF Complex Waste Tracking Plan" (PLN-914) 


\begin{tabular}{|c|c|c|c|c|}
\hline Requirement & $\begin{array}{l}\text { Substantive or } \\
\text { Administrative }\end{array}$ & Relevant or equivalent ARARs cited in the OU 3-13 ROD & CERCLA documents providing supporting information regarding compliance with requirement & $\begin{array}{c}\text { Requirement } \\
\text { Satisfied }\end{array}$ \\
\hline IV.N.(7) Staging & Administrative & 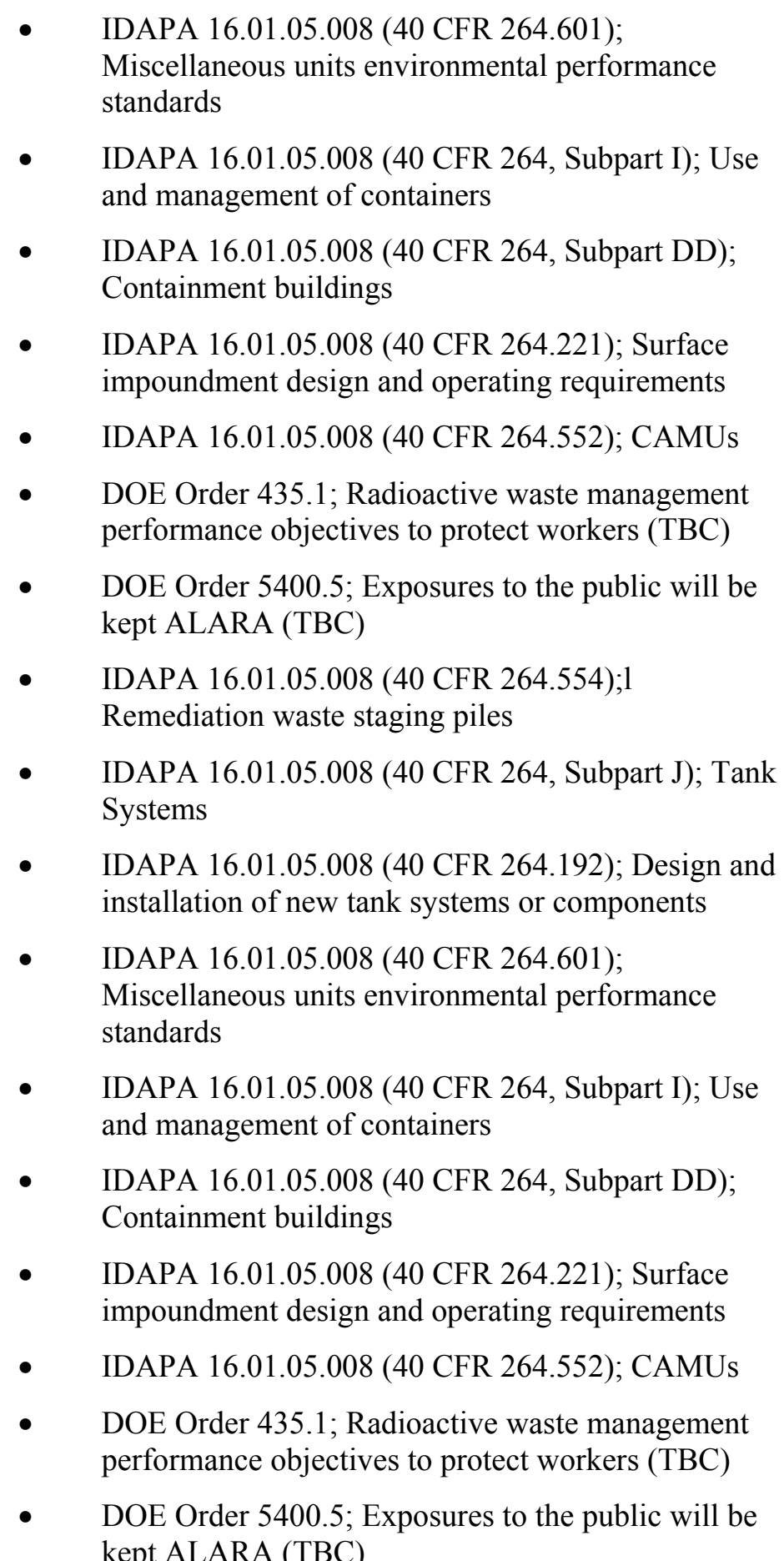 & $\begin{array}{l}\text { - INEEL CERCLA Disposal Facility Complex Remedial Action Work Plan, DOE/ID-10984 } \\
\text { - ICOE-ID 2003a) } \\
\text { - } \quad \text { ICDF Complex Operations and Maintenance Plan, DOE/ID-11000 (DOE-ID 2003b) } \\
\text { - } \quad \text { Final Record of Decision for the Idaho Technology and Engineering Center, Operable Unit 3-13 } \\
\text { at the INEEL, DOE/ID-10660 (DOE-ID 1999) }\end{array}$ & $\begin{array}{c}\text { Yes } \\
- \\
- \\
-\end{array}$ \\
\hline IV.O. Treatment & Substantive & $\begin{array}{l}\text { IDAPA 16.01.05.008 (40 CFR 264.601); } \\
\text { Miscellaneous units environmental performance } \\
\text { standards }\end{array}$ & $\begin{array}{l}\text { - } \quad \text { "Hazard Assessment Document, ICDF Complex Hazard Classification" (HAD-136) } \\
\text { - Waste Acceptance Criteria for ICDF Complex, DOE/ID-10881 (DOE-ID 2005) } \\
\text { - } \quad \text { "NESHAP Compliance Demonstration for the ICDF Complex" (EDF-2236) }\end{array}$ & $\begin{array}{l}\text { Yes } \\
- \\
-\end{array}$ \\
\hline
\end{tabular}




\begin{tabular}{|c|c|c|c|c|}
\hline Requirement & $\begin{array}{l}\text { Substantive or } \\
\text { Administrative }\end{array}$ & Relevant or equivalent ARARs cited in the OU 3-13 ROD & CERCLA documents providing supporting information regarding compliance with requirement & $\begin{array}{c}\text { Requirement } \\
\text { Satisfied }\end{array}$ \\
\hline & & - $\quad$ IDAPA 16.01.05.008 (40 CFR 264, Subpart DD); & - $\quad$ "NESHAP Modeling for the ICDF Complex" (EDF-ER-290) & - \\
\hline & & Containment buildings & - "INEEL CERCLA Disposal Facility Short-Term Risk Assessment" (EDF-ER-327) (This & - \\
\hline & & • IDAPA 16.01.05.008 (40 CFR 264.552); CAMUs & document also evaluates the impacts on botn pubirc receptors and non-ICDF Workers.) & \\
\hline & & DOE Order 435.1; Radioactive waste management & • “IDAPA Air Compliance Demonstration for the ICDF Complex” (EDF-2237) & - \\
\hline & & performance objectives to protect workers (TBC) & - $\quad$ “SSSTF Design Radiological Control Analysis" (EDF-ER-302) & - \\
\hline & & $\begin{array}{l}\text { - } \quad \text { DOE Order 5400.5; Exposures to the public will be } \\
\text { kept ALARA (TBC) }\end{array}$ & $\begin{array}{l}\text { - Health and Safety Plan for INEEL CERCLA Disposal Facility Operations, INEEL/EXT-01-01318 } \\
\text { (INEEL 2003) }\end{array}$ & - \\
\hline & & & $\begin{array}{l}\text { - INEEL CERCLA Disposal Facility Complex Remedial Action Work Plan, DOE/ID-10984 } \\
\text { (DOE-ID 2003a) }\end{array}$ & - \\
\hline & & & - ICDF Complex Operations and Maintenance Plan, DOE/ID-11000 (DOE-ID 2003b) & - \\
\hline & & & $\begin{array}{l}\text { - Remedial Design/Construction Work Plan for the Waste Area Group } 3 \text { Staging, Storage, Sizing, } \\
\text { and Treatment Facility, DOE/ID-10889 (DOE-ID 2002a), along with the supporting drawings, } \\
\text { specifications, and Engineering Design Files }\end{array}$ & - \\
\hline & & & $\begin{array}{l}\text { - Sampling and Analysis Plan for SSSTF Waste Stabilization Operations, DOE/ID-10924 } \\
\text { (DOE-ID 2003f) }\end{array}$ & - \\
\hline \multicolumn{5}{|l|}{ IV.P. Disposal } \\
\hline \multirow[t]{9}{*}{ IV.P.(1) Performance Objectives } & Substantive & None & $\begin{array}{l}\text { - "INEEL CERCLA Disposal Facility Short-Term Risk Assessment" (EDF-ER-327) (This } \\
\text { document also evaluates the impacts on both public receptors and non-ICDF workers.) }\end{array}$ & Yes \\
\hline & & & $\begin{array}{l}\text { - Performance Assessment for the INEEL CERCLA Disposal Facility, DOE/ID-10978 } \\
\text { (DOE-ID 2003i) }\end{array}$ & - \\
\hline & & & - $\quad$ "Hazard Assessment Document, ICDF Complex Hazard Classification" (HAD-136) & - \\
\hline & & & - “NESHAP Compliance Demonstration for the ICDF Complex" (EDF-2236) & - \\
\hline & & & - “NESHAP Modeling for the ICDF Complex" (EDF-ER-290) & \\
\hline & & & - “INEEL CERCLA Disposal Facility Short-Term Risk Assessment" (EDF-ER-327) (This & - \\
\hline & & & document also evaluates the impacts on both public receptors and non-ICDF workers.) & - \\
\hline & & & - “IDAPA Air Compliance Demonstration for the ICDF Complex" (EDF-2237) & - \\
\hline & & & & - \\
\hline IV.P.(2) Performance Assessment & Administrative & None & $\begin{array}{l}\text { - Performance Assessment for the INEEL CERCLA Disposal Facility, DOE/ID-10978 } \\
\text { (DOE-ID 2003i) }\end{array}$ & Yes \\
\hline IV.P.(3) Composite Analysis & Administrative & None & $\begin{array}{l}\text { - Composite Analysis for the INEEL CERCLA Disposal Facility Landfill, DOE/ID-10979 } \\
\text { (DOE-ID 2003j) }\end{array}$ & Yes \\
\hline $\begin{array}{l}\text { IV.P.(4) Performance Assessment and } \\
\text { Composite Analysis Maintenance }\end{array}$ & Administrative & None & - $\quad$ None & Yes \\
\hline \multirow[t]{2}{*}{ IV.P.(5) Disposal Authorization } & Administrative & None & $\begin{array}{l}\text { - Performance Assessment for the INEEL CERCLA Disposal Facility, DOE/ID-10978 } \\
\text { (DOE-ID 2003i) }\end{array}$ & Yes \\
\hline & & & & - \\
\hline
\end{tabular}


- Composite Analysis for the INEEL CERCLA Disposal Facility Landfill, DOE/ID-10979 (DOE-ID 2003j)

- ICDF Remedial Design/Construction Work Plan, DOE/ID-10848 (DOE-ID 2002b), along with the supporting drawings, specifications, and Engineering Design Files

- INEEL CERCLA Disposal Facility Complex Remedial Action Work Plan, DOE/ID-10984 (DOE-ID 2003a)

- IDAPA 16.01.05.008 (40 CFR 264.301); Landfill design and operating requirements

- DOE Order 435.1; Radioactive waste management performance objectives to protect workers (TBC)

- DOE Order 5400.5; Exposures to the public will be kept ALARA (TBC)

- $\quad 40$ CFR 61.92, 40 CFR 61.93; NESHAP for radionuclides from DOE facilities, emission monitoring and emission compliance

- $\quad$ IDAPA 16.01.01.585, IDAPA 16.01.01.586; Rules for the control of air pollution in Idaho

- IDAPA 16.01.05.008 (40 CFR 264.92); Groundwater protection standard

- IDAPA 16.01.05.008 (40 CFR 264.97); General groundwater monitoring requirements

- IDAPA 16.01.05.008 (40 CFR 264.98); Detection monitoring program

- IDAPA 16.01 .05 .008

[40 CFR 264.310(b)(1)(4)(5)(6)]; Landfill post-closure requirements

- IDAPA 16.01.05.008 (40 CFR 264.302); Landfill action leakage rate

- $\quad$ IDAPA 16.01.05.008 (40 CFR 264, Subpart G); Closure and post-closure
- ICDF Complex Operations and Maintenance Plan, DOE/ID-11000 (DOE-ID 2003b)

- “Hazard Assessment Document, ICDF Complex Hazard Classification” (HAD-136)

- ICDF Complex Waste Acceptance Criteria, DOE/ID-10881 (DOE-ID 2005)

- "NESHAP Compliance Demonstration for the ICDF Complex" (EDF-2236)

- "NESHAP Modeling for the ICDF Complex" (EDF-ER-290)

- "INEEL CERCLA Disposal Facility Short-Term Risk Assessment" (EDF-ER-327) (This document also evaluates the impacts on both public receptors and non-ICDF workers.)

- “IDAPA Air Compliance Demonstration for the ICDF Complex" (EDF-2237)

- $\quad$ "SSSTF Design Radiological Control Analysis" (EDF-ER-302)

- Health and Safety Plan for INEEL CERCLA Disposal Facility Operations, INEEL/EXT-01-01318 (INEEL 2003)

- INEEL CERCLA Disposal Facility Complex Remedial Action Work Plan, DOE/ID-10984 (DOE-ID 2003a)

- ICDF Complex Operations and Maintenance Plan, DOE/ID-11000 (DOE-ID 2003b)

- "Fate and Transport Modeling Results and Summary Report" (EDF-ER-275)

- "Hydrologic Modeling of Final Cover" (EDF-ER-279)

- $\quad$ "Liner and Final Cover Long-Term Performance Evaluation and Final Cover Life Cycle Expectation" (EDF-ER-281)

- $\quad$ "Screening Level Ecological Risk Assessment for the INEEL CERCLA Disposal Facility Complex" (EDF-ER-311)

- ICDF Complex Operational and Monitoring Sampling and Analysis Plan, DOE/ID-11005 (DOE-ID 2003e)

- $\quad$ ICDF Complex Groundwater Monitoring Plan, DOE/ID-10955 (DOE-ID 2002c)

- "ICDF Complex Waste Tracking Plan" (PLN-914)

- "Waste Placement Plan" (EDF-ER-286)

- ICDF Remedial Design/Construction Work Plan, DOE/ID-10848 (DOE-ID 2002b), along with the supporting drawings, specifications, and Engineering Design Files

- “INEEL CERCLA Disposal Facility (ICDF) Physical Security Plan” (PLN-940)

- "Subsurface Consolidation Calculations" (EDF-ER-266) 
- $\quad$ "Landfill Compaction/Subsidence Study" (EDF-ER-267)

- Performance Assessment for the INEEL CERCLA Disposal Facility, DOE/ID-10978 (DOE-ID 2003i)

- $\quad$ Composite Analysis for the INEEL CERCLA Disposal Facility Landfill, DOE/ID-10979 (DOE-ID 2003j)

IV.P.(7) Alternate Requirements for Low-Level Waste Disposal Facility Substantive • None

ICDF Remedial Design/Construction Work Plan, DOE/ID-10848 (DOE-ID 2002b), along with the supporting drawings, specifications, and Engineering Design Files

- " "Fate and Transport Modeling Results and Summary Report" (EDF-ER-275)

- "Hydrologic Modeling of Final Cover" (EDF-ER-279)

- "Liner and Final Cover Long-Term Performance Evaluation and Final Cover Life Cycle Expectation" (EDF-ER-281)

- Performance Assessment for the INEEL CERCLA Disposal Facility, DOE/ID-10978 (DOE-ID 2003i)

- Composite Analysis for the INEEL CERCLA Disposal Facility Landfill, DOE/ID-10979 (DOE-ID 2003j)

IV.Q. Closure

IV.Q.(1) Disposal Facility Closure Plans

- IDAPA 16.01.05.008

[40 CFR 264.310(a)(1)(2)(3)(4)(5)]; Landfill closure

requirements

IV.Q.(2) Disposal Facility Closure

- IDAPA 16.01.05.008 [40 CFR $264.310(\mathrm{a})(1)(2)(3)(4)(5)] ;$ Landfill closure requirements

- $\quad$ IDAPA 16.01.05.008 [40 CFR

264.310(b)(1)(4)(5)(6)]; Landfill post-closure requirements
- INEEL CERCLA Disposal Facility Complex Remedial Action Work Plan, DOE/ID-10984 (DOE-ID 2003a)

- ICDF Remedial Design/Construction Work Plan, DOE/ID-10848 (DOE-ID 2002b), along with the supporting drawings, specifications, and Engineering Design Files

- “INEEL CERCLA Disposal Facility Design Inventory” (EDF-ER-264)

- “ICDF Complex Waste Tracking Plan" (PLN-914)

- INEEL CERCLA Disposal Facility Complex Remedial Action Work Plan, DOE/ID-10984 (DOE-ID 2003a)

- ICDF Remedial Design/Construction Work Plan, DOE/ID-10848 (DOE-ID 2002b), along with the supporting drawings, specifications, and Engineering Design Files

- " "INEEL CERCLA Disposal Facility Design Inventory" (EDF-ER-264)

- "ICDF Complex Waste Tracking Plan" (PLN-914)

\section{IV.R. Monitoring}

IV.R.(1) All Facilities Substantive

DAPA 16.01.05.008 (40 CFR 264.301); Landfill design and operating requirements

- $\quad 40$ CFR 761.75(b)(1)(2); PCB landfill design requirements

- $\quad$ DOE Order 435.1; Radioactive waste management performance objectives to protect workers (TBC)
- INEEL CERCLA Disposal Facility Complex Remedial Action Work Plan, DOE/ID-10984 (DOE-ID 2003a)

- ICDF Complex Operations and Maintenance Plan, DOE/ID-11000 (DOE-ID 2003b)

- $\quad$ Also, detailed procedures are being developed for the various tasks that will be conducted at the ICDF Complex and these procedures will be included into the Operations and Maintenance 
- DOE Order 5400.5. Exposures to the public will be Manual.

- 40 CFR 61.92, 40 CFR 61.93; NESHAP for radionuclides from DOE facilities, emission monitoring and emission compliance

- IDAPA 16.01.01.585, IDAPA 16.01.01.586; Rules for the control of air pollution in Idaho

- IDAPA 16.01.05.008 (40 CFR 264.92); Groundwater protection standard

- IDAPA 16.01.05.008 (40 CFR 264.97); General groundwater monitoring requirements

- IDAPA 16.01.05.008 (40 CFR 264.98); Detection monitoring program

- IDAPA 16.01.05.008 [40 CFR 264.310(b)(1)(4)(5)(6)]; Landfill post-closure requirements

- IDAPA 16.01.05.008 (40 CFR 264.302); Landfill action leakage rate

- IDAPA 16.01.05.008 (40 CFR 264, Subpart J); Tank Systems

- $\quad$ IDAPA 16.01.05.008 (40 CFR 264.554); Remediation waste staging piles

- IDAPA 16.01.05.008 (40 CFR 264.192); Design and installation of new tank systems or components

- $\quad$ IDAPA 16.01.05.008 (40 CFR 264.601); Miscellaneous units environmental performance standards

- IDAPA 16.01.05.008 (40 CFR 264, Subpart I); Use and management of containers

- IDAPA 16.01.05.008 (40 CFR 264, Subpart DD); Containment buildings

- IDAPA 16.01.05.008 (40 CFR 264.1052 through 1062); Air emissions standards for equipment leaks

- IDAPA 16.01.05.008 (40 CFR 264.1082 through 1088); Air emission standards for tanks, surface impoundments, and containers

- IDAPA 16.01.05.008 (40 CFR 264.221); Surface impoundment design and operating requirement

IDAPA 16.01.05.008 (40 CFR 264.552): CAMUs
- ICDF Complex Waste Verification Sampling and Analysis Plan, DOE/ID-10985 (DOE-ID 2003g)

- Health and Safety Plan for INEEL CERCLA Disposal Facility Operations, INEEL/EXT-01-01318 (INEEL 2003)

- ICDF Complex Operational and Monitoring Sampling and Analysis Plan, DOE/ID-11005 (DOE-ID 2003e)

- ICDF Complex Groundwater Monitoring Plan, DOE/ID-10955 (DOE-ID 2002c)

- Sampling and Analysis Plan for SSSTF Waste Stabilization Operations, DOE/ID-10924 (DOE-ID 2003f) 
Requirement

IV.R.(2) Liquid Waste Storage Facilities

IV.R.(3) Disposal Facilities
Substantive or Substantive or
Administrative

IDAPA 16.01.05.008 (40 CFR 264, Subpart G);

Closure and post-closure

IDAPA 16.01.05.008 (40 CFR 264.192); Design and installation of new tank systems or components

Substantive

- IDAPA 16.01.05.008 (40 CFR 264.301); Landfill design and operating requirements

- $\quad 40$ CFR 761.75(b)(1)(2); PCB landfill design requirements

- DOE Order 435.1; Radioactive waste management performance objectives to protect workers (TBC)

- DOE Order 5400.5; Exposures to the public will be kept ALARA (TBC)

- $\quad 40$ CFR 61.92, 40 CFR 61.93; NESHAP for radionuclides from DOE facilities, emission monitoring and emission compliance

- $\quad$ IDAPA 16.01.01.585, IDAPA 16.01.01.586; Rules for the control of air pollution in Idaho

- IDAPA 16.01.05.008 (40 CFR 264.92) Groundwater protection standard

- IDAPA 16.01.05.008 (40 CFR 264.301); Landfill design and operating requirements

- IDAPA 16.01.05.008 (40 CFR 264.97); General groundwater monitoring requirements

- IDAPA 16.01.05.008 (40 CFR 264.98); Detection monitoring program

- IDAPA 16.01.05.008 [40 CFR 264.310(b)(1)(4)(5)(6)]; Landfil post-closure requirements

- IDAPA 16.01.05.008 (40 CFR 264.302); Landfill action leakage rate

- IDAPA 16.01.05.008 (40 CFR 264, Subpart J); Tank Systems

- $\quad$ IDAPA 16.01.05.008 (40 CFR 264.554);

Remediation waste staging piles

- IDAPA 16.01.05.008 (40 CFR 264.192); Design and
CERCLA documents providing supporting information regarding compliance with requirement

- "Hazard Assessment Document, ICDF Complex Hazard Classification" (HAD-136)

“ICDF Complex Waste Tracking Plan" (PLN-914)

- Health and Safety Plan for INEEL CERCLA Disposal Facility Operations, INEEL/EXT-01-01318 (INEEL 2003)

- ICDF Complex Operational and Monitoring Sampling and Analysis Plan, DOE/ID-11005 (DOE-ID 2003e)

- ICDF Complex Waste Verification Sampling and Analysis Plan, DOE/ID-10985 (DOE-ID 2003g)

- INEEL CERCLA Disposal Facility Complex Remedial Action Work Plan, DOE/ID-10984 (DOE-ID 2003a)

- ICDF Complex Operations and Maintenance Plan, DOE/ID-11000 (DOE-ID 2003b)

- Also, detailed procedures are being developed for the various tasks that will be conducted at the ICDF Complex and these procedures will be included into the Operations and Maintenance Manual.

- ICDF Complex Waste Verification Sampling and Analysis Plan, DOE/ID-10985 (DOE-ID 2003g)

- Health and Safety Plan for INEEL CERCLA Disposal Facility Operations, INEEL/EXT-01-01318 (INEEL 2003)

- ICDF Complex Operational and Monitoring Sampling and Analysis Plan, DOE/ID-11005 (DOE-ID 2003e)

- ICDF Complex Groundwater Monitoring Plan, DOE/ID-10955 (DOE-ID 2002c)

- Performance Assessment for the INEEL CERCLA Disposal Facility, DOE/ID-10978 (DOE-ID 2003i)

- Composite Analysis for the INEEL CERCLA Disposal Facility Landfill, DOE/ID-10979 (DOE-ID 2003j) 
Relevant or equivalent ARARs cited in the OU 3-13 ROD

CERCLA documents providing supporting information regarding compliance with requirement

IDAPA 16.01.05.008 (40 CFR 264.601)

Miscellaneous units environmental performance

$$
\begin{aligned}
& \text { Miscellaneous } \\
& \text { standards }
\end{aligned}
$$

- IDAPA 16.01.05.008 (40 CFR 264, Subpart I); Use and management of containers

- IDAPA 16.01.05.008 (40 CFR 264, Subpart DD);

Containment buildings

- IDAPA 16.01.05.008 (40 CFR 264.1052 through

1062); Air emissions standards for equipment leaks

- IDAPA 16.01.05.008 (40 CFR 264.1082 through

1088); Air emission standards for tanks, surface

impoundments, and containers

- IDAPA 16.01.05.008 (40 CFR 264.221); Surface

impoundment design and operating requirements

- IDAPA 16.01.05.008 (40 CFR 264.552); CAMUs

- IDAPA 16.01.05.008 (40 CFR 264, Subpart G);

Closure and post-closure 



\section{CONCLUSIONS}

Each of the requirements in the four chapters of DOE Manaual 435.1 were evaluated. This evaluation consisted of determining the classification of the requirement and determining how the requirement is being complied with. Sections 5, 6, 7, and 8 discuss the various requirements and conduct the evaluation on classification and compliance with the requirement. Also in Section 9, the ARARs are presented along with the requirement and the CERCLA documents that have dealt with the issue are also presented. Based on the evaluation and analysis in this compliance demonstration document, the ICDF Complex is in compliance with DOE Order 435.1. All of the substantive requirements are met and most of the administrative requirements are met. Requirements not dealing specifically with ICDF are not considered to require compliance. 
10-2 


\section{REFERENCES}

10 CFR 61, 1999, "Licensing Requirements for Land Disposal of Radioactive Waste," Code of Federal Regulations, Office of the Federal Register, July 1999.

10 CFR 61.55, 1999, "Waste Classification," Code of Federal Regulations, Office of the Federal Register, July 1999.

40 CFR 261, Subpart C, 2000, "Characteristics of Hazardous Waste," Code of Federal Regulations, Office of the Federal Register, July 2000 (as promulgated as of December 1999).

40 CFR 261, Subpart D, 2000, "Lists of Hazardous Wastes," Code of Federal Regulations, Office of the Federal Register, July 2000 (as promulgated as of December 1999).

40 CFR 261.22, 2000, "Characteristics of Hazardous Waste, Characteristic of Corrosivity," Code of Federal Regulations, Office of the Federal Register, July 2000 (as promulgated as of December 1999).

40 CFR 262.34, 1999, “Accumulation Time," Code of Federal Regulations, Office of the Federal Register, July 1999.

40 CFR 264, Subpart I, 1999, "Use and Management of Containers," Code of Federal Regulations, Office of the Federal Register, July 1999.

40 CFR 264, Subpart J, 1999, "Tank Systems," Code of Federal Regulations, Office of the Federal Register, July 1999.

40 CFR 264, Subpart K, 1999, "Surface impoundments," Code of Federal Regulations, Office of the Federal Register, July 1999.

40 CFR 264, Subpart BB, 1999, “Air emission standards for equipment leaks," Code of Federal Regulations, Office of the Federal Register, July 1999.

40 CFR 264, Subpart DD, 2000, "Containment Buildings," Code of Federal Regulations, Office of the Federal Register, July 2000 (as promulgated as of December 1999).

40 CFR 264, Subpart CC, 1999, “Air Emission Standards for Tanks, Surface Impoundments, and Containers," Code of Federal Regulations, Office of the Federal Register, July 1999.

40 CFR 264.301, 1992, "Design and Operating Requirements," Code of Federal Regulations, Office of the Federal Register, January 1992.

40 CFR 264.310, 1986, "Closure and Post-Closure Sources," Code of Federal Regulations, Office of the Federal Register, May 1986.

40 CFR 264.552, 1998, “Corrective Action Management Units," Code of Federal Regulations, Office of the Federal Register, November 1998.

40 CFR 264.554, 1999, "Staging Piles," Code of Federal Regulations, Office of the Federal Register, July 1999. 
40 CFR 264.1082, 1999, "Standards: General," Code of Federal Regulations, Office of the Federal Register, July 1999.

40 CFR 264.1100, 1999, “Applicability,” Code of Federal Regulations, Office of the Federal Register, July 1999.

40 CFR 268, 1999, "Land Disposal Restrictions," Code of Federal Regulations, Office of the Federal Register, July 1999.

40 CFR 268, Subpart D, 2000, "Treatment Standards," Code of Federal Regulations, Office of the Federal Register, July 2000 (as promulgated as of December 1999).

40 CFR 268.2, 2000, "Definitions Applicable in This Part," Code of Federal Regulations, Office of the Federal Register, July 2000 (as promulgated as of December 1999).

40 CFR 268.45, 2000, “Treatment Standards for Hazardous Debris," Code of Federal Regulations, Office of the Federal Register, July 2000 (as promulgated as of December 1999).

40 CFR 61, 2000, "Methods for Estimating Radionuclide Emissions," Code of Federal Regulations, Office of the Federal Register, July 2000 (as promulgated as of December 1999).

40 CFR 761.75, 1999, "Polychlorinated Biphenyls (PCBs) Processing, Distribution in Commerce and Use Prohibitions," Code of Federal Regulations, Office of the Federal Register, July 1999.

40 CFR 82, 1999, "Protection Of Stratospheric Ozone," Code of Federal Regulations, Office of the Federal Register, July 1999.

ANS, 1981, Nuclear Criticality Control of Special Actinide Elements, American Nuclear Society, ANS *8.15, 1981.

Barraclough, J. T., and R. G. Jensen, 1976, "Hydrologic Data for the Idaho National Engineering Laboratory Site, Idaho 1971 to 1973," Geological Survey Open-File Report 75-318, IDO-22055, January 1976.

Bartholomay, Roy C., and Betty J. Tucker, 2000, "Distribution of Selected Radiochemical and Chemical Constituents in Perched Ground Water, Idaho National Engineering and Environmental Laboratory, Idaho, 1996-98," Geological Survey Water-Resources Investigations Report 00-4222, DOE/ID-22168, October 2000.

DOE, 1994, "Secretarial Policy on the National Environmental Policy Act," U.S. Department of Energy, June 1994.

DOE, 1997a, “Decommissioning Handbook,” DOE/EM-0246, U.S. Department of Energy, 1997.

DOE, 1997b, "Working Group on Transition, Working Definitions, Memorandum of Understanding," EM-40/EM-60, U.S. Department of Energy, Office of Environmental Management, Washington D.C., 1997.

DOE N 251.38, 2001, “Cancellation of Directives," U.S. Department of Energy, March 3, 2001. (expired July 3, 2001)

DOE O 430.1A, 1998, “Life Cycle Asset Management,” U.S. Department of Energy, October 14, 1998. 
DOE O 433.1, 2001, “Maintenance Management Program for DOE Nuclear Facilities,” U.S. Department of Energy, June 1, 1999.

DOE O 435.1, Change 1, 2001, “Radioactive Waste Management,” U.S. Department of Energy, August 28, 2001.

DOE G 435.1-1, 1999, “Implementation Guide for use with DOE Manual 435.1-1," U.S. Department of Energy, July 9, 1999.

DOE M 435.1-1, 1999, “Radioactive Waste Management Manual,” U.S. Department of Energy, July $9,1999$.

DOE O 5400.5, 1993, "Radiation Protection of the Public and the Environment," U.S. Department of Energy, January 7, 1993.

DOE O 5480.19, Change 2, 2001, "Conduct of Operations Requirements for DOE Facilities," U.S. Department of Energy, October 23, 2001.

DOE-ID, 1994, INEL Reusable Property, Recyclable Materials, and Waste Acceptance Criteria (RRWAC), DOE/ID-10381, Rev. 1, U.S. Department of Energy Idaho Operations Office, November 1994.

DOE-ID, 1997a, Comprehensive RI/FS for the Idaho Chemical Processing Plant OU 3-13 at the INEEL, Part A RI/BRA Supplement Report, DOE/ID-10534, Rev. 0, U.S. Department of Energy Idaho Operations Office, November 1997.

DOE-ID, 1997b, Comprehensive RI/FS for the Idaho Chemical Processing Plant OU 3-13 at the INEEL, Part B FS Report, DOE/ID-10572, Rev. 0, U.S. Department of Energy Idaho Operations Office, November 1997.

DOE-ID, 1998, Comprehensive RI/FS for the Idaho Chemical Processing Plant OU 3-13 at the INEEL, Part B FS Supplement Report, DOE/ID-10619, Rev. 2, U.S. Department of Energy Idaho Operations Office, October 1998.

DOE-ID, 1999, Final Record of Decision, Idaho Nuclear Technology and Engineering Center, Operable Unit 3-13, DOE/ID-10660, Rev. 0, U.S. Department of Energy Idaho Operations Office, October 1999.

DOE-ID, 2000a, Geotechnical Report for the Conceptual Design of the INEEL CERCLA Disposal Facility at Waste Area Group 3, Operable Unit 3-13, DOE/ID-10812, Rev. 0, U.S. Department of Energy Idaho Operations Office, December 2000.

DOE-ID, 2000b, Quality Assurance Project Plan for Waste Area Group 1, 2, 3, 4, 5, 6, 7, 10, and Inactive Sites, DOE/ID-10587, Rev. 6, U.S. Department of Energy Idaho Operations Office, September 2000.

DOE-ID, 2000c, INEEL Interim Pollution Prevention Plan, DOE/ID-10333, Rev. 0, U.S. Department of Energy Idaho Operations Office, June 2000.

DOE-ID, 2002a, Remedial Design/Construction Work Plan for the Waste Area Group 3 Staging, Storage, Sizing, and Treatment Facility, DOE/ID-10889, Rev. 0, U.S. Department of Energy Idaho Operations Office, March 2002. 
DOE-ID, 2002b, ICDF Remedial Design/Construction Work Plan, DOE/ID-10848, Rev. 1, U.S. Department of Energy Idaho Operations Office, May 2002.

DOE-ID, 2002c, ICDF Complex Groundwater Monitoring Plan, DOE/ID-10955, Rev 0, U.S. Department of Energy Idaho Operations Office, May 2002.

DOE-ID, 2002d, INEEL CERCLA Disposal Facility Construction Waste Management Plan, DOE/ID-10958, Rev. 0, U.S. Department of Energy Idaho Operations Office, May 2002.

DOE-ID, 2002e, Staging, Storage, Sizing, and Treatment Facility Construction Waste Management Plan, DOE/ID-10873, Rev. 0, U.S. Department of Energy Idaho Operations Office, March 2002.

DOE-ID, 2002f, INEEL CERCLA Disposal Facility Construction Quality Assurance Plan, DOE/ID-10851, Rev. 2, U.S. Department of Energy Idaho Operations Office, May 2002.

DOE-ID, 2003a, INEEL CERCLA Disposal Facility Complex Remedial Action Work Plan, DOE/ID-10984, Rev. 0, U.S. Department of Energy Idaho Operations Office, February 2003.

DOE-ID, 2003b, ICDF Complex Operations and Maintenance Plan, DOE/ID-11000, Rev. 0, U.S. Department of Energy Idaho Operations Office, February 2003.

DOE-ID, 2003c, ICDF Complex Material Profile Guidance, DOE/ID-11046, Rev. 0, U.S. Department of Energy Idaho Operations Office, February 2003.

DOE-ID, 2003d, ICDF Complex Operations Waste Management Plan, DOE/ID-10886, Rev. 0, U.S. Department of Energy Idaho Operations Office, February 2003.

DOE-ID, 2003e, ICDF Complex Operational and Monitoring Sampling and Analysis Plan, DOE/ID-11005, Rev. 0, U.S. Department of Energy Idaho Operations Office, February 2003.

DOE-ID, 2003f, Sampling and Analysis Plan for SSSTF Waste Stabilization Operations, DOE/ID-10924, Rev. 0, U.S. Department of Energy Idaho Operations Office, February 2003.

DOE-ID, 2003g, ICDF Complex Waste Verification Sampling and Analysis Plan, DOE/ID-10985, Rev. 0, U.S. Department of Energy Idaho Operations Office, February 2003.

DOE-ID, 2003h, INEEL CERCLA Disposal Facility Groundwater Groundwater Detection Monitoring Program: Data Analysis Plan, DOE/ID-10998, Rev. 0, U.S. Department of Energy Idaho Operations Office, February 2003.

DOE-ID, 2003i, Performance Assessment for the INEEL CERCLA Disposal Facility Landfill, DOE/ID-10978, Rev. 0, U.S. Department of Energy Idaho Operations Office, August 2003.

DOE-ID, 2003j, Composite Analysis for the INEEL CERCLA Disposal Facility Landfill, DOE/ID-10979, Rev. 0, U.S. Department of Energy Idaho Operations Office, August 2003.

DOE-ID, 2005, ICDF Complex Waste Acceptance Criteria, DOE/ID-10881, Rev. 2, U.S. Department of Energy Idaho Operations Office, July 2005.

EDF-1548, 2000, "Staging, Storage, Sizing, and Treatment Facility (SSSTF) Siting Study," Rev. 0, Idaho National Engineering and Environmental Laboratory, December 2000. 
EDF-2236, 2003, "NESHAP Compliance Demonstration for the ICDF Complex," Rev. 0, Idaho National Engineering and Environmental Laboratory, February 2003.

EDF-2237, 2003, "IDAPA Air Compliance Demonstration for the ICDF Complex," Rev. 0, Idaho National Engineering and Environmental Laboratory, February 2003.

EDF-2385, 2003, "INEEL CERCLA Disposal Facility Complex On-Site Versus Off-Site Cost Comparison," Rev. 0, Idaho National Engineering and Environmental Laboratory, February 2003.

EDF-ER-264, 2002, “INEEL CERCLA Disposal Facility Design Inventory,” Rev. 1, Idaho National Engineering and Environmental Laboratory, December 2002.

EDF-ER-266, 2002, "Subsurface Consolidation Calculations," Rev. 1, Idaho National Engineering and Environmental Laboratory, May 2002.

EDF-ER-267, 2002, “Landfill Compaction/Subsidence Study,” Rev. 1, Idaho National Engineering and Environmental Laboratory, May 2002.

EDF-ER-269, 2002, “Leachate Generation Study,” Rev. 1, Idaho National Engineering and Environmental Laboratory, May 2002.

EDF-ER-274, 2002, "Leachate Contaminant Reduction Time Study," Rev. 1, Idaho National Engineering and Environmental Laboratory, May 2002.

EDF-ER-275, 2002, "Fate and Transport Modeling Results and Summary Report," Rev. 2, Idaho National Engineering and Environmental Laboratory, May 2002.

EDF-ER-279, 2002, “Hydrologic Modeling of Final Cover,” Rev. 2, Idaho National Engineering and Environmental Laboratory, May 2002.

EDF-ER-281, 2002, "Liner and Final Cover Long-Term Performance Evaluation and Final Cover Life Cycle Expectation," Rev. 1, Idaho National Engineering and Environmental Laboratory, May 2002.

EDF-ER-286, 2002, “Waste Placement Plan,” Rev. 1, Idaho National Engineering and Environmental Laboratory, May 2002.

EDF-ER-290, 2002, “NESHAP Modeling for the ICDF Complex,” Rev. 1, Idaho National Engineering and Environmental Laboratory, May 2002.

EDF-ER-302, 2002, “SSSTF Design Radiological Control Analysis,” Rev. 0, Idaho National Engineering and Environmental Laboratory, March 2002.

EDF-ER-311, 2002, "Screening Level Ecological Risk Assessment for the INEEL CERCLA Disposal Facility Complex,” Rev. 1, Idaho National Engineering and Environmental Laboratory, May 2002.

EDF-ER-312, 2001, "Evaporation Pond Lining System Equivalency Analysis (60\% Design Component)," Rev. 0, Idaho National Engineering and Environmental Laboratory, November 2001.

EDF-ER-327, 2003, "INEEL CERCLA Disposal Facility Short-Term Risk Assessment,” Rev. 0, Idaho National Engineering and Environmental Laboratory, February 2003. 
EPA, 1986, "Paint Filter Liquids Test," Method SW-846, 9095A, Environmental Protection Agency, November 1986.

EPA, 1989, “Policy Memo 9441.1989(30) J. Cannon to T. Jorling,” Environmental Protection Agency, 1989.

EPA, 1991, “ARARs Q's \& A's: General Policy, RCRA, CWA, SDWA, Post-ROD Information, and Contingent Waivers," EPA Publication 9234.2-01/FS-A, Environmental Protection Agency, July 1991.

EPA, 1997, "Multi-Agency Radiation Survey and Site Investigation Manual (MARSSIM)," NUREG-1575/EPA 402-R-97-016, Environmental Protection Agency, December 1997.

HAD-136, 2002, “ICDF Complex Hazard Classification,” Rev. 0, Idaho National Engineering and Environmental Laboratory, May 2002.

IDAPA 58.01.01.585, 1995, “Toxic Air Pollutants Non-Carcinogenic Increments,” Idaho Administrative Procedures Act, Idaho Department of Environmental Quality, June 1995.

IDAPA 58.01.01.586, 2001, “Toxic Air Pollutants Carcinogenic Increments,” Idaho Administrative Procedures Act, Idaho Department of Environmental Quality, March 2001 (as promulgated as of December 1999).

IDAPA 58.01.01.650, 1994, "Rules for Control of Fugitive Dust,” Idaho Administrative Procedures Act, Department of Environmental Quality, May 1994.

IDAPA 58.01.05.008, 2002, "Standards for Owners and Operators of Hazardous Waste Treatment Storage and Dispsoal Facilities," Idaho Administrative Procedures Act, Department of Environmental Quality, March 2002 (as promulgated as of December 1999).

INEEL, 2001a, "Environmental Checklist for ICDF Complex,” Idaho National Engineering and Environmental Laboratory, INEL-00-018R1, July 2001.

INEEL, 2001b, Health and Safety Plan for Construction of the INEEL CERCLA Disposal Facility and Evaporation Pond, INEEL/EXT-2000-01424, Rev. 0, Idaho National Engineering and Environmental Laboratory, July 2001.

INEEL, 2002a, Health and Safety Plan for Construction of Staging, Storage, Sizing, and Treatment Facility, INEEL/EXT-01-00271, Rev. 0, Idaho National Engineering and Environmental Laboratory, March 2002.

INEEL, 2002b, Preliminary Inspection Plan for SSSTF Construction Activities, INEEL/EXT-01-00777, Rev. 0, Idaho National Engineering and Environmental Laboratory, March 2002.

INEEL, 2003, Health and Safety Plan for INEEL CERCLA Disposal Facility Operations, INEEL/EXT-01-01318, Rev. 0, Idaho National Engineering and Environmental Laboratory, February 2003.

INEL, 1995, "Waste Area Group 3 Comprehensive Remedial Investigation/Feasibility Study Work Plan (FINAL)," Volume I, INEL-95/0056, Rev. 0, Idaho National Engineering and Environmental Laboratory, Lockheed Idaho Technologies Company, August 1995. 
NFPA, 1998, "Standard for Fire Protection for Facilities Handling Radioactive Materials," Volume II, NFPA 801, National Fire Protection Association, February 1998.

PLN-873, 2002, "Quality Program Plan for the INEEL CERCLA Disposal Facility Complex," Rev. 0, Idaho National Engineering and Environmental Laboratory, March 2002.

PLN-914, 2003, “ICDF Complex Waste Tracking Plan,” Rev. 0, Idaho National Engineering and Environmental Laboratory, February 2003.

PLN-940, 2001, “INEEL CERCLA Disposal Facility (ICDF) Physical Security Plan,” Rev. 0, Idaho National Engineering and Environmental Laboratory, September 2001.

PLN-963, 2001, “Training Plan for the INEEL CERCLA Disposal Facility (Draft Title II),” Rev. 0, Idaho National Engineering and Environmental Laboratory, 2001 (will be finalized prior to start of operations).

Rathburn, S. L., 1991, "Quaternary Channel Changes and Paleoflooding Along the Big Lost River," Idaho National Engineering Laboratory, EGG-WM-9909, 1991.

TFR-17, 2002, "WAG 3 Staging, Storage, Sizing, and Treatment Facility,” Rev. 2, Idaho National Engineering and Environmental Laboratory, March 2002.

TFR-71, 2002, "WAG 3 INEEL CERCLA Disposal Facility and Evaporation Pond," Rev. 2, Idaho National Engineering and Environmental Laboratory, May 2002.

TFR-2520, 2002, “Technical and Functional Requirements for the INEEL CERCLA Disposal Facility (ICDF) Control and Integrated Waste Tracking System," Rev. 0, Idaho National Engineering and Environmental Laboratory, May 2002.

Tucker, Betty J., and Brennon R. Orr, 1998, "Distribution of Selected Radiochemical and Chemical Constituents in Perched Ground Water," 1989-91, Geological Survey Water Resources Investigations Report 98-4028, DOE/ID-22144, Idaho National Engineering Laboratory, Idaho, January 1998. 
$11-8$ 